SUELANE GARCIA FONTES

ANIMOVEMINER: UM FRAMEWORK PARA A ANÁLISE EXPLORATÓRIA DA INTERAÇÃO ENTRE ANIMAIS E O MEIO AMBIENTE 
ANIMOVEMINER: UM FRAMEWORK PARA A ANÁLISE EXPLORATÓRIA DA INTERAÇÃO ENTRE ANIMAIS E O MEIO AMBIENTE

Tese apresentada à Escola Politécnica da Universidade de São Paulo para a obtenção do Título de Doutor em Ciências. 


\title{
ANIMOVEMINER: UM FRAMEWORK PARA A ANÁLISE EXPLORATÓRIA DA INTERAÇÃO ENTRE ANIMAIS E O MEIO AMBIENTE
}

\author{
Versão Corrigida \\ (Versão original encontra-se na unidade que aloja \\ o Programa de Pós-graduação
}

Tese apresentada à Escola Politécnica da Universidade de São Paulo para a obtenção do Título de Doutor em Ciências.

Área de Concentração: Engenharia da Computação

Orientador: Prof. Dr. Pedro Luiz Pizzigatti Corrêa 
Autorizo a reprodução e divulgação total ou parcial deste trabalho, por qualquer meio convencional ou eletrônico, para fins de estudo e pesquisa, desde que citada a fonte.

Este exemplar foi revisado e corrigido em relação à versão original, sob responsabilidade única do autor e com a anuência de seu orientador.

São Paulo, de de

Assinatura do autor:

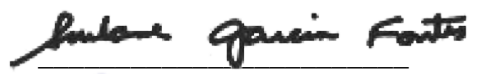

Assinatura do orientador:

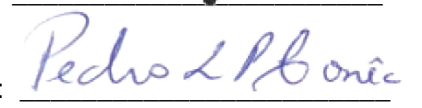

\section{Catalogação-na-publicação}

Fontes, Suelane Garcia

AniMoveMineR: um framework para a análise exploratória da interação entre animais e o meio ambiente / S. G. Fontes -- versão corr. -- São Paulo, 2020.

$156 \mathrm{p}$.

Tese (Doutorado) - Escola Politécnica da Universidade de São Paulo. Departamento de Engenharia de Computação e Sistemas Digitais.

1.Ciência dos dados 2.Análise de Dados 3.Mineração de Dados 4.Trajetória Animal 5.Comportamento Animal I.Universidade de São Paulo. Escola Politécnica. Departamento de Engenharia de Computação e Sistemas Digitais II.t. 
Fontes, Suelane Garcia. AniMoveMineR: um framework para a análise exploratória da interação entre animais e o meio ambiente. 2020. 156 p. Tese (Doutorado em Engenharia Elétrica) - Escola Politécnica, Universidade de São Paulo, São Paulo, 2020.

Aprovada em 29 de novembro de 2019.

\section{Banca Examinadora}

Prof. Dr. Pedro Luiz Pizzigatti Corrêa

Escola Politécnica da Universidade de São Paulo - POLI/USP

Julgamento: Aprovada

Prof. Dr. Flavio Soares Correa da Silva

Instituto de Matemática e Estatística - IME/USP

Julgamento: Aprovada

Prof. Dr. Carlos Roberto Valêncio

Instituto de Biociências, Letras e Ciências Exatas - IBILCE/UNESP

Julgamento: Aprovada

Prof. Dr. Katia Maria Paschoaletto Micchi de Barros Ferraz

Escola Superior de Agricultura "Luiz de Queiroz" - ESALQ/USP

Julgamento: Aprovada

Prof. Dr. Raphael Mendes de Oliveira Cobe

Núcleo de Computação Científica - NCC/UNESP

Julgamento: Aprovada 


\section{AGRADECIMENTOS}

Primeiramente, agradeço à Deus por ser a minha base de sustentação e meu guia em todos os momentos da minha vida e por tornar real o que era somente um sonho.

Aos meus pais, irmãs e sobrinhos, que são a razão da minha vida, pelo amor incondicional e por todo o incentivo, paciência e compreensão. Em especial, para minha mãe, Terezinha Garcia Fontes, e para a minha irmã, Suely Garcia Fontes, por sempre dedicarem seu tempo e suas palavras para me ajudarem nos momentos mais críticos.

Ao amigo e Co-orientador Dr. Silvio Luiz Stanzani, por ter participado ativamente e por sua atuação ter sido decisiva em cada etapa do meu doutoramento. Agradeço, também, pelo conhecimento compartilhado, pela dedicação, generosidade, profissionalismo, paciência, incentivo e amizade.

Ao meu namorado Ramilton Pereira dos Anjos, pelo incentivo, paciência e auxílio nas revisões de língua inglesa.

Aos membros do Grupo de Estudos, Pesquisa e Extensão em Big Data da Escola Politécnica da USP, pelo conhecimento e experiências compartilhadas e discussões e colaborações que contribuíram para a minha evolução profissional. Em especial, agradeço aos amigos, Dr. André Batista, Ms. Thiago Coleti e Dr. Daniel Lins pela parceria e amizade que ajudaram a amenizar as agruras dos momentos mais árduos.

Ao meu orientador, Prof. Dr. Pedro Luiz Pizzigatti Côrrea, pelas oportunidades oferecidas, pelo conhecimento compartilhado e orientações que foram decisivos para a minha evolução pessoal e profissional.

À Coordenação de Aperfeiçoamento de Pessoal de Nível Superior (CAPES) - Código Financeiro 001, pelo financiamento em parte dessa pesquisa. 
À Estação Ecológica ICMBio - Taiamã, com especial atenção aos analistas ambientais do ICMBIO, Daniel Kantek, Selma Onuma e Thadeu Pereira pelo compartilhamento dos dados de rastreamento de onças-pintadas utilizados nos estudos de caso.

Ao pesquisador do ICMBIO - CENAP, Ronaldo Morato, pelo compartilhamento de conhecimento sobre biodiversidade e, principalmente, sobre as onças-pintadas. Bem como, pela participação na elaboração dos artigos e estudos de caso.

Aos pesquisadores, nacionais e internacionais, Vânia Bogorny, Yu Zheng, Hai Phan, Fernando de Lucca Siqueira, Maria Luisa Damiani, Susanne Bleisch, Akiko Nakamura, Leigh Torres, Eliezer Gurarie, Mathieu Basille e Meg Crofoot pelo profissionalismo e disposição em compartilhar seu conhecimento, seus dados, ferramentas e algoritmos de seus projetos de pesquisa.

Aos amigos, professores e corpo técnico e administrativo da Escola Politécnica que, direta ou indiretamente, ajudaram no sucesso dessa jornada. 


\section{RESUMO}

Os dados espaço-temporais referentes à movimentação animal estão sendo amplamente coletados devido aos avanços das tecnologias e das iniciativas de instituições focadas no monitoramento da biodiversidade, tais como, o Institute Max Planck de Ornitologia (MAX PLANCK, 2019) e o Centro Nacional de Pesquisa e Conservação de Mamíferos Carnívoros (CENAP, 2019), integrante do Instituto Chico Mendes de Conservação da Biodiversidade (ICMBIO, 2019). Outras instituições como, o Instituto Nacional de Pesquisas Espaciais (INPE, 2019) e WorldClim - Global Climate Data (WORLDCLIM, 2019), também, estão focadas na coleta de dados, mas relativos aos fatores ambientais. Portanto, os dados de biodiversidade estão disponíveis ampliando a capacidade de acompanhamento, estudo e gerenciamento do movimento dos animais e dos fatores ambientais. $O$ desafio é como realizar a análise exploratória desses dados de forma a obter conhecimento sobre a interação entre os animais e o ambiente. Desta forma, nesta tese é apresentado um framework, denominado AniMoveMineR, que tem como objetivo permitir a análise das interações entre os animais e o ambiente, ao longo do tempo e espaço, utilizando dados espaçotemporais referentes à movimentação animal e aos fatores ambientais. A contribuição científica desse trabalho é fornecer o framework como uma solução unificada para a análise exploratória dos dados de movimentação animal para que os pesquisadores possam: realizar análises para compreender a evolução da vida do animal, seu comportamento, como utiliza o espaço ao longo do tempo e o nível de correlação entre os animais e o ambiente, provendo informações que orientem os pesquisadores e órgãos públicos na tomada de decisão relativa às ações de preservação e conservação do meio ambiente. A movimentação e o comportamento animal são amplamente estudados na literatura, mas nenhum trabalho correlato se aproxima do framework proposto. Para avaliar o AniMoveMineR foram realizados diversos estudos de caso, dos quais são apresentados dois aplicados na área de biodiversidade com onças pintadas, da região do Pantanal - Brasil, e macacos (Cebus Capucinus), de Barro Colorado Island - Panamá, mostrando como o framework pode ser utilizado na análise exploratória do movimento dos animais.

Palavras - Chave: Ciência dos dados, Análise de dados, Mineração de dados, Trajetória animal, Comportamento animal. 


\begin{abstract}
Spatio-temporal data on animal movement has been widely collected through sensors or Global Positioning Systems (GPS) tracking systems due to advances in technologies and initiatives from institutions focused on biodiversity monitoring, for example, the Max Planck Institute for Ornithology (MAX PLANCK, 2019) and the National Center for Research and Conservation of Carnivorous Mammals (CENAP, 2019), member of the Chico Mendes Institute for Biodiversity Conservation (ICMBIO, 2019). Other institutions, such as, National Institute for Space Research (INPE, 2019) and WordClim - Global Climate Data (WORLDCLIM, 2019) are also focused on data collection, but related to environmental factors. Thus, the biodiversity data available is increasing the ability to monitor, study and manage animal movement and environmental factors. The challenge is how to perform the exploratory analysis of such data in order to gain knowledge about the interaction between animals and the environment. Therefore, this thesis presents a framework titled AniMoveMineR, which seeks to enable the analysis of interactions between animals and the environment over time and space, using spatiotemporal data related to animal movement and environmental factors. The scientific contribution of this research is to provide the framework as a unified solution for exploratory analysis of animal movement data so that researchers can: perform analyses to understand the evolution of animal life, its behavior, how it uses space over time and the level of correlation between animals and the environment, providing information to guide researchers and public agencies in decision regarding environmental preservation and conservation efforts. Animal movement and behavior are widely studied in literature, but no related work matches the proposed framework. To evaluate AniMoveMineR several case studies were carried out, two of which are applied in the area of biodiversity, with jaguars from the Pantanal region - Brazil, and monkeys (Cebus Capucinus) from Barro Colorado Island - Panama, further highlighting how the framework can be used for exploratory analysis of animal movement.
\end{abstract}

Keywords: Data science, Data analytics, Data mining, Animal trajectory, Animal behavior. 


\section{LISTA DE FIGURAS}

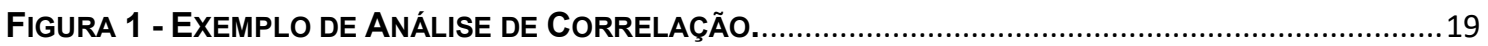

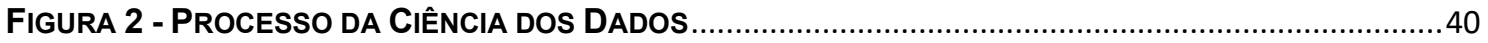

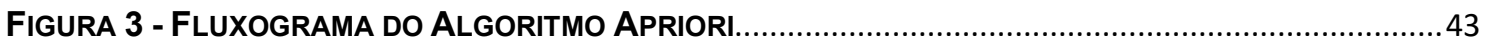

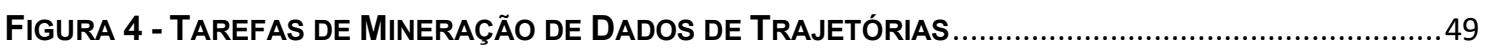

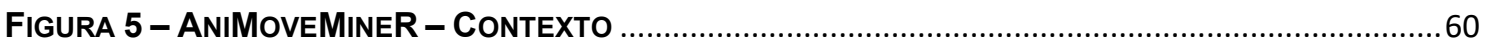

FIGURA 6 - ANIMOVEMINER - FRAMEWORK

FIGURA 7 - INTERFACE PARA ENTRADA DE DADOS DO ANIMOVEMINER - RSTUDIO (KNIT) ..................64

FIGURA 8 - ANIMOVEMINER - DESCRIÇÃO DAS ETAPAS DA ANÁLISE DE DADOS ……………...............6

FIGURA 9 - ETAPA A: IDENTIFICAR O COMPORTAMENTO INDIVIDUAL DO ANIMAL ..................................66

FIGURA 10 - FLUXOGRAMA DA ETAPA A1 - IDENTIFICAR OS ESTADOS DO COMPORTAMENTO ANIMAL 67

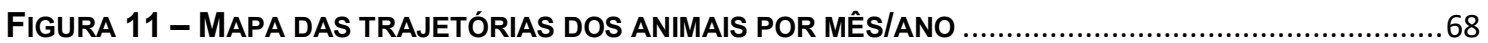

FIGURA 12 - FLUXOGRAMA DA ETAPA A2 - IDENTIFICAR OS PERÍODOS DE OCORRÊNCIA DOS ESTADOS

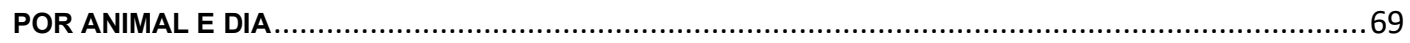

FIGURA 13 - ESTADOS DO COMPORTAMENTO ANIMAL POR DIA E HORA .......................................... 70

FIGURA 14 - TEMPO MÉDIO DE DURAÇÃO DOS ESTADOS DE COMPORTAMENTO DO ANIMAL POR MÊS E

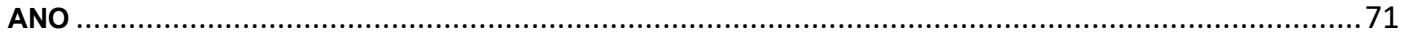

FIGURA 15 - FLUXOGRAMA DA ETAPA A3 - IDENTIFICAR A FREQUÊNCIA DE OCORRÊNCIA DO ESTADO 72

FIGURA 16 - HORÁRIOS DE MAIOR FREQUÊNCIA DE OCORRÊNCIA DOS ESTADOS DE COMPORTAMENTO POR MÊS/ANO

FIGURA 17 - FREQUÊNCIA DE OCORRÊNCIA DOS ESTADOS DE COMPORTAMENTO ANIMAL POR PERÍODO

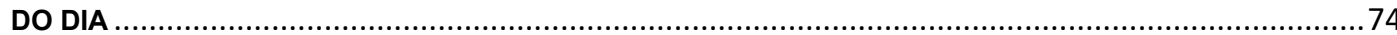

FIGURA 18 - FLUXOGRAMA DA ETAPA A4 - IDENTIFICAR O HOME RANGE ANIMAL ……………............

FIGURA 19 - MAPA DE HOME RANGE POR ANIMAL, MÊS E ANO ..................................................... 75

FIGURA 20 - MAPA DE HOME RANGE POR ANIMAL, MÊS E ANO E ESTADO DE COMPORTAMENTO, ........76

FIGURA 21 - ETAPA B: IDENTIFICAR OS FATORES AMBIENTAIS VIZINHOS DA OCORRÊNCIA DO

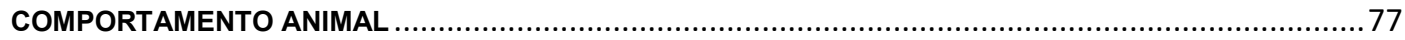

FIGURA 22 - FLUXOGRAMA DA ETAPA B1 E B2 - IDENTIFICAR OS FATORES AMBIENTAIS VIZINHOS DO

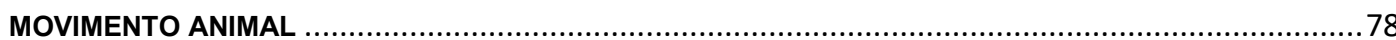

FIGURA 23 - ETAPA C: IDENTIFICAR A CORRELAÇÃO ENTRE O COMPORTAMENTO ANIMAL E OS FATORES AMBIENTAIS VIZINHOS.

FIGURA 24 - FLUXOGRAMA DA ETAPA C1 E C2 - IDENTIFICAR A CORRELAÇÃO ENTRE $O$ COMPORTAMENTO ANIMAL E OS FATORES AMBIENTAIS VIZINHOS ….......................................

FIGURA 25 - GRÁFICO DE CONFIANÇA ENTRE OS ANIMAIS POR MÊS E ANO …….................................. 82

FIGURA 26 - GRÁFICO DE NIIVEL DE CORRELAÇÃO ENTRE ANIMAIS POR MÊS E ANO $\ldots \ldots \ldots \ldots \ldots \ldots \ldots \ldots \ldots \ldots \ldots . . . . . . . . . . . . . .12$

FIGURA 27 - GRÁFICO DE NÍVEL DE CORRELAÇÃO ENTRE ANIMAIS POR ANO …..................................8

FIGURA 28 - GRAFOS DE DEPENDÊNCIA ENTRE OS ANIMAIS BASEADA NO LIFT ..................................8 84

FIGURA 29 - GRÁFICO DE CORRELAÇÃO ENTRE ANIMAIS PARA DIFERENTES VALORES DE MINSUP E

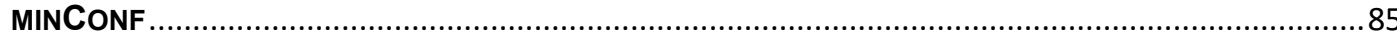

FIGURA 30 - RESULTADO DA ANÁLISE DA TABELA DE CONTINGÊNCIA E COEFICIENTE DE CRAMER .....85

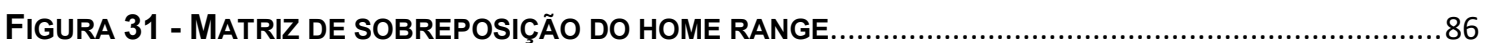

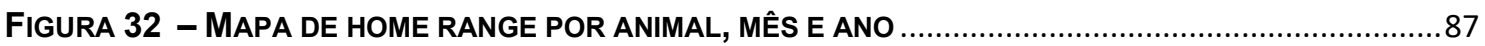

FIGURA 33 - MAPA DE HOME RANGE POR ANIMAL, ESTADO DO COMPORTAMENTO, MÊS E ANO ............87

FIGURA 34 - DISTÂNCIA MÉDIA ENTRE OS ANIMAIS PARA O RAIO DE DISTÂNCIA IGUAL A 400 METROS 88

FIGURA 35 - DISTÂNCIA MÉDIA ENTRE OS ANIMAIS PARA O RAIO DE DISTÂNCIA IGUAL A 900 METROS 89

FIGURA 36 - MAPA DA TRAJETÓRIA DA ONÇA PICOLÉ EM FEVEREIRO/2015 .................................... 91

FIGURA 37 - MATRIZ DE ESTADOS DE COMPORTAMENTO DA ONÇA PICOLÉ EM FEVEREIRO/2015 ........92

FIGURA 38 - TEMPO MÉdIO DE DURAÇÃo DOS ESTADOS DE COMPORTAMENTO DA ONÇA PICOLÉ EM 2015

FIGURA 39 - HORÁRIOS DE MAIOR FREQUÊNCIA DE OCORRÊNCIA DOS ESTADOS DE COMPORTAMENTO .

FIGURA 40 - FREQUÊNCIA DE OCORRÊNCIA DOS ESTADOS DE COMPORTAMENTO DA ONÇA PICOLÉ POR

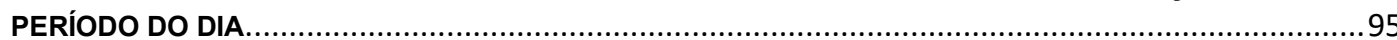

FIGURA 41 - MAPA DE HOME RANGE DA ONÇA PICOLÉ - (A) POR MÊS E ANO E (B) POR ESTADO DE COMPORTAMENTO, MÊS E ANO

FIGURA 42 - GRÁFICO DE NÍVEIS DE CORRELAÇÃO ENTRE PARES DE ONÇAS PARA DIFERENTES VALORES DE CONFIANÇA E SUPORTE MÍNIMO

FIGURA 43 - GRÁFICO DE CORRELAÇÃo ENTRE AS ONÇAS POR MÊS PARA O ANO DE 2015..................98 
FIgURA 44 - GRÁFICO dE NívEIS DE DEPENDÊNCIA (LIFT) ENTRE PARES DE ONÇAS PARA DIFERENTES VALORES DE CONFIANÇA E SUPORTE MÍNIMO

FIGURA 45 - GRÁFICO DE PROBABILIDADE DE OCORRÊNCIA DE UMA ONÇA EM FUNÇÃO DE OUTRA (MINSUP E MINCONF = 1\%)

FIGURA 46 - GRÁFICO DE PROBABILIDADE DE OCORRÊNCIA DE UMA ONÇA EM FUNÇÃO DE OUTRA (MINSUP

FIGURA 47 - RESULTADO DA ANÁLISE DE CRAMER PARA AS ONÇAS EM FEVEREIRO DE 2015 ...........101

FIGURA 48 - RESULTADO DA ANÁLISE DE CRAMER PARA AS ONÇAS EM MARÇO, ABRIL E MAIO DE 2015

FIGURA 49 - MATRIZ DE ÍNDICE DE SOBREPOSIÇÃO DE HOME RANGE DAS ONÇAS .............................1102

FiguRA 50 - HOME RANGE dAS ONÇAS PICOLÉ E AliCE EM JANEIRO (A), FEVEREIRO (B) E MARÇO (C)

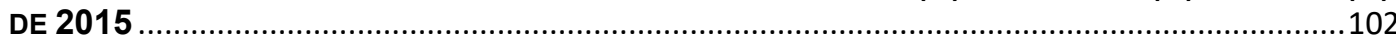

Figura 51 - Home RANGe das OnÇAS (A) CAIMAN E DALE (B) CAIMAN E FERA EM FeVEREIRo/2015 E (C) CAIMAN, FERA E PICOLÉ EM MARÇO/2015 .............................................................. 103

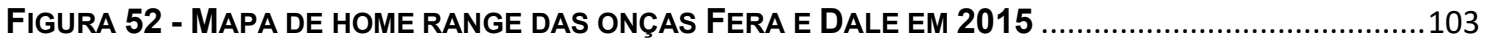

FIGURA 53 - HOME RANGE DAS ONÇAS PICOLÉ E ALICE DURANTE O FORRAGEAMENTO EM FEVEREIRO

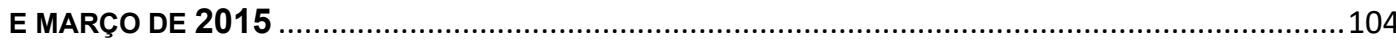

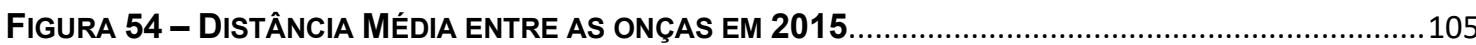

FIGURA 55 - DISTÂNCIA MÉDIA ENTRE AS ONÇAS FERA E DALE EM 2015 PARA A DISTÂNCIA LIMITE IGUAL A 400 METROS

FIGURA 56 - GRÁFICO DE CONFIANÇA ENTRE O ESTADO DE FORRAGEIO E AS ESTAÇÕES DO ANO....107

FIGURA 57 - NÍVEL DE DEPENDÊNCIA ENTRE O ESTADO DE FORRAGEIO E AS ESTAÇÕES DO ANO .....108

FIgURA 58 - NívEL dE CORRELAÇÃo ENTRE O ESTADO DE FORRAGEIO E AS ESTAÇÕES do ANO.......108

FIgURA 59 - RESULTADO dO COEFICIENTE DE CRAMER PARA A CORRELAÇÃO ENTRE O FORRAGEAMENTO E AS ESTAÇÕES DO ANO ....................................................................... 109

FIGURA 60 - GRÁFICO DE OCORRÊNCIA DO FORRAGEAMENTO POR PERÍODO DO DIA E ESTAÇÃO DO ANO

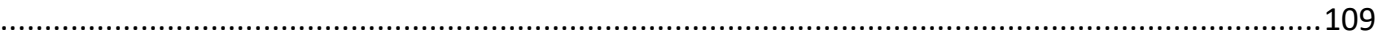

FIGURA 61 - GRÁFICO DE OCORRÊNCIA DOS ESTADOS DE COMPORTAMENTO PARA A ONÇA PICOLÉ POR PERÍODO DO DIA E ESTAÇÃO DO ANO.

FIgURA 62 - MAPA dE SOBREPOSIÇÃo dE HOME RANGE - MACACO 51 ........................................113

FiguRA 63 - MATRIZ DE ESTAdOS DE COMPORTAMENTO dO MACACO 51 - NoveMBRO/2004.........114

FIgURA 64 - MATRIZ DE ESTADOS DE COMPORTAMENTO DO MACACO 51 - JANEIRO/2005 .............114

FIGURA 65 - DURAÇÃO DOS ESTADOS DE COMPORTAMENTO DO MACACO 51 - NOVEMBRO/2004 ...115

FIGURA 66 - DURAÇÃO DOS ESTADOS DE COMPORTAMENTO DO MACACO 51 - JANEIRO À ABRIL DE 2005

FIGURA 67 - FREQUÊNCIA DE OCORRÊNCIA DOS ESTADOS DE COMPORTAMENTO DO MACACO 51 POR PERÍODO DO DIA EM 2004

FIGURA 68 - FREQUÊNCIA DE OCORRÊNCIA DOS ESTADOS DE COMPORTAMENTO DO MACACO 51 POR

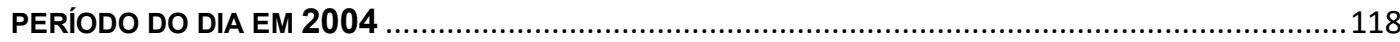

FIGURA 69 - NÍVEL DE CORRELAÇÃO ENTRE OS MACACOS EM NOVEMBRO/2004 .............................119

FIGURA 70 - MEDIDAS DE SUPORTE E CONFIANÇA PARA MINERAÇÃO DOS DADOS DOS MACACOS EM 2004

FIgURA 71 - NívEL DE CORRELAÇÃo ENTRE MACACOS EM MARÇO E ABRIL DE 2005 ........................121

FIGURA 72 - PROPORÇÃO DE SOBREPOSIÇÃO DA ÁREA DE VIDA DOS MACACOS EM 2004 .................122

FiguRA 73 - RESULTADO dO COEFICIENTE DE CRAMER ENTRE OS MACACOS EM NOVEMBRO DE 2004

IGURA 74 - MAPA DO HOME RANGE dOS MACACOS 54 E 55 EM NOVEMBRO/2004...........

FIgURA 75 - MAPA DO HOME RANGE dOS MACACOS 54 E 55 EM JANEIRO (A), FEVEREIRO (B), MARÇO

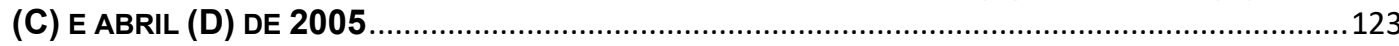

FiguRA 76 - MAPA DO HOME RANGE dos MACACOS 53 E 57 EM NOVEMBRo (A) E DEZEMBRo (B) DE 2004

FIgURA 77 - MAPA DO HOME RANGE dOS MACACOS 53 E 57 EM JANEIRO (A), FEVEREIRO (B), MARÇO (C) E ABRIL (D) DE 2005

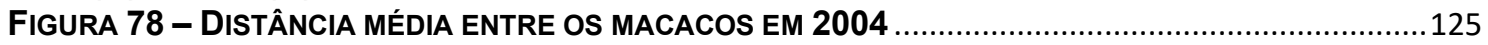

FIGURA 79 - DISTÂNCIA MÉDIA ENTRE OS MACACOS 54 E 55 EM NOVEMBRO E DEZEMBRO DE 2004.126

FIGURA 80 - ARQUITETURA DE COMPONENTES DO ALGORITMO ANIMOVEMINER - ETAPA A ...........150

FIgURA 81 - ARQUITETURA DE COMPONENTES DO ALGORITMO ANIMOVEMINER - ETAPA B ..........151

FIgURA 82 - ARQUITETURA DE COMPONENTES DO ALGORITMO ANIMOVEMINER - ETAPA C ............151 


\section{LISTA DE TABELAS}

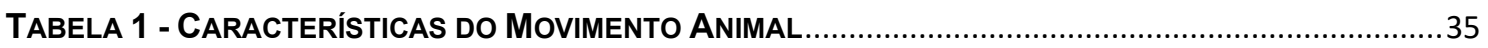

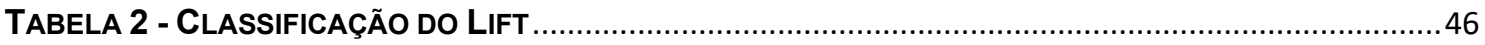

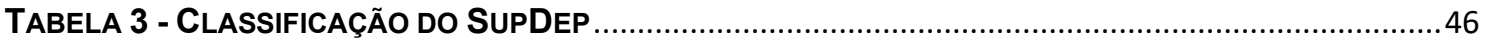

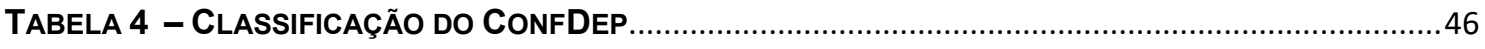

TABELA 5 - CLASSIFICAÇÃo do CoEfICIENTE dE CoRRELAÇÃO (PHI) ..............................................47

TABELA 6 - EXEMPLO DE RESULTADO DO ALGORITMO APRIORI - REGRAS DE ASSOCIAÇÃO ................47

TABELA 7 - PADRÕES DE MOVIMENTO: DEFINIÇÃo E ALGORITMOS ...................................................50

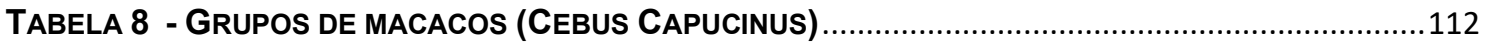

TABELA 9 - PERÍODOS DE OCORRÊNCIA DOS ESTADOS DO MACACO 51 EM NOVEMBRO/2004 ............115

TABELA 10 - ESTADOS DO COMPORTAMENTO DO ANIMAL 51 POR PERÍODO DO DIA - JANEIRO/2005 


\section{LISTA DE ABREVIATURAS E SIGLAS}

$\begin{array}{ll}\text { ALA } & \text { Atlas of Living Australia } \\ \text { BISON } & \text { Biodiversity Information Serving Our Nation } \\ \text { CENAP } & \text { Centro Nacional de Pesquisa e Conservação de Mamíferos Carnívoros } \\ \text { DataONE } & \text { Data Observation Network for Earth } \\ \text { GBIF } & \text { Global Biodiversity Information Facility } \\ \text { ICMBIO } & \text { Instituto Chico Mendes de Conservação da Biodiversidade } \\ \text { INPE } & \text { Instituto Nacional de Pesquisas Espaciais } \\ \text { KDD } & \text { Knowledge Discovery in Database } \\ \text { UD } & \text { Utilization Distribution }\end{array}$




\section{Sumário}

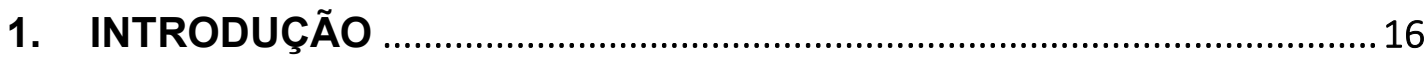

$1.1 \quad$ Caracterização do problema .......................................................................................18

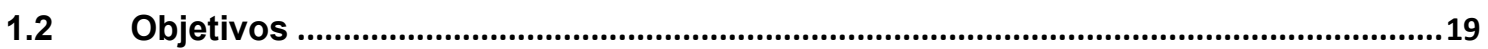

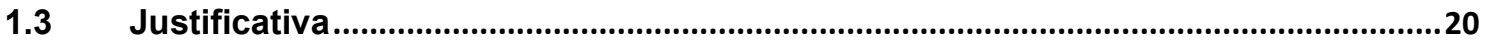

$1.4 \quad$ Materiais e métodos ……………………...............................................................21

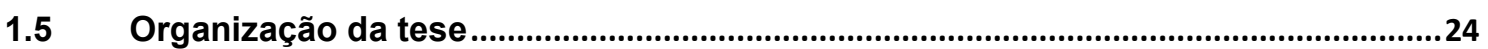

2. FUNDAMENTOS SOBRE DADOS ESPAÇO-TEMPORAIS .................... 26

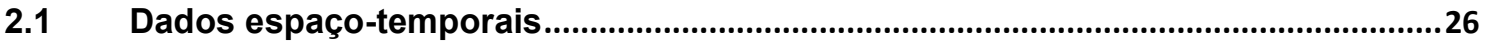

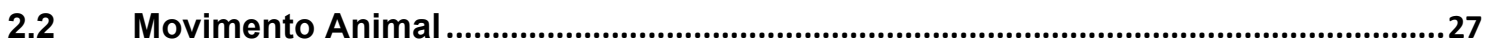

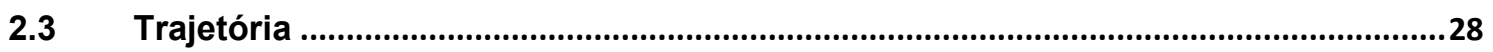

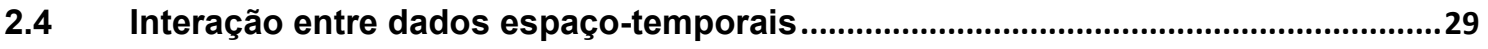

2.5 Distância baseada em coordenadas geográficas ........................................................30

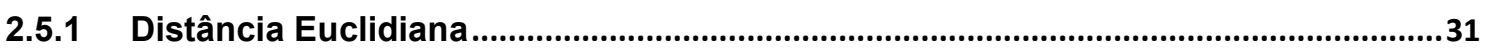

2.5.2 Fórmula de Haversine …...............................................................................................

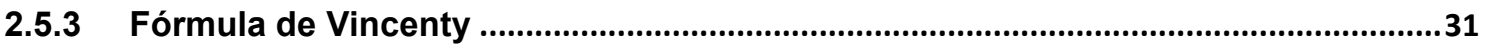

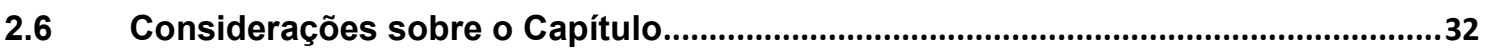

3 FUNDAMENTOS SOBRE O COMPORTAMENTO ANIMAL .....................33

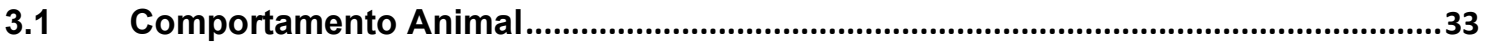

3.2 Segmentação de trajetória para identificar o comportamento animal .......................35

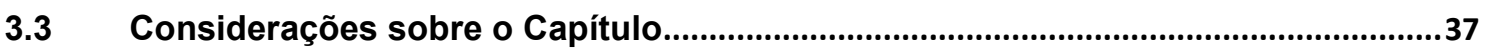

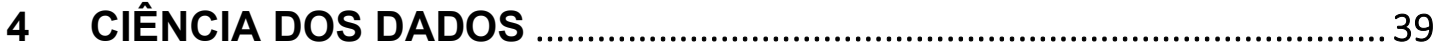

4.1 Processo da Ciência dos Dados ........................................................................................

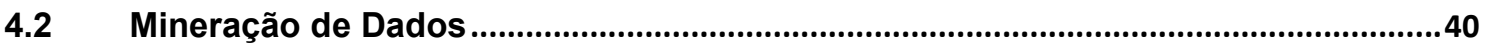

4.3 Tarefas de Mineração de Dados .....................................................................................

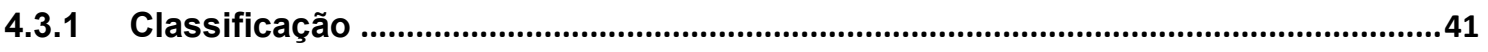

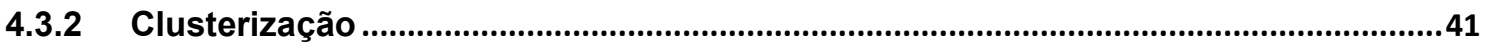

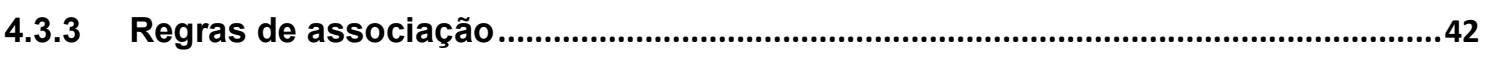




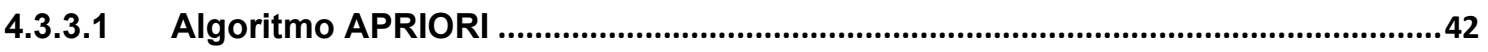

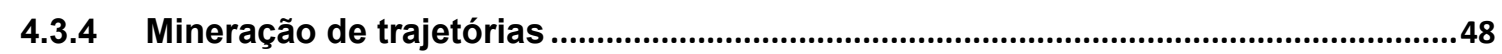

4.4 Considerações sobre o Capítulo......................................................................................50

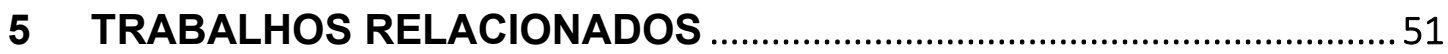

5.1 Considerações sobre o Capítulo.....................................................................................59

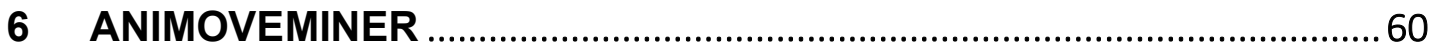

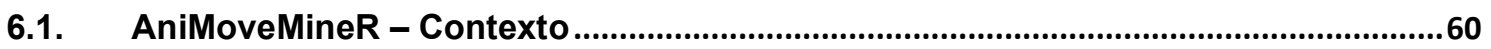

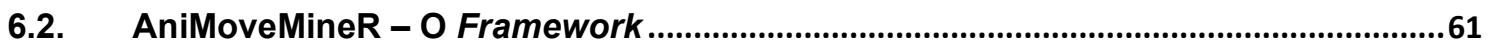

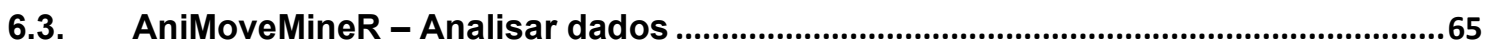

6.3.1. Etapa A - Identificar o comportamento individual dos animais ..............................66

6.3.2. Etapa B - Identificar os fatores ambientais vizinhos das ocorrências dos animais 76

6.3.3. Etapa C - Identificar a correlação entre o comportamento animal e os fatores ambientais vizinhos ................................................................................................................... 79

6.4. Considerações sobre o Capítulo.......................................................................................89

7 AVALIAÇÃO DO ANIMOVEMINER - ESTUDOS DE CASO ..................... 90

7.1 Estudo de Caso I - Análise exploratória da movimentação de onças do Pantanal Brasil 90

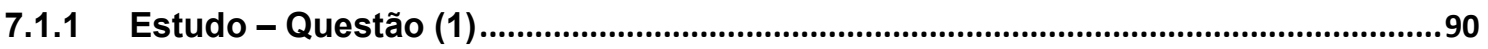

7.1.2 Estudo - Questão (2) ......................................................................................................106

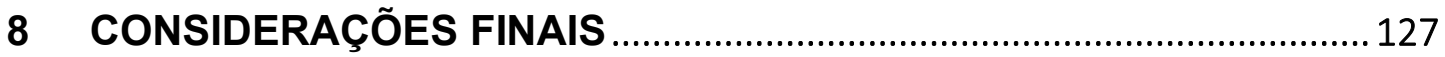

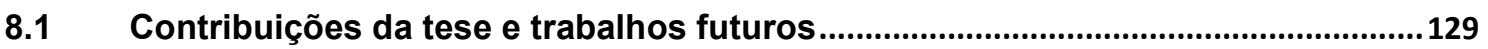

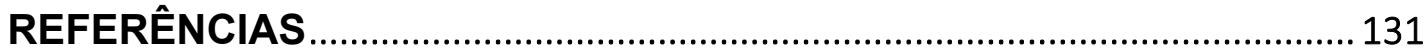

APÊNDICE A - PSEUDOCÓDIGOS - ANIMOVEMINER .............................. 146

A1. Pseudocódigo da etapa A1 - Identificar o Comportamento Animal ..............................146

A2. Pseudocódigo da etapa A2 - Identificar os períodos e duração da ocorrência dos

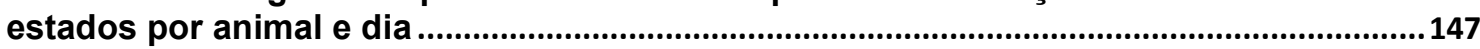

A3. Pseudocódigo da etapa A3 - Identificar a frequência de ocorrência do estado de comportamento por período.

A4. Pseudocódigo da etapa A4 - Identificar o home range animal 
A5. Pseudocódigo da etapa B1 e B2 - Identificar os fatores ambientais da vizinhança..148

A6. Pseudocódigo da etapa C1 e C2 - Identificar a correlação entre o animal e os fatores ambientais. 


\section{INTRODUÇÃO}

A sociedade convive com o risco iminente de grandes desastres e catástrofes naturais causadas em grande parte pela exploração humana inadequada dos recursos naturais. A degradação ambiental está ocorrendo em todo o mundo, o que leva à diminuição dos recursos naturais e ecossistemas (KELLING et al., 2009) e agrava a frequência e o impacto das secas, inundações, incêndios florestais e outros desastres naturais.

Diante disso, diversas organizações no mundo voltaram seus esforços para estudar e desenvolver meios de coletar informações que permitam o monitoramento das ocorrências ambientais e forneça subsídios para análises que orientem as ações dos órgãos governamentais e da sociedade. $\mathrm{Na}$ área de estudo da biodiversidade foram criados portais na internet (CORRÊA et al., 2018) que disponibilizam dados centralizados sobre ocorrências de espécies, tais como, o Global Biodiversity Information Facility (GIBF, 2019), o Atlas of Living Australia (ALA, 2019), o Biodiversity Information Serving Our Nation (BISON, 2019) e o Portal da Biodiversidade Brasileira (PORTALBIO, 2019). Esses dados são essenciais para diversos tipos de análises relacionadas ao impacto da atividade humana na biodiversidade.

O monitoramento da biodiversidade tem um papel fundamental, porque $\mathrm{o}$ seu objetivo é oferecer informações sobre mudanças, status e tendências, de espécies ou conjunto de espécies, por meio de repetidas observações e medições da diversidade biológica ao longo do tempo. Com estas informações pode-se detectar flutuações em populações ou perturbações, tais como, ações antrópicas, espécies invasoras, caça, poluição, mudanças climáticas e outras alterações do meio ambiente.

A análise da movimentação animal, também, é uma forma de identificar as transformações que ocorrem na natureza por fornecer subsídios para a descoberta de conhecimento sobre o comportamento animal ao longo do tempo e espaço. O comportamento animal é estudado em uma área da Ecologia, denominada Etologia, sendo utilizado como base para compreender como as espécies se relacionam e como interagem com o meio ambiente (SCOTT, 2009). Neste contexto, a interdisciplinaridade entre a ecologia e a ciência da computação na análise do movimento dos animais é de suma importância 
(DEMŠAR et al., 2015), porque os avanços tecnológicos ampliaram a capacidade de acompanhar, estudar e gerenciar os movimentos dos animais, por meio da coleta de dados espaço-temporais com dispositivos, tais como, sensores e sistemas de rastreamento Global Positioning Systems (GPS) (PHAN, 2013). Esses dados representam a evolução espaço-temporal de um objeto em movimento (WAGNER et al., 2013), a sua trajetória.

A análise da trajetória dos animais (CALENGE; ROYER, 2015) permite identificar as características do movimento dos animais (SARKAR et al., 2015), rastrear os vestígios migratórios dos animais (DAMIANI; ISSA; CAGNACCI, 2014), o comportamento (ALVARES et al., 2011) (DODGE; WEIBEL; LAUBE, 2009) e a situação de vida dos animais (WU et al., 2014). Este tipo de análise fornece ainda subsídios para a descoberta de padrões de comportamento (OLIVEIRA, 2013), que representam a maneira como o animal interage com o ambiente, tais como, animais que se movem juntos (HAl et al., 2012a) (AUNG; TAN, 2010) ou que se encontram ao longo das trajetórias (LI et al., 2010a) e as áreas, frequentemente, visitadas pelos animais (PALMA et al., 2008).

Instituições como o Instituto Max Planck de Ornitologia (MAX PLANCK, 2019) e o Instituto Chico Mendes de Conservação da Biodiversidade (ICMBIO, 2019) têm focado esforços na aquisição de dados de movimentação dos animais para melhorar a pesquisa sobre o comportamento dos animais e sua interação com o ambiente e as mudanças ambientais. O Instituto Max Planck de Ornitologia, em coordenação com o Museu de Ciências Naturais da Carolina do Norte, a Universidade do Estado de Ohio e a Universidade de Konstanz organizam o projeto internacional Movebank (WIKELSKI;KAYS, 2016) que disponibiliza dados sobre rastreamento de animais e o sistema Environmental Data Automated Track Annotation System - Env-DATA (DODGE et al., 2013) que consiste em um conjunto de ferramentas de análise que vinculam, por meio de mapas e gráficos, dados de movimentação animal com dados ambientais colocalizados.

No Brasil, o Centro Nacional de Pesquisa e Conservação de Mamíferos Carnívoros (CENAP, 2019), integrante do Instituto Chico Mendes de Conservação da Biodiversidade (ICMBIO, 2019), possui projetos que utilizam dados de movimentação animal com o foco em entender a ecologia das espécies de mamíferos carnívoros como forma de estimular, coordenar, desenvolver 
atividades de manejo, pesquisa e conservação e a resolução de conflitos entre predadores e a comunidade (CENAP, 2019).

Com base na distribuição dos dados espaço-temporais do movimento dos animais, o comportamento animal pode ser identificado. No entanto, o comportamento animal corresponde à caracterização de como o animal interage com o ambiente e exige que diferentes análises sejam realizadas para obter indicações sobre o comportamento animal. Desta forma, o desafio é como usar a análise exploratória dos dados espaço-temporais do movimento animal para obter indicações sobre como o animal se comporta no tempo e no espaço.

Em face desse desafio, torna-se oportuno apropriar-se de algoritmos de definição de trajetórias, de classificação de comportamento animal e de mineração de dados, por regras de associação, para propor um framework que combine esses algoritmos e permita realizar a análise exploratória do movimento animal ao longo do tempo e espaço.

\subsection{Caracterização do problema}

Com base na distribuição dos dados espaço-temporais, relativos à movimentação animal, pode-se obter padrões de comportamento dos animais e identificar quais fatores ambientais ocorreram próximos ao animal ao longo do tempo e espaço.

Há diversas iniciativas que tratam a aquisição de dados de movimentação animal, no entanto o desafio é como realizar a análise exploratória desses dados, conjuntamente, com os dados ambientais de forma a descobrir conhecimento sobre a interação entre animais e fatores ambientais e classificar estas relações.

Por interação entende-se a correlação entre animais e os fatores ambientais ao longo do espaço e do tempo. Na Figura 1, é representada uma sequência de pontos distribuídos ao longo do tempo e espaço que formam a trajetória de um animal. Ao redor de cada ponto há uma área demarcada por um círculo de raio determinado que define o espaço de análise do comportamento animal em relação aos fatores ambientais. $\mathrm{Na}$ análise da interação entre o comportamento animal e os fatores ambientais podem ocorrer no mínimo três situações baseadas no conceito de correlação para diferentes locais, mas no mesmo intervalo de tempo. Na situação $(A)$, na vizinhança da ocorrência do comportamento animal não ocorre o fator ambiental. Na situação (B), a 
ocorrência do fator implica na não ocorrência do comportamento animal negativamente correlacionados. Na situação (C), há alta frequência de ocorrência do fator próximo à ocorrência do comportamento animal positivamente correlacionado.

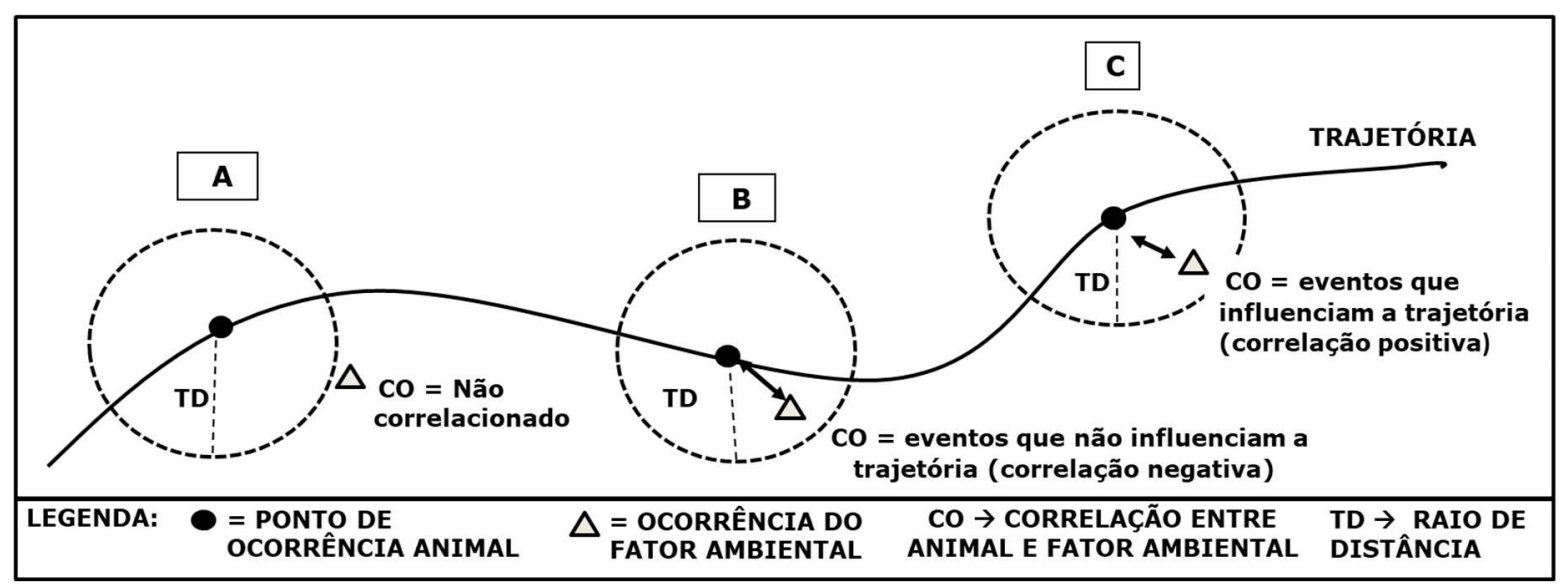

Figura 1 - Exemplo de Análise de Correlação.

Outro aspecto do desafio é como correlacionar os dados de movimentação animal, que são compostos por informações espaço-temporais (latitude, longitude e data/hora), com os dados ambientais que são heterogêneos e podem conter:

- Dados espaço-temporais (latitude, longitude, data/hora);

- Somente dados temporais (data/hora), sendo o espaço caracterizado por uma região, área ou estação;

- Dados categóricos ou nominais.

A granularidade dos dados, também, pode representar um aspecto do desafio já que algumas análises requerem um nível maior de detalhamento e utilizam data (dd/mm/aaaa) e a hora (hh:mm:ss), e outras são mais alto nível, e consideram somente mês/ano e intervalos entre horas.

\subsection{Objetivos}

Esta tese de doutorado teve por objetivo geral propor um framework para a análise exploratória dos dados de movimentação animal para a obtenção de conhecimento sobre as interações entre animais e fatores ambientais ao longo do tempo e espaço.

Para atender ao objetivo principal alguns objetivos específicos foram estabelecidos: 
- Estudo de técnicas computacionais para descoberta, classificação e análise do comportamento animal ao longo do tempo e espaço;

- Propor um framework para a análise exploratória dos dados espaçotemporais relativos à movimentação animal para a obtenção de indicativos sobre a interação entre os animais e o meio ambiente ao longo do tempo e espaço. A análise exploratória no contexto do framework proposto inclui: classificar o comportamento animal em estados; identificar a duração e a frequência dos estados comportamentais; identificar o uso do espaço (home range) pelo animal; identificar animais ou fatores ambientais vizinhos e a correlação entre animais e diferentes fenômenos ambientais, como chuva, variação de temperatura e presença de outros animais.

- Avaliar o framework por meio de estudos de caso, aplicados à área de biodiversidade, com espécies das regiões do Pantanal - Brasil e Barro Colorado Island - Panamá.

\subsection{Justificativa}

Os conhecimentos obtidos por meio das análises espaço-temporais são essenciais em qualquer domínio da ciência. No âmbito específico da biodiversidade as análises de dados espaço-temporais podem fornecer informações valiosas para direcionar as ações de preservação e conservação da biodiversidade, tais como:

- Mudanças, status e tendências de espécies ou conjunto de espécies que abrange acompanhar o comportamento animal por meio de observações e medições da diversidade biológica ao longo do tempo;

- Flutuações em populações e perturbações, tais como, ações antrópicas, espécies invasoras, caça, poluição, mudanças climáticas e outras alterações do meio ambiente;

- Presença, ausência ou abundância de uma determinada espécie, que pode refletir uma condição ambiental específica que pode ser analisada com a finalidade de diagnosticar a saúde de um ecossistema;

- A análise da distribuição das espécies que identifica a ocorrência de espécies raras e ameaçadas e fornece subsídios para a definição de áreas prioritárias para ações de conservação e preservação ambiental. 
- A coleta sistemática de dados primários sobre o ambiente, fauna e flora permite comparações e análises padronizadas e podem ser utilizadas para inferir tendências e orientar ações de gestão preditivas, adaptativas e corretivas para mitigar as perdas e prejuízos futuros para a natureza e a sociedade.

Nessa pesquisa tem-se como premissa que os dados de movimentação animal e sobre fatores ambientais são dados espaço-temporais que já foram coletados e estão disponíveis para o uso. O desafio é como realizar a análise exploratória dos dados de movimentação animal como um primeiro passo para responder questões relacionadas ao comportamento individual do animal e sua interação com o ambiente. Desta forma, com um framework que permita a análise exploratória dos dados de movimentação os pesquisadores podem: realizar as análises dos dados espaço-temporais de movimentação animal e relacionar estes dados com os fatores ambientais de forma a compreender a história de vida dos animais; identificar as áreas ou regiões onde prevalece sua existência ao longo do tempo; as mudanças comportamentais dos animais e os possiveis fatores ambientais que influenciaram estas mudanças.

Compreender a evolução da vida do animal, seu comportamento, como utiliza o espaço ao longo do tempo e com quais fatores ambientais está mais ou menos correlacionado pode fornecer informações que orientem os pesquisadores e órgãos públicos na tomada de decisão relativa às ações de preservação e conservação do meio ambiente que possuem impacto direto na vida humana.

\subsection{Materiais e métodos}

Para atender aos objetivos desta pesquisa não experimental foram definidas atividades organizadas em quatro etapas:

I. Revisão da literatura que abrange os estudo dos conceitos básicos, recursos e ferramentas disponíveis relacionadas à área pesquisada;

II. Experimentação que envolve a aplicação dos conceitos e exploração do uso dos recursos e ferramentas disponíveis acerca da área pesquisada por meio de estudos de caso;

III. Elaboração do framework proposto que consiste na definição do framework e na descrição de cada etapa - contribuição da pesquisa; e 
IV. Validação do framework proposto por meio de estudos de caso.

Na etapa de revisão da literatura foram realizadas pesquisas bibliográficas e a reprodução de experimentos relacionados aos temas: dados espaçotemporais, movimento animal, análise de trajetórias, análise de dados espaçotemporais, comportamento animal, ciência dos dados e mineração de dados.

Algumas ferramentas e algoritmos para análise de dados foram utilizadas como forma de explorar e compreender as funcionalidades já disponíveis e identificar lacunas a serem preenchidas. As ferramentas e algoritmos utilizados foram: Weka (SHETTY; VADIVEL; VAGHELLA, 2010), Movebank (WIKELSKI; KAYS, 2016), o Environmental Data Automated Track Annotation System (EnvDATA)(DODGE et al., 2013), Rapidminer (RAPIDMINER, 2015), SatScan (SATSCAN, 2015), Tableau (TABLEAU, 2017) e algoritmos como o Get_Move (HAI; PONCELET; TEISSEIRE, 2012), Weka-SpatialTemporal (BOGORNY et al., 2011) e as bibliotecas do R com o uso da ferramenta RStudio (RSTUDIO, 2014).

$\mathrm{Na}$ etapa de experimentação foram realizados estudos de casos exploratórios de mineração de dados de ocorrências de espécies, extraídos do portal de dados Global Biodiversity Information Facility (GBIF, 2019), cujos resultados estão consolidados em artigo (FONTES; STANZANI; CORREA, 2015). Estes estudos acerca da biodiversidade foram desenvolvidos com base nos conhecimentos adquiridos ao longo da participação do projeto "Sistema de Informação para o Monitoramento da biodiversidade em Unidades de Conservação Brasileiras", que tem como resultado o Portal da Biodiversidade Brasileiro (PORTALBIO, 2019). Este projeto foi desenvolvido pelos pesquisadores da POLI-USP, numa parceria entre o Instituto Chico Mendes de Conservação da Biodiversidade (ICMBIO) e o Ministério do Meio Ambiente (MMA) e apoiado pela Deutsche Gesellschaft für Internationale Zusammenarbeit (GIZ).

A etapa de elaboração do framework foi norteada pelo processo da ciência dos dados. O processo da ciência dos dados (DEKHTYAR, 2016), abrange as atividades desde a aquisição dos dados, formulação de perguntas e a análise de dados, até a visualização dos resultados e a aquisição de novos conhecimentos. 
O framework proposto tem como foco a etapa de análise de dados do processo de ciência dos dados, no entanto, para a realização da análise é fundamental considerar as outras etapas do processo. Desta forma, o primeiro passo é formular questões que devem ser respondidas com o uso do framework. Os dados devem ser recuperados e preparados para a análise e, por meio da combinação de algoritmos contemplados no framework, é realizada a análise dos dados e os resultados obtidos podem ser visualizados e analisados pelos pesquisadores por meio de listas, gráficos e mapas.

$\mathrm{Na}$ composição do framework proposto foi efetuada a combinação dos algoritmos e métodos, que são:

- O Residence in Space and Time Method (RST) (TORRES et al., 2017): que classifica o comportamento animal em estados;

- O algoritmo Apriori (AGRAWAL; SRIKANT, 1994): que identifica as regras de associação entre animais e os fatores ambientais;

- A Fórmula de Vincenty (VINCENTY, 1975): usada para calcular a distância entre animais e fatores ambientais;

- O AdehabitatLT (CALENGE; ROYER, 2015): fornece classes e métodos em $\mathrm{R}$ que permitem manipular, analisar e segmentar as trajetórias dos animais;

- O AdehabitatHR (CALENGE, 2006): fornece classes e métodos em R para analisar e identificar o home range do animal, que consiste na área que o animal percorreu em suas atividades de cuidado parental, busca de alimento e acasalamento (BURT, 1943);

- O Outliers (KOMSTA, 2011): pacote do R, aplicado para identificar os períodos (hora início/fim) da ocorrência dos estados de comportamento animal, que estão muito acima ou abaixo da média dos períodos.

- Coeficiente de Cramer (ACOCK; STAVIG, 1979): utilizado na análise da correlação entre os animais e os fatores ambientais. O coeficiente de Cramer é uma medida de associação entre variáveis categóricas.

No Apêndice $\mathbf{C}$ pode-se consultar a arquitetura do framework que descreve a finalidade, como são aplicados e a relação entre os algoritmos e métodos.

$\mathrm{Na}$ fase de validação do framework foram realizados estudos de caso com datasets de movimentação animal extraídos de repositórios de dados abertos 
como o Movebank (WIKELSKI; KAYS, 2016): dados de movimentação de doze Cebus Capucinus (macaco-prego-de-cara-branca), na região de Barro Colorado Island no Panamá, referentes aos anos de 2004 e 2005 (LI et al., 2013).

Foram utilizados, também, um dataset de rastreamento de onças-pintadas (MORATO et al., 2018), fornecidos por pesquisadores do CENAP, sendo um composto por dados de nove onças pintadas da região de Taiamã. Estes pesquisadores contribuiram com a pesquisa por meio do compartilhamento de conhecimento sobre a área de biodiversidade, análise dos estudos de caso e na elaboração de artigos.

Já os datasets referentes aos dados ambientais foram extraídos de repositórios online. Os dados climáticos e sobre as estações do ano de Barro Colorado Island foram extraídos do repositório (STRI, 2019) e a definição das estações do ano de Taiamã de (ICMBIO, 2017).

\subsection{Organização da tese}

Esta tese está organizada em nove capítulos, incluindo os capítulos de Introdução (1) e Conclusão (9).

O Capítulo 2, apresenta os conceitos sobre dados espaço-temporais, movimento animal e trajetórias dos animais, bem como, sobre a interação entre dados espaço-temporais e os recursos utilizados para o cálculo da distância entre esses dados.

O Capítulo 3, apresenta os conceitos e padrões referentes ao comportamento animal que abrange os métodos de segmentação de trajetórias utilizados para identificar as mudanças de comportamento animal.

O Capítulo 4, são mostrados os conceitos sobre ciência dos dados e mineração de dados. As técnicas de mineração de dados são detalhadas, sendo apresentadas as especificidades que norteiam a mineração de dados de trajetórias.

O Capítulo 5, apresenta as pesquisas contidas na literatura que possuem a mesma linha de atuação da presente pesquisa, ressaltando semelhanças e diferenças entre as abordagens.

O Capítulo 6, apresenta o AniMoveMineR detalhando as etapas e os algoritmos que compõem o framework. 
O Capítulo 7, apresenta a avaliação do framework que consiste em estudos de casos aplicados na área de biodiversidade.

O Capítulo 8, apresenta uma sumarização das contribuições e resultados obtidos com a proposta, ressaltando os pontos de melhoria e trabalhos futuros. 


\section{FUNDAMENTOS SOBRE DADOS ESPAÇO-TEMPORAIS}

Neste Capítulo é apresentada a fundamentação sobre dados, dados espaço-temporais, movimento animal e trajetórias dos animais. Os fundamentos sobre as relações entre o movimento e o comportamento animal também são explorados neste capítulo.

\subsection{Dados espaço-temporais}

Antes de conceituar dados espaço-temporais cabe definir o que são: dados, informação e conhecimento. Os dados são símbolos ou signos não estruturados, sem significado. A informação agrega significado e utilidade aos dados. O conhecimento é algo que permite a tomada de decisão para a agregação de valor (CASTRO; FERRARI, 2016). Desta forma, os dados são a matéria-prima da informação, a informação são os dados processados e o conhecimento consiste na informação processada e convertida em experiência pelo indivíduo.

Os dados podem ser classificados como:

- Dados espaciais: descrevem a localização de um objeto no espaço por meio de pontos expressos, por exemplo, pela combinação de coordenadas de latitude e longitude, determinando locais ou lugares;

- Dados temporais: representam a evolução de uma característica do objeto ao longo de um período, determinando o momento, a duração ou o período que separa dois pontos usados como base para classificar um evento, sendo expressos por data (ano/mês/dia) e hora (hora/minuto/ segundo);

- Dados espaço-temporais: registram o estado do objeto, eventos ou posição no espaço ao longo do tempo.

Os dados espaço-temporais podem ser categorizados (ATLURI; KARPATNE; KUMAR, 2018) como:

- Evento: caracterizado por um ponto de localização e hora, que denota onde e quando o evento ocorreu, respectivamente;

- Trajetória: indica os caminhos traçados por corpos que se movem no espaço ao longo do tempo; 
- Ponto: um ponto espaço-temporal pode ser representado como uma tupla contendo as informações espaciais e temporais de uma observação;

- Raster: medições de um campo espaço-temporal contínuo ou discreto que ocorrem em locais fixos no espaço e pontos fixos no tempo.

\subsection{Movimento Animal}

O movimento animal corresponde à variação da posição espacial de um objeto em relação a um referencial ao longo do tempo, gerando um traço ou caminho em espaços geográficos representados por uma série de pontos cronologicamente ordenados que formam a trajetória.

O estudo do movimento dos animais possui uma hierarquia de questões exploratórias, explicativas e preditivas (GURARIE et al., 2016).

- Questões exploratórias, relacionadas aos movimentos individuais, auxiliam na identificação do que o animal está fazendo;

- Questões explicativas, buscam explicar os comportamentos e/ou transições entre comportamento em termos de padrões sazonais, estímulos ambientais ou presença de membros da mesma espécie;

- Questões preditivas, buscam antecipar o uso do espaço por um animal com base numa análise do comportamento e depende de uma boa compreensão das propriedades e da estrutura do comportamento animal.

$\mathrm{Na}$ tese a análise tem como foco as questões exploratórias e explicativas sobre o movimento animal.

Por meio das análises dos dados espaciais do movimento animal podese determinar o home range do animal. O home range (área de vida) corresponde à área percorrida pelo animal em suas atividades de busca de alimento, acasalamento e cuidado parental (BURT, 1943), podendo o tamanho dessa área variar com base nas características do animal, como o tamanho.

Para formalizar a definição de home range foi criado o modelo Utilization Distribution (UD) (WINKLE, 1975). O UD provê a densidade de probabilidade de um animal estar localizado em um ponto com base em suas coordenadas geográficas. Por meio deste modelo define-se o home range do animal como a menor área em que um animal tem probabilidade de ser localizado. A kernelUD é uma função bivariada utilizada para estimar o UD (WORTON, 1989), 
basicamente, a função é colocada sobre cada realocação e os valores dessas funções são calculados em média juntos (CALENGE, 2006).

\subsection{Trajetória}

O movimento dos animais gera dados espaço-temporais que resultam nas trajetórias que descrevem os caminhos percorridos pelo animal. A trajetória é um traço gerado por uma entidade em movimento em espaços geográficos representados por uma série de pontos ordenados cronologicamente (ZHENG, 2015), podendo ser descrita como o movimento de uma entidade, pessoa, veículo ou um animal, ao longo do tempo (GÜTING; VALDÉS; DAMIANI, 2015); é uma representação da evolução espaço-temporal de um objeto em movimento.

Uma trajetória representa a localização de um objeto em movimento ao longo de um certo intervalo de tempo (BUCHIN et al., 2011) (DODGE; WEIBEL; LAUBE, 2009). As trajetórias são classificadas em dois tipos:

- tipo I, o tempo não é precisamente conhecido ou não são considerados os deslocamentos da trajetória;

- tipo II, o tempo é conhecido para cada deslocamento. Este tipo de trajetória pode ser dividido em dois subtipos: trajetórias regulares, caracterizadas por intervalos de tempo constantes entre sucessivos deslocamentos; trajetórias irregulares, caracterizadas por um intervalo de tempo variável entre deslocamentos sucessivos.

As características de uma trajetória (GIANNOTTI; PEDRESCHI, 2008) podem ser: a forma geométrica da trajetória no espaço; distância viajada ou comprimento da trajetória; duração da trajetória no tempo; direção da trajetória; média, mediana e velocidade máxima; períodos de velocidade constante, aceleração, desaceleração e quietude; tempo de início e fim, duração, posição inicial e final, velocidade inicial e final; comportamento das direções, tais como, períodos retos, curvilíneos, movimento circular; posições iniciais e finais e direções dos períodos, duração e ângulos das curvas.

O AdehabitatLT (CALENGE; ROYER, 2015) fornece classes e métodos em $\mathrm{R}$ que permitem manipular, analisar e segmentar as trajetórias dos animais. A função Itraj (CALENGE; DRAY; ROYER-CARENZI, 2009) gera trajetórias a partir de dados de localização, como a longitude e latitude, e de tempo (data/hora). Um objeto da classe Itraj pode conter dados de vários animais, com 
várias trajetórias por animal e, basicamente, é uma lista (data frame R), contendo: as coordenadas das realocações da trajetória ( "burst" de realocação); seu tempo (tipo II) ou uma variável numérica indicando sua ordem (tipo I) na trajetória e alguns parâmetros descritivos dos passos.

Cada trajetória deve conter um atributo identificador (ID) do animal monitorado e uma identificação única (burst) para cada trajetória. O burst foi utilizado para gerar trajetórias com o foco em diferentes aspectos do movimento, tais como: trajetórias por data, estado de comportamento e identificador do animal; ano, mês e identificador do animal; ano, mês, identificador do animal e estado de comportamento.

\subsection{Interação entre dados espaço-temporais}

O movimento animal ocorre em uma área e pode ser influenciado por eventos, fenômenos ou pelo movimento de outros objetos que estão no mesmo ambiente.

A análise de movimento (GIANNOTTI; PEDRESCHI, 2008) engloba detectar correlações e dependências: entre características do movimento; entre o movimento e características dos locais, momentos no tempo e entidades e/ou eventos e fatores externos; e representar o movimento como diferentes movimentos interagindo. Algumas das relações que podem ocorrer são:

- Coocorrência: que consiste em subconjuntos de eventos que ocorrem juntos no espaço e no tempo (PILLAl et al., 2012) (AYDIN et al., 2014);

- Correlação: que indica o grau de relacionamento entre duas variáveis (HOFFMANN; VIEIRA, 1998). Segundo Mukaka (2012), a correlação estatística é um método de avaliação da probabilidade de associação linear bidirecional entre duas variáveis. O coeficiente de correlação mede a correlação estatística entre variáveis, que representa a força da associação linear entre elas. O valor do coeficiente pode variar entre -1 e 1, e quanto mais próximo desses valores maior a correlação. Coeficiente positivo indica que o valor de uma variável aumenta em função do aumento do valor de outra. Coeficiente negativo indica que o valor de uma variável diminui em função do aumento do valor de outra. $\mathrm{Na}$ presente pesquisa entende-se por correlação o grau de associação 
entre duas variáveis determinado pela frequência de coocorrência entre elas.

- Causalidade: refere-se à relação entre um evento, a causa, e um segundo evento, o efeito. Considera-se o segundo acontecimento como uma consequência do primeiro (NARAYAN; RAMAKRISHNAN, 2014).

- Similaridade: permite calcular a distância entre trajetórias e pontos vizinhos ou outras trajetórias (DODGE; WEIBEL; LAUBE, 2009). Quanto maior a similaridade, menor a distância entre os pontos (GOLDSCHMIDT; PASSOS, 2005). Há várias formas de definir similaridade entre instâncias de dados espaço-temporais, tais como pontos e trajetórias (ATLURI; KARPATNE; KUMAR, 2018):

- Similaridade entre pontos: dois pontos são considerados próximos, estejam eles dentro de uma vizinhança espaço-temporal. A vizinhança espaço-temporal de um ponto pode ser definida usando uma distância limite fixa no espaço e no tempo;

- Similaridade entre trajetórias: é medida em termos de frequência de coocorrência, que é o número de vezes que dois corpos em movimento aparecem espacialmente próximos.

\subsection{Distância baseada em coordenadas geográficas}

No framework proposto um dos aspectos que deve ser considerado é mapear a vizinhança dos pontos de movimentação do animal ao longo de sua trajetória, identificando animais próximos ou fatores ambientais que ocorreram nas proximidades.

Como a movimentação animal é realizada ao longo da superfície da Terra, determinar a distância entre dois pontos de localização é um pouco mais complicado do que traçar uma linha reta entre eles e medi-la, é preciso considerar no cálculo a curvatura do planeta.

Desta forma, foram estudadas métricas e fórmulas que permitem calcular a distância entre duas localizações, tomando como ponto de partida suas coordenadas de latitude e longitude, tais como, a distância euclidiana e as fórmulas de Haversine e Vincenty. 


\subsubsection{Distância Euclidiana}

A distância entre dois pontos ou o comprimento do caminho que os conecta, é denominada Distância Euclidiana e pode ser calculada utilizando o teorema de Pitágoras. Quando os dados são densos ou contínuos, essa é a melhor medida de proximidade (CASTRO; FERRARI, 2016).

\subsubsection{Fórmula de Haversine}

A fórmula de Haversine é uma equação de navegação que, baseada na longitude e latitude, proporciona um espaçamento circular entre dois pontos na superfície da esfera (BRUMMELEN, 2013). Esta fórmula retorna a menor distância entre dois pontos sobre a superfície da Terra, considerando a curvatura da Terra, o raio dela, cujo valor é aproximadamente $6371 \mathrm{~km}$, ignorando elevação, colinas, entre outros.

\subsubsection{Fórmula de Vincenty}

A fórmula de Vincenty (VINCENTY, 1975) calcula a distância geodésica entre pares de pontos (latitude/longitude), na superfície da Terra, usando a precisão elipsoidal do modelo da Terra que considera o achatamento dos polos. Geodésica é a distância mais curta que une dois pontos de tal forma que, para pequenas variações na forma da curva, seu comprimento é estacionário, ou seja, a curva mais curta entre dois pontos. O cálculo da distância geodésica considera a distância percorrida sobre uma esfera com raio equivalente ao raio médio da terra igual a $6378 \mathrm{~km}$.

Comparando a distância Euclidiana e as fórmulas de Haversine e Vincenty, tem-se que a primeira é adequada quando os objetos sob análise estão em uma superfície plana (DEZA, M.; DEZA, E., 2009) e as outras duas são adequadas para contextos geográficos, em situações nas quais os objetos estão dispostos em uma superfície esférica, planeta Terra, e são representados pelas coordenadas geográficas latitude e longitude.

Segundo Hijmans, Williams e Vennes (2016) há quatro formas de se calcular a distância entre dois objetos geográficos, que são: lei esférica dos cossenos, Haversine, Vincenty Sphere e Vincenty Ellipsoid (VINCENTY, 1975). Os cálculos de distância utilizando os três primeiros métodos geram resultados idênticos e consideram que a Terra é uma esfera perfeita. No entanto, quando 
necessário maior precisão nos resultados deve-se utilizar a Vincenty Ellipsoid (HIJMANS; WILLIAMS; VENNES, 2016).

\subsection{Considerações sobre o Capítulo}

Neste Capítulo foram apresentados os conceitos sobre dados espaçotemporais, movimento e trajetória animal, que fornecem subsídios para analisar a movimentação dos animais com a finalidade de identificar suas trajetórias e a distância geográfica entre a ocorrência do movimento animal e os fatores ambientais, bem como, compreender quais as interações que podem ser estabelecidas utilizando os dados espaço-temporais relativos ao movimento animal. O AdehabitatLT é utilizado na pesquisa para identificar as trajetórias dos animais, a fórmula de Vincenty é adotada para o cálculo da distância entre pontos, referentes ao movimento animal e aos fatores ambientais, e o AdehabitatHR é aplicado para identificar a área de vida do animal (home range). 


\section{FUNDAMENTOS SOBRE O COMPORTAMENTO ANIMAL}

Neste Capítulo é apresentada a fundamentação sobre a classificação e os padrões de comportamento animal e, também, a segmentação de trajetórias para identificar comportamento animal.

\subsection{Comportamento Animal}

O comportamento animal é a caracterização da forma como o animal interage com o ambiente (SNOWDON, 1999). O comportamento animal é dividido em:

- Estados: comportamento que ocorre por um período prolongado, por exemplo, repouso, em trânsito e forrageamento;

- Eventos: comportamento de curta duração e medido ao longo do tempo, por exemplo, lutando, perseguindo e desviando.

Com os dados dos movimentos individuais dos animais pode-se analisar os eventos e estados de comportamento animal, utilizando um método de segmentação que particione as trajetórias com base em determinadas características do movimento, tais como, velocidade, direção e tempo de permanência, determinando os pontos de mudança do comportamento animal (EDELHOFF; SIGNER; BALKENHOL, 2016). O ponto de mudança do comportamento animal indica o local e o momento (latitude/longitude/data/hora) da ocorrência da transição do comportamento animal.

O comportamento animal é influenciado por fatores internos e externos. Os fatores internos podem ser: os genes, variação genética entre indivíduos relacionados com a sobrevivência e reprodução, ou a fisiologia. Os fatores externos podem ser as mudanças climáticas, outros animais, o relevo, entre outros.

A análise da trajetória animal (DEMŠAR et al., 2015) pode fornecer informações sobre por que, como, quando e onde os animais se movimentam e como esse processo está relacionado ao meio ambiente, o que permite rastrear os vestígios migratórios, o comportamento e a situação de vida dos animais. $O$ movimento animal possui características, tais como, velocidade, tempo de residência, direção e distância percorrida ou a frequência com que os animais são encontrados no mesmo tempo e espaço, que são utilizadas para identificar os padrões de comportamento dos animais. A análise de padrão de 
comportamento dos animais em movimento tem como objetivo identificar como os animais se comportam ao longo das trajetórias, obtendo indícios sobre fatores que influenciaram este comportamento.

$\mathrm{Na}$ literatura destacam-se duas referências que abordam o processo de descoberta de padrões de comportamento baseado em dados de movimentação: Laube, Imfield e Weibel (2005), que definem cinco tipos de padrões de comportamento animal; Dodge, Weibel, Lautenschütz (2008) que definem sete padrões de comportamento. Dentre os padrões definidos por Laube, Imfield e Weibel (2005) estão os padrões de:

- Convergência: um grupo que vai para o mesmo lugar e chegam no mesmo ponto (convergem), mas não, necessariamente, ao mesmo tempo, por exemplo, pessoas indo para a estação de trem.

- Encontro: entidades que estão simultaneamente dentro de uma mesma região circular de raio R. (BUCHIN et al., 2012)

- Recorrência: entidades que visitam uma região circular pelo menos $k$ vezes.

- Flock: grupos de animais que se movem na mesma direção e tempo, por exemplo, um rebanho de ovelhas..

- Liderança, corresponde a um líder que se move para uma direção e, após um certo tempo, outros animais com distância próxima ao líder passam a se mover na mesma direção, por exemplo, a migração de aves.

Dentre os padrões definidos por Dodge, Weibel, Lautenschütz (2008) estão os padrões:

- Perseguição/Evasão (pursuit/evasion): comportamentos que ocorrem juntos. A evasão refere-se a uma entidade, exemplo presa, tentando se afastar e escapar de uma entidade perseguidora, exemplo predador. $\mathrm{O}$ padrão de perseguição refere-se a duas trajetórias que permanecem próximas por um período de tempo, de acordo com uma tolerância de tempo. Neste padrão considera-se como principais limites o tempo, a distância e a velocidade.

- Luta (fighting): combinação de perseguição e evasão, ataque e defesa. Referese a uma combinação de diferentes padrões no espaço e no tempo como: incidentes, concordância, a repetição e co-localização.

- Brincar (play): em animais, particularmente os jovens, o brincar é um forma de comportamento, composto por uma combinação de 
comportamentos de movimento, exibindo looping, traços rápidos e longos e com pausa.

- Congestionamento (Congestion): movimento com velocidade mais lenta do que a velocidade habitual e o tempo de viagem mais longa, por exemplo, um congestionamento seguido de um engarrafamento.

- Sacádico/fixação (Saccade/fixation): acompanhamento dos movimentos oculares, relacionados às pausas sobre regiões de interesse (fixações) e os movimentos rápidos entre fixações (sacádicos).

\subsection{Segmentação de trajetória para identificar o comportamento animal}

A segmentação envolve a partição de uma trajetória em um número de subtrajetórias, denominados segmentos (EDELHOFF; SIGNER; BALKENHOL, 2016). Os métodos de segmentação de trajetória utilizam as características do movimento animal ou a combinação destas variáveis determinando os pontos de mudança de comportamento do animal ao longo da trajetória. Na Tabela 1 , são apresentadas as características do movimento animal citadas ao longo da tese.

Tabela 1 - Características do Movimento Animal

\begin{tabular}{|l|l|}
\hline \multicolumn{1}{|c|}{ Característica } & Descrição \\
\hline Ângulo de rotação (turning angles) & $\begin{array}{l}\text { Ângulo de rotação relativo e absoluto entre consecutivas } \\
\text { realocações, mudança de direção. }\end{array}$ \\
\hline Comprimento do passo (step length) & Distância Euclidiana entre duas realocações consecutivas. \\
\hline Velocidade (velocity/speed) & $\begin{array}{l}\text { Distância percorrida entre duas realocações em um determinado } \\
\text { intervalo de tempo. }\end{array}$ \\
\hline $\begin{array}{l}\text { Persistência/velocidade de rotação } \\
\text { (persistence/ turning velocity) }\end{array}$ & Transformações de velocidade e ângulo de rotação. \\
\hline $\begin{array}{l}\text { Primeiro tempo de passagem (first } \\
\text { passage time) }\end{array}$ & $\begin{array}{l}\text { Tempo para cruzar um ponto final pré-determinado com base em um } \\
\text { círculo em torno de um deslocamento inicial. Soma os tempos de } \\
\text { todos os deslocamentos para frente e para trás no raio. }\end{array}$ \\
\hline $\begin{array}{l}\text { Tempo de Residência } \\
\text { (Residence time) }\end{array}$ & $\begin{array}{l}\text { Soma os tempos de todas as realocações (para trás e para a frente) } \\
\text { de uma trajetória dentro de uma determinada vizinhança em torno de } \\
\text { um deslocamento. }\end{array}$ \\
\hline
\end{tabular}

Fonte: (EDELHOFF; SIGNER; BALKENHOL, 2016)

Como exemplo de aplicação dos métodos de segmentação, com base nas características do movimento, pode-se citar o modelo de classificação de comportamento animal (SIPPEL et al., 2011) que classifica a trajetória em intervalos de tempo regulares, dentro de quatro modos, baseados nas mudanças das características de velocidade e ângulo de curvatura. O movimento é 
calculado com base na média do comprimento do passo, classificando o comportamento animal, como: slow - straight (lento - reto); slow - turning (lento - curva); fast - straight (rápido - reto) e fast - turning (rápido - curva). Na teoria do movimento animal os movimentos de migração, dispersão ou fuga tendem a ser caracterizados por percursos relativamente em linha reta e os comportamentos, tais como, descanso, forrageamento e reprodução são representados por caminhos tortuosos.

Outra abordagem que baseia-se nas características de velocidade e ângulo de curvatura do movimento é a DivClust (WU; YEH; CHEN, 2013) uma abordagem para encontrar estilos típicos regionais em movimento, dividindo e agrupando as trajetórias, considerando as restrições espaciais e temporais, sendo este seu diferencial já que os trabalhos existentes consideram apenas as propriedades espaciais das trajetórias. O DivClust particiona as trajetórias em segmentos com similar direção (ângulo de curvatura) e velocidade. Já o método Behavioral Change Point Analysis - BCPA (GURARIE; ANDREWS; LAIDRE, 2009) baseia-se na probabilidade de detectar pontos de mudança e segmenta as trajetórias com o foco na velocidade de trajetórias individuais.

Há abordagens, também, que analisam o tempo de residência, estadia ou permanência do animal em uma determinada área ou região. O método de Lavielle (LAVIELLE, 2005), é um método estatístico que pode ser utilizado para detectar os pontos de mudança na trajetória do movimento baseado na característica de tempo de residência (residence time). A quantidade de tempo que o animal permanece num determinado raio corresponde ao tempo de residência (RT). Foi criado para segmentar a trajetória com base nos locais onde o animal permaneceu muito tempo.

Outro método baseado no tempo de residência é o método Residence in Space and Time Method (RST) (TORRES et al., 2017) que tem como função classificar padrões de comportamento com base em dados de movimento, considerando o conceito de que estados de comportamento podem ser particionados pela quantidade de espaço e tempo ocupados em uma área de escala constante (por exemplo, $1 \times 1 \mathrm{~km}$ ). Desta forma, um círculo de raio $(R)$ é construído em torno de cada ponto de trajetória e a distância de residência (RD) e o tempo de permanência (RT) são calculados: 
- Distância de residência (RD): refere-se à somatória dos comprimentos do caminho dentro do círculo;

- Tempo de residência (RT): refere-se à somatória do tempo dispendido entre os locais dentro do círculo.

Os valores de RD e RT são normalizados dividindo-se o RD pelos valores máximos de RD e a RT pela RT máxima. Assim, todos os valores variam entre 0 e 1. O RT e o RD normalizados são subtraídos (RT - RD), gerando o resultado residual (entre -1 e 1). Assim, os estados podem ser classificados com base na análise de resíduos, considerando três estados de comportamento:

- Resíduo = 0: Tráfego, comportamento com pouco tempo e distância na área;

- Resíduo < 0: Descanso, comportamento com tempo alto na área, mas curta distância;

- Resíduo > 0: Area restricted search (ARS), forrageamento, que consiste na busca de alimentos, com alto tempo e distância percorrida na área.

Os dados de entrada para o método RST são os atributos:

- Nome do animal: refere-se ao identificador do animal;

- Posição do animal: refere-se à localização do animal (latitude/ longitude);

- Tempo: refere-se à data/hora do movimento do animal;

- Círculo de raio: refere-se ao raio em torno de cada ponto usado para encontrar o tempo de residência e a distância;

- Limiar: refere-se ao máximo de desvio permitido ao círculo em torno dos pontos de movimentação dos animais;

- Unidade de tempo: refere-se ao intervalo utilizado na análise dos dados, podendo ser definida como, segundos, minutos, horas, dias ou semanas.

\subsection{Considerações sobre o Capítulo}

Neste Capítulo foram apresentados os conceitos sobre comportamento animal, os tipos de comportamento existentes, os padrões de comportamento e as técnicas e métodos que segmentam as trajetórias dos animais de acordo com as características do movimento animal, tais como, velocidade, tempo de residência, e classificam o comportamento animal em estados e eventos. 
No framework proposto o comportamento animal é classificado em três estados: descanso (rest), trânsito (transit) e forrageamento (forage). Esses estados são identificados utilizando o Método RST que segmenta a trajetória animal com base na quantidade de espaço e tempo ocupados em uma área de escala constante. 


\section{CIÊNCIA DOS DADOS}

Neste Capítulo são apresentados conceitos sobre a Ciência dos Dados e as técnicas de Mineração de dados e de trajetórias.

\subsection{Processo da Ciência dos Dados}

A Ciência dos Dados, ou Data Intensive Science (HEY; TANSLEY; TOLLE, 2009), é um novo paradigma da ciência, que envolve a captura, curadoria e análise de grandes quantidades de dados, tais como, dados de sensoriamento remoto, por satélite e aéreo, instrumentos, sensores e a observação humana (MICHENER; JONES, 2012).

Diversos grupos de pesquisa estão voltados para estudos em Ciência dos Dados nas mais diferenciadas áreas. Um exemplo é o projeto DataONE (COBB, 2011) (REICHMAN; JONES; SCHILDHAUER, 2011) que visa a conservação de dados digitais biológicos, ecológicos e ambientais permitindo análises e predições. Algumas iniciativas de pesquisa englobam estudos sobre biodiversidade como a distribuição e abundância das aves (KELLING et al., 2009) e o estudo de genomas para diagnóstico e prognóstico de doenças como o câncer (PATEL et al., 2015).

O processo da Ciência dos Dados (DEKHTYAR, 2016) é considerado um ciclo formado por atividades que vão desde a formulação de questionamentos, a aquisição e adequação dos dados para a análise, passando pela análise dos dados, até a visualização dos resultados e a aquisição de novos conhecimentos. As oito etapas que compõem o processo da ciência dos dados são mostradas na Figura 2.

O framework proposto na tese é aderente ao processo de Ciência dos dados e abrange todas as etapas desse processo, mas com ênfase na etapa de análise de dados na qual a mineração de dados por regras de associação, combinada com algoritmos de análise de dados espaço-temporais, é utilizada para explorar os dados de movimentação animal e obter conhecimento sobre o comportamento animal. 


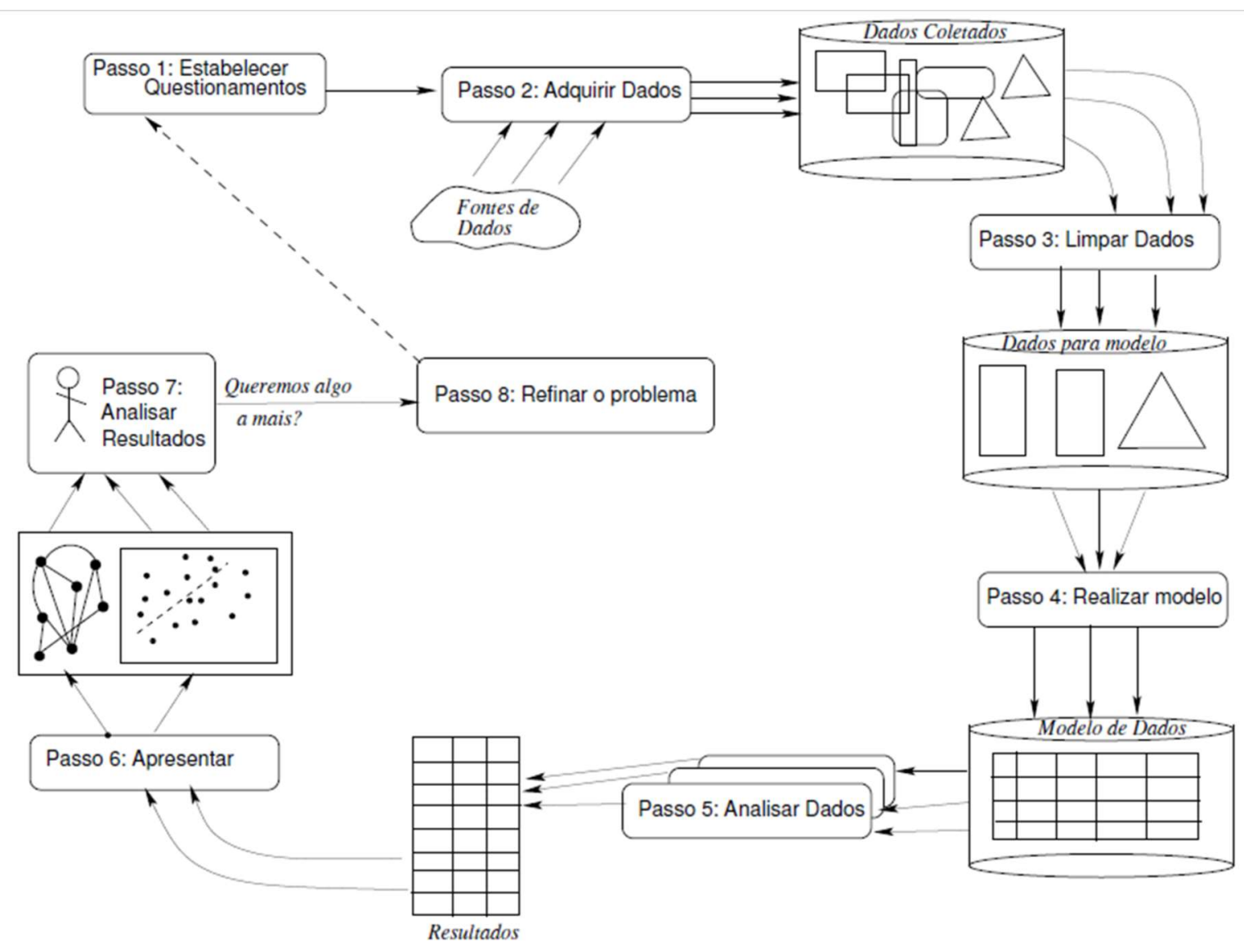

Figura 2 - Processo da Ciência dos Dados

Fonte: traduzido de (DEKHTYAR, 2016)

\subsection{Mineração de Dados}

A mineração de dados é uma parte do processo de Descoberta de Conhecimento em Banco de Dados (Knowledge Discovery in Database - KDD) (FAYYAD; PIATETSKY-SHAPIRO; SMYTH, 1996a) que consiste em uma metodologia para preparar e explorar dados, interpretar os resultados obtidos e adquirir conhecimento a partir dos dados.

No contexto da Ciência dos Dados, a mineração de dados é chamada de etapa de análise dos dados e compreende o conjunto de estratégias, ferramentas e algoritmos que permitem a exploração dos dados e a extração de padrões dos dados (FAYYAD; PIATETSKY-SHAPIRO; SMYTH, 1996b). Estes algoritmos compõem as técnicas de mineração de dados que podem ser classificadas como: supervisionadas e não supervisionadas.

A mineração de dados utiliza técnicas provenientes da aprendizagem de máquina, mas com objetivos distintos, considera-se que a mineração tem como 
foco a extração de conhecimento dos dados e a aprendizagem estuda e desenvolve sistemas que podem aprender com os dados.

\subsection{Tarefas de Mineração de Dados}

As técnicas supervisionadas, como a classificação, exigem a definição de parâmetros de entrada, as classes, que servem como referência para mineração. As técnicas não supervisionadas, como a clusterização, não requerem a entrada de parâmetros para serem utilizadas como referência (WITTEN; FRANK, 2005). A classificação, clusterização e regras de associação podem ser consideradas as principais tarefas de mineração de dados.

\subsubsection{Classificação}

A classificação (CASTRO; FERRARI, 2016) identifica grupos de itens e indivíduos baseado em um atributo ou classe pré-definido. Classificar um objeto significa atribuir a ele um rótulo, chamado classe. Um exemplo de algoritmo utilizado na classificação é o C4.5 (QUINLAN, 1992), que classifica os dados por meio da criação de uma árvore de decisão.

\subsubsection{Clusterização}

A clusterização de dados ou análise de agrupamentos é uma técnica que identifica grupos de itens baseados em um atributo ou classe não definido previamente. Esta tarefa pode ser utilizada para identificar similaridade entre trajetórias. O k-means (MACQUEEN, 1967) é um exemplo de algoritmo de clusterização amplamente utilizado. A técnica de clusterização é utilizada para identificar similaridade e pode ser um dos tipos a seguir (SHEKHAR et al., 2015):

- Hierárquica: inicia como um único cluster e, sucessivamente, desempenha a divisão ou a junção até que um critério de parada é encontrado. Com resultado fornece uma árvore de cluster denominado dendograma. Um exemplo de algoritmo utilizado na clusterização hierárquica é o Agnes (Aglomerative Nesting) (KAUFMAN; ROUSSEEUW, 2005);

- Particional: inicia como um único cluster e, iterativamente, realoca os pontos de dados para cada cluster até um critério de parada ser encontrado, um exemplo é o algoritmo k-means (MACQUEEN, 1967); 
- Baseado em densidade: identifica clusters com base na densidade de pontos de dados em uma região. Corresponde aos algoritmos que consideram os clusters como regiões densas de objetos no espaço, como por exemplo o algoritmo DBSCAN (ESTER et al., 1996).

\subsubsection{Regras de associação}

A mineração de regras de associação tem como finalidade encontrar elementos que determinam a presença de outros elementos no mesmo conjunto de dados, indicando a frequência de coocorrência dos elementos. A associação entre os itens é diferente da correlação entre eles, enquanto a associação busca relações de coocorrência, a correlação avalia a dependência linear entre eles. Portanto, a coocorrência de dois itens indica que ambos ocorrem juntos e a correlação entre dois itens, indica que uma influência na ocorrência do outro. O algoritmo Apriori (AGRAWAL; SRIKANT, 1994) é o principal algoritmo de mineração de regras de associação.

A mineração de dados é utilizada na exploração de dados de diversas áreas alguns exemplos são: o uso na área de aviação, para controle de trajetórias de voos (TANG et al., 2015) e na área de biotecnologia, para a análise de metagenomas (RASHEED, 2013) que envolve o sequenciamento do material genético de organismos coexistentes nos ecossistemas, tais como o mar, o solo e o corpo humano.

\subsubsection{Algoritmo APRIORI}

Para a aplicação da técnica de regras de associação é utilizado o algoritmo Apriori (AGRAWAL; SRIKANT, 1994), que identifica as regras de associação entre os dados com base na busca de itens frequentes que ocorrem simultaneamente em um conjunto de dados. Foi, inicialmente, utilizado na análise de cesta de compras em supermercados (Market Basket Analysis) para determinar como os itens comprados pelos clientes estavam relacionados, por exemplo, obtendo uma regra de associação que indica que um cliente quando compra pão também compra leite.

O detalhamento do algoritmo Apriori pode ser consultado no Apêndice B, no entanto, a Figura 3 mostra a estratégia adotada pelo algoritmo Apriori que consiste em decompor o problema em duas subtarefas: 
1. Geração do conjunto de itens frequentes: determina o conjunto de itens frequentes que possuem suporte maior ou igual ao suporte mínimo (minSup), definido como parâmetro de entrada. O suporte indica a frequência em que um ou mais itens ocorrem juntos;

2. Geração das regras: gera as regras de associação, considerando apenas aquelas que possuem confiança maior ou igual ao mínimo de confiança (minConf), definido como parâmetro de entrada. A confiança indica a probabilidade condicional de um item ocorrer, dada uma ocorrência de outro item.

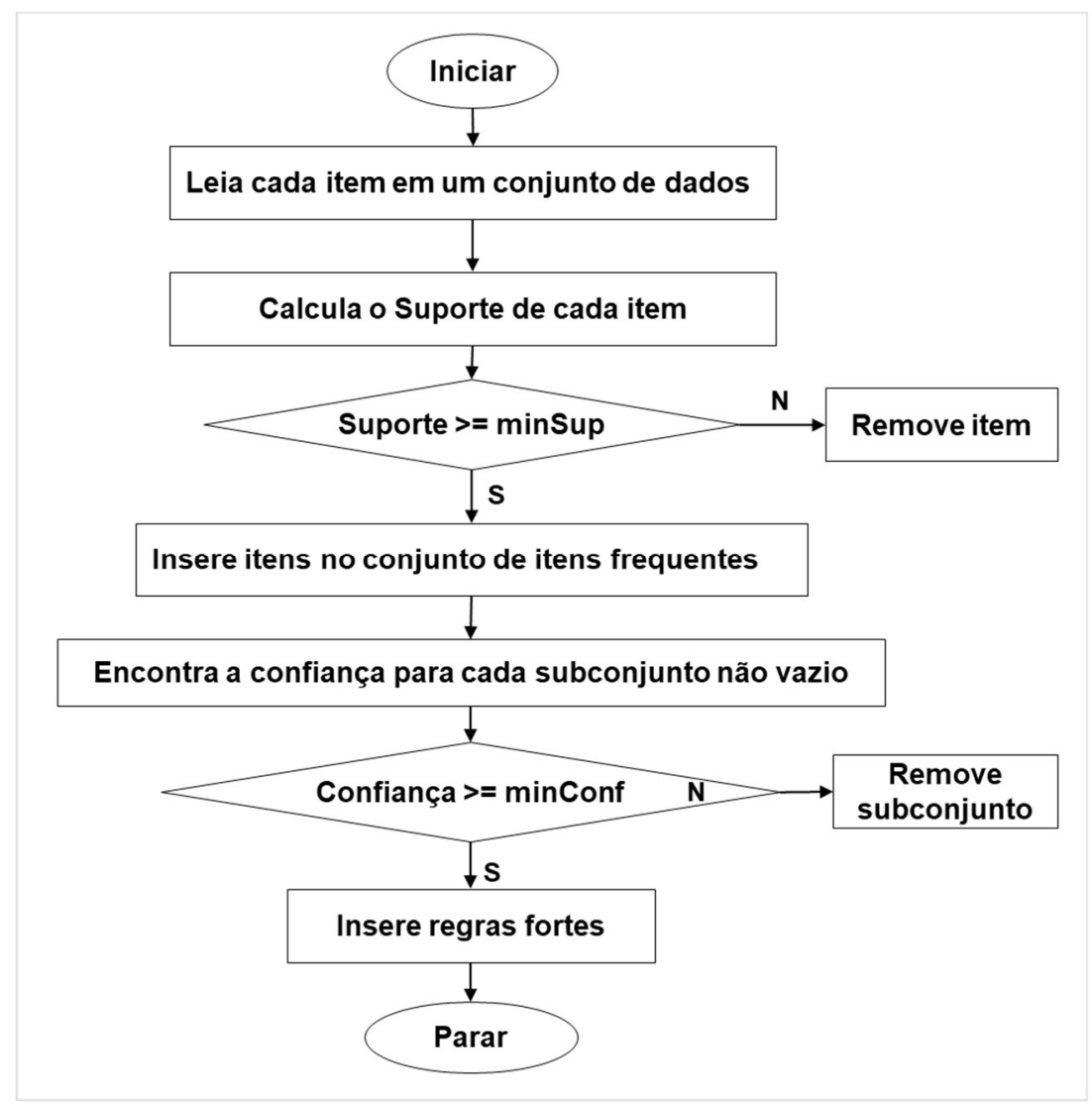

Figura 3 - Fluxograma do Algoritmo Apriori

Fonte: (MITTAL; PAREEK; AGARWAL, 2015)

A mineração de regras de associação pode gerar muitas regras como resultado, desta forma o problema corresponde a encontrar todas as regras que satisfazem um valor mínimo predefinido de suporte (minSup) e um valor mínimo predefinido de confiança (minConf). Suporte mínimo (minSup) é o percentual de frequência mínima de coocorrência de duas variáveis e a confiança mínima (minConf) é o percentual de probabilidade mínima de uma variável ocorrer dada a ocorrência de outra. O minSup e o minConf são usados pelo algoritmo Apriori 
para limitar a quantidade de regras de associação extraídas e para validar o conjunto de dados, tornando possível descartar regras menos relevantes e frequentes. Quanto menor o valor de minSup, menor a frequência de coocorrência entre as variáveis contidas nas regras para ser considerada relevante na análise. Quanto menor o valor de minConf, menor a probabilidade de ocorrência de uma variável em função da outra. As regras de associação são regras que ultrapassam o suporte mínimo (minSup) e um limite mínimo de confiança (minConf).

O algoritmo Apriori recebe como entrada ao menos duas variáveis ( $\mathrm{A}$ e $\mathrm{B}$ ) a serem relacionadas, por exemplo a variável A (Animal 1) e B (Animal 2), e a mineração dos dados é realizada para os valores dos parâmetros minSup e minConf. Diante disso, na tese as análises foram realizadas para os valores de minConf e minSup, definidos como:

- Baixo: 0,01 (1\%) ou 0,10 (10\%) valores, recuperam até mesmo as regras de associação que têm baixa frequência de coocorrência de variáveis (Sup.) e/ou a probabilidade de ocorrência de uma variável em relação a outras (Conf);

- Intermediário: 0,50 (50\%) ou 0,70 (70\%) valores, recuperam as regras de associação que apresentam um valor intermediário de frequência de coocorrência das variáveis (Sup) e/ou a probabilidade de ocorrência de uma variável em relação a outra (Conf);

- Alto: 0,9 (90\%) ou 1 (100\%) valores, recuperam as regras de associação que apresentam alta frequência de coocorrência das variáveis (Sup) e/ou a probabilidade de ocorrência de uma variável em relação à outras variáveis (Conf).

O resultado obtido são as regras de associação entre os dados e as medidas que identificam a correlação e dependência entre as variáveis analisadas (MANIMARAN; VELMURUGAN, 2015). As medidas obtidas com as regras de associação são:

- Suporte A (SupA): que indica a frequência de ocorrência da variável A no conjunto de dados (D).

$$
\operatorname{Sup}(A)=\frac{\text { Total de ocorrências de A }}{\text { Total de registros (D) }}
$$


- Suporte B (SupB): que indica a frequência de ocorrência da variável B no conjunto de dados (D).

$$
\operatorname{Sup}(B)=\frac{\text { Total de ocorrências de B }}{\text { Total de registros (D) }}
$$

- Suporte (Sup): percentual de frequência de coocorrência das duas variáveis ( $A$ e $B$ ) no conjunto de dados (D). Demonstra a frequência com que os itens ocorrem em relação ao total de dados analisados.

$$
\text { Sup }=\frac{\text { Total de ocorrências de A } \cup \text { B }}{\text { Total de registros (D) }}
$$

- Suporte Esperado (SupEsp) é a frequência esperada de coocorrência das variáveis $A$ e $B$.

$$
\text { SupEsp }=\frac{\text { SupA }}{\text { Sup }}
$$

- Confiança (Conf): percentual de probabilidade de B ocorrer devido à ocorrência da variável A.

$$
\text { Conf }=\frac{\text { Total de ocorrência de } A \cup B}{\text { Total de ocorrências de A }}
$$

Outras medidas obtidas com as regras de associação indicam a dependência entre as variáveis $A$ e $B$. A dependência entre as variáveis é classificada como:

- Dependência positiva: indica que a presença de uma variável aumenta a presença de outra variável;

- Dependência negativa: indica que a presença de uma variável diminui a presença de outra;

- Independente: indica que uma variável não influencia a presença de outra.

As medidas de dependência são:

- Lift: indica a dependência entre as variáveis. Quanto maior o lift (lift >1) mais forte as associações. É calculado usando o valor Conf dividido pela frequência de $B$.

$$
\text { Lift }=\frac{\operatorname{Conf}}{\operatorname{SupB}}
$$


A classificação do Lift, Tabela 2, determina que o valor de Lift $>1$ indica que há uma dependência positiva entre as duas variáveis $A$ e $B$. O valor de Lift $<1$ indica dependência negativa entre A e B e valor de Lift igual a 1, indica que A e B são independentes.

Tabela 2 - Classificação do Lift

\begin{tabular}{|l|}
\hline \multicolumn{1}{|c|}{ Classificação do Lift } \\
\hline$L>1, A$ e B frequentemente, aparecem juntos. A tem efeito sobre B. \\
\hline $\begin{array}{l}L<1, \text { aparece menos frequentemente juntos, a ocorrência de A tem um efeito } \\
\text { negativo sobre B. }\end{array}$ \\
\hline$L=1, A$ e B são independentes, B não tem efeito sobre A. \\
\hline
\end{tabular}

- SupDep: classifica a dependência baseada em Sup, que indica a real frequência de coocorrência de $A$ e $B$, em relação à SupEsp, que indica a coocorrência de A e B. Na Tabela 3, é mostrada a classificação SupDep e o valor associado a cada nível de classificação.

Tabela 3 - Classificação do SupDep

\begin{tabular}{l|c}
\hline \multicolumn{1}{c|}{ Classificação do SupDep } & SupDep (valor) \\
\hline Sup > SupEsp: dependência positiva & 1 \\
\hline Sup < SupEsp: dependência negativa & -1 \\
\hline Sup = SupEsp: independentes & 0 \\
\hline
\end{tabular}

- ConfDep: classifica a dependência baseada no valor de confiança (Conf), que indica a porcentagem de probabilidade de B aparecer quando A ocorre, e SupB, que indica a frequência de ocorrência de B. Na Tabela 4, é mostrada a classificação ConfDep e o valor definido para cada nível de classificação.

Tabela 4 - Classificação do ConfDep

\begin{tabular}{l|c}
\hline \multicolumn{1}{c|}{ Classificação do ConfDep } & ConfDep (valor) \\
\hline Conf > SupB: dependência positiva & 1 \\
\hline Conf < SupB: dependência negativa & -1 \\
\hline Conf $=$ SupB: independentes & 0 \\
\hline
\end{tabular}

Outra medida obtida é o coeficiente de correlação (Phi) que indica o grau de relação entre $A$ e $B$, determinando o nível de correlação (TAYLOR, 2016). A fórmula para o cálculo do coeficiente de correlação (Phi) é:

$$
\boldsymbol{P h i}=\frac{\operatorname{Sup}-(\operatorname{Sup} A)(\operatorname{Sup} B)}{\sqrt{(\operatorname{Sup} A)(\operatorname{Sup} B)(1-\operatorname{Sup} A)(1-\operatorname{Sup} B)}}
$$


O coeficiente como valor positivo, significa que à medida que o valor de uma variável aumenta, o valor do outro também tende a aumentar. Valor negativo, significa que à medida que o valor de uma variável aumenta, o valor do outro tende a diminuir (MUKAKA, 2012). Na Tabela 5, é apresentada a classificação do coeficiente de correlação (Phi).

Tabela 5 - Classificação do Coeficiente de Correlação (Phi)
\begin{tabular}{l|c}
\hline \multicolumn{1}{c}{ Classificação do Phi } & Phi (valor) \\
\hline Correlação negativa perfeita & -1 \\
\hline Forte correlação negativa & -1 a -0.68 \\
\hline Moderada correlação negativa & -0.67 a -0.36 \\
\hline Fraca ou nenhuma correlação & -0.35 a 0.35 \\
\hline Moderada correlação positiva & 0.36 a 0.67 \\
\hline Forte correlação positiva & 0.68 a 1 \\
\hline Não correlacionado & 0 \\
\hline Perfeita correlação positiva & 1 \\
\hline
\end{tabular}

Fonte: (TAYLOR, 2016)

\section{Exemplo de cálculo das medidas obtidas com as regras de associação}

Dado um dataset (D) contendo as ocorrências dos animais:

- Variáveis analisadas: Animal1 (A) e Animal2 (B)

- Animal1 $=55$

- Animal2 $=54$

- $\operatorname{minSup}=0.01(1 \%)$

- ConfSup $=0.01(1 \%)$

De acordo com as medidas obtidas com as regras de associação, exemplo Tabela 6, é mostrada a forma de cálculo de cada medida.

Tabela 6 - Exemplo de Resultado do Algoritmo Apriori - Regras de Associação

\begin{tabular}{|c|l|l|l|l|l|l|l|l|l|l|l}
\hline \hline year & mon lhs & rhs & support & confidence & lift & count & phi & supA & supB & supEsp \\
\hline 2004 & 11 & find $1=55\}$ & find $2=54\}$ & $0.71578 \ldots$ & 0.8 & $1.11764 \ldots$ & 68 & $0.5443 \ldots$ & $0.894736 \ldots$ & $0.715 \ldots$ & $0.6404 \ldots$
\end{tabular}

\section{Como calcular as medidas:}

- Total de registros contidos no Dataset $(D)=95$

- Total de ocorrências do Animal1 (A): 85

- Total de ocorrências do Animal2 (B): 68 
Count $=$ Total de ocorrências de AUB $\rightarrow \mathbf{6 8}$

Sup $(A)=$ Total de ocorrências de A/Total de registros $(D) \rightarrow$ 85/95 = 0.894

Sup $(B)=$ Total de ocorrências de $B /$ Total de registros $(D) \rightarrow$ 68/95 $=\mathbf{0 . 7 1 5 7}$

Sup $=$ Count $/$ Total de registros $(D) \rightarrow 68 / 95=0.7157$

Conf $=$ Count $/$ Total de ocorrências de $A \rightarrow 68 / 85=\mathbf{0 . 8}$

SupEsp $=(\operatorname{Sup} A *$ Sup $) \rightarrow(0.894 * 0.7157)=\mathbf{0 . 6 3 9 8}$

SupDep $=$ Sup $>$ SupEsp $\rightarrow 0.7157>0.6398=$ dependência positiva

ConfDep $=\operatorname{Conf}>\operatorname{SupB} \rightarrow 0.8>0.7157=$ dependência positiva

Lift $=\operatorname{Conf} / \operatorname{Sup} B \rightarrow 0.8 / 0.7157=1.1177$ (dependência positiva)

$\mathbf{P h i}=\frac{\operatorname{Sup}-(\operatorname{Sup} A)(\operatorname{Sup} B)}{\sqrt{(\operatorname{Sup} A)(\operatorname{Sup} B)(1-\operatorname{Sup} A)(1-\operatorname{Sup} B)}}$

$\frac{0.7157-(0.894)(0.7157)}{\sqrt{(0.894)(0.7157)(1-0.894)(1-0.7157)}}=\mathbf{0 . 5 4 6 8}($ moderada correlação positiva)

\subsubsection{Mineração de trajetórias}

A mineração de dados de trajetórias pode ser aplicada para uma trajetória individual, contendo um certo padrão, ou para um grupo de trajetórias compartilhando padrões similares, e pode ser dividida, Figura 4, em quatro tarefas: detecção de anomalias, gestão de incertezas, extrapolação e detecção de padrões (KIHLSTRÖM, 2015)(ZHENG, 2015).

No contexto deste trabalho são relevantes as técnicas de mineração de dados aplicadas nas tarefas de extrapolação e de detecção de padrões de grupos. A extrapolação por ser focada nas abordagens de classificação e predição que permitem classificar as trajetórias ou subtrajetórias e realizar predições. Já a tarefa de detecção de padrões de grupos por ser focada em abordagens que permitem descobrir padrões de movimento de grupos de animais, que podem ser: flock, convoy, swarm, travelling companion e gathering (KIHLSTRÖM, 2015)(ZHENG, Y. et al., 2013)(SPACCAPIETRA et al., 2008)(KALVANI; CHATURVEDI, 2012). Estes padrões podem ser diferenciados dos outros nos fatores: formato ou densidade do grupo, o número de entidades no grupo e a duração de um padrão. 


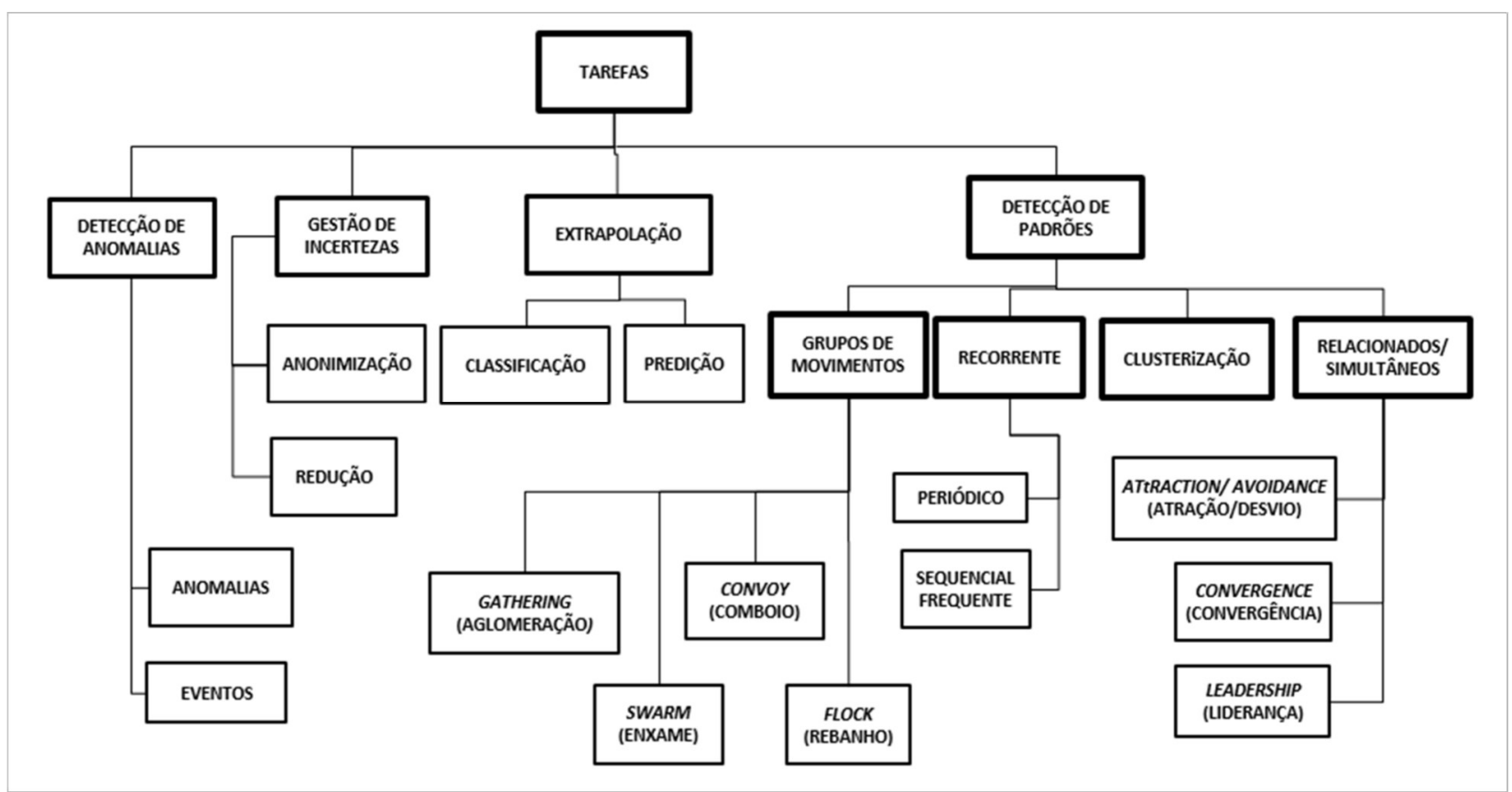

Figura 4 - Tarefas de Mineração de Dados de Trajetórias

Fonte: (adaptado de KIHLSTRÖM, 2015)

A mineração de dados compreende o conjunto de estratégias de aprendizagem, ferramentas e algoritmos, que permitem explorar dados e extrair padrões de dados (KIHLSTRÖM, 2015). A descoberta de padrões em trajetórias abrange (ZHENG, 2015):

- grupos de entidades que se movimentam juntos;

- clusterização, agrupa pontos de diferentes trajetórias dentro de regiões de interesse, buscando caminhos ou tendências comuns compartilhadas por diferentes entidades em movimento. Identifica grupos similares de trajetórias, por meio da análise da distância (ZHENG, 2015) (HAl et al., 2012a);

- padrão periódico, diferentes entidades visitam os mesmos lugares com intervalos de tempo semelhantes (GIANNOTTI et al., 2007) como, por exemplo, a migração de aves ou detecção de regiões de interesse (PHAN, 2013);

- padrão sequencial, um determinado número de entidades movendo-se em uma sequência comum de localizações em intervalo de tempo similar, por exemplo, recomendação de viagens (ZHENG, 2015). 
A definição dos grupos de movimento e os algoritmos utilizados para identificá-los são mostrados na Tabela 7.

Tabela 7 - Padrões de Movimento: Definição e Algoritmos

\begin{tabular}{|c|c|c|}
\hline Grupo de Movimento & Definição & Algoritmo \\
\hline $\begin{array}{l}\text { Flock (LAUBE; IMFELD, } \\
\text { 2002) }\end{array}$ & $\begin{array}{l}\text { Grupo de objetos que viajam juntos } \\
\text { dentro de um disco de algum tamanho } \\
\text { especificado pelo usuário por, pelo } \\
\text { menos } k \text { timestamps consecutivos. }\end{array}$ & $\begin{array}{l}\text { Sparrow - Spatial clustering } \\
\text { algorithm through swarm } \\
\text { intelligence (JACOB; IDICULA, } \\
\text { 2012) }\end{array}$ \\
\hline $\begin{array}{l}\text { Convoy } \\
\text { HAI; PONCELET; } \\
\text { TEISSEIRE, 2012), }\end{array}$ & $\begin{array}{l}\text { Captura padrões de trajetórias, } \\
\text { utilizando agrupamento baseado em } \\
\text { densidade. }\end{array}$ & $\begin{array}{l}\text { Get_Move (HAl; PONCELET; } \\
\text { TEISSEIRE, 2012), baseado no } \\
\text { DBSCAN; CUTS (JEUNG et al., } \\
\text { 2008) }\end{array}$ \\
\hline $\begin{array}{l}\text { Swarm } \\
\text { (Ll et al., 2010a) }\end{array}$ & $\begin{array}{l}\text { Captura as entidades que se movem } \\
\text { com formas de grupos aleatórios por } \\
\text { certo intervalo de tempo, possivelmente, } \\
\text { não consecutivos. }\end{array}$ & $\begin{array}{l}\text { Get_Move (HAl; PONCELET; } \\
\text { TEISSEIRE, 2012) baseado no } \\
\text { DBSCAN); FCS-Miner - Fuzzy } \\
\text { closed swarms (HAl et al., } \\
\text { 2012b) }\end{array}$ \\
\hline $\begin{array}{l}\text { Traveling companion } \\
\text { (TANG et al., 2014) }\end{array}$ & $\begin{array}{l}\text { Convoy e swarm precisam carregar } \\
\text { trajetórias inteiras na memória para a } \\
\text { mineração. Este padrão utiliza uma } \\
\text { estrutura de dados para identificar } \\
\text { continuamente esses padrões. }\end{array}$ & $\begin{array}{l}\text { Algoritmos Smart-and-Closed } \\
\text { (SC) e Buddy-based discovery } \\
\text { (BU) (TANG et al., 2014) }\end{array}$ \\
\hline $\begin{array}{l}\text { Gathering } \\
\text { (ZHANG et al., 2015) }\end{array}$ & $\begin{array}{l}\text { Detecta incidentes, como desfiles, onde } \\
\text { os objetos se juntam e deixam um } \\
\text { evento com frequência. }\end{array}$ & $\begin{array}{l}\text { Algoritmo TAD (ZHENG, Y. et al., } \\
\text { 2013) }\end{array}$ \\
\hline
\end{tabular}

Fonte: adaptado pelo autor de (KIHLSTRÖM, 2015)

Há diferentes abordagens que tratam a mineração de dados de trajetórias o que permite a descoberta de padrões de movimento.

\subsection{Considerações sobre o Capítulo}

Neste Capítulo foram apresentados os conceitos sobre Ciência dos Dados e Mineração de dados. O processo da Ciência dos Dados é a base para a elaboração dos passos que compõem o framework proposto nesta tese. Já a mineração de dados por regras de associação, com o algoritmo Apriori, é explorada na etapa de análise dos dados para identificar a correlação entre os animais e o meio ambiente. 


\section{TRABALHOS RELACIONADOS}

Neste Capítulo são apresentados trabalhos relacionados aos conceitos, métodos e diferentes abordagens utilizadas como referência na elaboração da tese, tais como, características do movimento animal, comportamento animal, segmentação de trajetórias, tarefas de mineração de dados e tipos de relações entre os animais e os fatores ambientais.

Com o avanço das tecnologias de rastreamento animal houve o aumento da aquisição de dados espaço-temporais enfatizando a importância da análise desses dados para a descoberta de conhecimento sobre o comportamento animal. Cagnacci et al. (2010), reforça essa importância e prevê que a combinação de dados de movimentação com informações sobre características do habitat em uma variedade de escalas pode permitir representar inclusive o mapa cognitivo de um animal em seu ambiente.

Gurarie et al. (2016), ressalta que os dados de movimento são complexos, multivariados e dependentes e que o estudo do movimento animal pode ser dividido em uma hierarquia de questões exploratórias, explicativas e preditivas. As exploratórias correspondem à identificação do comportamento individual, que corresponde ao que o animal está fazendo, onde e quando. A explicativa tenta explicar o comportamento e/ou suas transições. A preditiva tenta antecipar o uso do espaço pelo animal por meio da análise de seu comportamento.

Laube, Imfield e Weibel (2005) e Dodge, Weibel, Lautenschütz (2008) descrevem os padrões de comportamento obtidos por meio da movimentação animal, tais como: flock, grupos de animais que se movem na mesma direção e tempo; e liderança, um líder que se move para uma direção e seus seguidores.

A análise da trajetória animal para identificar o comportamento dos animais utiliza as características do movimento, tais como, velocidade, direção, tempo de residência e First Passage Time (FPT). As características são a base para os métodos de segmentação de trajetórias identificarem as mudanças no comportamento dos animais. Fauchald e Tveraa (2003) definem o FPT como uma medida de quanto tempo um animal permanece dentro de uma determinada área e apresenta sua utilização na análise da busca de área restrita e na seleção de habitat. Lavielle (2005) propôs um método estatístico para detectar os pontos de mudança na trajetória do movimento baseado na característica de tempo de 
residência (residence time). Barraquand e Benhamou (2008) utilizaram o método de Lavielle na segmentação de trajetórias para identificar lugares onde os animais permaneceram por um longo tempo.

Edelhoff, Signer e Balkenhol (2016) apresentam métodos para deteç̧ão de mudanças nos padrões de movimento dos animais, tais como: o Bayesian Partitioning of Markov Models (BPMM) e o Behavioural Change Point Analysis (BCPA). O BPMM (GUÉGUEN, 2001) é uma abordagem de classificação, desenvolvida para sequenciar DNA, que também pode ser usado como algoritmo de particionamento de movimento animal. O BPMM determina o número e a sequência de modelos homogêneos ("estados") dentro de um caminho sequencial baseado nas características de topologia, que correspondem às propriedade geométricas da trajetória e o tempo do movimento. O BCPA (GURARIE; ANDREWS; LAIDRE, 2009) é um método probabilístico que detecta pontos de mudança relevantes no movimento animal. Este método segmenta as trajetórias que varrem uma janela sobre uma série temporal e localiza o ponto de mudança dentro de cada janela, baseado na velocidade e na direção do movimento, e agrupa os segmentos semelhantes para identificar os estados comportamentais.

Há diversos métodos de segmentação de trajetórias com a finalidade de classificação do comportamento, no entanto a maioria tem como foco a característica de tempo do movimento como nos casos dos métodos de Lavielle e BCPA. Não considerar as métricas espaciais restringe a capacidade desses métodos de discriminar entre comportamentos relevantes no tempo, como o descanso e forrageamento que apresentam semelhança nos valores de tempo, mas distância variável (TORRES et al., 2017). Diferente desses métodos, o Residence in Space and Time (RST)(TORRES et al., 2017) contempla em suas análises as características de tempo e espaço, o que aprimora as análises realizadas pelos métodos BCPA e Lavielle. $O$ método RST segmenta as trajetórias com base nas características de tempo de residência e distância do movimento animal para classificar o comportamento nos estados de forrageio, descanso e trânsito.

Dada a complexidade inerente aos dados espaço-temporais e o volume crescente desses, um meio automatizado de analisar a movimentação animal é necessário para se identificar o comportamento animal. Desta forma, a 
mineração de dados espaço-temporais ou de trajetórias passou a ser amplamente estudada por ser um processo que permite a descoberta de padrões em grandes conjuntos de dados (ATLURI; KARPATNE; KUMAR, 2018). Diversas revisões sobre o tema estão disponíveis na literatura e, em geral, ressaltam a importância do uso das técnicas de mineração, na área de análise de dados espaço-temporais, bem como suas deficiências, melhorias requeridas e a aplicabilidade dessas técnicas em diferentes áreas.

Faghmous e Kumar (2014), por exemplo, abordam o uso das técnicas de mineração de dados na análise de dados climáticos e fornecem uma visão geral sobre os avanços, desafios e oportunidades no uso dessas técnicas no campo de estudo do clima. Rao, Govardhan e Rao (2012) ressaltam a importância da análise e mineração de dados espaço-temporais em domínios diversos. Apresentam, também, a natureza dos dados espaço-temporais, a complexidade e a necessidade de melhoria dos algoritmos clássicos de mineração. Abordam as regras de associação, co-localização, detecção de outlier e enfatiza a mineração por agrupamento de dados espaço-temporais. Vaka e Govindarajulu (2016), também, enfatizam a tarefa de agrupamento de dados de trajetória e apresentam uma revisão detalhada sobre o tema, suas tendências e oportunidades.

Shekhar et al. (2015) apresenta uma visão geral das pesquisas no campo de mineração de dados espaço-temporais sob a perspectiva computacional e ressalta sua ampla aplicação em ecologia e gestão ambiental, segurança pública, transportes, ciências da terra, epidemiologia e climatologia. Zheng (2015) apresenta uma revisão sistemática sobre as principais pesquisas em mineração de dados de trajetória e fornece um panorama da área e possibilidades de pesquisa. Aborda desde a derivação de dados de trajetória, ao pré-processamento e gerenciamento dos dados de trajetória e as tarefas de mineração e suas conexões, correlações e diferenças. Além, de introduzir os métodos que transformam trajetórias em outros formatos de dados, como gráficos, matrizes e tensores, para os quais mais técnicas de mineração e de aprendizado de máquina podem ser aplicadas.

Kihlström (2015) aborda as técnicas de mineração com ênfase em suas definições, limitações, informações que fornece e, principalmente, apresenta um resumo sobre os algoritmos e ferramentas de mineração de dados de trajetórias 
disponíveis. Atluri, Karpatne e Kumar (2018) abordam as definições e problemas da mineração de dados espaço-temporais, mas fornecem uma taxonomia para os diferentes tipos de dados espaço-temporais e mostram diversas formas de calcular a similaridade entre instâncias de dados espaço-temporais.

A aplicação da mineração de dados na análise da movimentação animal é explorada por Oliveira (2013) que estuda o comportamento de bovinos, por meio dos algoritmos Clustering-Based Stops and Moves of Trajectories (CBSMOT)(PALMA et al., 2008) e Intersection-Based Stops and Moves of Trajectories (IB-SMOT)(ALVARES et al., 2007), para identificar pontos de parada e movimento do animal e obter os pontos de desvio do animal ao longo de suas trajetórias. O CB-SMOT é baseado no algoritmo de mineração por agrupamento DBSCan (ESTER et al., 1996) e aplica a definição semântica de paradas e movimentos ao longo de uma trajetória. O IB-SMOT é aplicado para marcar os pontos de parada na trajetória.

A mineração por agrupamento, também, é aplicada por Jacob e Idicula (2012) para identificar padrões de comportamento flock, conjunto de animais que se movem junto por um determinado período contínuo. $O$ algoritmo de agrupamento Sparrow é utilizado para determinar os padrões frequentes de movimento em conjuntos de dados de trajetória e descobrir grupos. BERKHIN (2006) apresenta uma revisão sobre os algoritmos utilizados na mineração por agrupamento que consiste na divisão dos dados em grupos de objetos semelhantes. MOORTER et al. (2010) apresenta um framework baseado em mineração por agrupamento com $k$-means para identificar estados do movimento e avalia o framework com o uso de dados de movimentação de cervos do Canadá.

Zhang et al. (2015) analisa o comportamento animal combinando o método Behavioral Change Point Analysis (BCPA)(GURARIE; ANDREWS; LAIDRE, 2009) e a técnica de mineração por agrupamento $k$-means para classificar as trajetórias dos animais em estados de comportamento. Esta abordagem segmenta a trajetória com foco nas características de tempo do movimento, considerando a velocidade e na direção, mas não o espaço. Apresenta a relação entre a trajetória do animal e os dados ambientais somente por meio da sobreposição de mapas. 
LI et al (2010a) propõe o algoritmo Periodica para mineração do comportamento periódico baseado no movimento animal. O algoritmo Periodica identifica os períodos por meio dos pontos de referência, por meio da transformação de Fourier com a autocorrelação, e resume estatisticamente os comportamentos periódicos com o método de agrupamento hierárquico. SARKAR et al. (2015) adapta o uso do Periodica para extrair comportamento periódico do movimento de gansos.

O método ObjectGrowth (LI et al., 2010b) foi proposto para descobrir closed swarms usando o agrupamento baseado em densidade com o algoritmo DBSCAN (ESTER et al., 1996) para gerar grupos e o método Monte Carlo para calcular a significância do relacionamento. O ObjectGrowth (LI et al., 2010b) e o Periodica (LI et al., 2010a) formam o MoveMine (WU et al., 2014), sistema de mineração de dados de movimento para descoberta de comportamento. ObjectGrowth extrai os padrões de swarm, usando agrupamento por densidade com o DBSCAN e o Periodica detecta comportamentos periódicos.

O algoritmo Get_move (HAl; PONCELET; TEISSEIRE, 2012) é utilizado, juntamente com o algoritmo de densidade DBSCAN (ESTER et al., 1996), numa abordagem unificada que permite a descoberta dos padrões de movimento closed swarms, convoys e padrões de grupo. O DBSCAN, também, é utilizado na descoberta de padrões de movimento evolving convoy, por meio dos algoritmos Traj-Dbscan e simple slice-by-slice (AUNG; TAN, 2010), e na descoberta de padrões de grupos de movimento (KALNIS; MAMOULIS; BAKIRAS, 2005). Padrões de movimento baseados na periodicidade dos dados são identificados, utilizando o algoritmo Apriori (AGRAWAL; SRIKANT, 1994) para encontrar padrões de movimento de aves e espécies com movimento coletivo periódico (WANG et al., 2013).

A mineração por regras de associação consiste em um método amplamente conhecido e pesquisado para descobrir relações interessantes entre variáveis em grandes conjuntos de dados (JAISWAL; AGARWAL, 2012). As regras de associação foram usadas em diversas aplicações para encontrar padrões frequentes nos dados sendo, principalmente, aplicadas na descoberta de relações entre produtos de cestas de compras (BRIN et al., 1997) para orientar ações de marketing. No diagnóstico médico a descoberta de padrões frequentes, permite descobrir, por exemplo, doenças que frequentemente 
ocorrem em uma área (SHAUKAT; ZAHEER; NAWAZ, 2015). Na análise do movimento animal há referências que utilizam a mineração por regras de associação para identificar co-localização de episódios (CAO, MAMOULIS E CHEUNG, 2006), por exemplo dois animais se movendo juntos, que capturam as regularidades intermovimento entre diferentes animais.

A mineração de dados por agrupamento é amplamente utilizada na descoberta de grupos de animais, mas em alguns casos exige a definição de um número de grupos como parâmetro inicial, como no k-means, e não fornecem medidas estatísticas sobre a interação entre animal e fatores ambientais. Já as regras de associação fornecem medidas estatísticas de correlação e dependência entre associações. Quanto maior a frequência de coocorrência desses animais, maior a probabilidade de pertencerem a um mesmo grupo.

$\mathrm{Na}$ literatura há algumas iniciativas com a finalidade de identificar a interação entre os fatores ambientais e o comportamento animal. LI et al. (2013), por exemplo, analisa a interação entre animais e classifica as relações como atração e repulsão entre pares de objetos em movimento. Nessa iniciativa, os pares de trajetórias são analisados, a frequência de coocorrência desses pares em um determinado limite de distância é determinada e o valor de significância da relação é verificado com base nos testes de permutação. Teste de permutação (Ll et al., 2013) é uma abordagem não paramétrica para a realização de testes de hipóteses. Esta abordagem utiliza a análise da frequência de coocorrência dos animais com o foco específico na identificação de relações de atração e repulsão.

Há também iniciativas que focam na trajetória animal para identificar a direção do movimento, os caminhos escolhidos pelos animais, em possíveis rotas, e como os fatores ambientais influenciaram essas escolhas. KANDA (2015), por exemplo, analisa os fatores que influenciam no uso do espaço pelas onças-pintadas no Pantanal - Brasil. Essa iniciativa utiliza a Step Selection Functions (SSF)(THURFJELL; CIUTI; BOYCE, 2014) para segmentar a trajetória com base nas características do comprimento e direção do movimento e a regressão logística condicional (AGRESTI, 2007) para identificar a relação entre o movimento animal e o ambiente. A SSF é um modelo que compara os passos dados pelo animal com os possíveis caminhos existentes, sorteados aleatoriamente a partir de uma distribuição baseada no comprimento do passo e 
no ângulo de curvatura. Essa iniciativa compara possíveis rotas, geradas aleatoriamente, com a rota real buscando a diferença e, possíveis relações entre essas rotas e os aspectos ambientais.

Teimouri et al. (2018) apresenta uma metodologia para classificar o comportamento animal em estados (forrageio, repouso e caminhada) com base nos dados de rastreamento do animal. As trajetórias são segmentadas por uma versão modificada do método de análise de ponto de mudança comportamental (BCPA), baseado na velocidade de persistência e rotação do movimento, a distância entre os pares de segmentos é calculada com a métrica de distância de Kolmogorov-Smirnov e um modelo de agrupamento hierárquico aglomerativo dos segmentos (MILLER; HAN, 2009). Esta referência tem objetivo identificar estados de comportamento de animais por meio do uso de dados de movimentação, no entanto somente foca em segmentar as trajetórias e depois agrupá-las, de acordo com suas similaridades, para identificar os estados de comportamento.

Wikelski e Kays (2016) disponibilizam a plataforma Movebank que é um portal de dados abertos de rastreamento de animais e o sistema Environmental Data Automated Track Annotation System (Env-DATA)(DODGE et al., 2013) que consiste em um conjunto de ferramentas de análise que vinculam, por meio de mapas e gráficos, dados de movimentação animal com dados ambientais colocalizados. A plataforma é a mais completa dentre as analisadas no que tange a análise da interação entre o movimento e os fatores ambientais, no entanto não dispõe de recursos para a realização da análise exploratória do movimento animal por meio de mineração de dados e não classifica o comportamento animal em estados.

Colchero et al. (2011) apresenta a modelagem da movimentação de onças para facilitar os planos de conservação de uma região e abrange a definição de corredores e unidades de conservação. A localização das onças é obtida por meio do algoritmo de Markov Chain Monte Carlo (MCMC). O Resource Selection Functions (RSF)(MANLY et al., 2002) é aplicado para estimar a probabilidade da onça mover-se de um lugar para outro em função das variáveis ambientais. RSF são funções utilizadas em ecologia espacial para identificar quais características do habitat são importantes para uma população ou espécie de animais. Por meio dessa função pode-se avaliar a probabilidade do animal 
utilizar um determinado recurso em função da disponibilidade desse recurso no ambiente (BOYCE et al., 2002).

Com a análise da movimentação pode-se identificar, também, como o animal utiliza o espaço ou sua área de vida (home range), que corresponde à área percorrida pelo animal em suas atividades de busca de alimento, acasalamento e cuidado parental (BURT, 1943). Kranstauber et al. (2012) afirma que na estimativa de área de vida dos animais os métodos quantificam não apenas o tamanho da área, mas também a intensidade do uso das diferentes áreas dentro da área de vida desses animais, que é a Utilization Distribution (UD) (WORTON, 1989). Essa distribuição é calculada, geralmente, com métodos de kernel com base em um conjunto de pontos espaciais que ignoram a estrutura temporal. O Brownian Bridge Movement Model (BBMM) (KRANSTAUBER et al., 2012) incorpora a estrutura temporal de rastreamento de dados e modela explicitamente o caminho do movimento (BULLARD, 1991), contendo a ordem dos locais e a quantidade de tempo entre eles. Horne et al. (2007) utiliza o BBMM para estimar as áreas de vida e rotas de migração dos animais e avaliar a influência da seleção de recursos nos padrões de movimento dos animais. Buchin et al. (2012) propõe um framework para a análise de movimento usando o BBMM, que identifica padrões como encontro, evasão/atração e visitas frequentes. CAVALCANTI e GESE (2009) analisaram a frequência de coocorrência e as interações de onça-pintada com o uso do kernel (WORTON, 1989) e GRAW; KRANSTAUBER; MANSER (2019) usou a função kerneloverlap (CALENGE, 2006) para obter a sobreposição de espaço pelos mangustos. As análises de home range com as funções kernel e kerneloverlap não consideram o tempo, então necessitam de adaptações para serem realizadas com base no espaço e tempo.

Como o movimento animal ocorre em uma área, pode ser influenciado por eventos, fenômenos ou pelo movimento de outros objetos que estão no mesmo ambiente e essas relações podem apresentar correlação, co-ocorrência e autocorrelação. Shirabe (2006) define a diferença entre correlação, correlaçãocruzada e autocorrelação e enfatiza que o coeficiente de correlação permite encontrar movimentos linearmente relacionados e que o coeficiente de correlação cruzada é a medida alternativa quando um movimento está correlacionado com outro de forma defasada. 


\subsection{Considerações sobre o Capítulo}

Neste Capítulo foram apresentados trabalhos relacionados aos conceitos, métodos e diferentes abordagens utilizadas como referência na elaboração da tese. Essas referências abrangem desde as definições sobre comportamento animal, movimento animal, trajetórias, passando pelas discussões acerca da análise e mineração de dados espaço-temporais até às técnicas, métodos e algoritmos utilizados nessas áreas.

No apêndice $D$, são mostradas tabelas contendo as principais referências utilizadas na pesquisa com ênfase no objetivo ou finalidade da referência, qual a característica de mineração usada na segmentação da trajetória, a tarefa de mineração e os métodos, algoritmos ou ferramentas aplicados e os resultados obtidos. O AniMoveMiner também é mostrado nessas tabelas como forma de permitir a comparação com os trabalhos relacionados. 


\section{ANIMOVEMINER}

Neste Capítulo é apresentado o framework AniMoveMineR que permite a análise exploratória do movimento animal, ao longo do tempo e espaço, por meio da combinação de algoritmos de análise de dados espaço-temporais e de mineração de regras de associação. A análise exploratória do movimento animal, abrange a classificação do comportamento em estados, a identificação de quando, onde e por quanto tempo estes estados de comportamento ocorreram e dos níveis de correlação entre os animais e os fatores ambientais.

\subsection{AniMoveMineR - Contexto}

No contexto do framework AniMoveMineR, Figura 5, observa-se que os dados de movimentação animal estão sendo amplamente coletadas por meio de dispositivos móveis de rastreamento, como por exemplo, os colares. Essa movimentação animal, formada por pontos distribuídos ao longo do tempoespaço, descrevem a trajetória do animal. A análise de trajetórias (DEMSAR et al., 2015) pode fornecer informações sobre o porquê, como, quando e onde os animais se moveram e como este processo está relacionado aos fatores ambientais. Com base nesses dados pode-se identificar o comportamento animal e classificá-lo como descanso, forrageio ou trânsito.

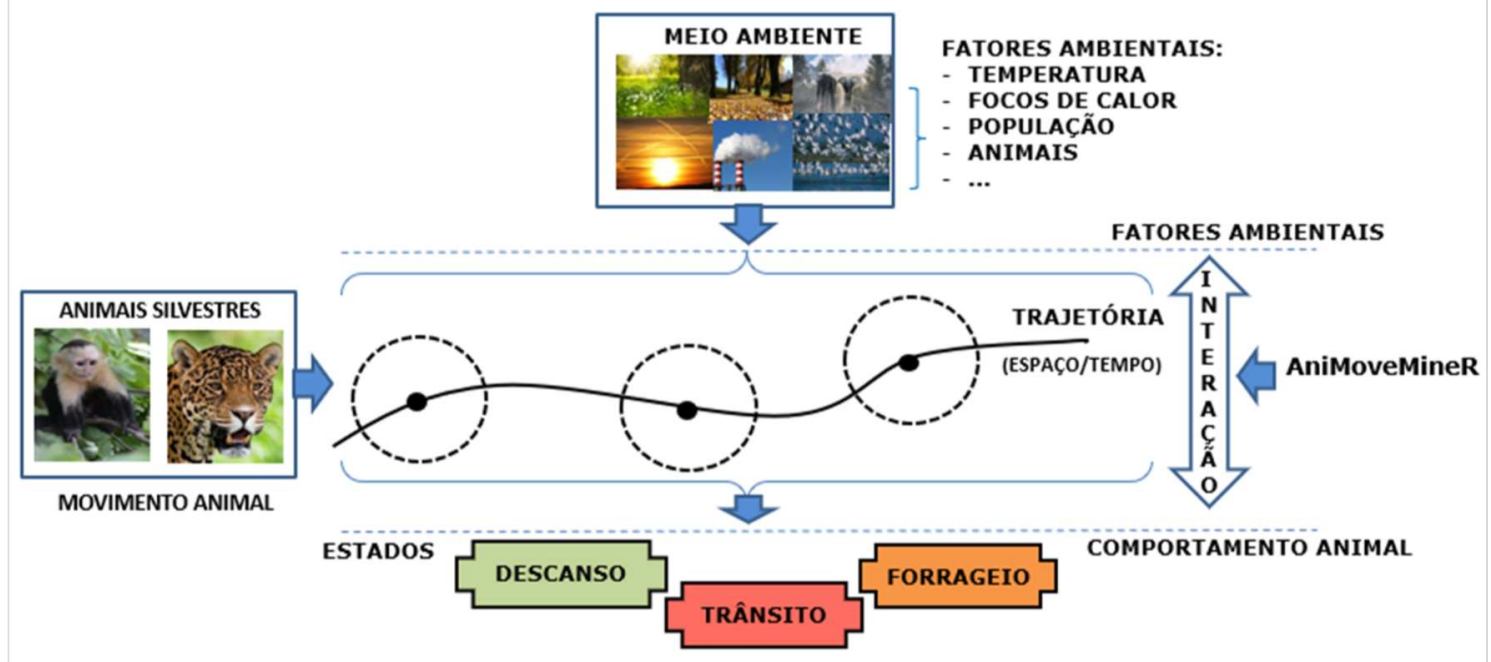

Figura 5 - AniMoveMineR - Contexto

Fonte: Autor

Por outro lado os dados sobre fatores ambientais, tais como temperatura, precipitação e focos de calor, também estão sendo amplamente coletados e 
podem ocorrer ao longo das trajetórias dos animais influenciando ou não o seu comportamento. Desta forma, com base no comportamento animal e na proximidade entre os animais e os fatores ambientais é explorada a interação entre estas variáveis por meio da técnica de mineração de dados por regras de associação, com o framework AniMoveMineR.

O framework deve receber como entrada dados espaço-temporais, que são: datasets de movimento animal e dataset de fator ambiental. Os datasets de movimento animal devem ser compostos por dados espaço-temporais que descrevem o movimento de um ou mais animais, caracterizados por pontos de localização (latitude/longitude), tempo (data/hora) de registro do movimento do animal e nome do animal. Estes dados podem ser de grupos de animais da mesma espécie, grupos de espécies diferentes ou de um único animal. Os datasets de fator ambiental devem ser compostos por dados espaço-temporais que descrevem os fatores ambientais, contendo: o nome do fator, a posição de ocorrência (latitude/longitude), o tempo de ocorrência (data/hora) e o status que identifica o fator, por exemplo, indicador de presença de foco de calor (Sim/Não) ou a classificação da temperatura (alta/baixa).

\subsection{AniMoveMineR - O Framework}

O framework AniMoveMineR tem os sete passos que o compõem detalhados na Figura 6. Esses passos foram elaborados com base no processo da ciência dos dados (DEKHTYAR, 2016), no entanto enfatiza-se o passo (4) que corresponde à Análise de Dados. Os sete passos que compõem o AniMoveMineR são: (1) formular questões e hipóteses, (2) adquirir dados, (3) limpar dados, (4) analisar dados, (5) apresentar resultados, (6) analisar resultados e (7) refinar o problema.

Os passos do AniMoveMineR são descritos da seguinte forma:

1. Passo - Formular questões: os pesquisadores determinam quais questões devem ser respondidas com a aplicação do framework. 


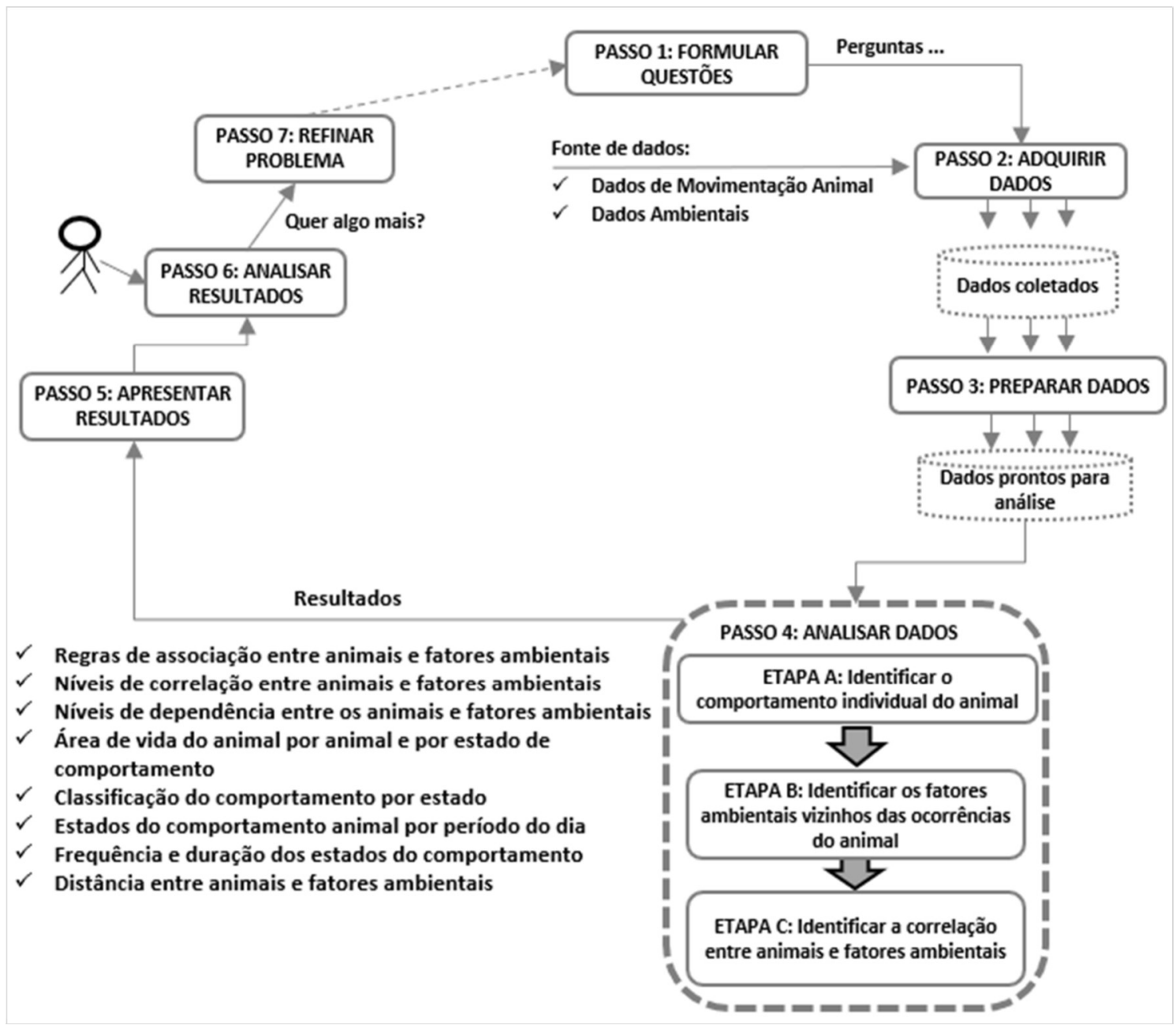

Figura 6 - AniMoveMineR - Framework

2. Passo - Adquirir dados: dados sobre a movimentação animal e fatores ambientais devem ser submetidos para as análises. Neste passo, são definidos também os parâmetros a serem usados na análise dos dados, são eles: thresold distance (TD), intervalo de tempo (TI) e o indicador de análise da estação do ano. O Thresold distance (TD), ou distância limite, indica o tamanho máximo do raio da distância em metros. Este valor é usado para limitar o raio de pesquisa em torno de cada ponto de localização (latitude/longitude) e tempo (data/hora) do movimento do animal para a análise da distância entre os pontos. O intervalo de tempo (TI), em minutos, é utilizado para calcular a faixa de ocorrência do fator ambiental. O indicador de análise de estação do ano determina se deve ser avaliada a correlação entre os estados de comportamento dos animais e as estações do ano.

O framework deve receber dois datasets, em formato de arquivo .csv, um referente aos dados de movimentação do (s) animal (s) e o outro referente 
aos dados de ocorrência do fator ambiental. Cada dataset deve ser referente a um ano específico. $\mathrm{O}$ arquivo com os dados de movimentação animal deve conter os campos:

- timestamp: a data e hora de ocorrência do movimento animal. O formato deve ser, por exemplo, '2014-01-01 00:03:00';

- location.long: a coordenada de longitude do ponto de ocorrência do movimento animal. Exemplo: -57.6197408;

- location.lat: a coordenada de latitude do ponto de ocorrência do movimento animal. Exemplo: -16.8472931

- individual.local.identifier: a identificação do animal que pode ser um código ou nome. Exemplo: 51 ou Picolé.

$\mathrm{O}$ arquivo com os dados de fatores ambientais deve conter os campos:

- Id: identificador do fator ambiental;

- Lat: a coordenada de latitude do ponto de ocorrência do fator ambiental;

- Lon: a coordenada de longitude do ponto de ocorrência do fator ambiental;

- Datetime: data e hora de ocorrência do fator ambiental. De acordo com fator ambiental em análise pode-se ter ou não a data e hora de ocorrência do fator;

- Factor: contém a classificação do fator. Por exemplo, no caso do fator de calor esse campo teria como valor "Sim" (há ocorrência de foco de calor) ou "Não" (não há ocorrência de foco de calor);

- Yearf: ano de ocorrência do fator ambiental;

- Monf: mês de ocorrência do fator ambiental.

Na Figura 7, é mostrada a interface do framework AniMoveMineR, no Rstudio (RSTUDIO, 2014), que permite a seleção dos arquivos de dados e os parâmetros que norteiam as análises por meio do Knit. Após a seleção dos parâmetros, ao clicar no botão Knit são executadas todas as etapas do framework AniMoveMineR. 


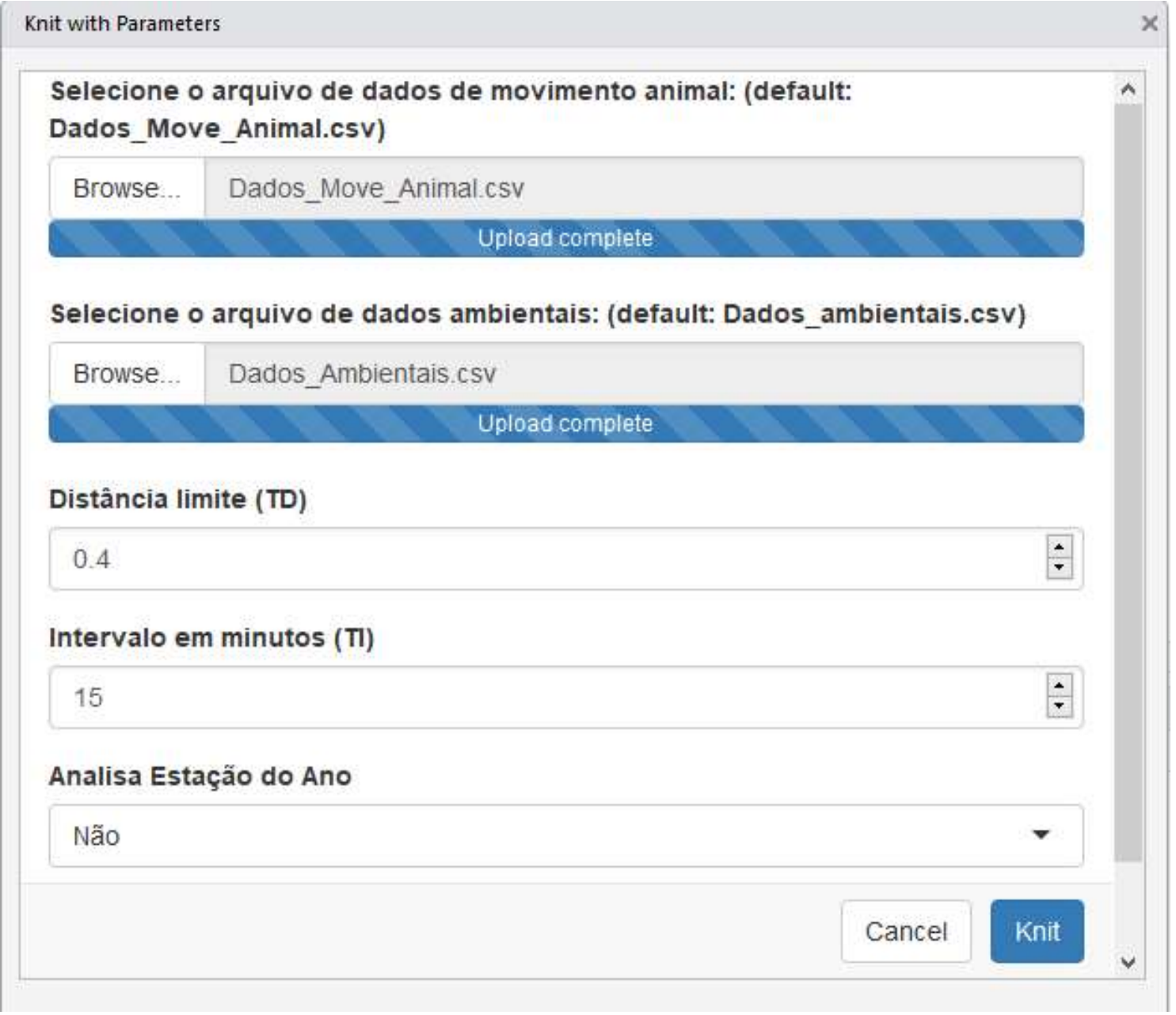

Figura 7 - Interface para entrada de dados do AniMoveMineR - Rstudio (Knit)

3. Passo - Preparar dados: os dados são verificados de forma a eliminar dados incorretos ou inadequados e identificar dados faltantes. Rotinas em SQL e pacotes do $\mathrm{R}$, como o outliers, são utilizados para identificar dados inapropriados e efetuar a limpeza do dataset. Os dados são também formatados de acordo com os padrões esperados para a análise.

4. Passo - Analisar dados: neste passo é realizada a análise exploratória do movimento animal, que utiliza algoritmos de análise de dados espaçotemporais e de mineração de regras de associação, para a obtenção de indicativos sobre o comportamento animal. Este passo é composto por três etapas: $(A)$ identificar o comportamento individual do animal; $(B)$ identificar as ocorrências dos fatores ambientais vizinhos da ocorrência do comportamento animal; (C) identificar a correlação entre o comportamento animal e os fatores ambientais. 
5. Passo - Apresentar resultados: os resultados obtidos com as análises são apresentados por meio de listas, gráficos e mapas.

6. Passo - Analisar resultados: os resultados produzidos devem ser analisados e discutidos pelos pesquisadores especialistas na área de aplicação da AniMoveMineR;

7. Passo - Refinar problema: com base no conhecimento adquirido com a análise dos resultados, os pesquisadores podem refinar o problema e formular novas questões a serem respondidas numa nova rodada da aplicação do AniMoveMineR.

\subsection{AniMoveMineR - Analisar dados}

Na Figura 8, é detalhado o passo (4) referente à Análise dos dados, do framework AniMoveMineR. Esse passo é composto por três etapas, que são: Etapa (A): Identificar o comportamento individual do animal; Etapa (B): Identificar os fatores ambientais vizinhos das ocorrências do animal; Etapa (C): Identificar a correlação entre os animais e os fatores ambientais.

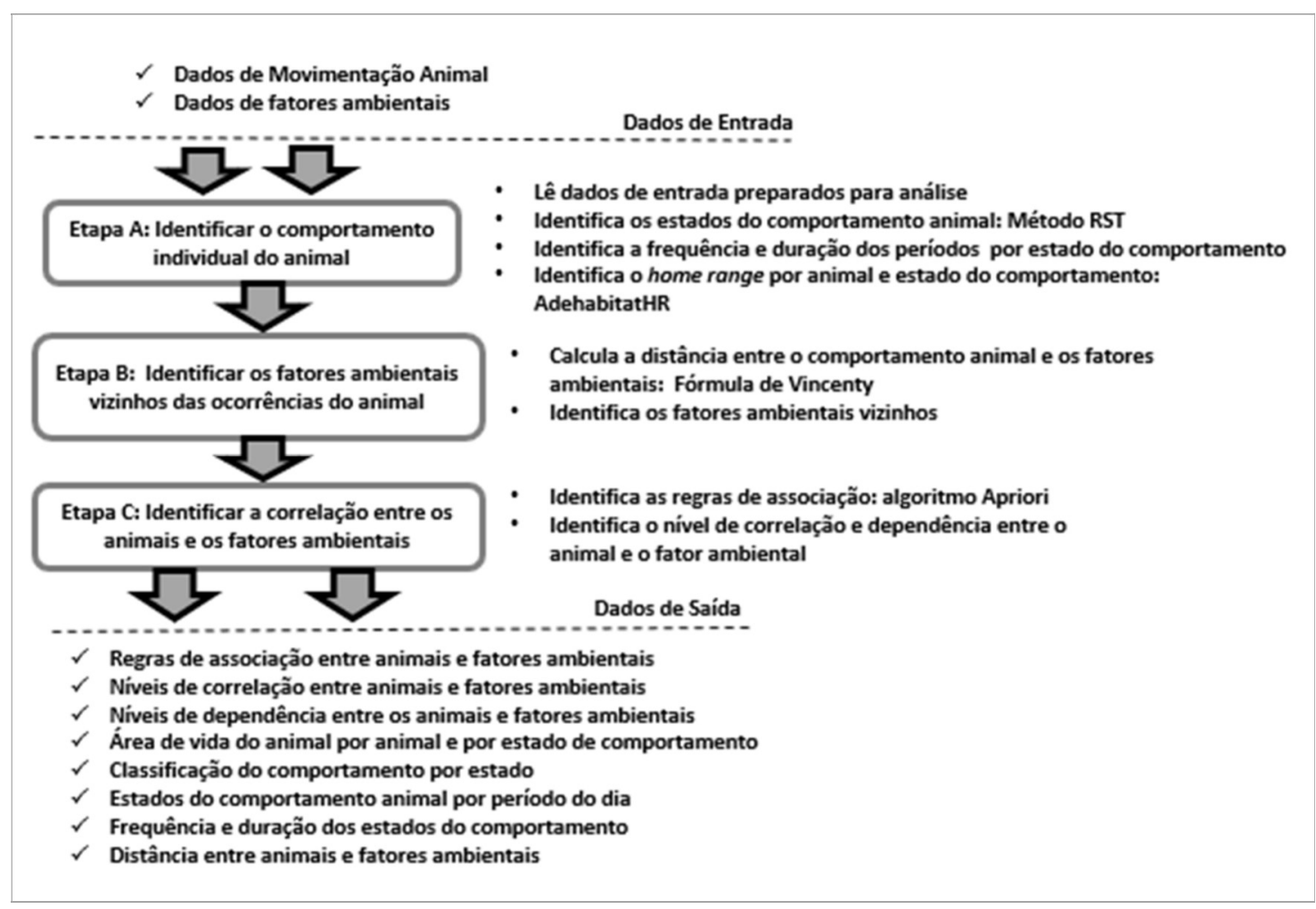

Figura 8 - AniMoveMineR - Descrição das etapas da Análise de Dados

Para cada etapa são descritas as atividades que abrangem os recursos utilizados, tais como algoritmos e métodos, e os resultados obtidos. 


\subsubsection{Etapa A - Identificar o comportamento individual dos animais}

$\mathrm{Na}$ Etapa A são abordadas as atividades realizadas para identificar o comportamento individual dos animais ao longo de suas trajetórias baseado nos dados espaço-temporais que descrevem o movimento desses animais. $\mathrm{Na}$ Figura 9, são mostradas as quatro atividades que compõem a etapa de identificação do comportamento animal que abrange a identificação:

- dos estados do comportamento animal por meio da segmentação das trajetórias;

- dos períodos (hora início e fim) e da duração da ocorrência dos estados por animal e dia;

- da frequência de ocorrência dos estados do comportamento por período (dia/noite);

- do home range por animal e por animal e estado de comportamento;

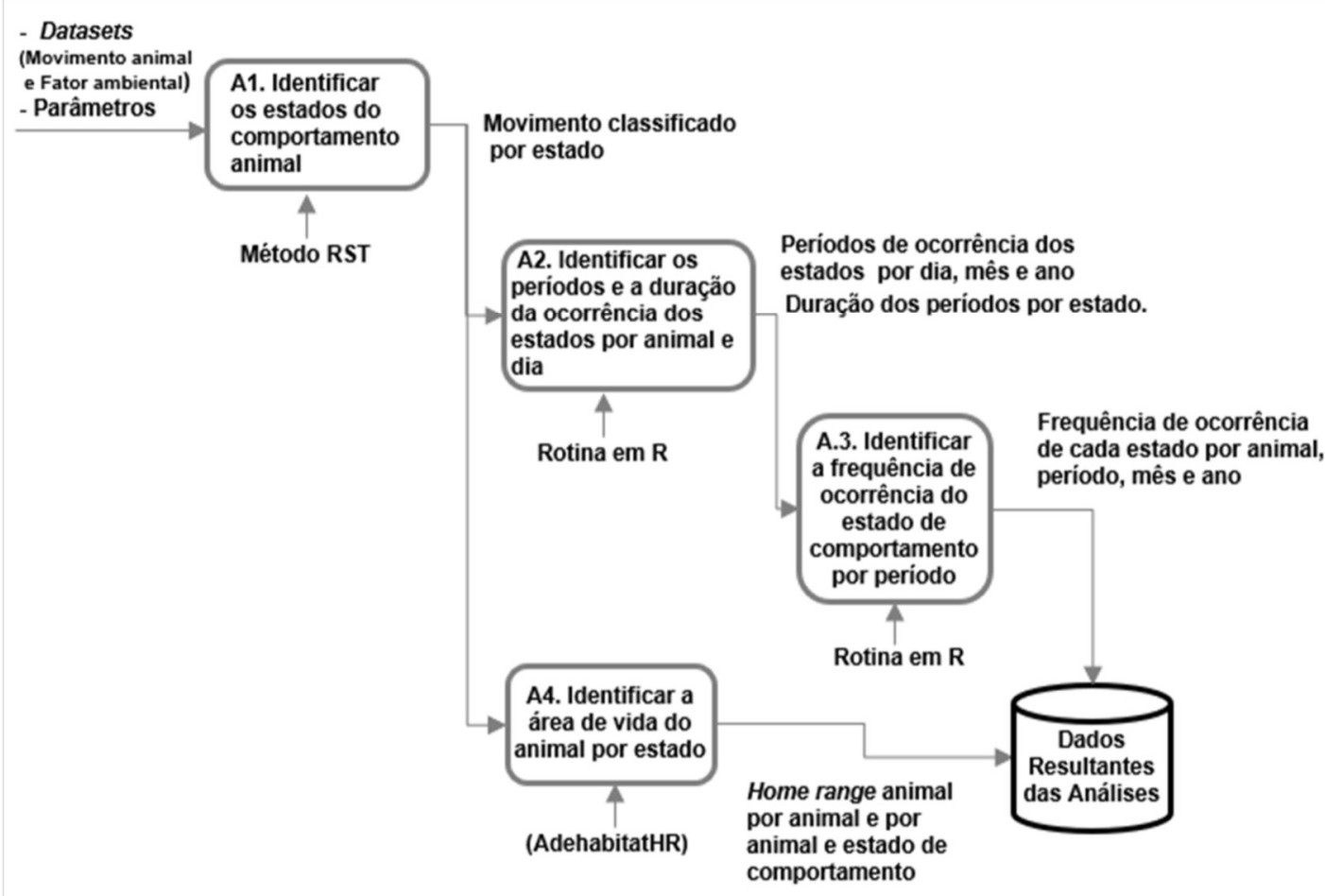

Figura 9 - Etapa A: Identificar o comportamento individual do animal

\subsubsection{A1 - Identificar os estados do comportamento animal}

$\mathrm{Na}$ etapa $\mathrm{A} 1$, é realizada a inicialização do algoritmo que prepara as tabelas de armazenamento de resultados e recupera os datasets de com os dados de movimentação animal e fatores ambientais que serão utilizados nas análises. Na Figura 10, é apresentado um fluxograma que detalha as rotinas 
executadas pelo algoritmo na etapa A1 e o pseudocódigo pode ser consultado no Apêndice A.

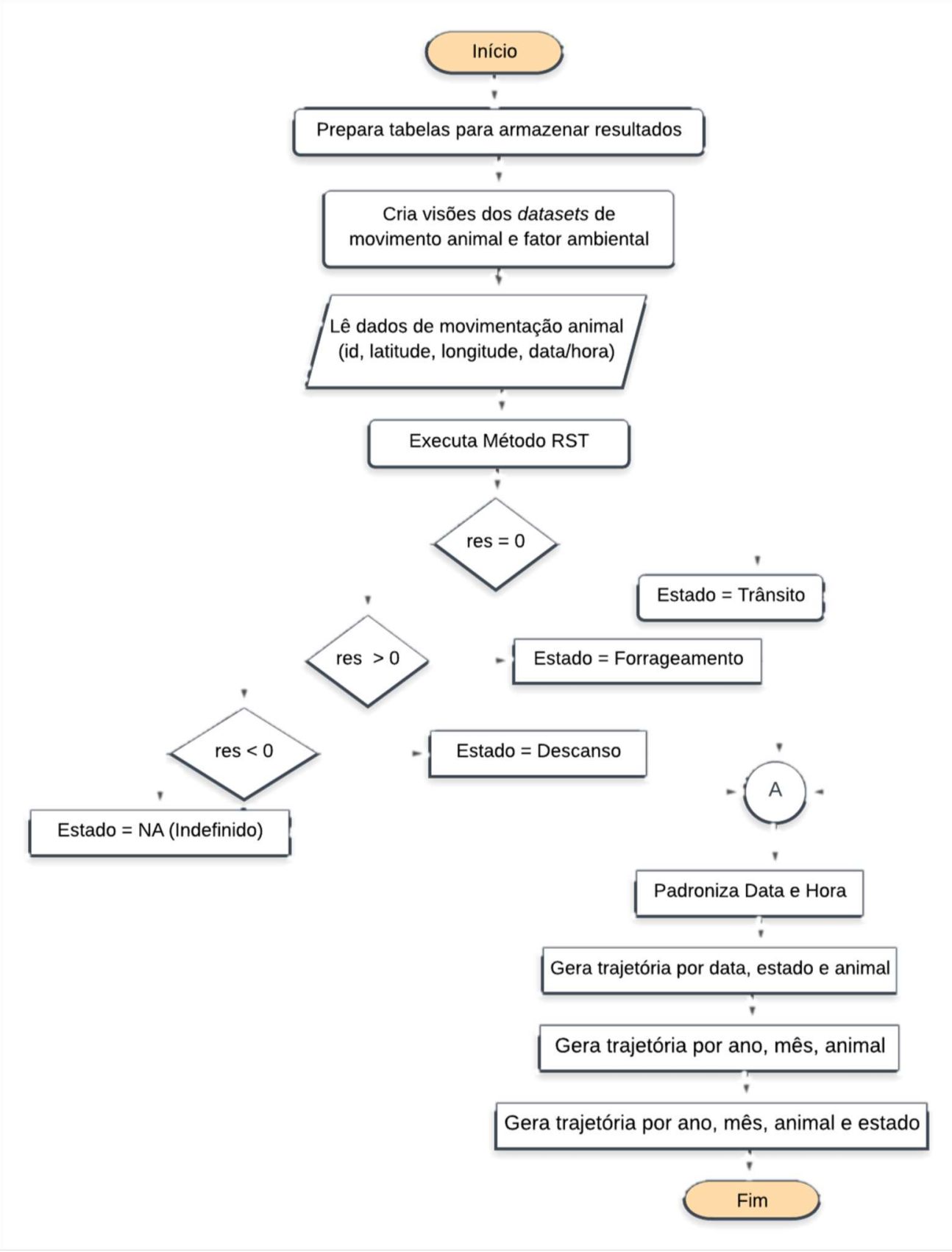

Figura 10 - Fluxograma da Etapa A1 - Identificar os estados do comportamento animal

Com a preparação do ambiente finalizada os dados de movimentação animal e fatores ambientais são recuperados e analisados, com o método RST (TORRES et al., 2017), que classifica o comportamento animal em estados (descanso, trânsito e forrageio) por meio da segmentação das trajetórias de acordo com a quantidade de espaço e tempo gasto em uma área. 
Como resultado da etapa são obtidas as trajetórias com a classificação do comportamento animal em estados. Como resultado da etapa A1 tem-se o mapa da região de ocorrência da movimentação animal e uma lista (menu) onde o animal, ano e mês pode ser selecionado para consulta. Ao selecionar um item na lista é mostrada a trajetória do animal, de acordo com o ano e mês selecionado, e os pontos de início e fim da trajetória com a data e estado de comportamento do animal. Na Figura 11, é mostrado que ao selecionar o mês de fevereiro de 2015 para o animal Picolé, como pode ser observado na lista à direita, tem-se a trajetória efetuada pelo animal ao longo do mês e os pontos de início e fim da trajetória e o estado de comportamento do animal.

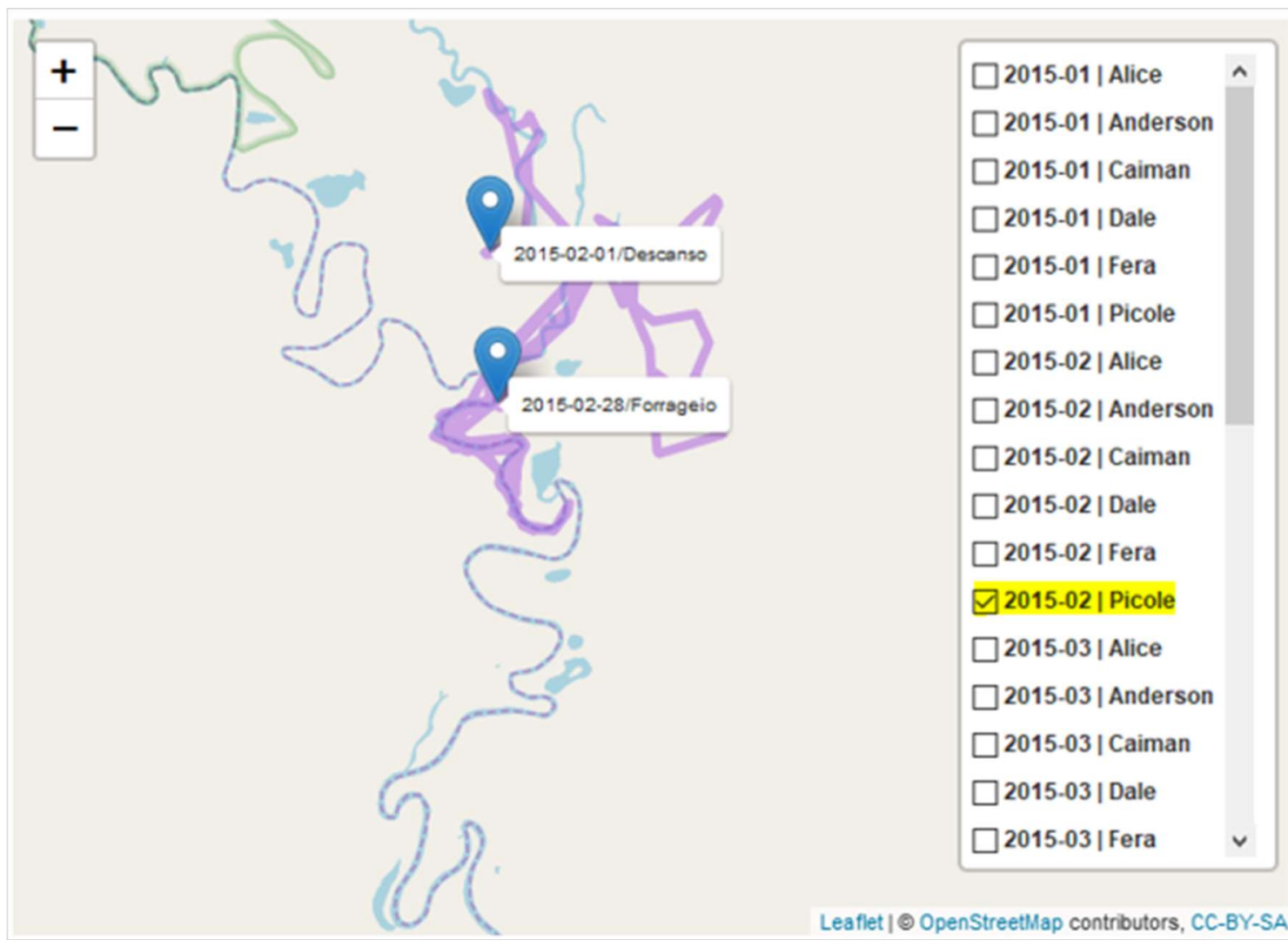

Figura 11 - Mapa das trajetórias dos animais por mês/ano

\subsubsection{A2 - Identificar os períodos e a duração da ocorrência dos estados por animal e dia}

$\mathrm{Na}$ etapa $\mathrm{A} 2$, uma rotina em $\mathrm{R}$ é usada para ler os dados de movimentação de cada animal e identificar os períodos (hora de início e término) da ocorrência de cada estado de comportamento animal por dia. Na Figura 12, é apresentado o fluxograma que detalha as rotinas executadas pelo algoritmo na etapa A2 e o pseudocódigo pode ser consultado no Apêndice A. 


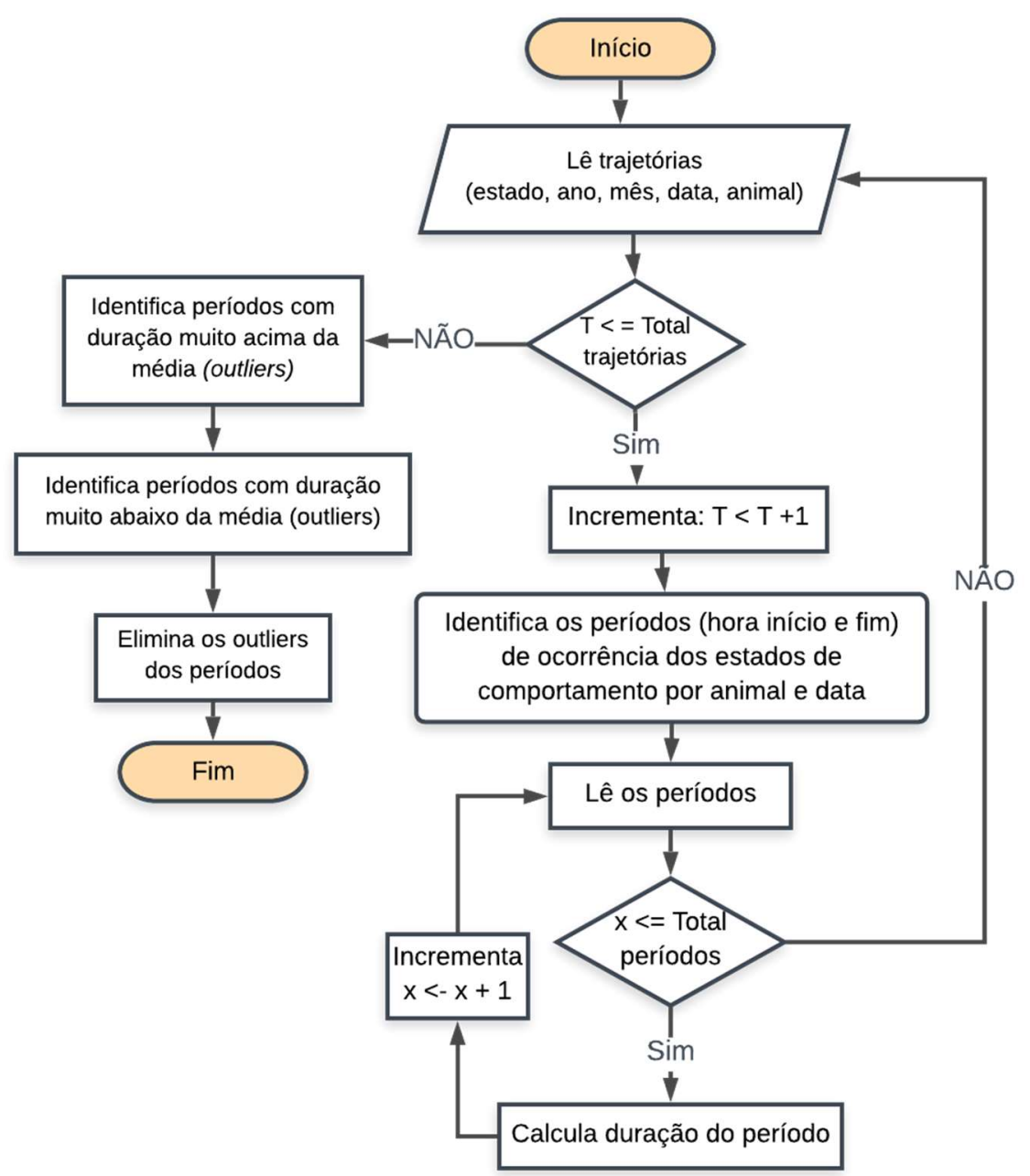

Figura 12 - Fluxograma da Etapa A2 - Identificar os períodos de ocorrência dos estados por animal e dia

A duração de cada período é calculada para obter o tempo que o animal permaneceu em um determinado estado de comportamento. A duração dos períodos é analisada, com a função outliers do pacote $R$ (KOMSTA, 2011), para identificar e remover os períodos com duração muito acima ou abaixo da média, os outliers. Os outliers são registros de duração do estado de comportamento que diferem fortemente de todos os outros e podem causar anomalias nos resultados das análises.

Como resultado da etapa são obtidos os estados de comportamento animal, forrageio, trânsito e descanso distribuídos em intervalos de tempo (hora início e hora fim) ao longo dos dias, meses e anos. Quando não há registros de movimentação no dia ou intervalo de horas o espaço é mostrado em branco.

Na Figura 13, é mostrado o gráfico com a distribuição dos estados de comportamento (descanso, forrageio e trânsito) para o animal Picolé, ao longo 
dos dias e horas do mês de janeiro (1) de 2015. Observa-se no período de 5 a 8 de janeiro foi identificado somente o estado de forrageio e de 16 a 22 de janeiro somente o estado de descanso. No dia 30 , o animal descansou das 0 h. às $3 \mathrm{~h}$., forrageou das $3 \mathrm{~h}$ às $5 \mathrm{~h}$ e depois transitou das $6 \mathrm{~h}$ às $8 \mathrm{~h}$ e voltou a forragear até às $14 \mathrm{~h}$.

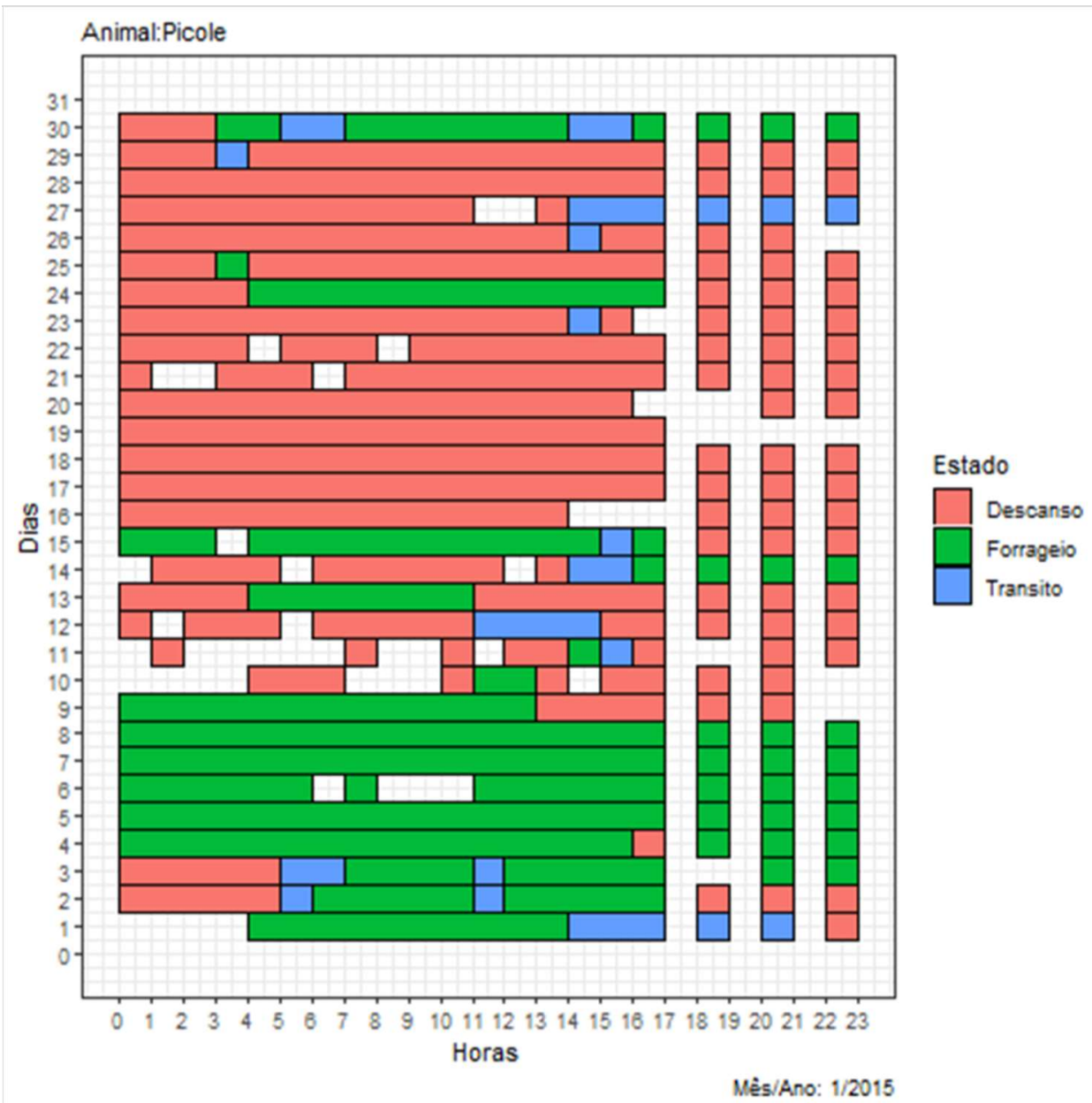

Figura 13 - Estados do comportamento animal por dia e hora

Outro resultado obtido na etapa A2 é o tempo médio de duração de cada estado de comportamento animal por mês e ano. Na Figura 14, é apresentado um gráfico onde as linhas contínuas indicam a variação do tempo de duração (horas e minutos) dos estados de comportamento do animal (forrageio, descanso e trânsito), ao longo dos meses e anos. Os estados de comportamento são diferenciados pela cor da linha. O gráfico permite, por exemplo, a análise do dataset de movimentação do animal Picole, que mostra a indicação de que em março de 2015, o animal permaneceu em média duas horas e cinquenta e seis 
minutos descansando, diferente de janeiro de 2015 , onde permaneceu em média duas horas e vinte minutos.

As linhas tracejadas mostram a regressão linear aplicada à variação do tempo médio de cada estado de comportamento e fornece indicações sobre a tendência de comportamento do animal ao longo dos meses de um determinado ano. Na Figura 14, por exemplo, as linhas tracejadas indicam que em janeiro de 2015 o tempo médio de duração do estado de forrageamento de Picolé foi de duas horas e quarenta e um minutos e teve uma tendência de queda ao longo dos meses seguintes. Já a duração do estado de descanso foi indicada como 2 horas e 21 minutos, em janeiro, e apresentou elevação nos meses seguintes. Já para o estado de trânsito não houve registro.

Tempo médio de duração do Comportamento Animal por Mês/Ano

Animal:Picole

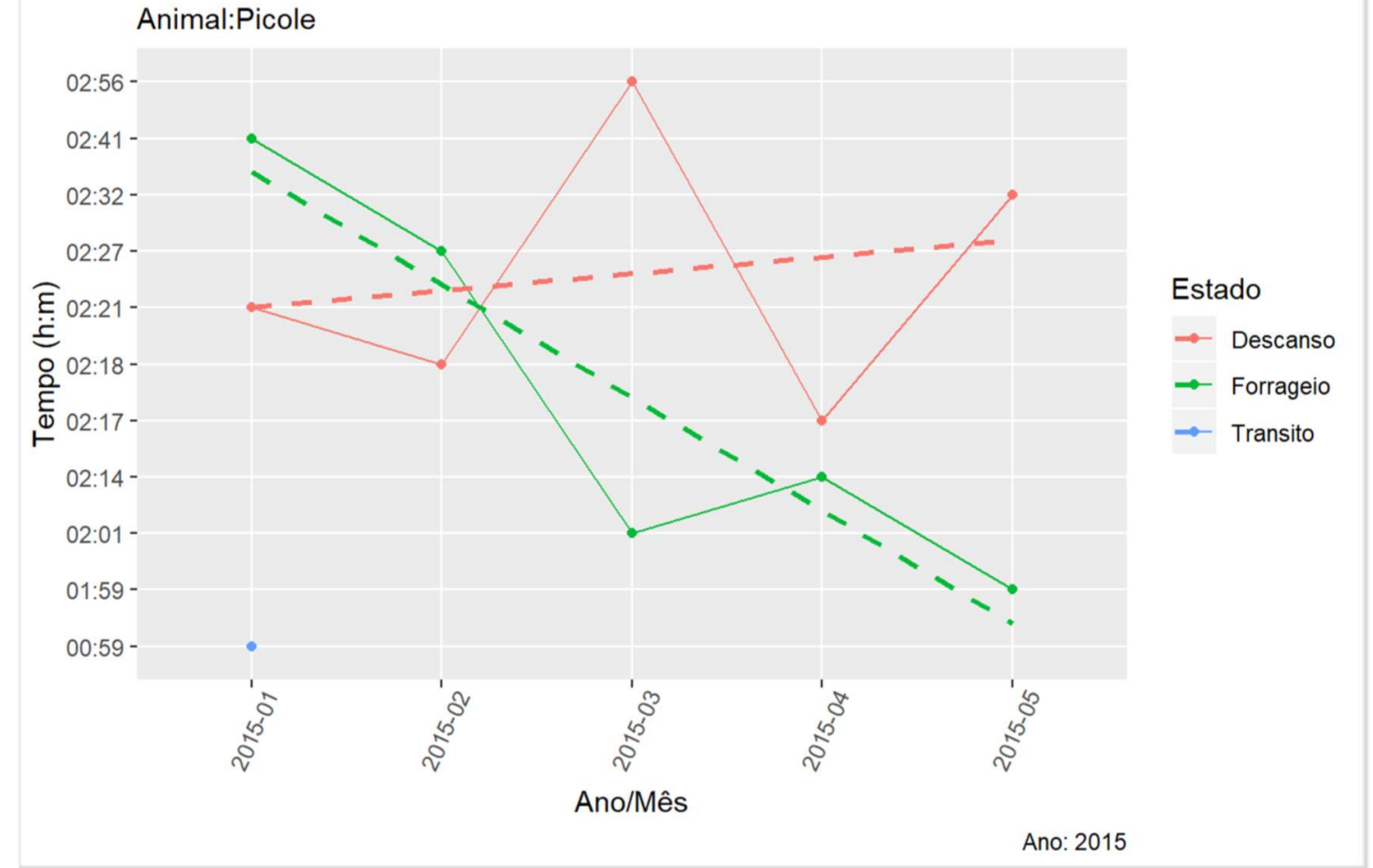

Figura 14 - Tempo médio de duração dos estados de comportamento do animal por mês e ano

\subsubsection{A3 - Identificar a frequência de ocorrência do estado de comportamento por período}

Na etapa A3 foram considerados os períodos previamente identificados e sem outliers para calcular a frequência de ocorrência de cada período (hora de início e término) por estado de comportamento. Desta forma, pode-se identificar quais horários apresentam maior frequência de ocorrência de um estado de 
comportamento animal. Na Figura 15, é apresentado o fluxograma que detalha as rotinas executadas pelo algoritmo na etapa A3 e o pseudocódigo pode ser consultado no Apêndice $\mathbf{A}$.

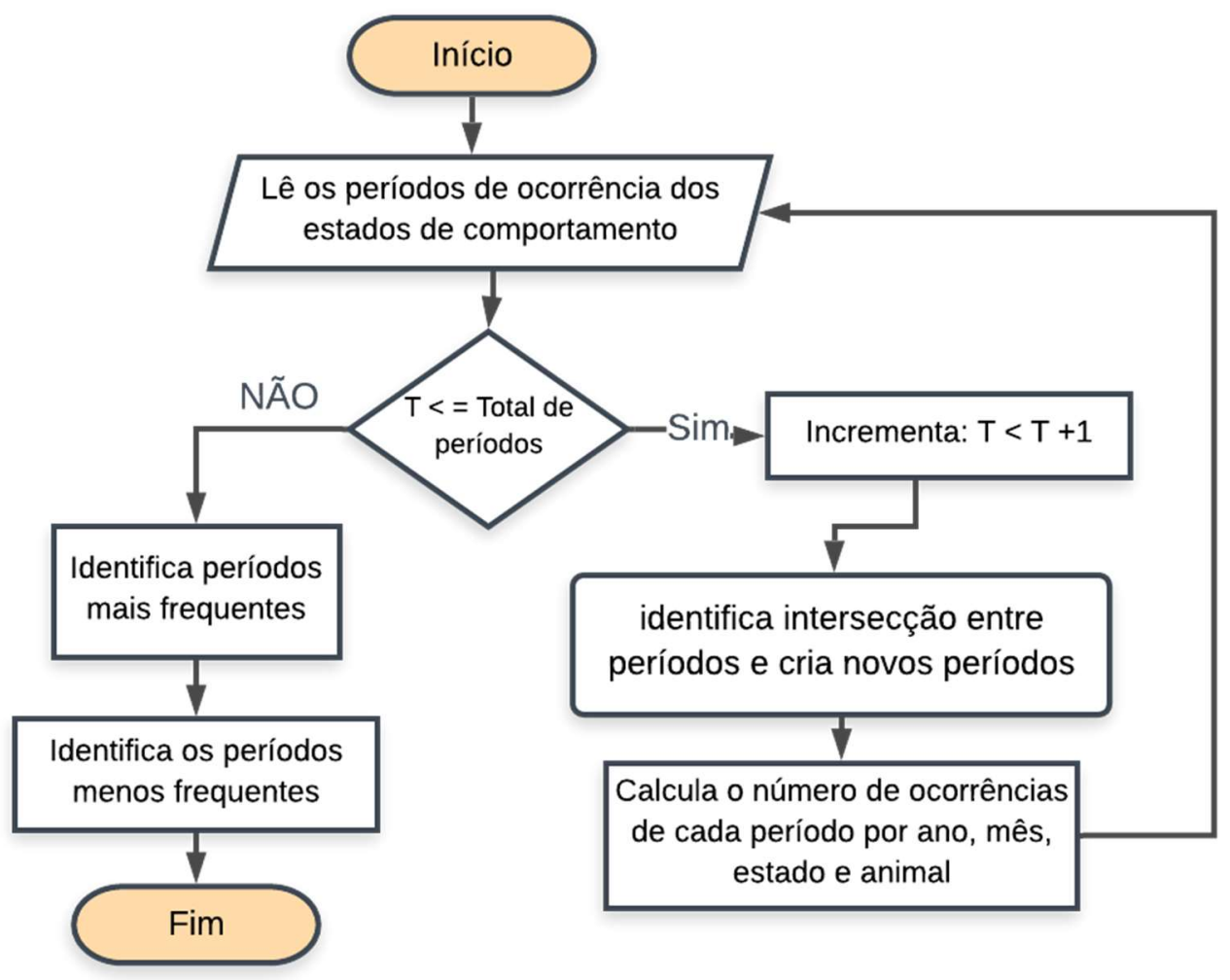

Figura 15 - Fluxograma da etapa A3 - Identificar a frequência de ocorrência do estado de comportamento por período

O primeiro passo consiste em identificar os períodos (hora de início e término) que ocorrem cada estado de comportamento. Para os períodos menos frequentes, uma rotina é aplicada para identificar os períodos sobrepostos e gerar novos períodos com essas intersecções. Com base nos resultados das análises uma rotina identifica a frequência de ocorrência de cada período por animal, estado, mês e ano. Os períodos com maior frequência por animal, estado, mês e ano são determinados com base na frequência total de ocorrência de cada período. Desta forma, os períodos de maior e menor frequência de ocorrência são identificados com base no cálculo do ranking de frequência de ocorrência de cada estado, por animal, período, mês e ano.

Como resultado da etapa são obtidos os intervalos entre horas, ou horários, de maior ocorrência dos estados do comportamento animal. Na Figura 16, é ilustrado um exemplo do gráfico de intervalos entre horas (horários) de 
maior frequência de ocorrência do estado de forrageamento para o animal Picolé em 2015. No gráfico observa-se que em fevereiro, abril e maio o forrageamento ocorreu mais no periodo das 0 hàs $8 \mathrm{~h}$.

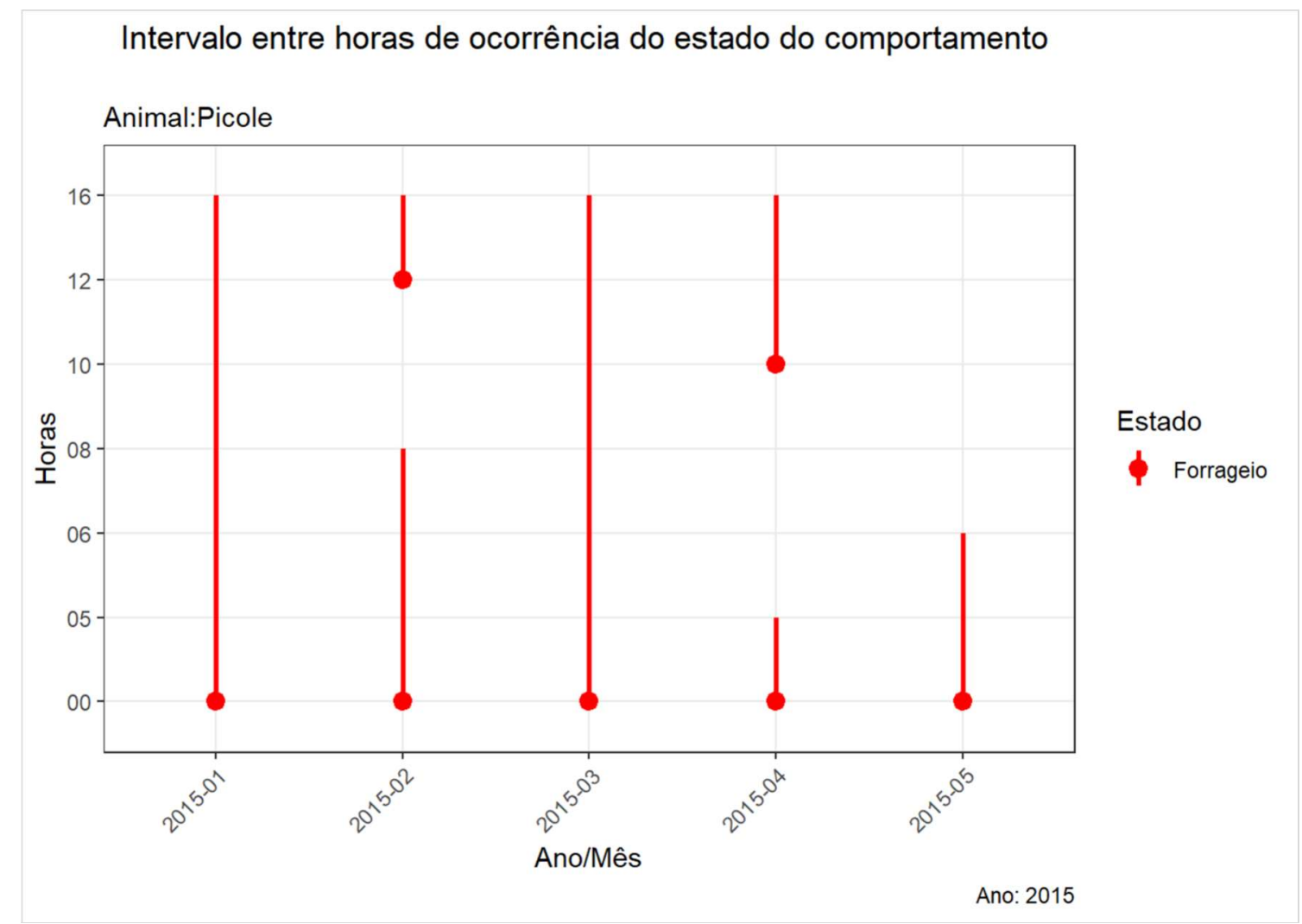

Figura 16 - Horários de maior frequência de ocorrência dos estados de comportamento por mês/ano

Outro resultado obtido na etapa é a frequência de ocorrência dos estados de comportamento por período do dia (dia/noite) para cada animal ao longo dos meses e anos. Na Figura 17, é ilustrado um exemplo do resultado da análise de frequência de ocorrência dos estados de comportamento para o animal Picolé ao longo dos meses de 2015. O gráfico é dividido em três áreas, que correspondem, aos estados de forrageamento, descanso e trânsito e para cada estado tem-se os meses e a frequência de ocorrência. As cores diferenciam os períodos: dia, noite e dia/noite (início do período durante o dia e término a noite) e indicam a variação da ocorrência de cada estado de comportamento por mês.

O total de ocorrências, mostrado no rodapé do gráfico, juntamente com o ano, corresponde ao número de registros analisados. Observando o exemplo, têm-se que foram analisadas 36 ocorrências da onça Picolé que indicaram que 
o animal forrageou mais durante o período da noite e descansou durante o dia ao longo dos meses de janeiro à maio de 2015.

Frequência de ocorrência dos estados do comportamento animal

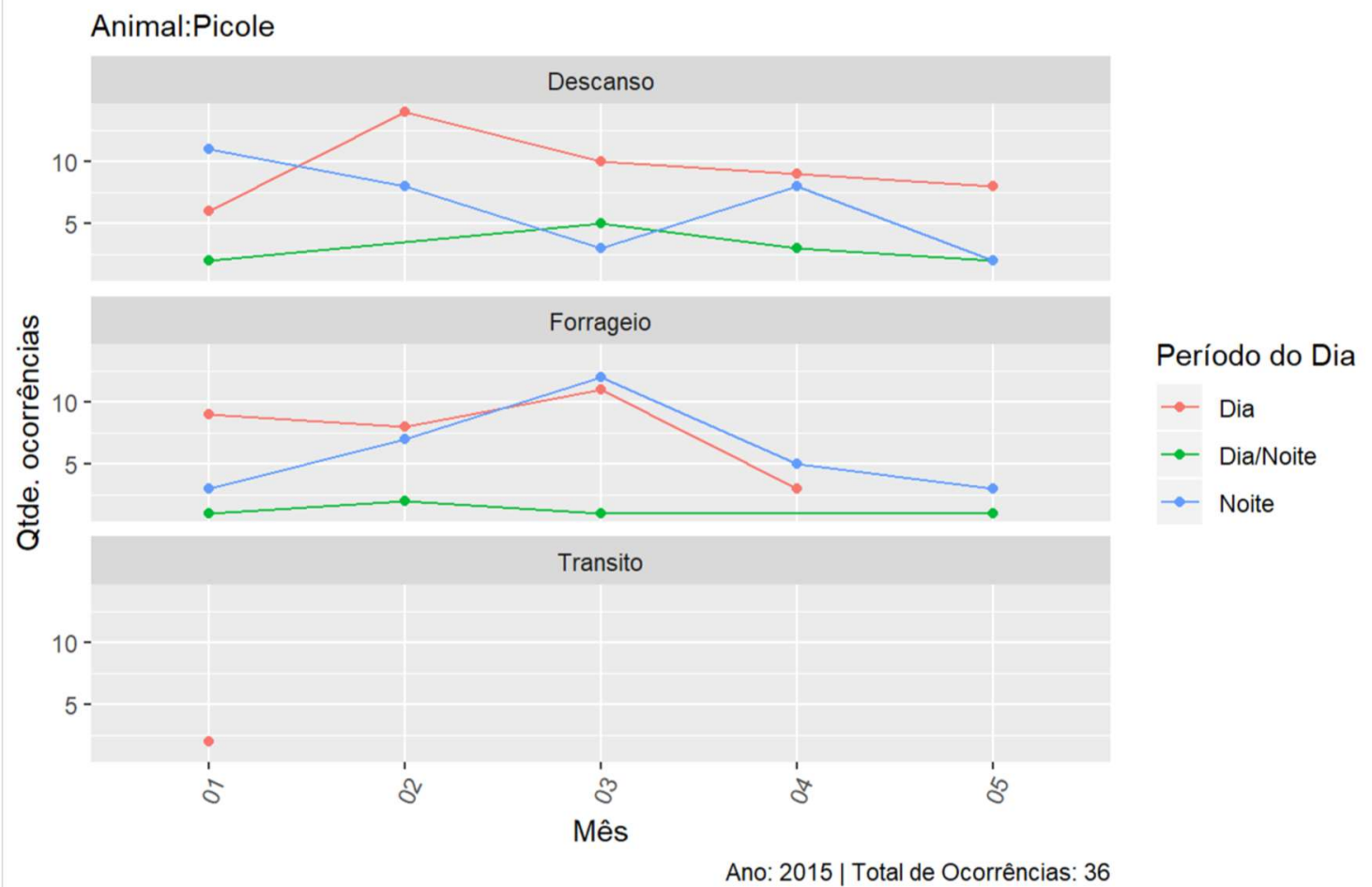

Figura 17 - Frequência de ocorrência dos estados de comportamento animal por período do dia

\subsubsection{A4 - Identificar a área de vida do animal}

Nesta Etapa, a área de vida do animal (home range) é identificada sobre dois aspectos: por animal, mês e ano e por animal, estado de comportamento, mês e ano. As trajetórias dos animais foram analisadas para determinar o home range dos animais com a função kernelUD, do pacote $R$ - AdehabitatHR (CALENGE, 2006). A Figura 18 mostra o fluxograma que detalha as rotinas executadas pelo algoritmo na etapa A4 e o pseudocódigo pode ser consultado no Apêndice $\mathbf{A}$.

Como resultado da etapa são obtidos os mapas de home range do animal por mês e ano e por estado de comportamento, mês e ano. Na Figura 19, por exemplo, é mostrado o mapa com a área ocupada pelos animais Picolé e Anderson no mês de fevereiro de 2015, que foram selecionados na lista de itens do menu lateral. 


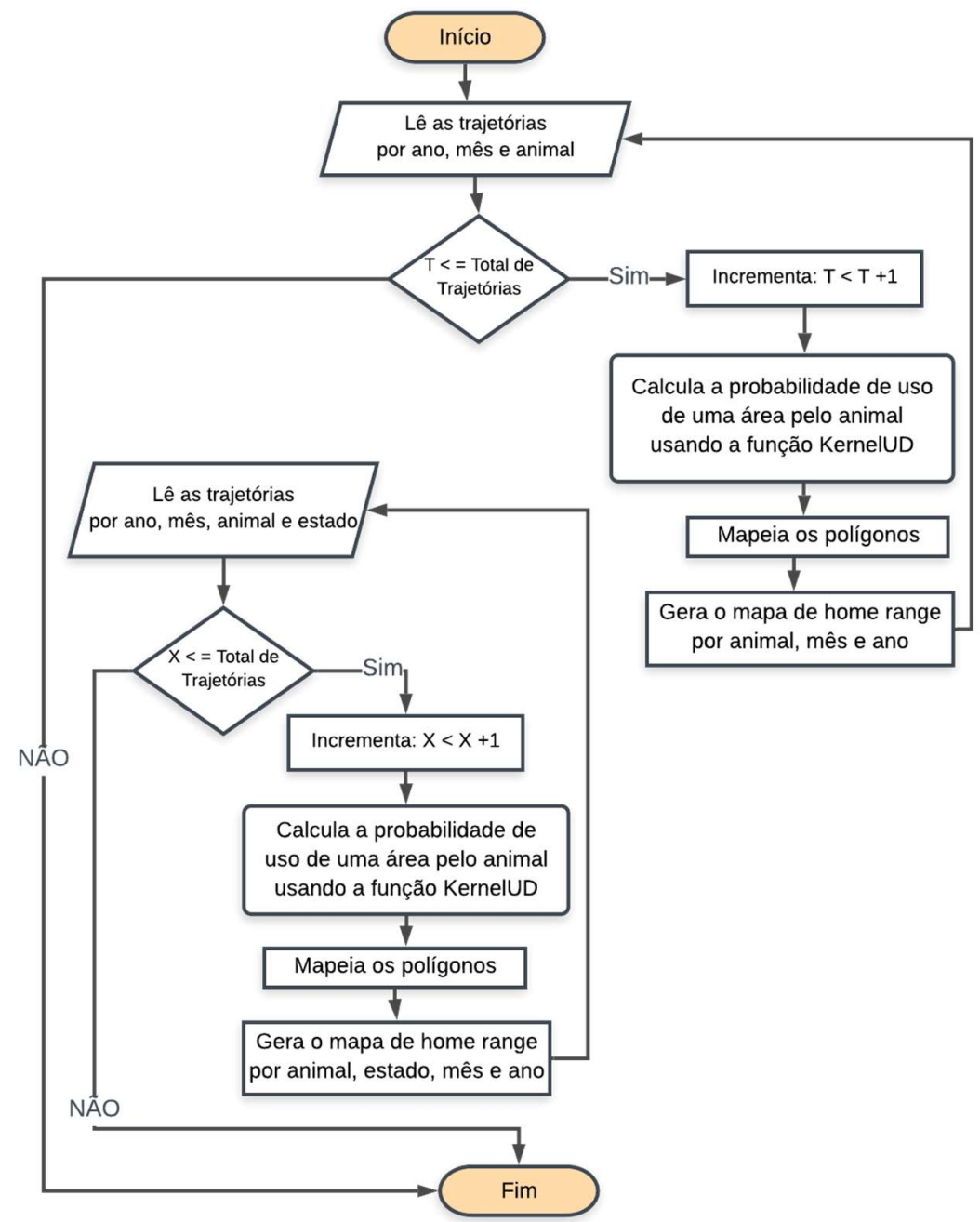

Figura 18 - Fluxograma da Etapa A4 - Identificar o home range animal
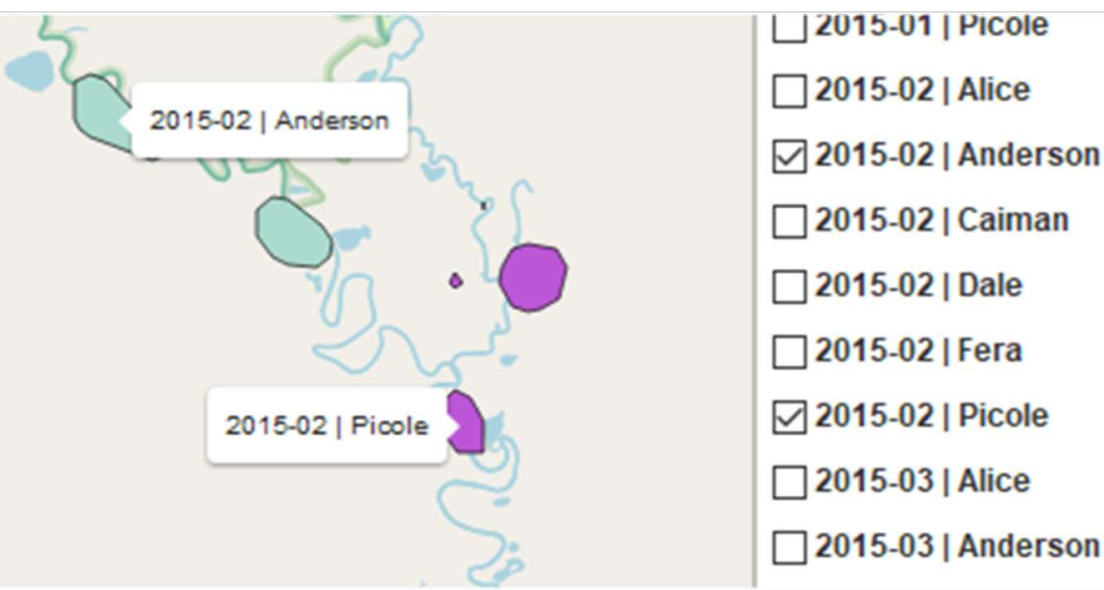

Figura 19 - Mapa de Home Range por animal, mês e ano.

Na Figura 20, é mostrado o exemplo do mapa da área ocupada pelo animal Picolé, que foi selecionado na lista de itens do menu lateral, e indica a área de forrageamento do animal em fevereiro de 2015. 

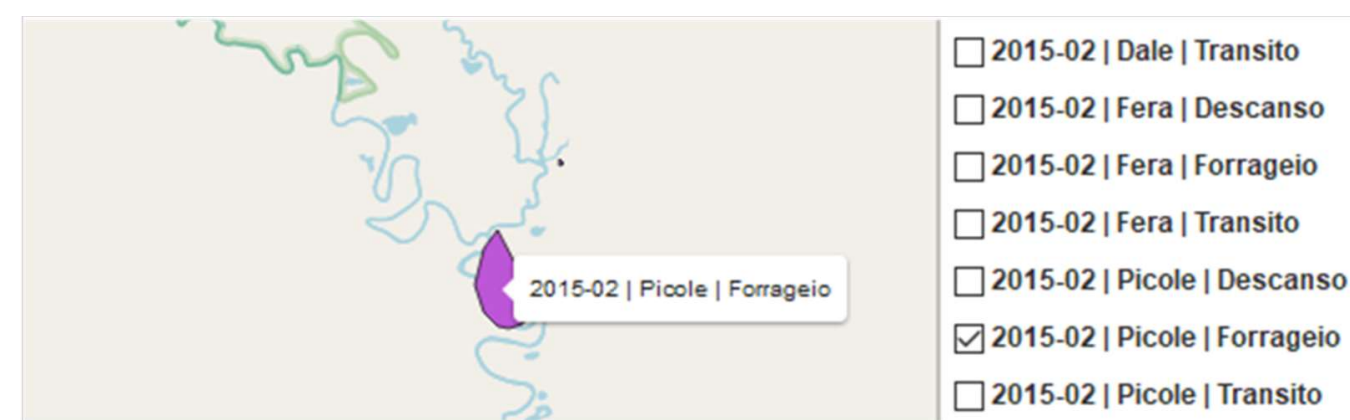

Figura 20 - Mapa de Home Range por animal, mês e ano e estado de comportamento,

\subsubsection{Etapa B - Identificar os fatores ambientais vizinhos das ocorrências dos animais}

$\mathrm{Na}$ etapa $\mathrm{B}$ os dados sobre movimento animal e fatores ambientais são analisados para identificar os fatores presentes ao longo do movimento dos animais. Quanto maior a proximidade entre o comportamento animal e o fator ambiental, maior a probabilidade de uma relação entre eles. Duas situações são consideradas: fatores que possuem informações sobre espaço (latitude/ longitude) e tempo, onde a distância entre o ponto de registro do fator e o comportamento animal é calculada com a fórmula de Vincenty e a segunda situação, é quando o fator está na área de ocorrência do comportamento animal, mas possui apenas informações de tempo não sendo possível calcular a distância entre eles.

A sequência de atividades, Figura 21, que compõem a etapa de identificação dos fatores ambientais vizinhos da ocorrência do comportamento animal abrange a identificação:

- dos fatores ambientais vizinhos por meio da distância entre o animal e o fator ambiental;

- dos fatores ambientais vizinhos por meio da data e a hora.

O fluxograma que detalha as rotinas executadas pelo algoritmo nas etapas B1 e B2, para identificar fatores ambientais que ocorreram próximos ao movimento animal, é apresentado na Figura 22. O pseudocódigo pode ser consultado no Apêndice A. 


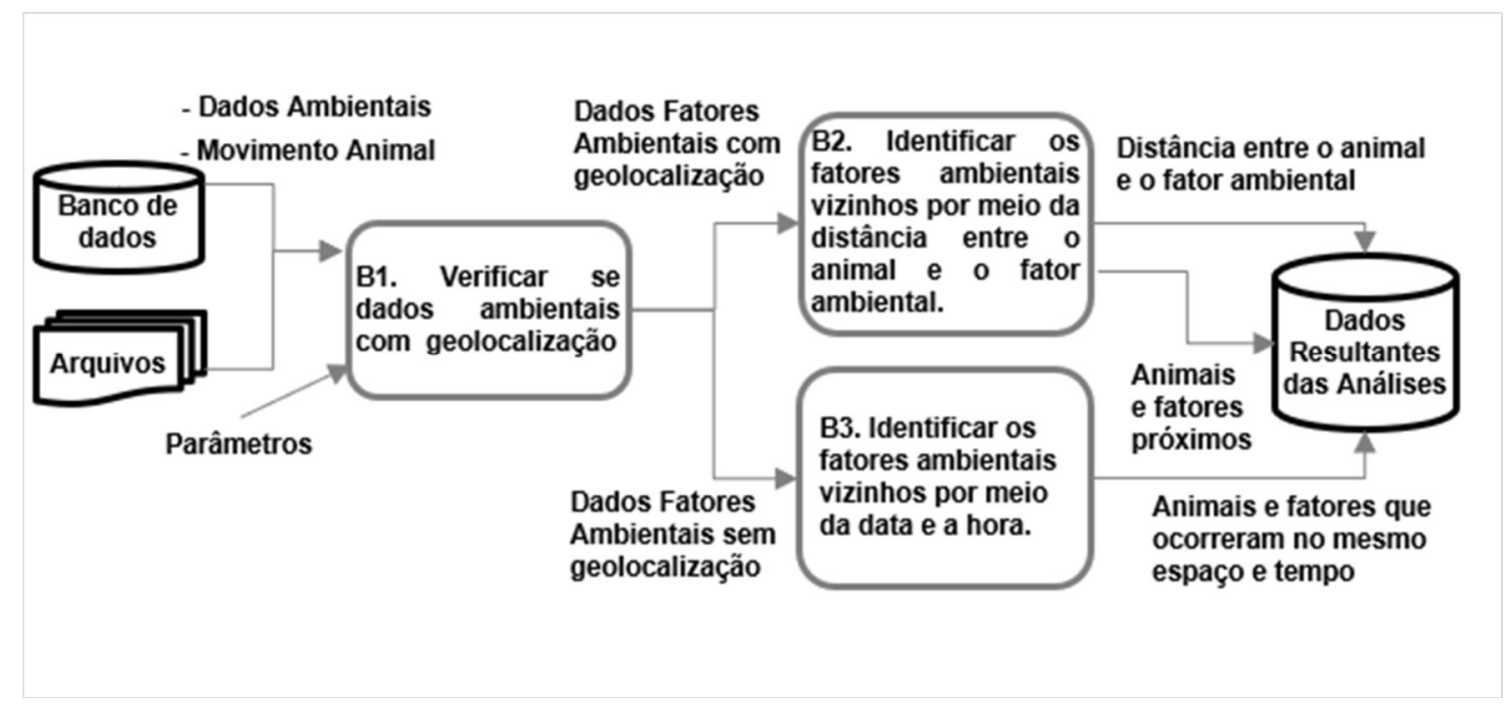

Figura 21 - Etapa B: Identificar os fatores ambientais vizinhos da ocorrência do comportamento animal

\subsubsection{B1 - Identificar os fatores ambientais vizinhos por meio da distância entre o animal e o fator ambiental}

$\mathrm{Na}$ Etapa B1, quando o conjunto de dados do fator ambiental possui informações espaciais sobre a localização (latitude e longitude) e hora (data e hora) das ocorrências, pode-se calcular a distância entre os pontos do movimento animal e do fator ambiental. O fator ambiental pode ser a ocorrência de outros animais que também estão contidos no mesmo conjunto de dados ou outros fatores contidos em um conjunto de dados separado.

Para calcular a distância entre os pontos de movimentação dos animais e a ocorrência do fator ambiental é criada uma matriz que relaciona os dados e calcula a distância entre os pontos de localização, com a fórmula de Vincenty (VINCENTY, 1975). Assim, para cada registro do movimento do animal, um círculo é criado em torno deste ponto (posição e tempo), com base em um raio de distância limite (parâmetro de entrada TD). Em seguida, calcula-se a distância entre o ponto de movimentação do animal e os fatores ambientais contidos no raio de pesquisa. Compara-se a data e a hora da ocorrência do movimento do animal com a data e hora da ocorrência do fator ambiental para identificar a distância e observa-se que ambos devem ocorrer em uma mesma data e hora. No entanto, o movimento do animal e o fator ambiental raramente ocorrerão no mesmo minuto e segundo. Assim, para cada data de movimentação do animal utiliza-se o parâmetro TI para adicionar uma margem, em minutos, antes e 
depois da hora inicial e final para recuperar as ocorrências dos fatores ambientais.

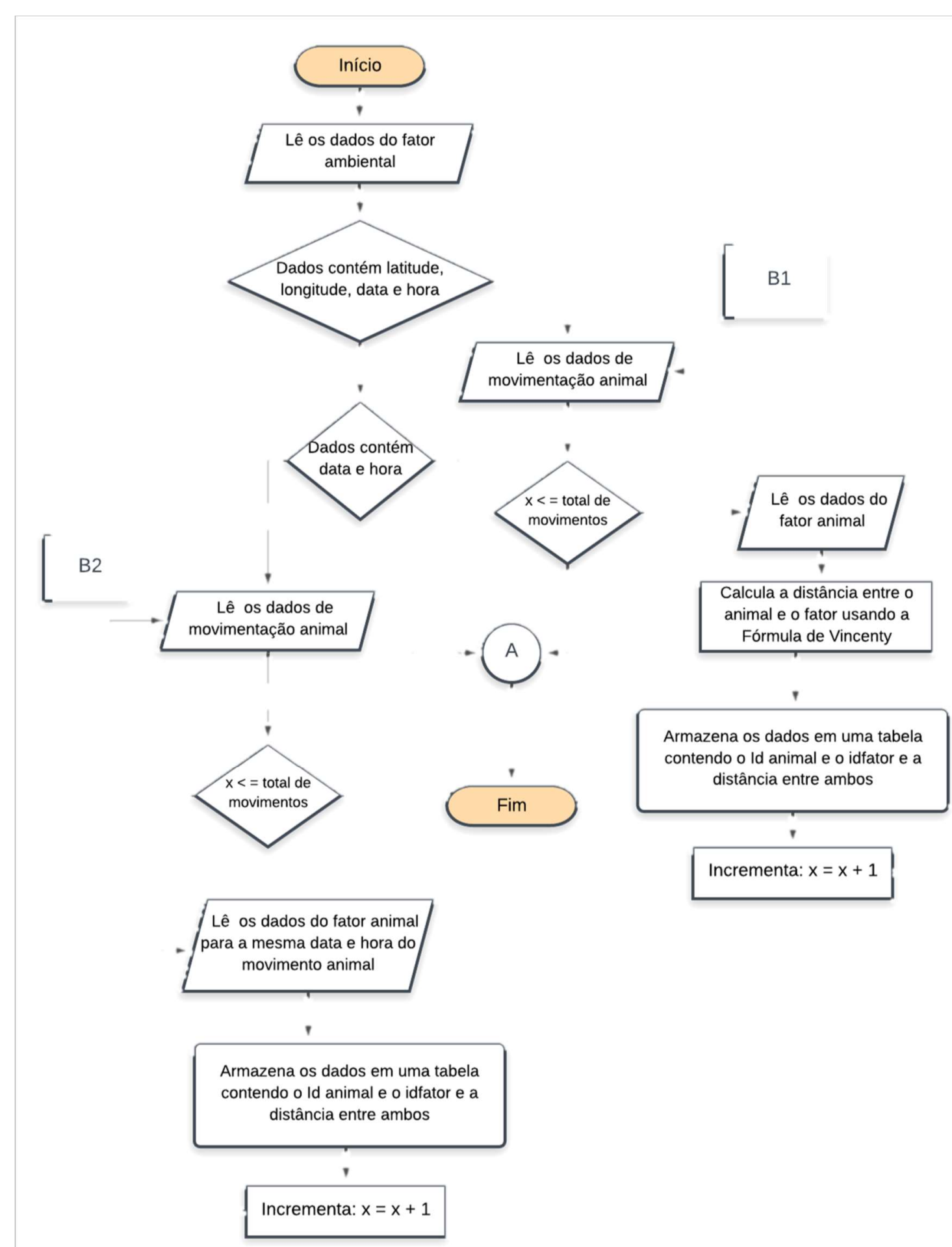

Figura 22 - Fluxograma da Etapa B1 e B2 - Identificar os fatores ambientais vizinhos do movimento animal

Como resultado da etapa é obtida uma tabela contendo os identificadores do animal e do fator e a distância em quilômetros (KM). 


\subsubsection{B2 - Identificar os fatores ambientais vizinhos por meio da data/hora.}

$\mathrm{Na}$ Etapa B2, quando o fator ambiental não possui as informações de espaço (latitude e longitude), porém sabe-se que os dados são da mesma área do movimento animal analisado, utiliza-se a data e hora para explorar os dados. Para cada movimento animal, a data do movimento é sincronizada com a data do fator ambiental e utiliza-se o parâmetro TI para adicionar uma margem, em minutos, antes e depois da hora inicial e final para recuperar as ocorrências dos fatores ambientais. Como resultado da etapa, é obtida uma relação dos animais e os fatores ambientais vizinhos.

\subsubsection{Etapa C - Identificar a correlação entre o comportamento animal e os fatores ambientais vizinhos}

Na Etapa C, são abordadas as atividades realizadas para identificar a interação entre os animais e os fatores ambientais vizinhos. Na Figura 23, é mostrada a sequência de atividades que compõem a etapa de identificação da correlação entre o comportamento animal e os fatores ambientais vizinhos que abrange a identificação:

- da correlação entre animais vizinhos;

- da correlação entre estado de comportamento e fatores ambientais.

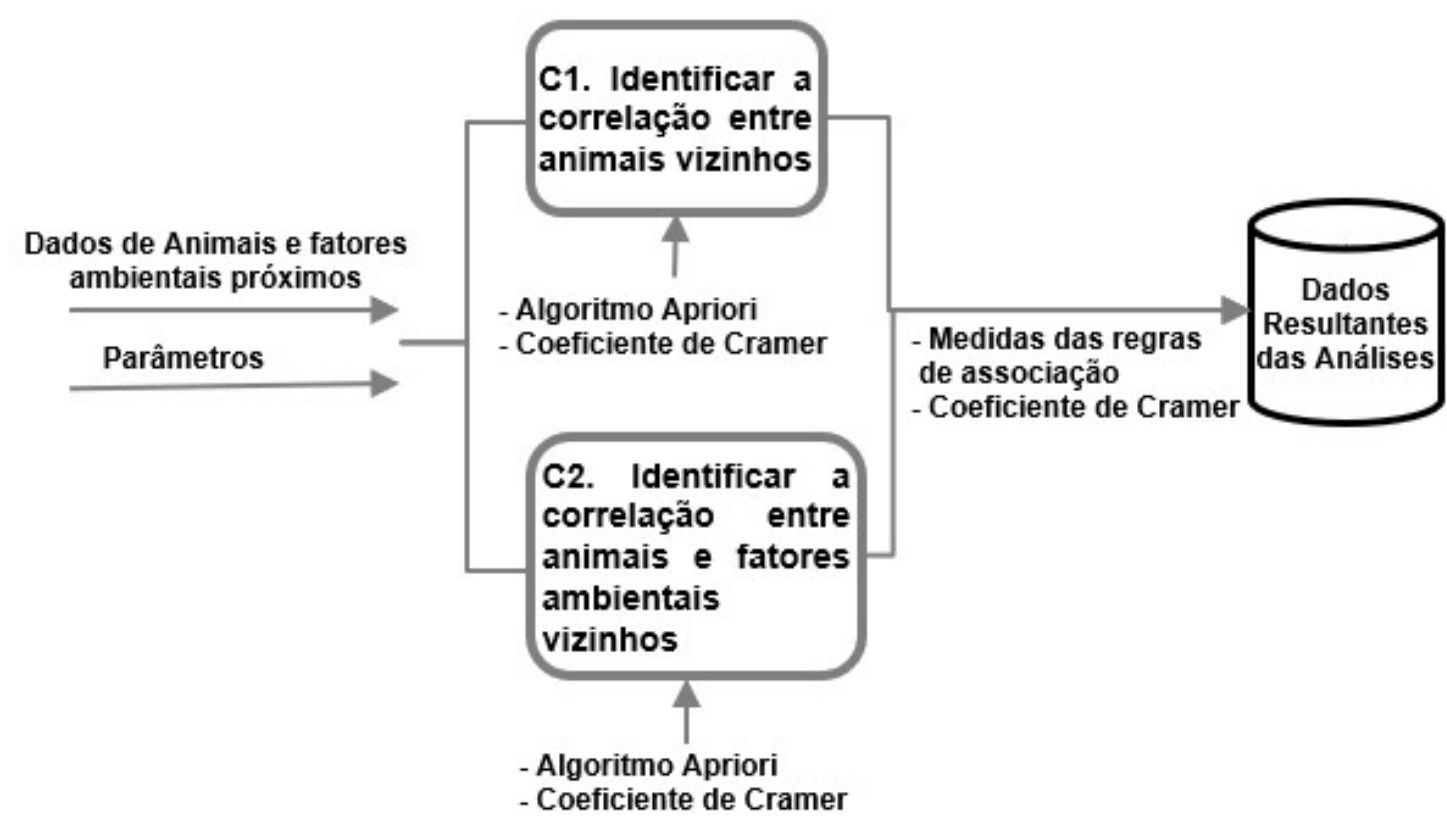

Figura 23 - Etapa C: Identificar a correlação entre o comportamento animal e os fatores ambientais vizinhos 
Para identificar a correlação as variáveis são selecionadas para serem analisadas e a técnica de regras de associação é aplicada com o algoritmo Apriori, do pacote Arules (HAHSLER; GRUEN; HORNIK, 2005), para obter indicativos sobre a interação entre essas variáveis. Na análise da correlação entre os animais são consideradas as variáveis Animal 1 e Animal 2 e na correlação entre o estado do comportamento animal e outros fatores têm-se as variáveis Estado e Status do Fator, respectivamente. Na Figura 24, é apresentado o fluxograma que detalha as rotinas executadas pelo algoritmo, nas etapas C1 e C2, e o pseudocódigo pode ser consultado no Apêndice A.

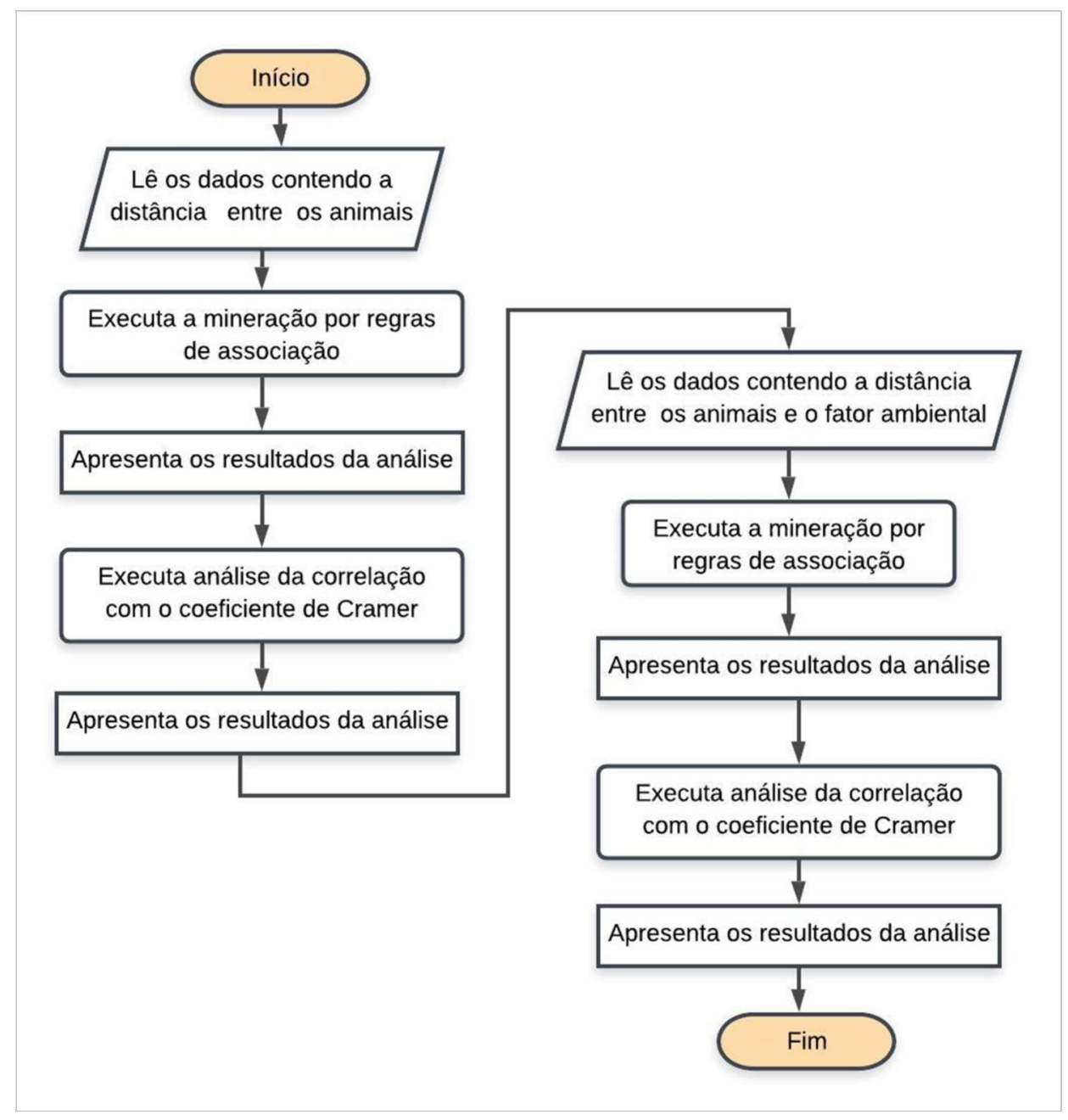

Figura 24 - Fluxograma da etapa C1 e C2 - Identificar a correlação entre o comportamento animal e os fatores ambientais vizinhos

O algoritmo Apriori identifica as regras de associação entre as variáveis, com base na frequência com que ocorrem juntas e reduz as regras que estão abaixo dos limites de minSup e minConf para identificar as regras de associação relevantes. O AniMoveMineR está preparado para gerar as regras de associação 
para minSup e minConf com os valores: baixo (0.01), igual a $1 \%$; intermediário (0.50), igual a $50 \%$; alto (0.9), igual a $90 \%$.

O framework realiza a mineração por regras de associação e particiona os dados por ano, quantos estejam contidos no dataset, e por mês e ano. Como resultado da mineração são obtidas as regras de associação entre os dados e as medidas que identificam a correlação e dependência entre as variáveis analisadas (MANIMARAN; VELMURUGAN, 2015). As medidas obtidas indicam a frequência de coocorrência (Sup) das duas variáveis; a frequência de ocorrência somente da variável A (SupA) e da B (SupB); a frequência esperada (SupEsp) de coocorrência das variáveis A e B; e a confiança (Conf), que é a probabilidade de $B$ ocorrer em função da ocorrência da variável A. Outras medidas obtidas são o coeficiente de correlação (Phi), que indica o nível de correlação entre as variáveis, e o Lift, que determina o nível de dependência entre as variáveis analisadas.

Com base nas medidas é calculado um percentual de dependência entre as variáveis para cada regra, usando a fórmula:

$$
\text { Dep }=\text { confDep.valor }+ \text { SupDep.valor }+ \text { Lift.valor }
$$

Como resultado da etapa são mostrados gráficos baseados nas medidas de suporte, confiança, phi e lift obtidas na mineração dos dados por ano e por mês e ano. O gráfico, Figura 25, apresenta o percentual de confiança entre os pares de animais e indica a probabilidade de ocorrência de um animal em função de outro por mês e ano. No exemplo, é mostrada a relação entre os animais Fera e Dale que apresentam frequência de coocorrência alta (Sup = 100\%), alta probabilidade de um animal ocorrer em função da ocorrência do outro (Conf = $100 \%$ ) obtidos com a análise de 63 registros de movimentação dos animais. A medida de confiança representada pela intensidade das cores que indica a probabilidade de coocorrência dos animais, quanto maior a probabilidade maior a intensidade da cor. 


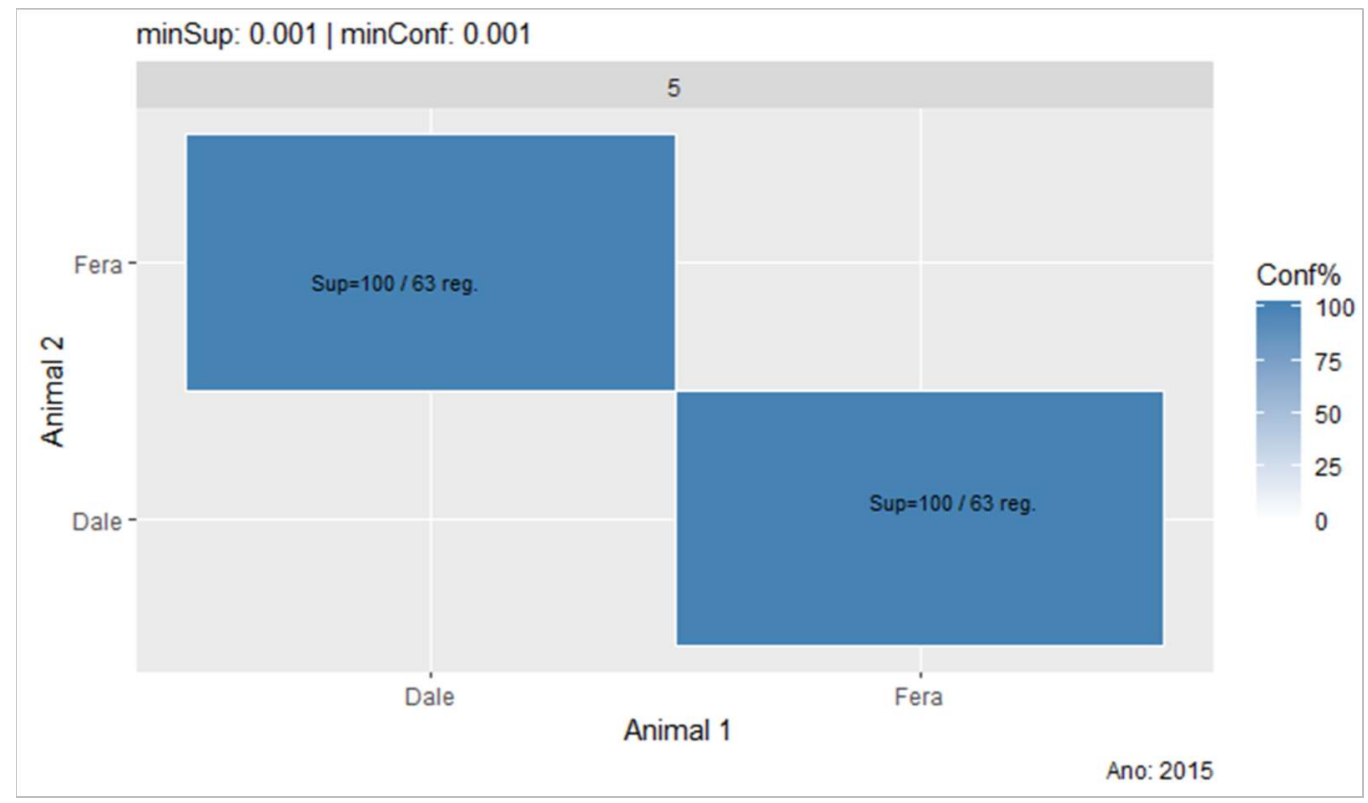

Figura 25 - Gráfico de Confiança entre os animais por mês e ano

O mesmo padrão de gráfico, Figura 26, é utilizado para analisar o nível de correlação entre os animais por mês com base no coeficiente de correlação (phi). Os meses no gráfico são representados por números, por exemplo, 2 (fevereiro), 3 (março), 4 (abril) e 5 (maio).

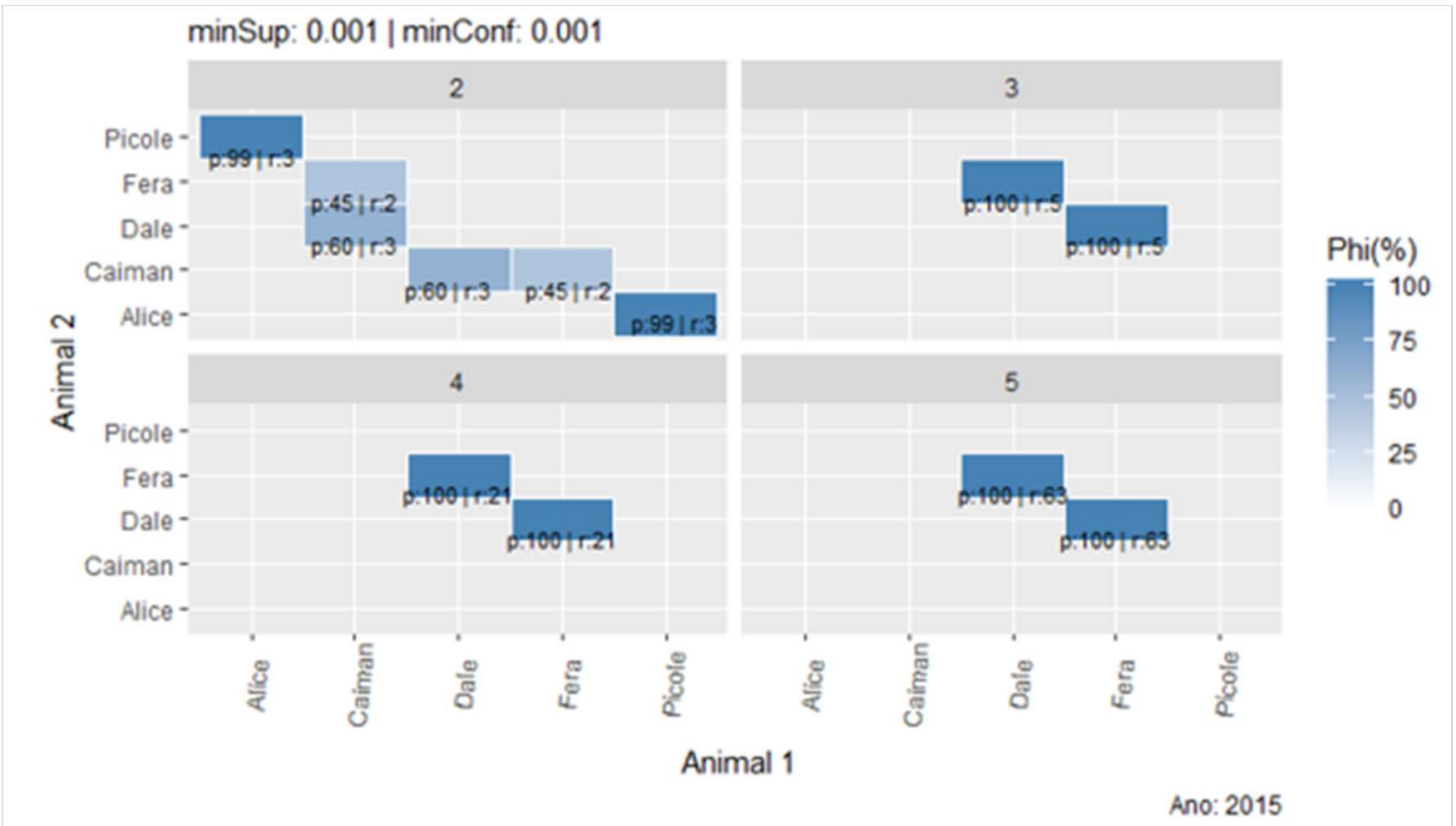

Figura 26 - Gráfico de nível de correlação entre animais por mês e ano 
O nível de correlação entre os animais por ano é mostrado na Figura 27 e os quadros em cinza indicam as correlações negativas entre Caiman e Dale para 2015.

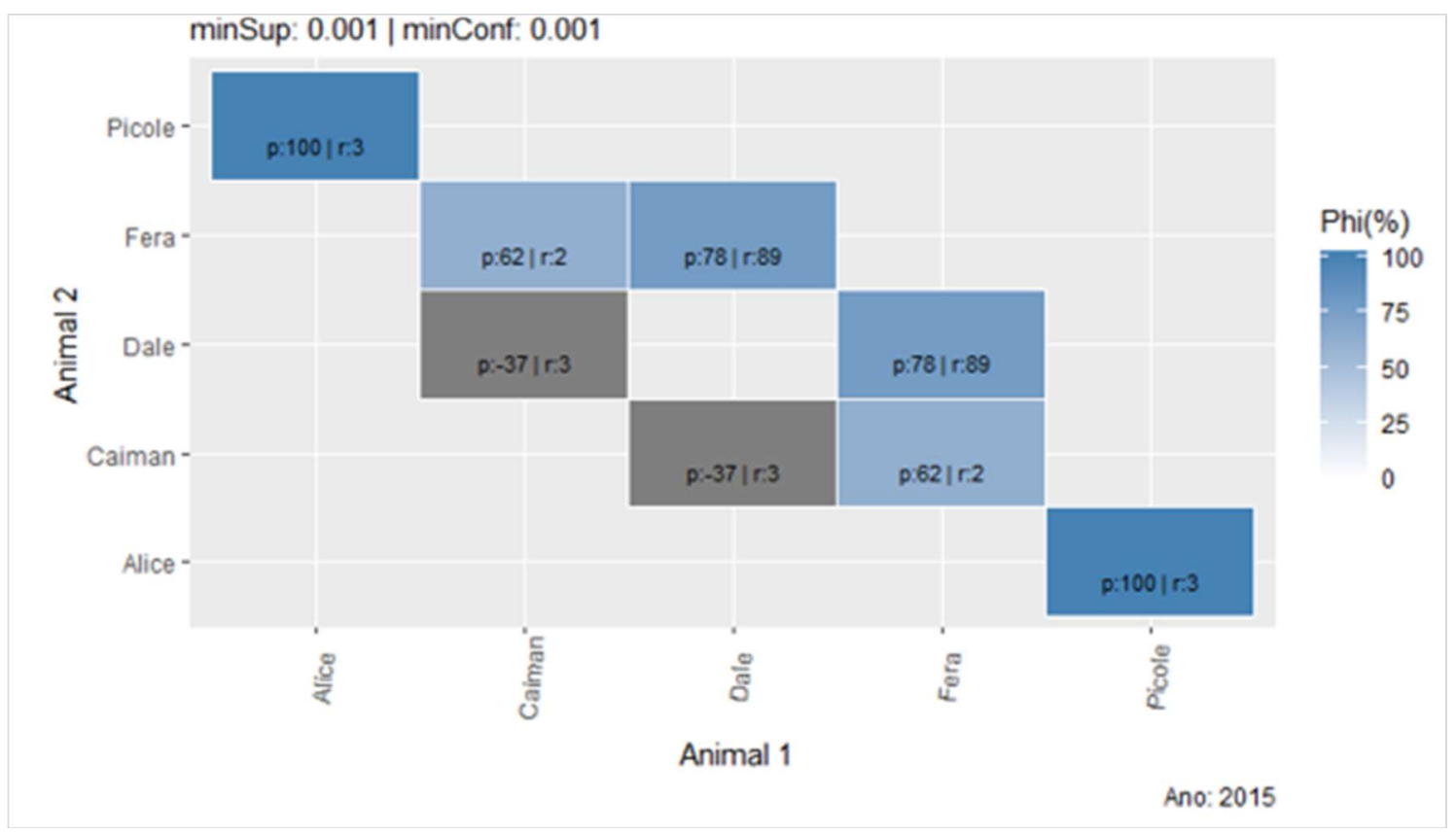

Figura 27 - Gráfico de nível de correlação entre animais por ano

Outro resultado da etapa é a dependência entre as variáveis, baseada na medida de Lift, obtida com as regras de associação. Na Figura 28, é mostrado um exemplo de grafo que indica a relação de dependência entre os animais Alice e Picolé. Os grafos são formados por vértices e arestas, onde a cor dos vértices determina a intensidade da dependência entre os animais de acordo com o Lift, e o tamanho dos vértices consiste na frequência de coocorrência entre os animais com base no valor da medida de suporte (Sup).

O algoritmo Apriori ao realizar a mineração por regras de associação utiliza os parâmetros de minConf e minSup para filtrar as regras mais relevantes, desta forma, os valores que são utilizados para estes parâmetros podem influenciar diretamente nos resultados obtidos. Caso, por exemplo, a frequência mínima de coocorrência dos animais seja elevada alguns encontros esporádicos entre os animais não serão identificados, no entanto poderiam ser relevantes dependendo do contexto e do dataset analisado. Diante disso, o AniMoveMineR foi preparado para aplicar a mineração por regras de associação para um conjunto de diferentes valores para minSup e minConf. 


\section{Mês/Ano:2/2015 | minSup:0.001 |minConf:0.001}

size: support $(0.25-0.625)$ color: lift $(1-2.667)$

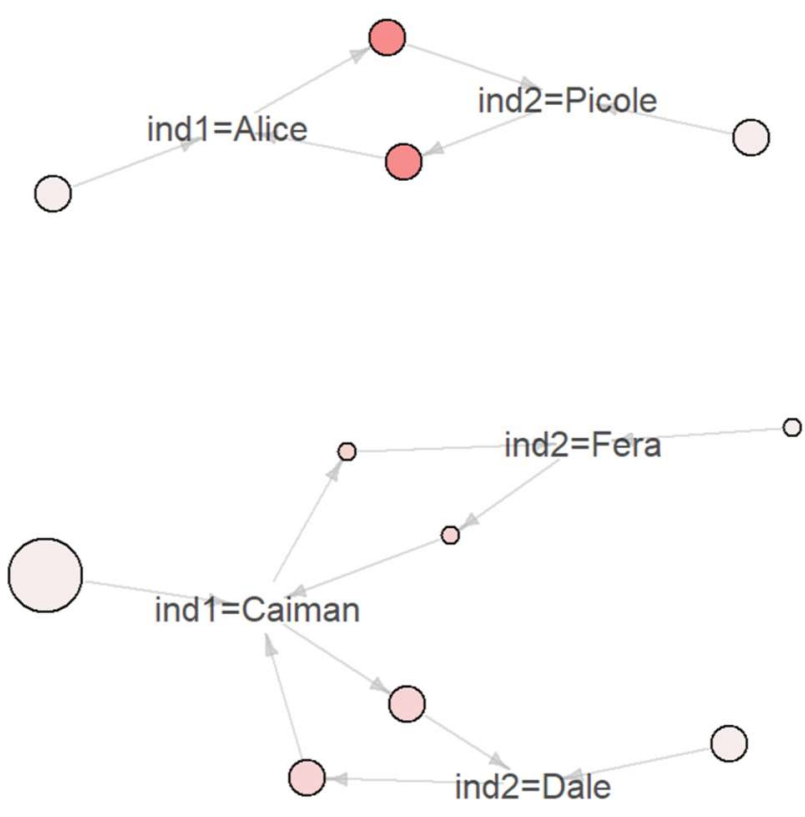

Figura 28 - Grafos de Dependência entre os animais baseada no Lift

O gráfico de níveis de dependência entre os animais, Figura 29, permite observar os pares de animais identificados pelas regras de associação e a dependência (lift) entre esses animais em diferentes testes realizados variando os valores de minSup e minConf.

As cores diferentes para as barras indicam os valores obtidos nas avaliações, por meio de valores diversos para o minSup e minConf, que permite identificar como a dependência entre os animais varia de acordo com a frequência mínima de coocorrência ou a probabilidade de um animal ocorrer em função de outro. No gráfico, o exemplo indica que os animais Alice e Picolé apresentaram valores acima de 1 , dependência positiva durante o mês de fevereiro de 2015 para o teste com minSup e minConf 0.001 (1\%). No entanto, para os testes com o minSup e minConf iguais a $0.5(50 \%)$ e $0.9(90 \%)$ a relação entre esses animais não foi identificada.

Para complementar e validar os resultados da análise da correlação obtidos com a mineração por regras de associação o framework fornece o coeficiente de Cramer, Figura 30, que indica a associação entre duas variáveis 
medidas numa escala categórica, sendo calculado com base no valor do chisquare (qui-quadrado) (PLACKETT, 1983)(ALVAREZ, 2003). O coeficiente é obtido com base na análise de uma tabela de contingência.

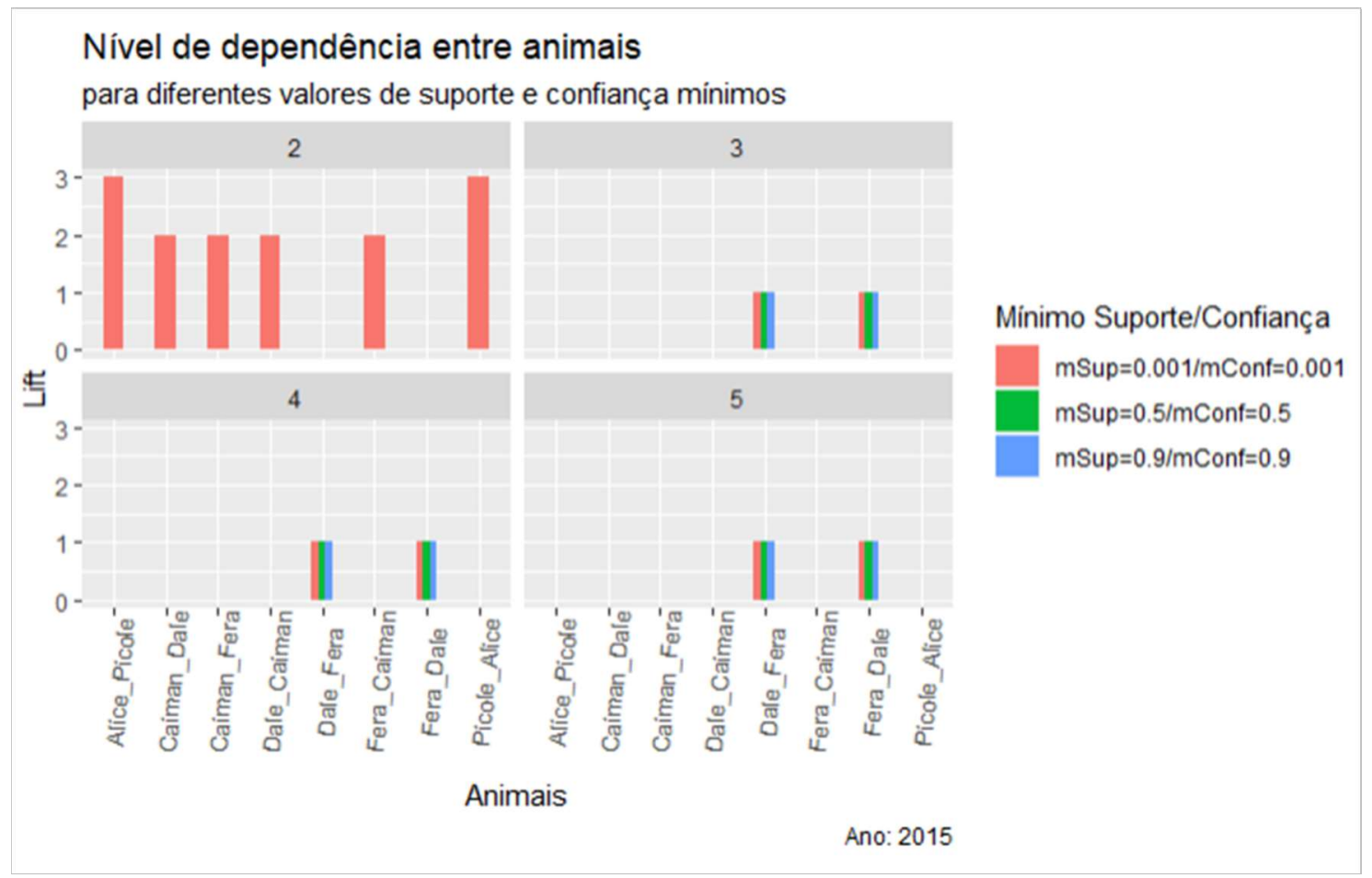

Figura 29 - Gráfico de correlação entre animais para diferentes valores de minSup e minConf

Na fórmula de $\mathrm{V}$ de Crámer, (n) representa o número total de ocorrências e (I) representa o mínimo entre o número de linhas e colunas da tabela de contingência.

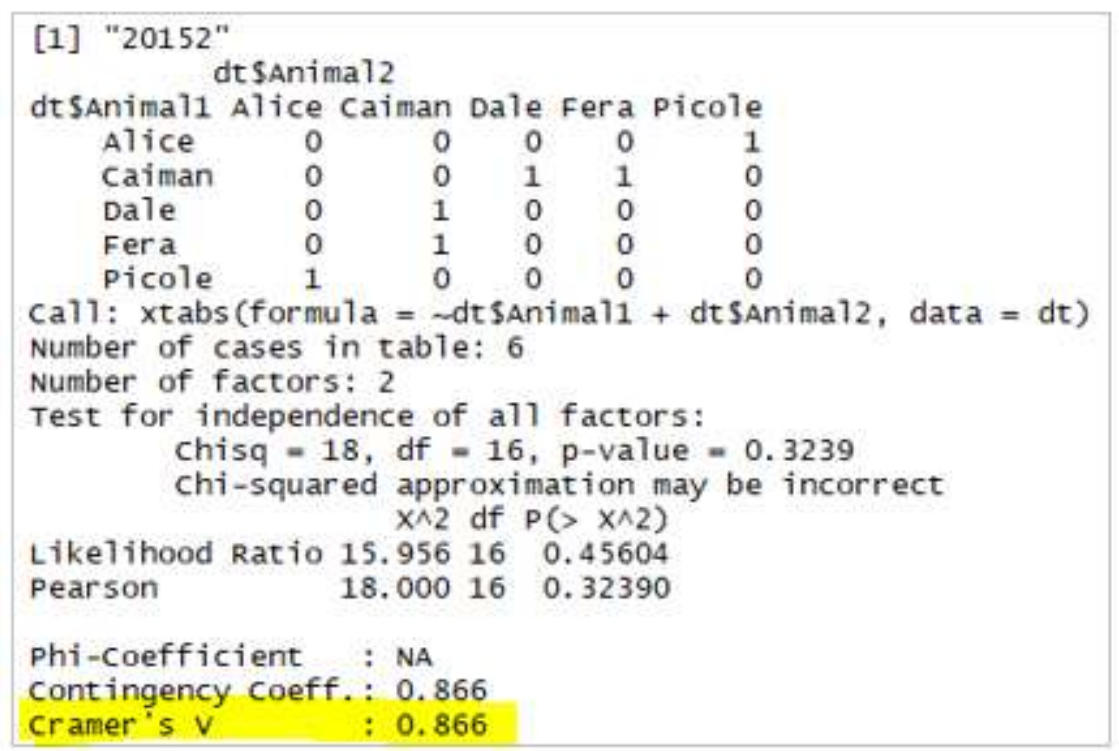

Figura 30 - Resultado da análise da tabela de contingência e coeficiente de Cramer 
O resultado obtido varia entre 0 , totalmente independentes, e 1 , totalmente associados, quanto maior a associação maior o valor do coeficiente.

Fórmula de Cramer:

$$
(\boldsymbol{C})=\sqrt{\frac{X^{2}}{n(l-1)}}
$$

A tabela de contingência é uma tabela em que as frequências correspondem a duas classificações, uma classificação está nas linhas da tabela e a outra está nas colunas. A tabela terá tantas linhas e colunas quantas as categorias em cada uma das variáveis.

$\mathrm{Na}$ etapa ainda são explorados outros aspectos da interação entre os animais como a sobreposição da área de vida e a distância entre os animais ao longo do tempo e espaço. A sobreposição da área de vida é calculada com a função kerneloverlap (CALENGE, 2006) que gera uma matriz de relação entre os animais e indica a probabilidade de apresentarem sobreposição de espaço para o dataset analisado. Esta função não efetua a análise dos dados por mês e ano. Na Figura 31, é mostrada a matriz de sobreposição entre os animais. Quanto mais próximo ou igual a 1 maior a sobreposição da área. A matriz indica, por exemplo, que entre Fera e Dale há uma sobreposição de área de 0.587 que significa uma moderada sobreposição. Já entre Fera e Picolé o valor é igual a zero e indica que não houve sobreposição de espaço entre esses animais.

\begin{tabular}{|lrrrrrr|}
\hline \multicolumn{1}{|c}{ Alice } & Anderson & Caiman & Dale & Fera & Picole \\
Alice & 1.44471039 & 0.000000000 & 0.010687737 & 0.000000000 & 0.0000000 & 0.30537827 \\
Anderson & 0.00000000 & 1.225943528 & 0.009778837 & 0.003070979 & 0.0000000 & 0.00000000 \\
Caiman & 0.01068774 & 0.009778837 & 1.235229979 & 0.383405522 & 0.3244139 & 0.08479725 \\
Dale & 0.00000000 & 0.003070979 & 0.383405522 & 1.471428137 & 0.5870313 & 0.00000000 \\
Fera & 0.00000000 & 0.000000000 & 0.324413906 & 0.587031338 & 1.7508665 & 0.00000000 \\
Picole & 0.30537827 & 0.000000000 & 0.084797247 & 0.000000000 & 0.0000000 & 1.37550625 \\
\hline
\end{tabular}

Figura 31 - Matriz de sobreposição do home range

A sobreposição do home range dos animais pode ser observada, também, por meio de mapa. Um menu lateral permite selecionar os animais que serão visualizados no mapa, sendo possível selecionar múltiplos animais. O mapa, Figura 32, mostra a sobreposição de área de vida dos animais Fera, Caiman e Dale para fevereiro de 2015. 


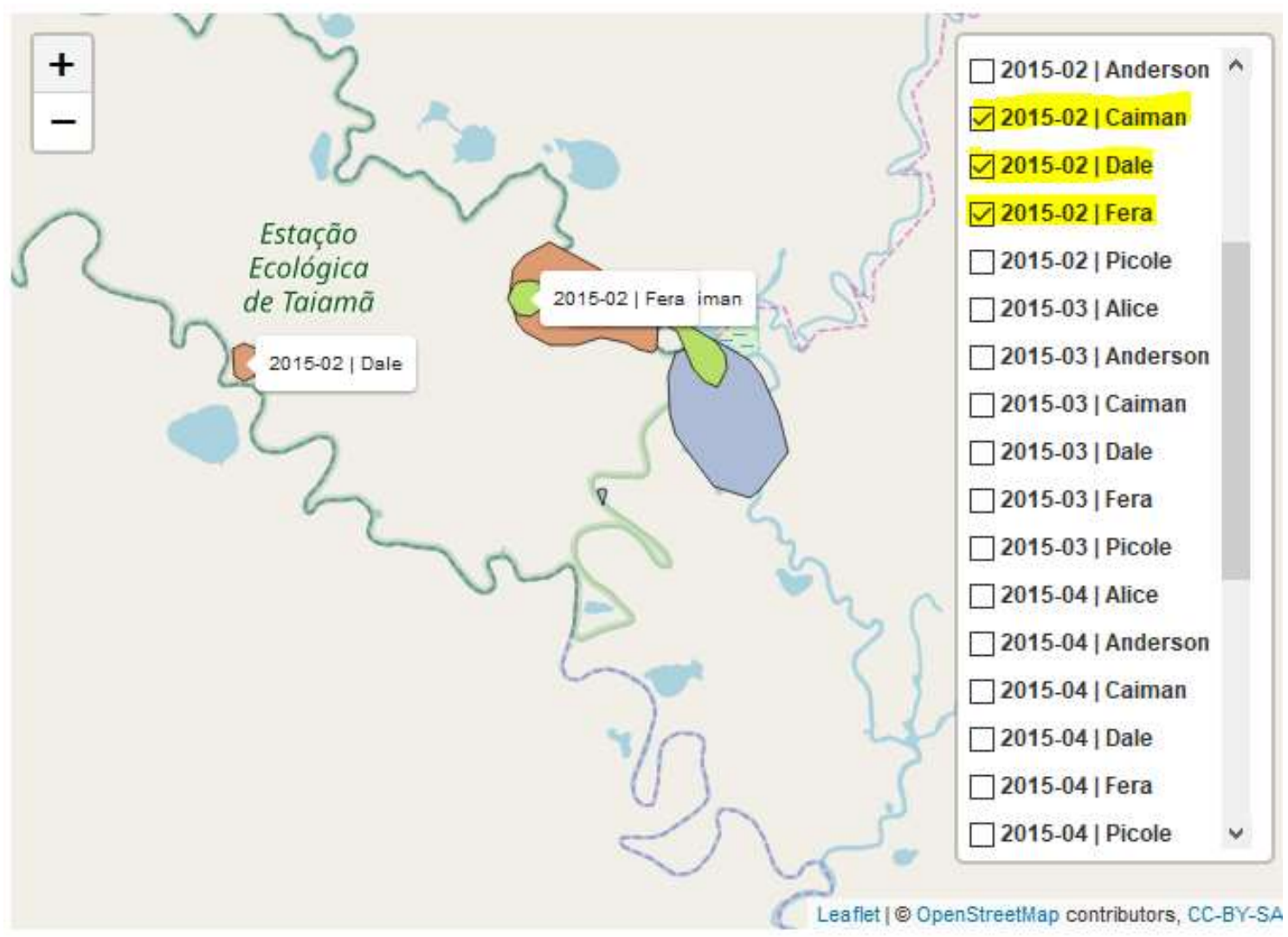

Figura 32 - Mapa de home range por animal, mês e ano

No mapa, Figura 33, é mostrada a sobreposição da área de vida por estado de comportamento de forrageio dos animais Caiman, Dale e Fera em fevereiro de 2015.

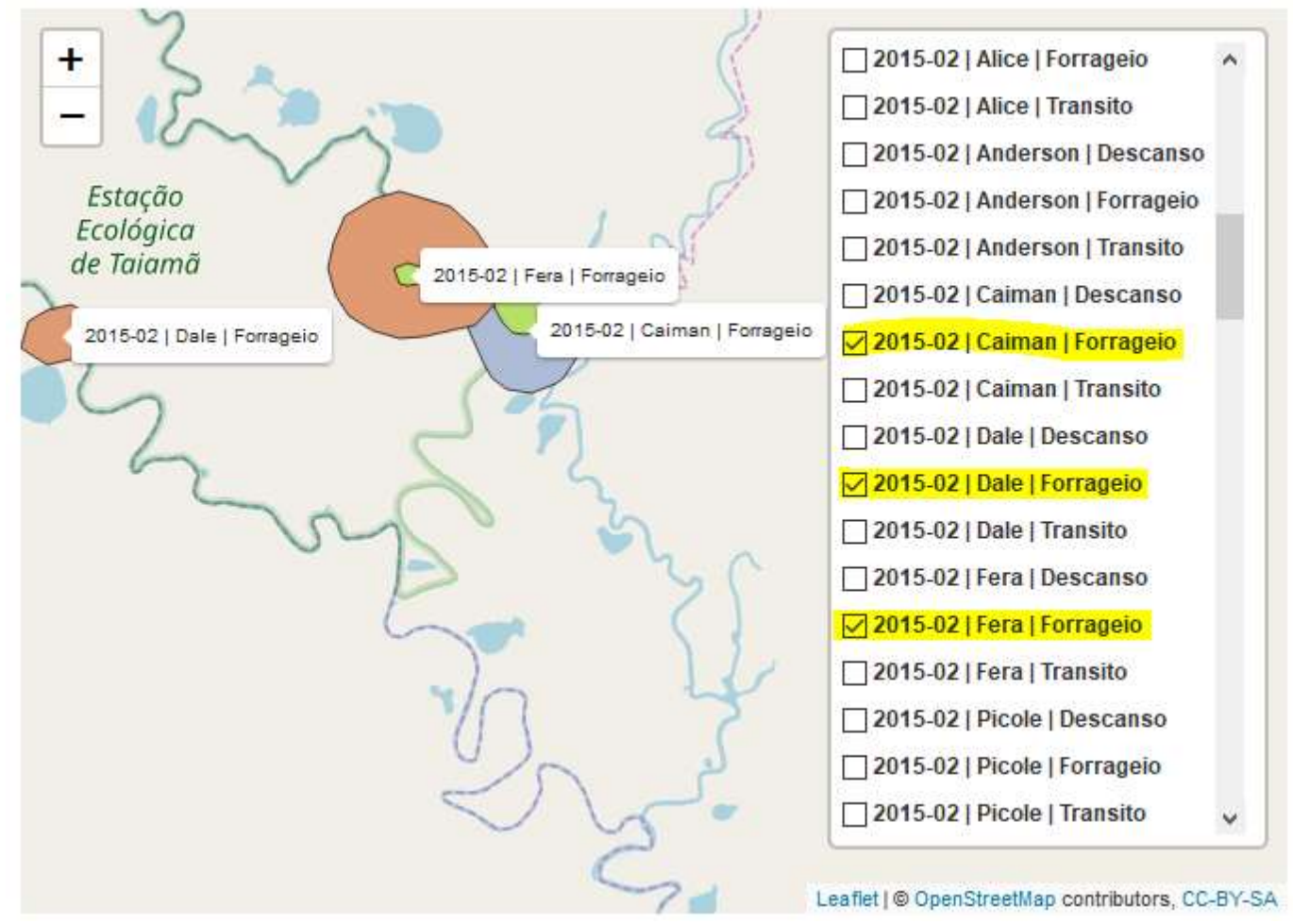

Figura 33 - Mapa de home range por animal, estado do comportamento, mês e ano 
Outro aspecto da interação entre os animais e os fatores ambientais é a distância média entre eles ao longo do tempo. Na etapa B, da análise de dados, são calculadas as distâncias entre os animais e fatores ambientais e para aplicar a mineração por regras de associação são utilizados os dados com distância igual ou abaixo da distância limite (TD).

Com base nos pares de animais obtidos com as regras de associação um gráfico indica as datas onde a distância entre os animais estava dentro do raio de distância definido como limite. Na Figura 34, é ilustrado um exemplo do gráfico de distância entre os animais Picolé e Wendy que considera a movimentação de ambos num raio de distância de 400 metros $(0.4 \mathrm{~km})$ para o mês de março de 2014.

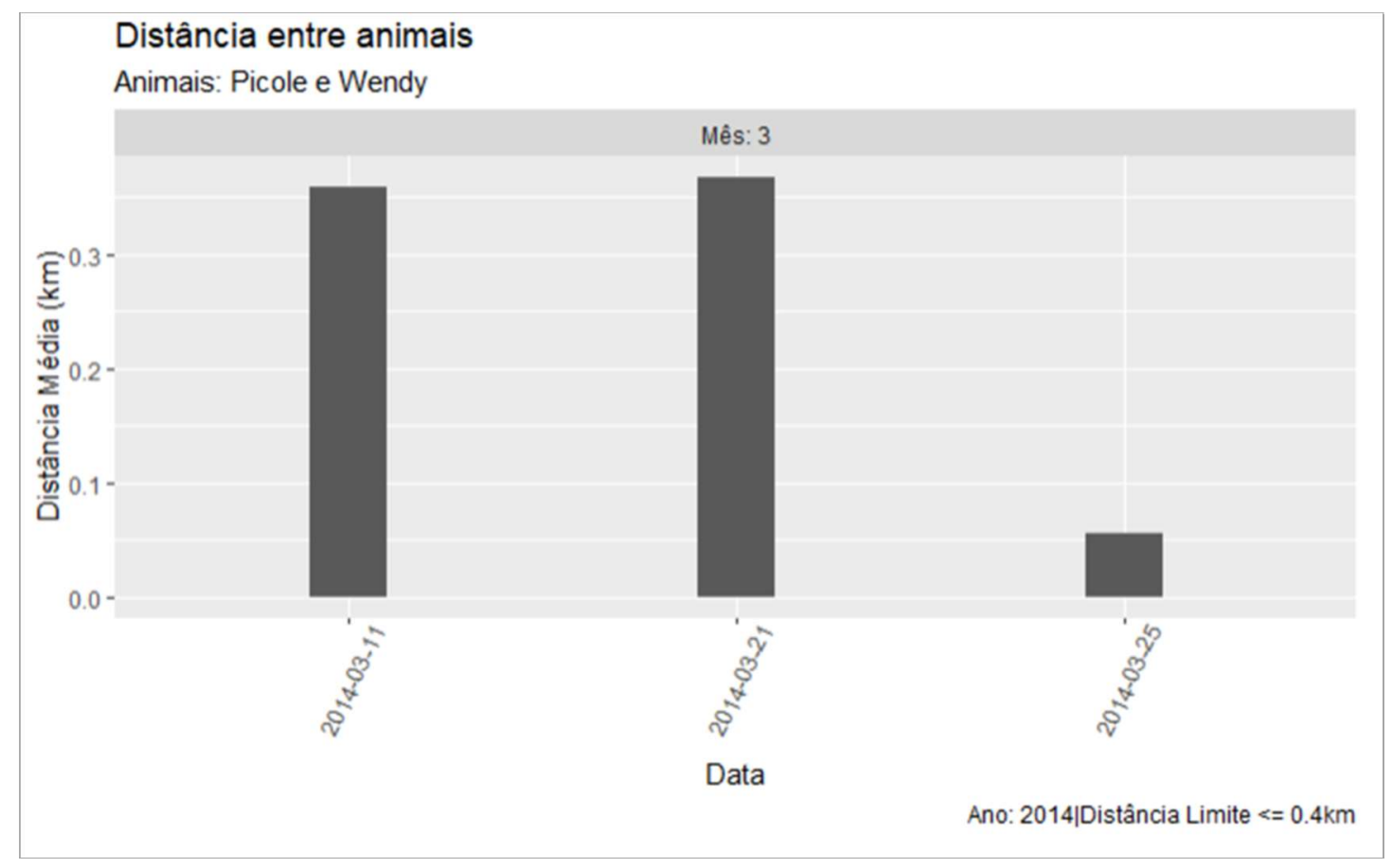

Figura 34 - Distância Média entre os animais para o raio de distância igual a 400 metros

Como o AniMoveMineR permite que sejam realizadas as análises com diferentes valores para o raio de distância limite. Quando o resultado apresenta diferentes meses para um determinado ano, o gráfico é dividido em meses e são apresentadas as variações das distâncias para um par de variáveis. O gráfico, Figura 35, apresenta um exemplo da distribuição das distâncias entre o par de animais Picolé e Wendy, de acordo com o raio de distância limite de 900 metros $(0.9 \mathrm{~km})$ e para os dados de movimentação dos animais referentes aos meses de fevereiro, março e abril de 2014. 


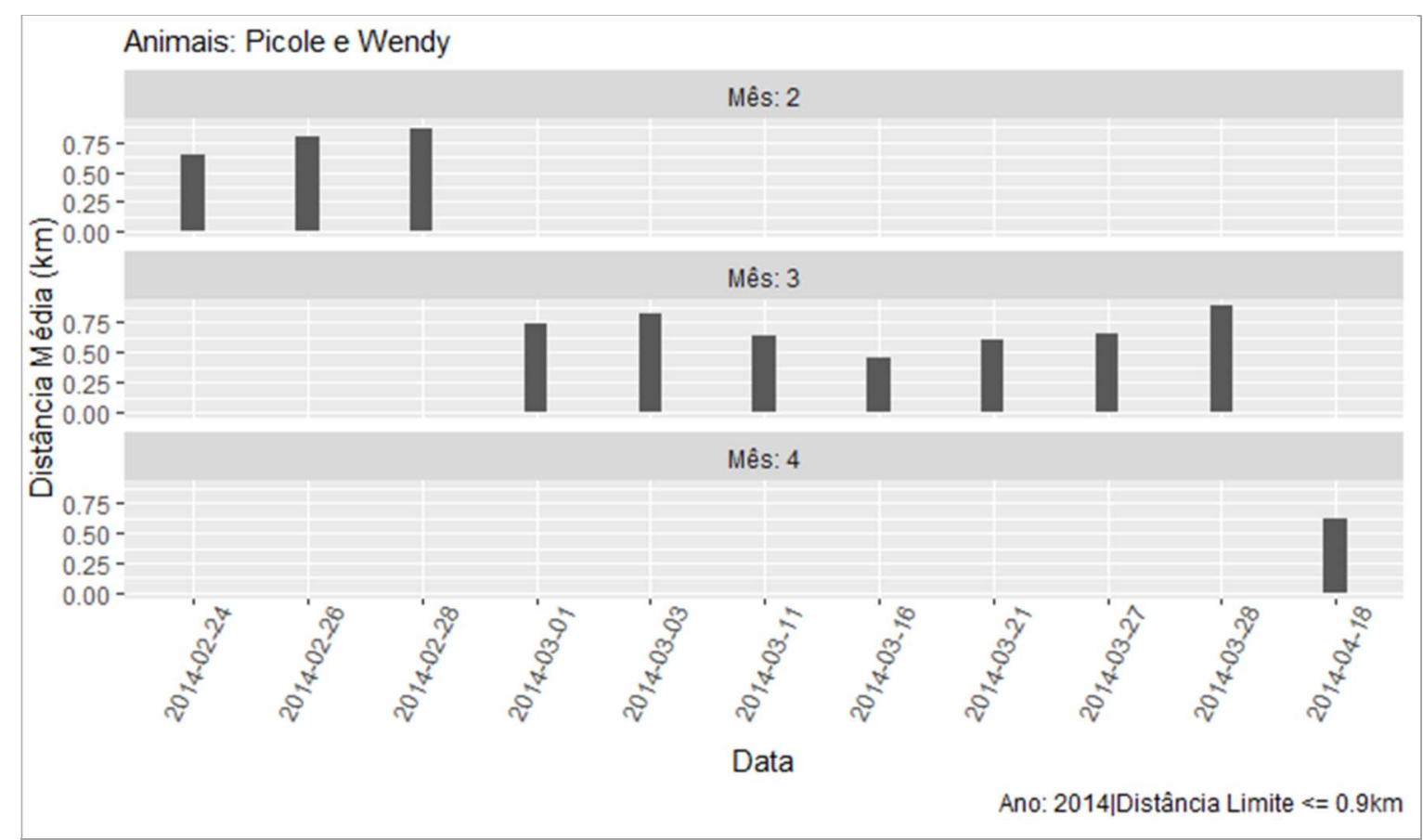

Figura 35 - Distância Média entre os animais para o raio de distância igual a 900 metros

\subsection{Considerações sobre o Capítulo}

Neste Capítulo foi apresentado o AniMoveMineR, como essse framework se insere no processo de Ciência dos Dados e quais os passos e etapas que o compõem, com destaque para a Análise de Dados.

O passo de Análise de dados determina quais atividades devem ser realizadas para a análise exploratória dos dados de movimentação animal com a finalidade de obter conhecimento sobre a interação entre animais e os fatores ambientais.

Os resultados, obtidos com cada etapa da Análise de dados, permite explorar os aspectos do comportamento individual dos animais, identificar os fatores ambientais vizinhos das ocorrências da movimentação dos animais e a interação entre os animais e os fatores ambientais ao longo do tempo e espaço. 


\section{AVALIAÇÃO DO ANIMOVEMINER - ESTUDOS DE CASO}

Neste Capítulo são apresentados dois experimentos realizados para avaliar o framework AniMoveMineR, aplicados na área de biodiversidade, com o uso de dados de onças-pintadas da região de Taiamã - Pantanal - Brasil e dados de macacos (Cebus Capucinus) da região da Barro Colorado Island Panamá.

\subsection{Estudo de Caso I - Análise exploratória da movimentação de onças do Pantanal - Brasil \\ Nesta seção é apresentado o experimento realizado para avaliar o} framework, com o dataset contendo o rastreamento de nove onças que residem na região da Estação Ecológica de Taiamã, Pantanal, Brasil, coletados entre 2013 e 2015 (MORATO et al., 2018). O dataset contém informações sobre a posição (latitude/longitude) e a hora (data/hora) do movimento do animal. As análises foram realizadas, em separado, para cada ano. No entanto, serão mostrados como exemplo somente os resultados obtidos para o ano de 2015.

Foram realizados dois estudos com o foco na análise exploratória do movimento das onças para a obtenção de indicativos: primeiro, sobre o comportamento e interação entre esses animais; e o segundo, sobre a interação entre o estado de forrageamento desses animais e as estações do ano. As perguntas $(P)$ definidas para os estudos de caso:

- P1: A análise exploratória da movimentação de onças permite identificar o nível de correlação entre pares de onças ao longo do tempo e espaço?

- P2: A análise exploratória da movimentação das onças permite identificar o nível de dependência entre as estações do ano e os períodos do dia em que as onças forrageiam?

\subsubsection{Estudo - Questão (1)}

O primeiro estudo teve como finalidade responder à questão (1): "A análise exploratória da movimentação de onças permite identificar o nível de correlação entre pares de onças ao longo do tempo e espaço? ".

Desta forma, as três etapas de análise de dados do framework foram aplicadas na análise exploratória da movimentação das onças: $(A)$ identificar o 
comportamento individual do animal; (B) identificar os fatores ambientais vizinhos à ocorrência do comportamento animal; $(C)$ identificar a correlação entre animais e fatores ambientais.

$\mathrm{Na}$ etapa $\mathrm{A}$, a análise exploratória teve como objetivo o conhecimento sobre o comportamento individual do animal que consiste em identificar os estados de comportamento das onças (forrageio, descanso e trânsito) ao longo de suas trajetórias, a frequência e a duração dos estados de comportamento e a área de vida (home range) das onças.

A classificação do comportamento em estados permite explorar a frequência de ocorrência desses estados durante os períodos do dia (dia/noite), em quais horários (intervalos entre horas) ocorrem, a duração dos estados e o espaço ocupado (home range) pelas onças ao longo do tempo.

Como resultado da etapa $\mathrm{A}$, é apresentado um mapa da região, onde os dados foram coletados, com as trajetórias das onças ao longo do tempo (mês e ano) e espaço. Na Figura 36, o mapa mostra a trajetória da onça Picolé, em fevereiro de 2015, e contém um menu com a relação das onças e meses nos quais foram registradas as ocorrências de movimentação para cada onça. Assim, pode-se comparar as trajetórias dos animais ao longo dos meses por ano.

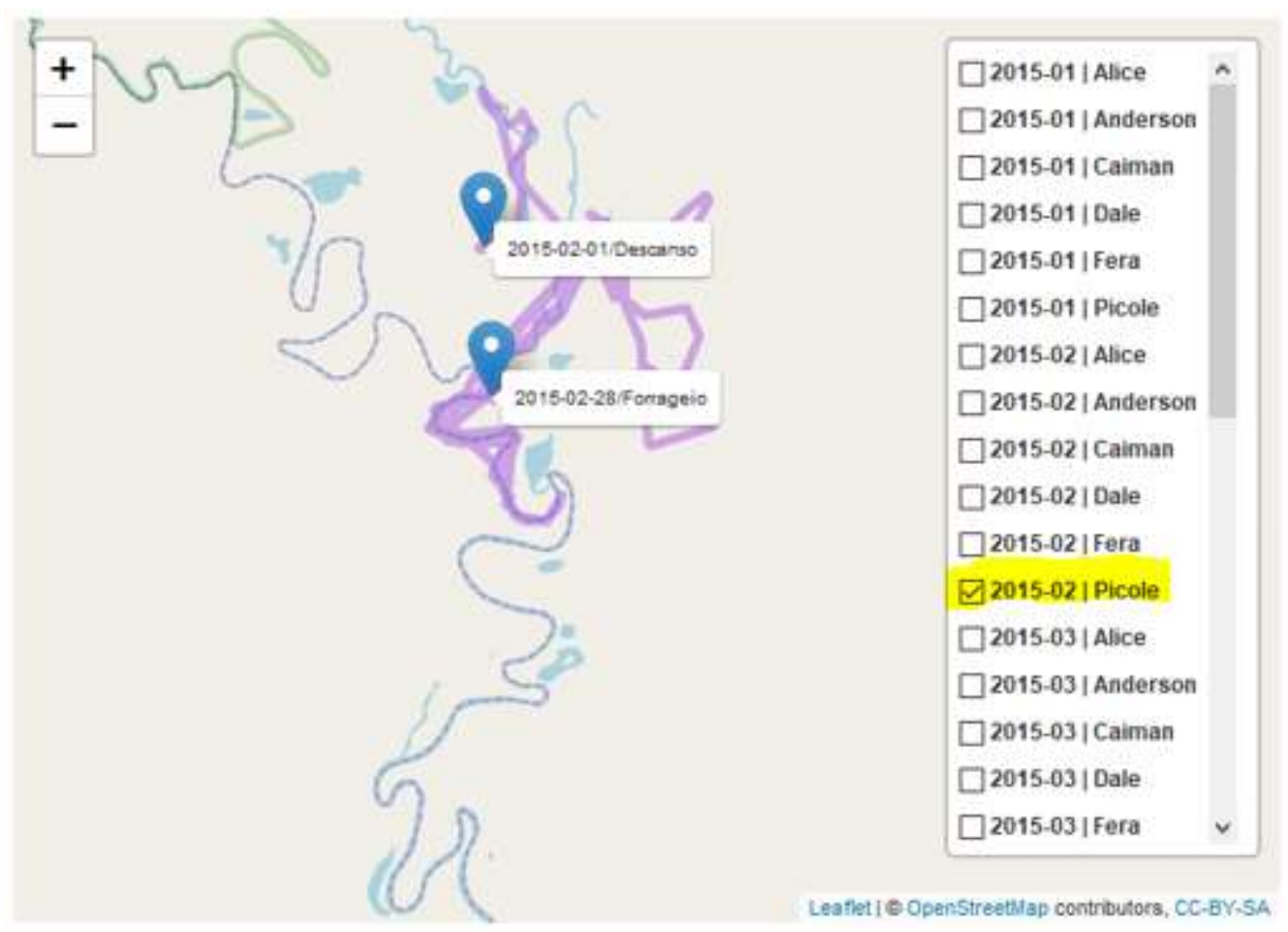

Figura 36 - Mapa da trajetória da onça Picolé em fevereiro/2015 
Outro resultado da etapa A é a matriz de estados de comportamento da onça, Figura 37, que apresenta a distribuição dos estados nos intervalos entre horas ao longo dos dias de cada mês/ano. A matriz indica o tempo gasto pela onça Picolé no forrageio, descanso ou trânsito ao longo dos dias. Na matriz pode-se observar a indicação de que nos primeiros dias do mês de fevereiro a onça Picolé apresentou maior frequência do estado de descanso e nos dias 10 , 11, 16 e 17 houve o registro de maior frequência de forrageamento. Esta distribuição permite identificar o comportamento individual do animal em suas atividades diárias, possibilitando determinar as mudanças de comportamento do animal ao longo dos dias e meses do ano.

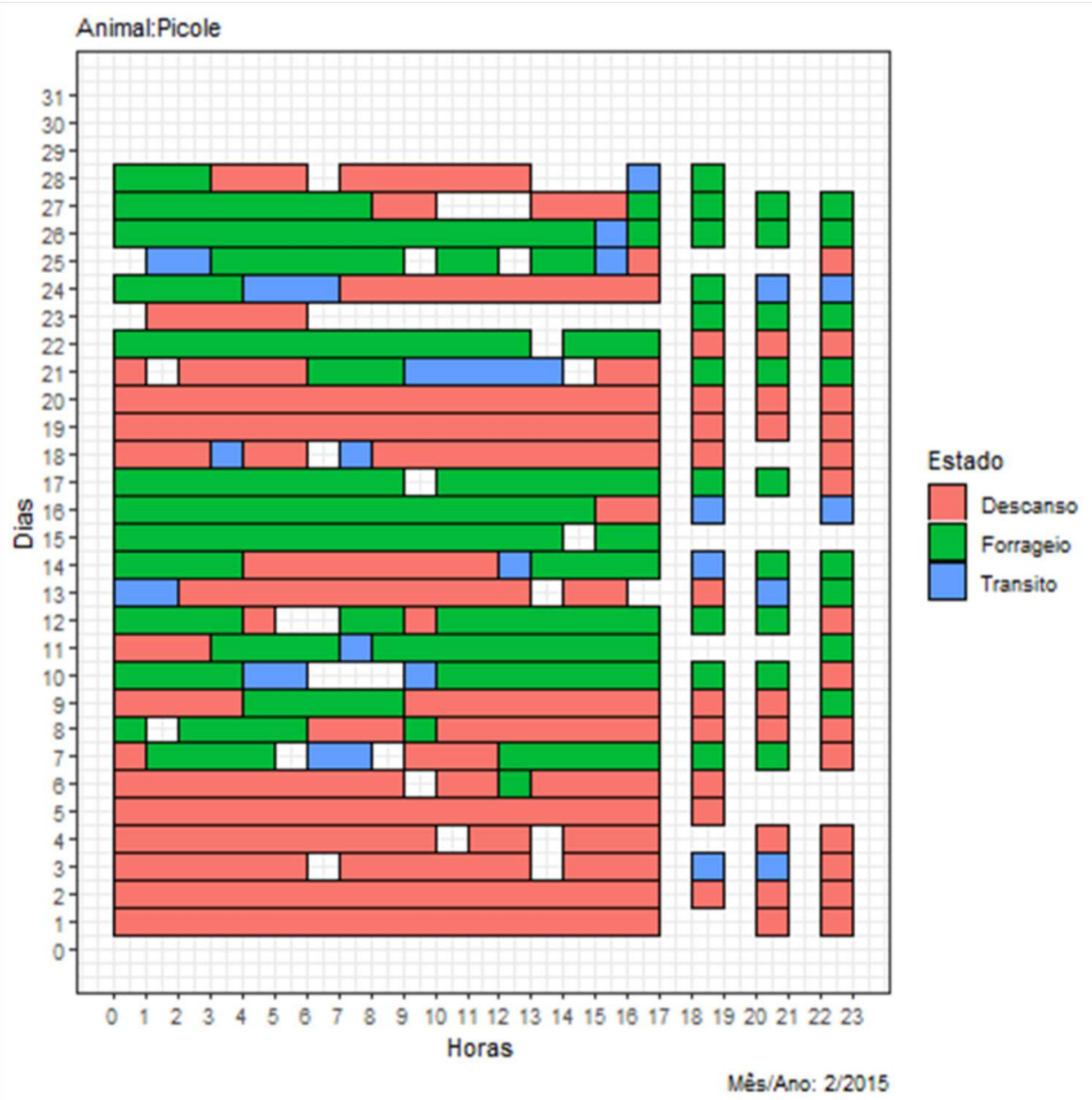

Figura 37 - Matriz de estados de comportamento da onça Picolé em fevereiro/2015

Outro aspecto do comportamento individual das onças, que é fornecido pelo framework, é a duração dos estados de comportamento que indica o tempo médio que a onça gasta em suas atividades de forrageamento, descanso e 
trânsito. O gráfico, Figura 38, apresenta a duração média de cada estado de comportamento da onça Picolé, ao longo dos meses do ano de 2015, indicando a tendência de aumento ou diminuição da duração em função dos meses do ano. Em fevereiro/2015, os resultados indicam que a onça Picolé apresentou uma queda na duração do estado de forrageio e, em março/2015, um aumento do tempo de descanso.

Tempo médio de duração do Comportamento Animal por Mês/Ano

Animal:Picole

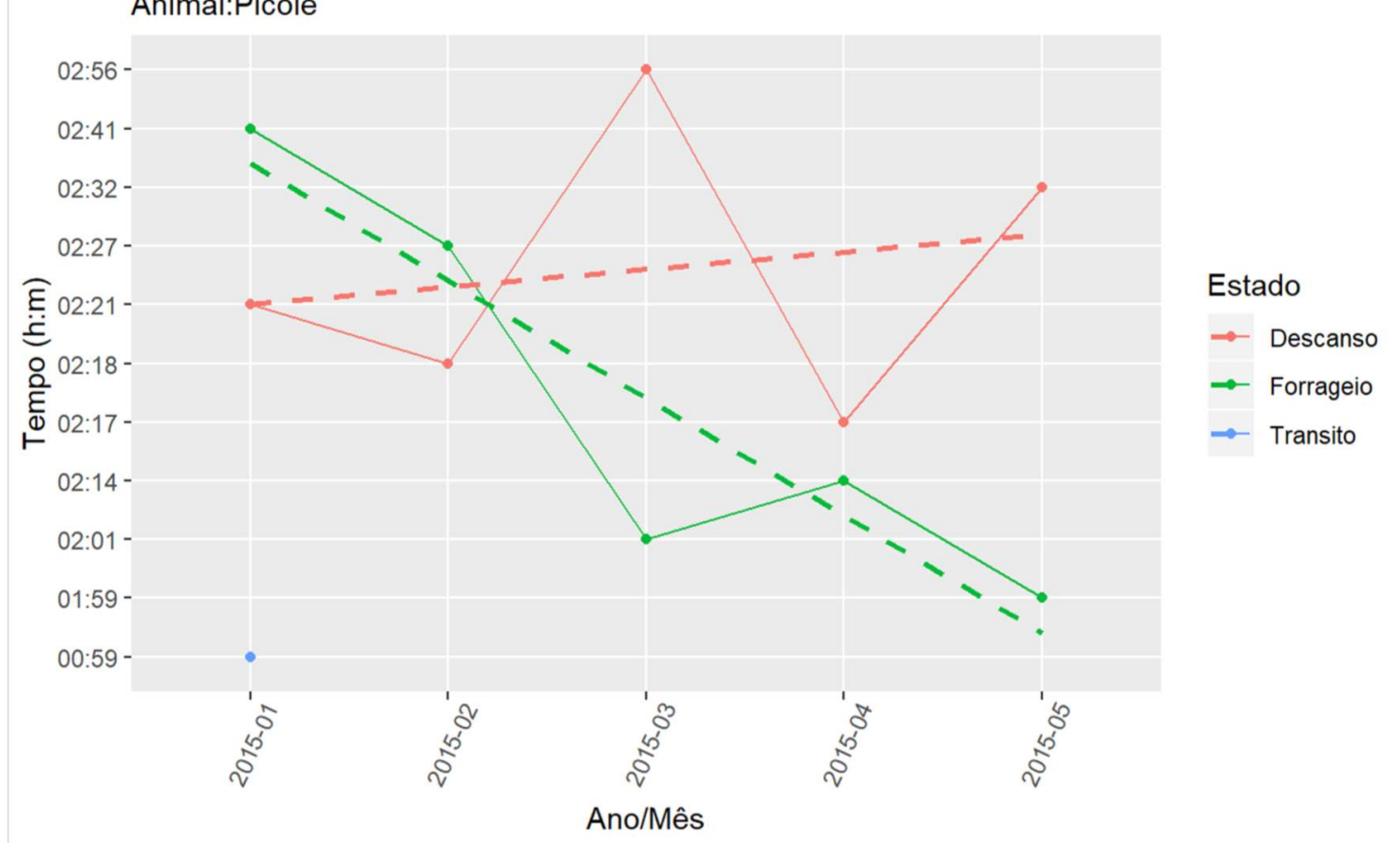

Ano: 2015

Figura 38 - Tempo médio de duração dos estados de comportamento da onça Picolé em 2015

Com a análise exploratória dos períodos de ocorrência dos estados de comportamento animal são identificados os horários nos quais os estados ocorreram com maior frequência. O gráfico, Figura 39, mostra os intervalos entre horas nos quais o estado de forrageamento ocorreu com maior frequência ao longo dos meses de 2015 para a onça Picolé, onde o círculo, representa a hora de início, e a linha, a duração, determinando o início e o fim do período. Os resultados mostram os meses de janeiro a maio de 2015 e indicam que Picolé forrageou mais nos horários das $0 \mathrm{~h}$ às $8 \mathrm{~h}$, com algumas variações ao longo dos meses. 


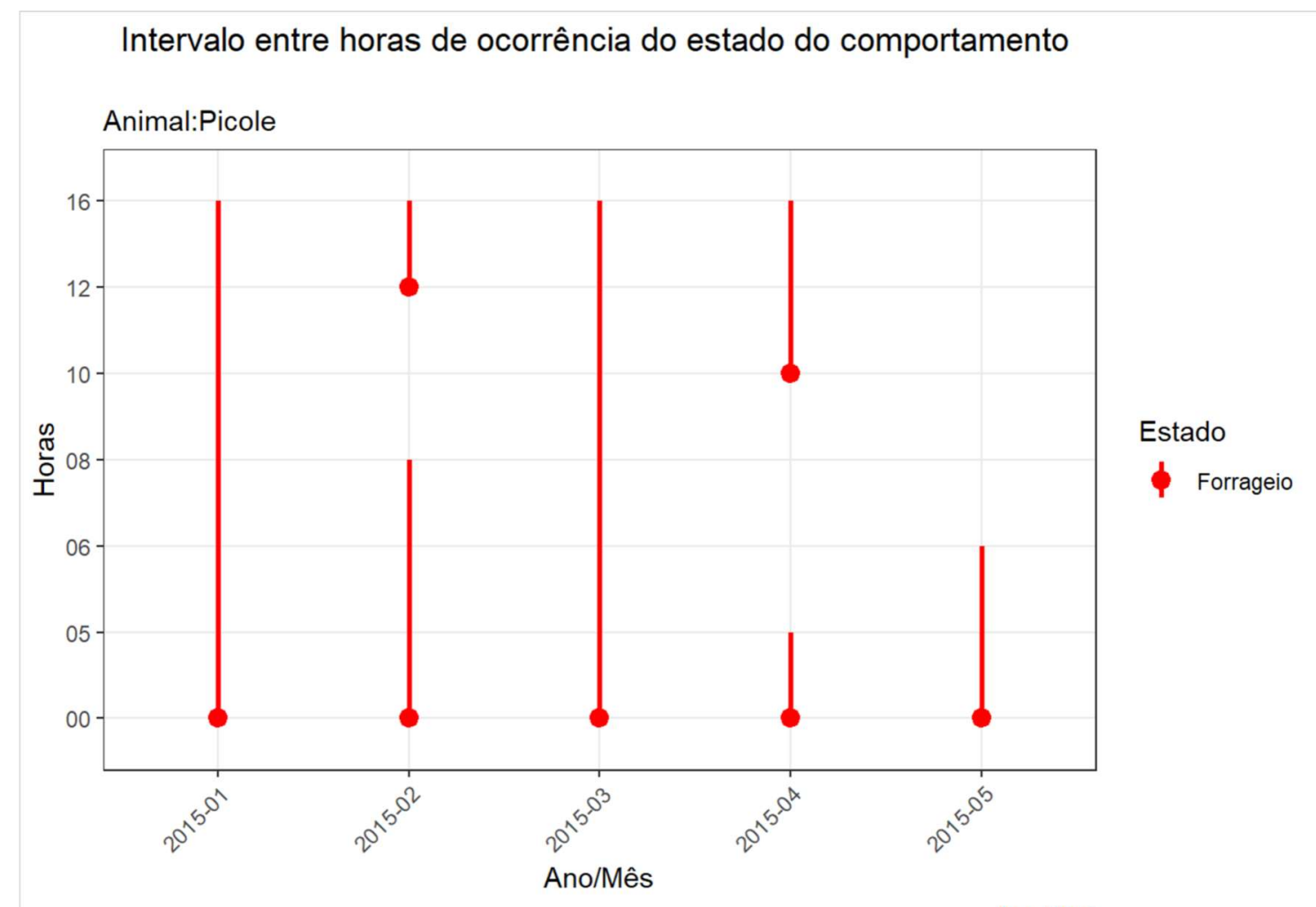

Ano: 2015

Figura 39 - Horários de maior frequência de ocorrência dos estados de comportamento

Com o detalhamento dos horários de ocorrência dos estados de comportamento animal é identificada a frequência de ocorrência dos estados ao longo dos períodos do dia (dia/noite). O gráfico, Figura 40, mostra a frequência de ocorrência de cada estado de comportamento da onça Picolé ao longo dos meses de janeiro a maio de 2015 e indica um maior número de ocorrências de forrageamento durante a noite. Já nos meses de fevereiro e março há um aumento das ocorrências, seguido de uma queda nos meses de abril e maio de 2015. 


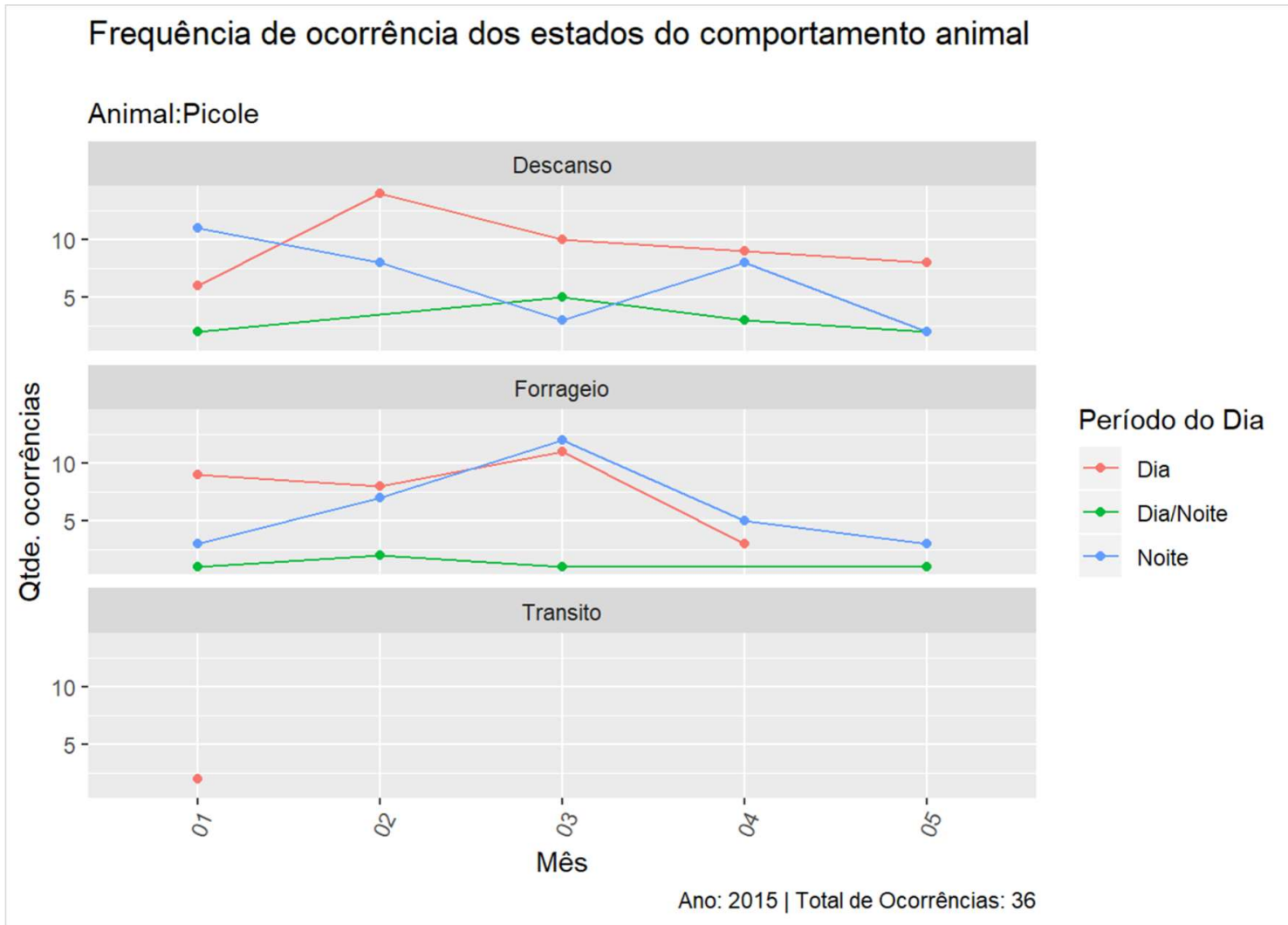

Figura 40 - Frequência de ocorrência dos estados de comportamento da onça Picolé por período do dia

Outro aspecto analisado do comportamento individual do animal foi a área de vida (home range). A área de vida dos animais que permite verificar como o espaço foi ocupado pelo animal ao longo dos meses do não e, também, pode ser observada com base nos estados de comportamento do animal.

$\mathrm{Na}$ Figura 41, o mapa na parte (A) mostra a área de vida da onça Picolé, por mês e ano, e na parte $(B)$, mostra a área de vida da mesma onça por estado de forrageamento ao longo dos meses do ano de 2015. O mapa fornece indicativos sobre a variação da ocupação do espaço pelo animal ao longo dos meses e anos indicando, por exemplo, que o animal Picolé ocupava uma determinada área em janeiro de 2015 e migrou, ao longo de fevereiro, para uma nova área permanecendo nesta área ao longo dos meses seguintes. 


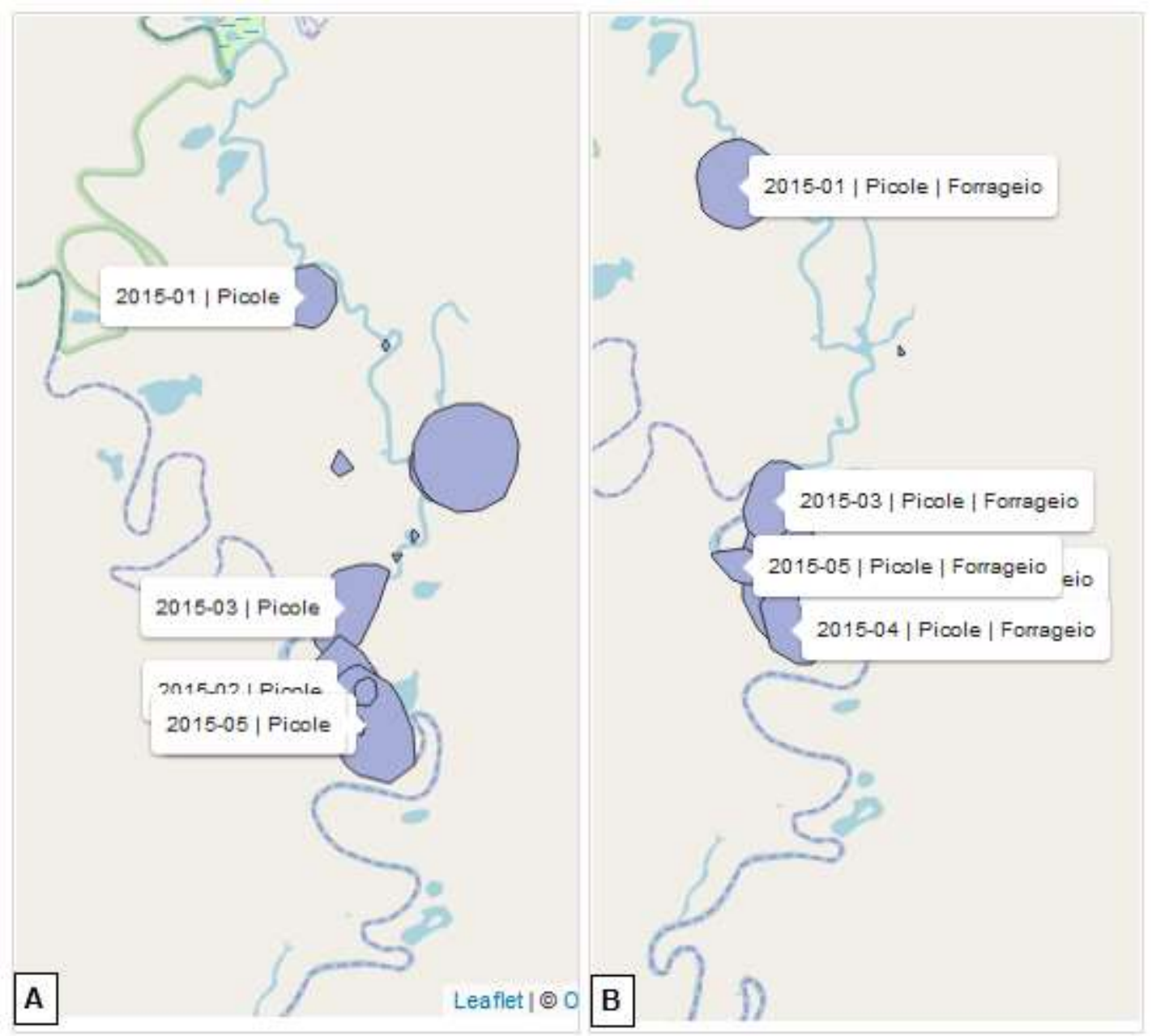

Figura 41 - Mapa de home range da onça Picolé - (A) por mês e ano e (B) por estado de comportamento, mês e ano

Na etapa B, da análise de dados no AniMoveMineR, foram identificados os fatores ambientais vizinhos às ocorrências de movimentação do animal. Para determinar os animais vizinhos, o raio de distância limite foi definido como 400 metros $(0.4 \mathrm{~km})$, numa primeira avaliação, e 900 metros $(0.9 \mathrm{~km})$, na segunda avaliação.

A etapa C da análise de dados do AniMoveMineR tem como foco identificar a correlação entre os animais e fatores ambientais. Nesta etapa a mineração por regras de associação foi utilizada em duas análises: primeira, entre as onças, para explorar a interação entre esses animais; e, a segunda, o estado de forrageamento das onças e as estações do ano (fator ambiental). As avaliações utilizaram uma variação de valores para os parâmetros minSup e minConf, definidas como: 0.01 (1\%); 0,50 (50\%) e 0,9 (90\%), filtrando as regras mais relevantes para a análise. 
Com a mineração por regras de associação dos dados de movimentação das onças foram fornecidas as medidas que indicam o nível de correlação (phi\%), dependência (Lift), confiança (Conf) e coocorrência (Sup). Para os diferentes testes realizados, Figura 42, os resultados indicam a variação dos níveis de correlação entre os pares de onças. Para o mês de fevereiro foram identificados níveis de correlação de $100 \%$ para os pares de onças Alice e Picolé e acima de $40 \%$ para Caiman e Dale e Caiman e Fera. Observa-se que essas correlações aparecem somente em fevereiro (2) para de mínimo suporte e confiança extremamente baixo (0.001) e que Dale e Fera não apresentam correlação.

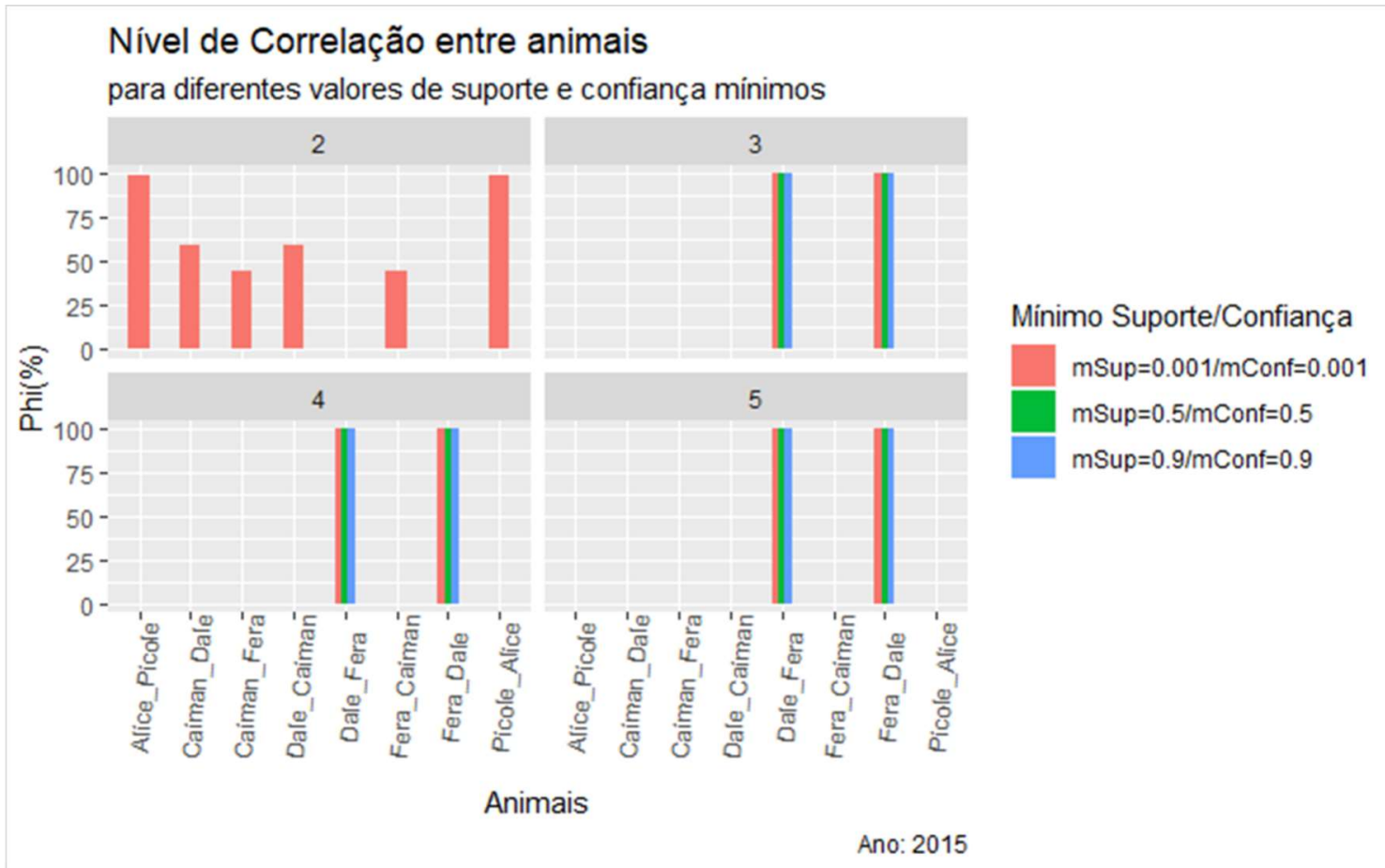

Figura 42 - Gráfico de Níveis de correlação entre pares de onças para diferentes valores de confiança e suporte mínimo

Para os meses de março, abril e maio não foram identificadas correlações entre os pares de onças Alice e Picolé, Caiman e Dale e Caiman e Fera, mas há a indicação de forte correlação entre as onças Dale e Fera para todas as variações de valores de minConf e minSup, inclusive para os valores de minConf e minSup igual a $90 \%$.

Quando a coocorrência (Sup) e a probabilidade de uma animal ocorrer em função de outro (Conf) são iguais a 100\%, o resultado do coeficiente phi não é 
determinante nas regras de associação, então foram necessários ajustes no algoritmo para tratar essa condição.

Na Figura 43, são mostrados os níveis de correlação entre os pares de onças de forma detalhada, para cada teste com valores de minSup e minConf diferentes e indicam os percentuais do coeficiente de Phi $(p)$ e o total de registros analisados $(r)$.

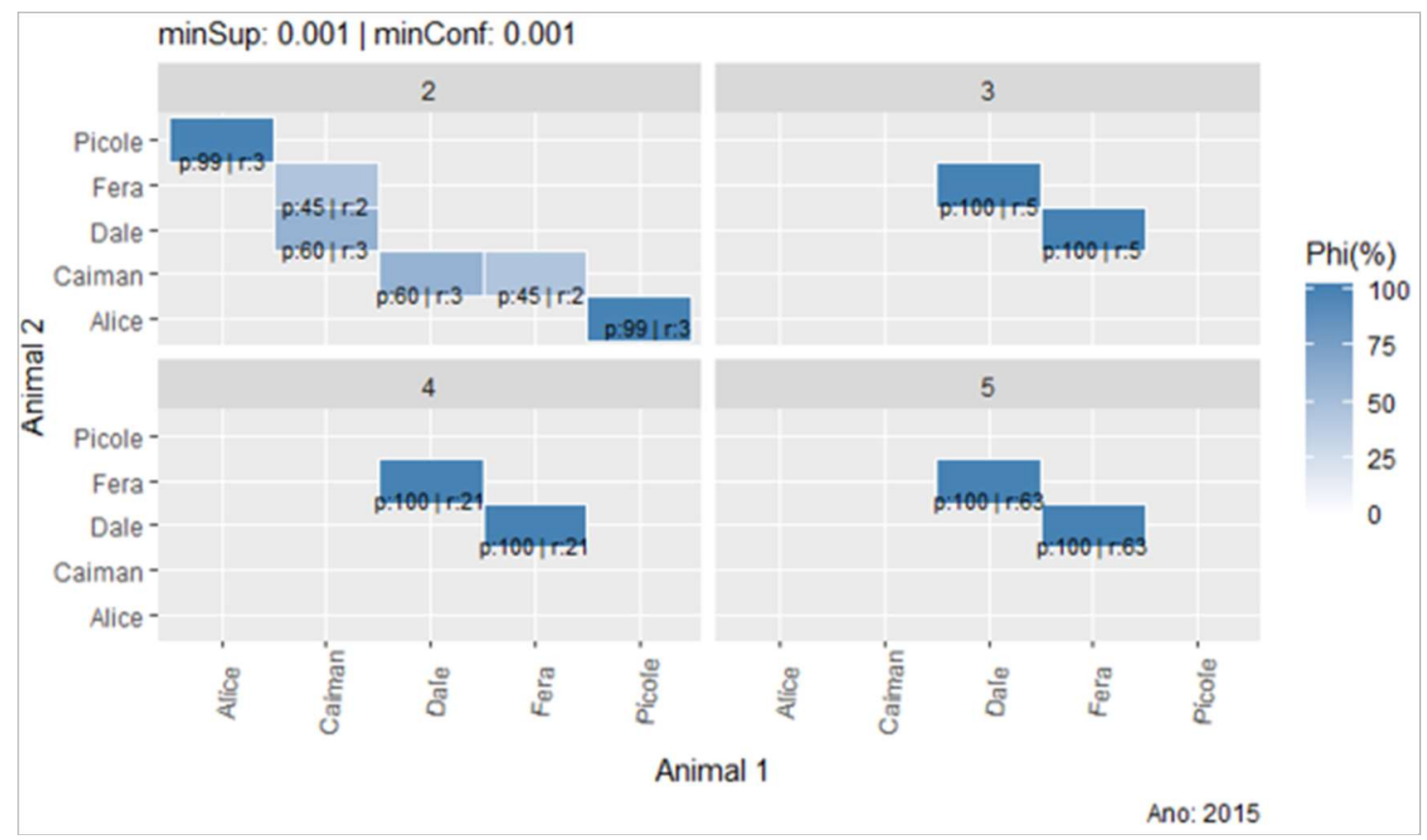

Figura 43 - Gráfico de correlação entre as onças por mês para o ano de 2015

Para os diferentes testes também foram analisados os resultados da variação dos níveis de dependência, Figura 44, entre os pares de onças. No mês de fevereiro os valores de Lift são maiores que 1 , o que indica a dependência positiva entre os pares de onças Alice e Picolé, Caiman e Dale e Caiman e Fera. Para os meses de março, abril e maio somente foram obtidos os indicativos de dependência para as onças Dale e Fera com valor igual a 1, o que significa independência entre essas onças. 


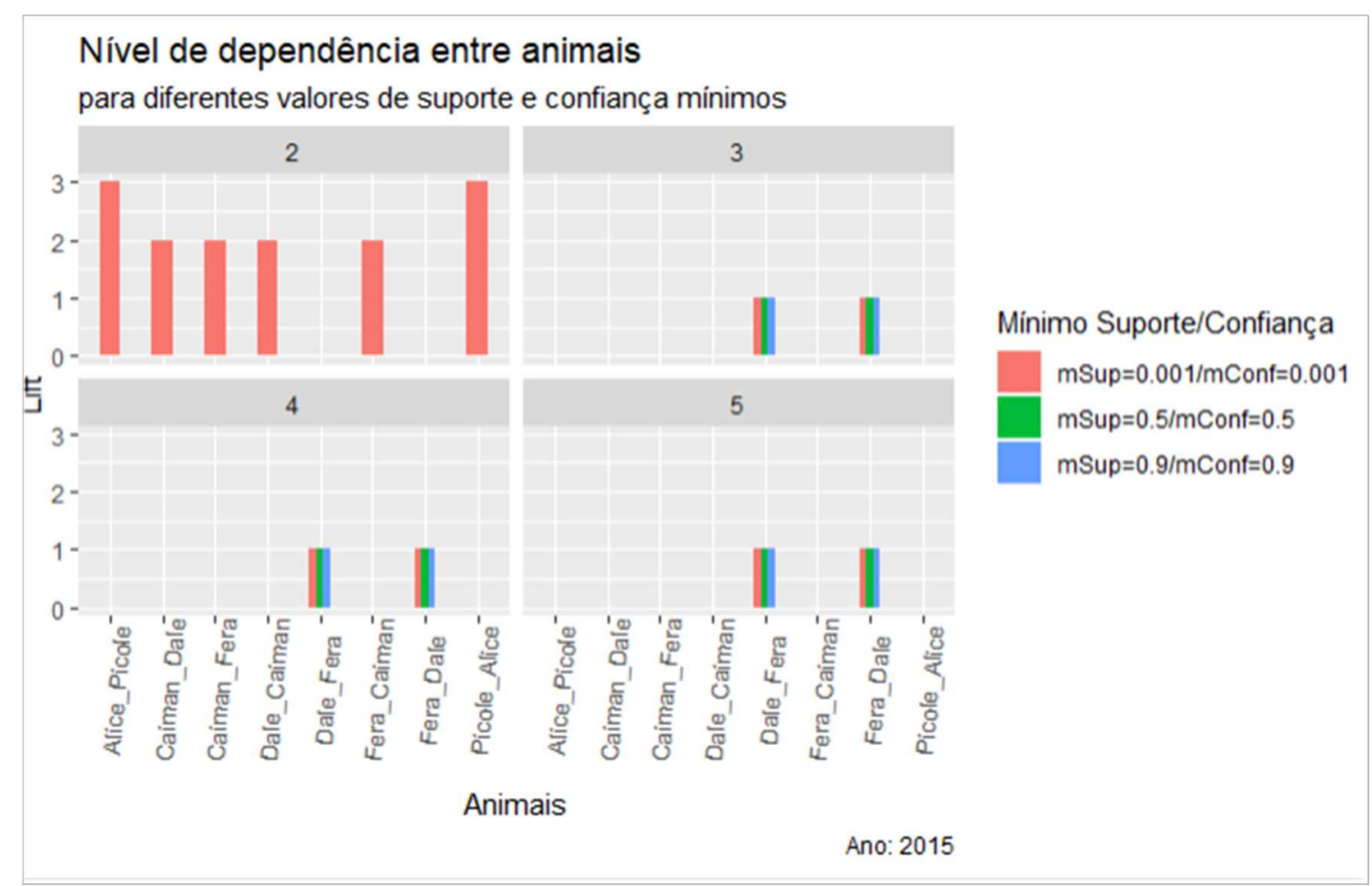

Figura 44 - Gráfico de Níveis de dependência (lift) entre pares de onças para diferentes valores de confiança e suporte mínimo

Outra medida fornecida é a confiança que indica a probabilidade de uma onça ocorrer em função da ocorrência de outra. No gráfico, Figura 45, é mostrada a variação da medida de confiança ao longo dos meses de 2015 para os testes realizados com minSup e minConf igual a 0.001. Os valores contidos nas barras correspondem ao percentual de suporte (s), que consiste na frequência de coocorrência dos animais e ao total de ocorrências analisadas ( $r$ ).

Desta forma, em (2) fevereiro foram identificados 3 registros de movimentação dos animais e que Picolé e Alice estavam juntos em 38\% desses registros, com uma probabilidade de $100 \%$ de um ocorrer em função do outro. A onça Caiman possui indicação de relação com as onças Fera e Dale, com probabilidade de Caiman ocorrer em função de ambas as onças abaixo de $75 \%$.

Já nos meses de março, abril e maio de 2015, as onças Fera e Dale não apresentaram relação com a onça Caiman, mas indicam $100 \%$ de probabilidade de uma ocorrer em função da ocorrência da outra (Conf). 


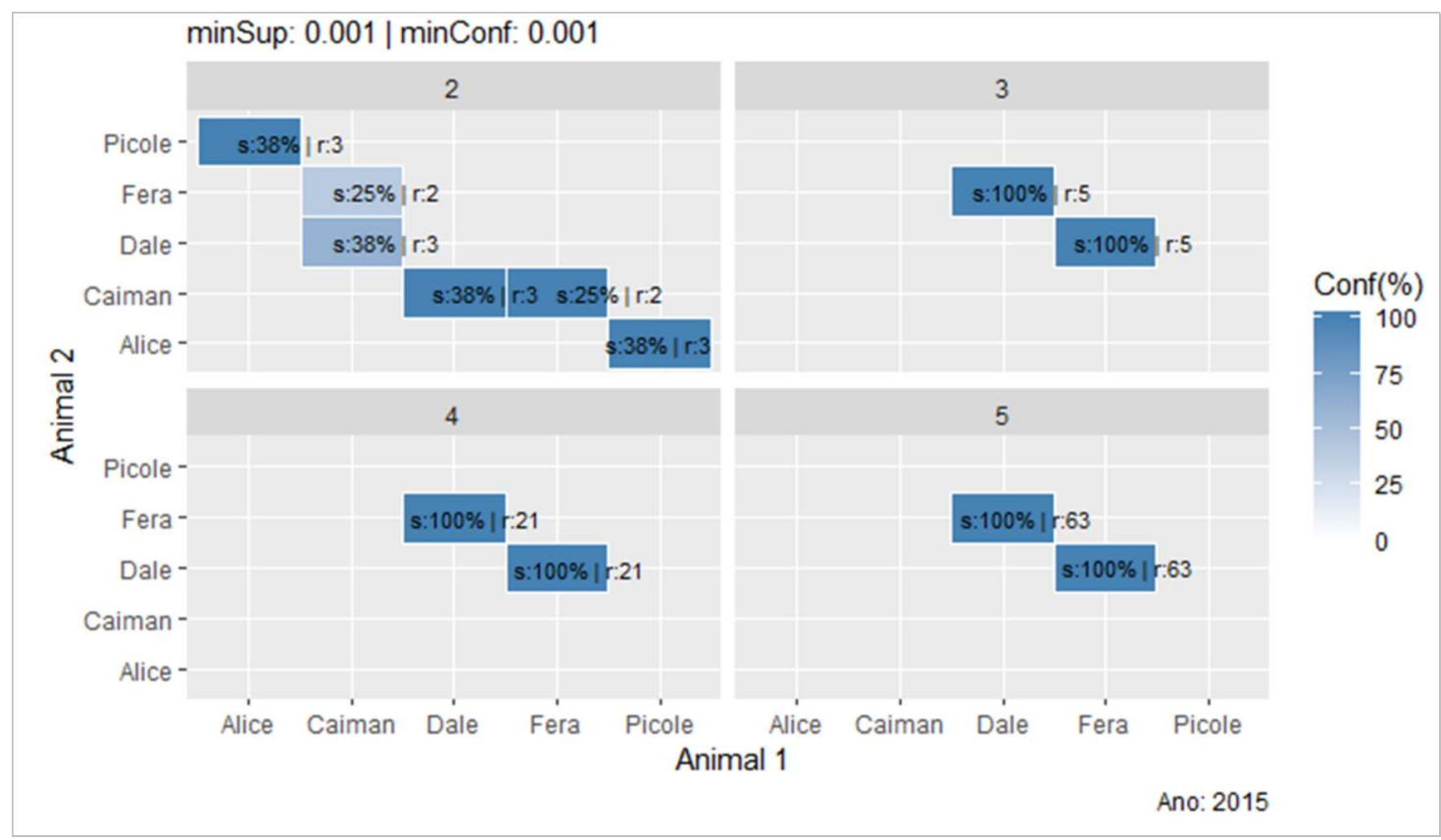

Figura 45 - Gráfico de probabilidade de ocorrência de uma onça em função de outra (minSup e $\min$ Conf $=1 \%$ )

Para os testes realizados com minSup e minConf iguais a 50\% (0.05) somente foram identificadas as relações entre Fera e Dale, Figura 46, nos meses de (3) março, (4) abril e (5) maio de 2015.

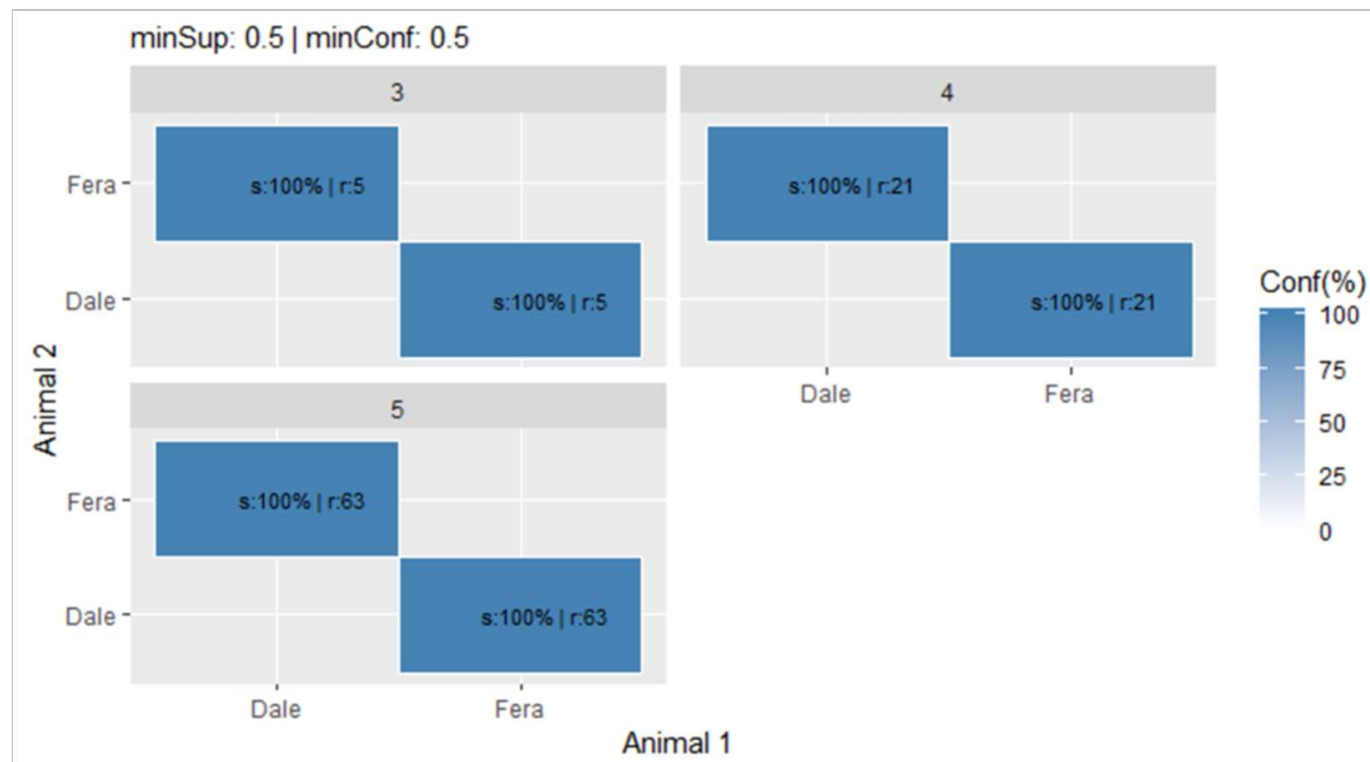

Ano: 2015

Figura 46 - Gráfico de probabilidade de ocorrência de uma onça em função de outra (minSup e $\operatorname{minConf}=50 \%$ )

A correlação entre os animais foi analisada, também, por meio da tabela de contingência e coeficiente de Cramer. Os resultados foram obtidos por mês e ano e indicaram para fevereiro de 2015, Figura 47, um coeficiente de Cramer 
igual a 0.866 que é próximo de 1 e indica forte associação entre as onças Picolé e Alice, Caiman e Dale e Caiman e Fera. Esses indicativos confirmam os resultados obtidos com as regras de associação.

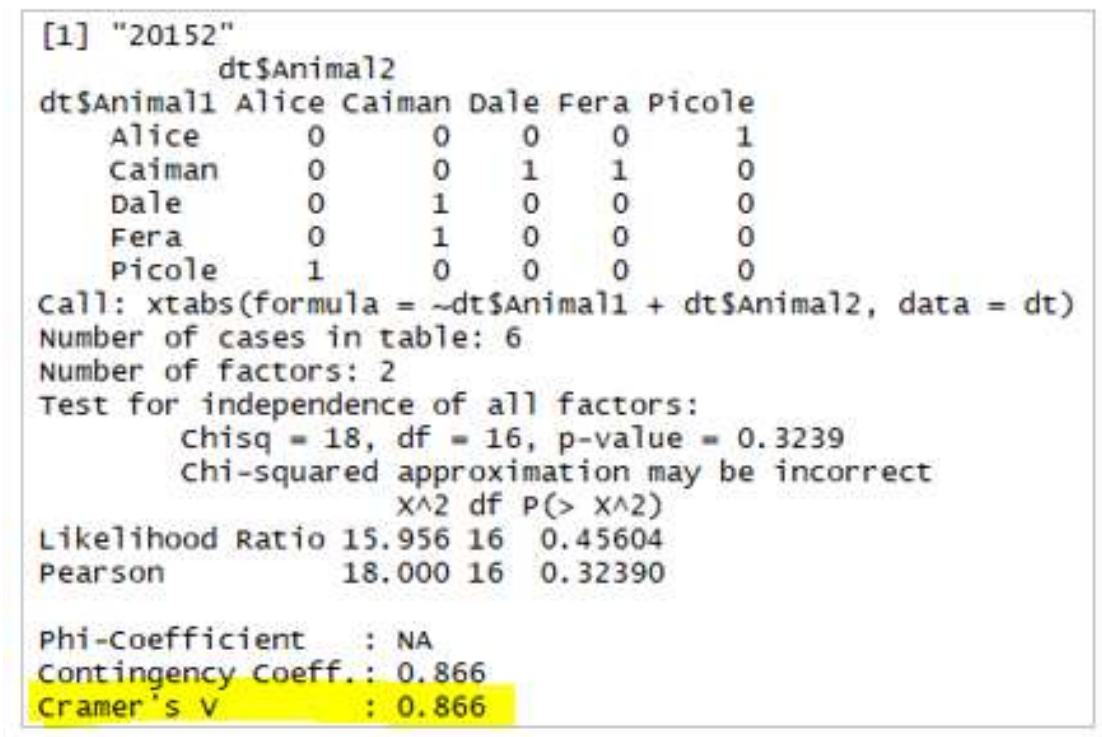

Figura 47 - Resultado da análise de Cramer para as onças em fevereiro de 2015

Para os meses de março, abril e maio de 2015 o coeficiente de Cramer foi igual a 1, que indica forte correlação entre as onças Dale e Fera. Na Figura 48, é ilustrado um exemplo do resultado da análise do coeficiente de Cramer para março de 2015 (20153). Desta forma, observa-se que a correlação entre as onças indicada pelas regras de associação foram confirmadas com o uso da tabela de contingência e do coeficiente de Cramer.

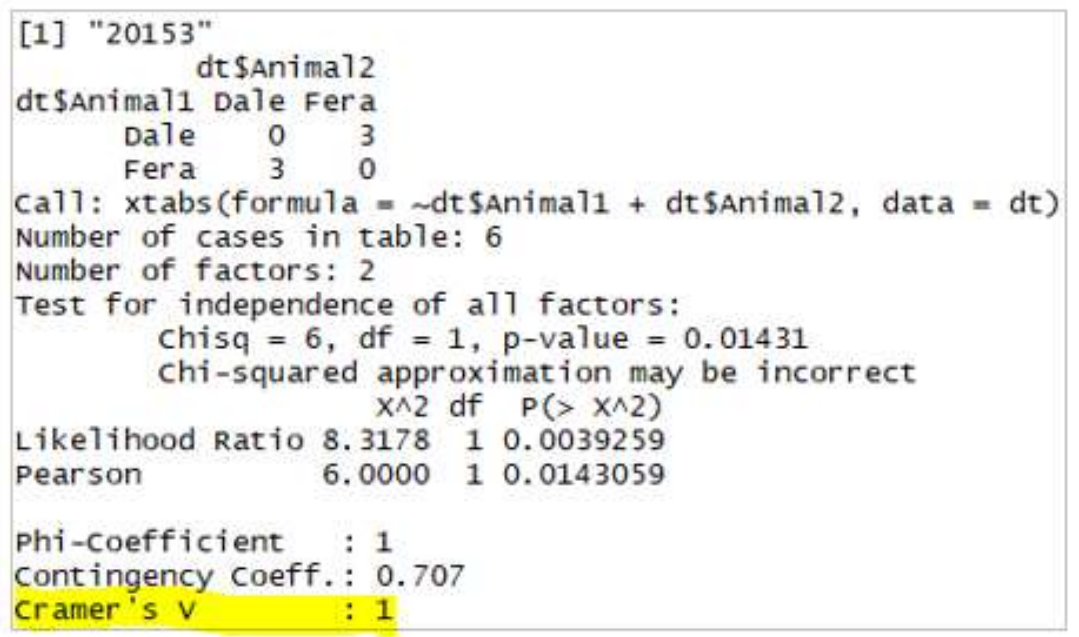

Figura 48 - Resultado da análise de Cramer para as onças em março, abril e maio de 2015

O AniMoveMineR permite analisar outro aspecto das interações entre as onças que é a sobreposição de home range. Observa-se que os animais que 
apresentam indicação de forte correlação têm uma probabilidade maior de compartilharem o mesmo espaço ao longo do tempo.

A matriz de sobreposição de home range, Figura 49, apresenta uma visão geral sobre o índice de sobreposição entre os animais, sem considerar os meses em que ocorreram as sobreposições. Para os pares de onças Alice e Picolé, Caiman e Dale, Caiman e Fera e Fera e Dale os índices de sobreposição maiores que zero indicam que houve sobreposição de área de vida entre esses pares de onças.

$\begin{array}{lrrrrrr} & \text { Alice } & \text { Anderson } & \text { Caiman } & \text { Dale } & \text { Fera } & \text { Picole } \\ \text { Alice } & 1.44471039 & 0.000000000 & 0.010687737 & 0.000000000 & 0.0000000 & 0.30537827 \\ \text { Anderson } & 0.00000000 & 1.225943528 & 0.009778837 & 0.003070979 & 0.0000000 & 0.00000000 \\ \text { Caiman } & 0.01068774 & 0.009778837 & 1.235229979 & 0.383405522 & 0.3244139 & 0.08479725 \\ \text { Dale } & 0.00000000 & 0.003070979 & 0.383405522 & 1.471428137 & 0.5870313 & 0.00000000 \\ \text { Fera } & 0.00000009 & 0.000000000 & 0.324413906 & 0.587031338 & 1.7508665 & 0.00000000 \\ \text { Picole } & 0.30537827 & 0.000000000 & 0.084797247 & 0.000000000 & 0.0000000 & 1.37550625\end{array}$

Figura 49 - Matriz de índice de sobreposição de home range das onças

A sobreposição do home range pode ser explorada no framework por meio do mapa que mostra a área ocupada pelos animais por mês e ano ou por mês, ano e estado de comportamento. Com a análise do home range das onças Picolé e Alice, Figura 50, observa-se que em (A) janeiro/2015 não houve sobreposição de área, em (B) fevereiro/2015 houve sobreposição e em (C) março/2015 não houve sobreposição novamente. A sobreposição entre Picolé e Alice confirma o resultado das regras de associação que indicaram forte correlação entre esses animais em fevereiro de 2015.
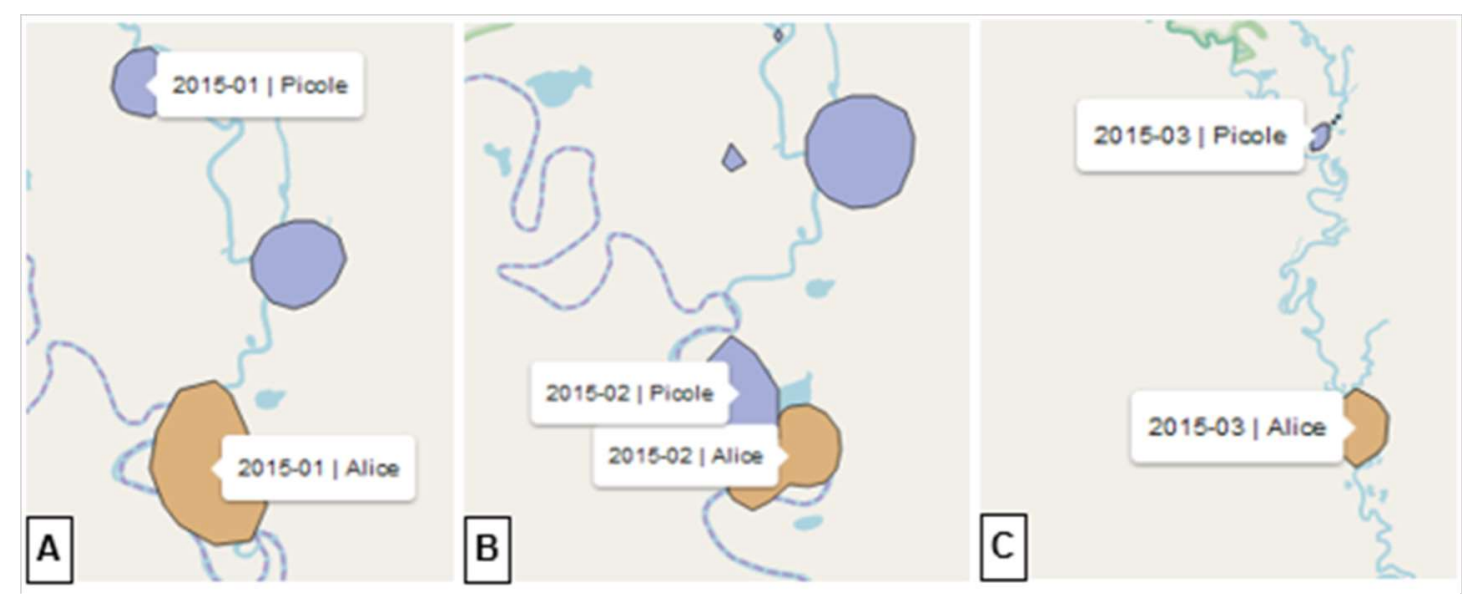

Figura 50 - Home range das onças Picolé e Alice em janeiro (A), fevereiro (B) e março (C) de 2015

Para as onças Dale, Fera e Caiman o mapa de sobreposição de home range, Figura 51, indica que (A) Caiman e Dale e (B) Caiman e Fera 
apresentaram sobreposição em fevereiro/2015, mas em (C) março/2015 a onça Caiman distanciou-se da onça Dale aproximando-se da onça Picolé.

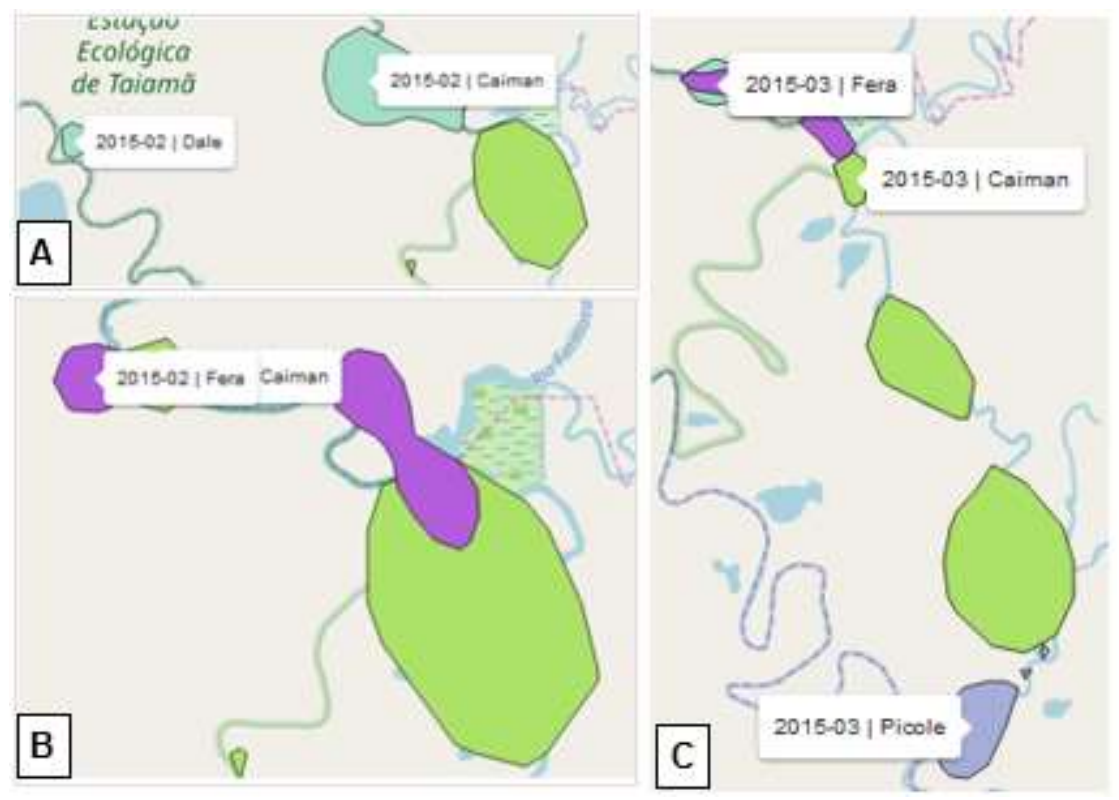

Figura 51 - Home range das onças (A) Caiman e Dale (B) Caiman e Fera em fevereiro/2015 e (C) Caiman, Fera e Picolé em março/2015

Para as onças Dale e Fera, Figura 52, o mapa de sobreposição de home range indica sobreposição em todos os meses analisados em 2015: (A) fevereiro, (B) março, (C) abril e (D) maio.

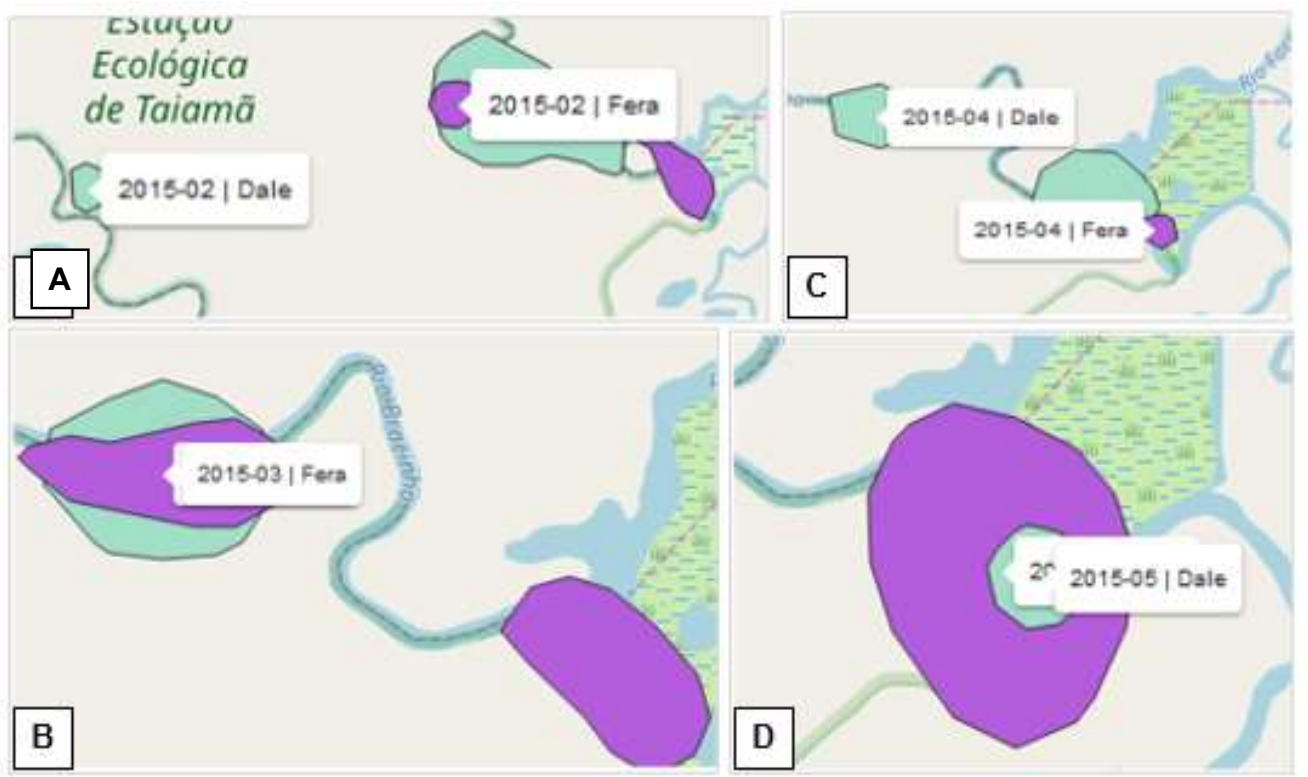

Figura 52 - Mapa de home range das onças Fera e Dale em 2015 
Com o AniMoveMineR também pode-se observar o home range dos animais com base nos estados de comportamento. Na Figura 53, é mostrado o home range das onças Picolé e Alice durante o forrageio nos meses de (A) fevereiro e (B) março de 2015, o que indica que em fevereiro compartilharam o espaço em algum momento.

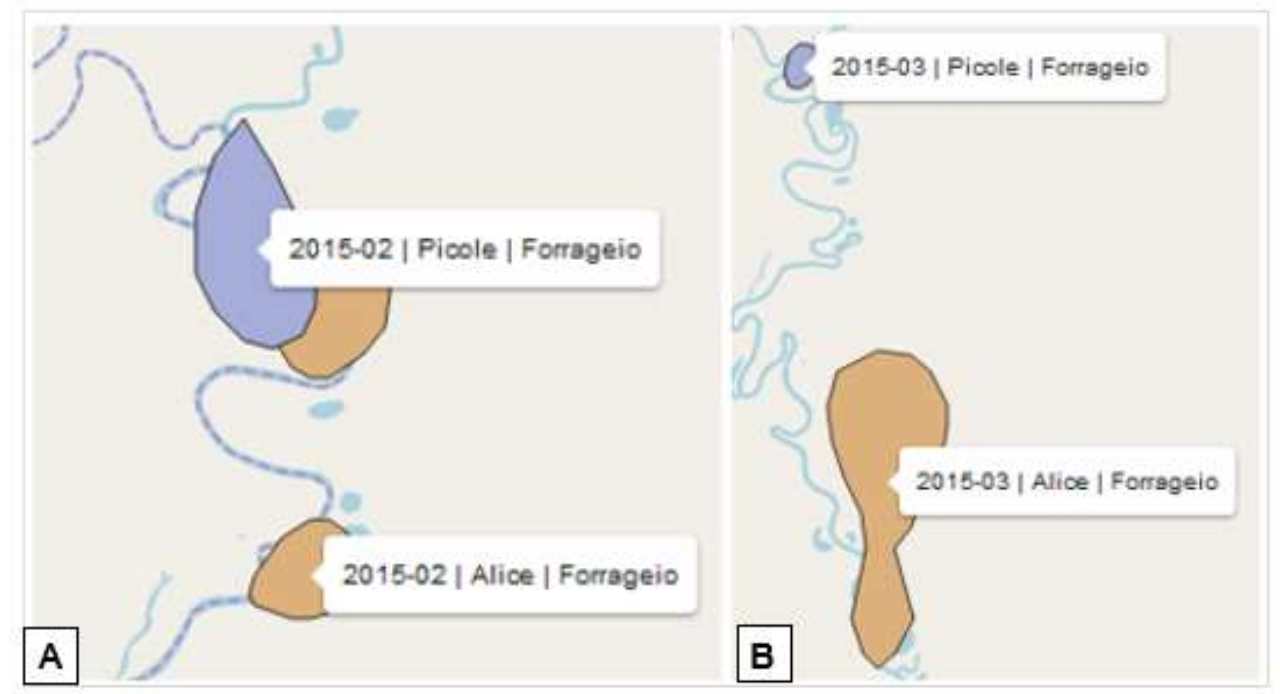

Figura 53 - Home range das onças Picolé e Alice durante o forrageamento em fevereiro e março de 2015

Deste modo, a análise da sobreposição de home range pode ser usada para confirmar os resultados obtidos com as regras de associação, para identificar encontros ou momentos que as onças permaneceram juntas e para acompanhar as mudanças no comportamento dessas onças com relação ao uso do espaço ao longo do tempo. Outro aspecto que pode ser analisado da interação entre os animais é a distância média entre eles ao longo do tempo.

No gráfico, Figura 54, é apresentada a distância média em quilômetros $(\mathrm{km})$ para os pares de onças no ano de 2015. Observa-se que os resultados indicam que Dale e Fera foram as onças com menor distância média para o período e Alice e Dale e as com maior distância foram a Alice e Fera. 


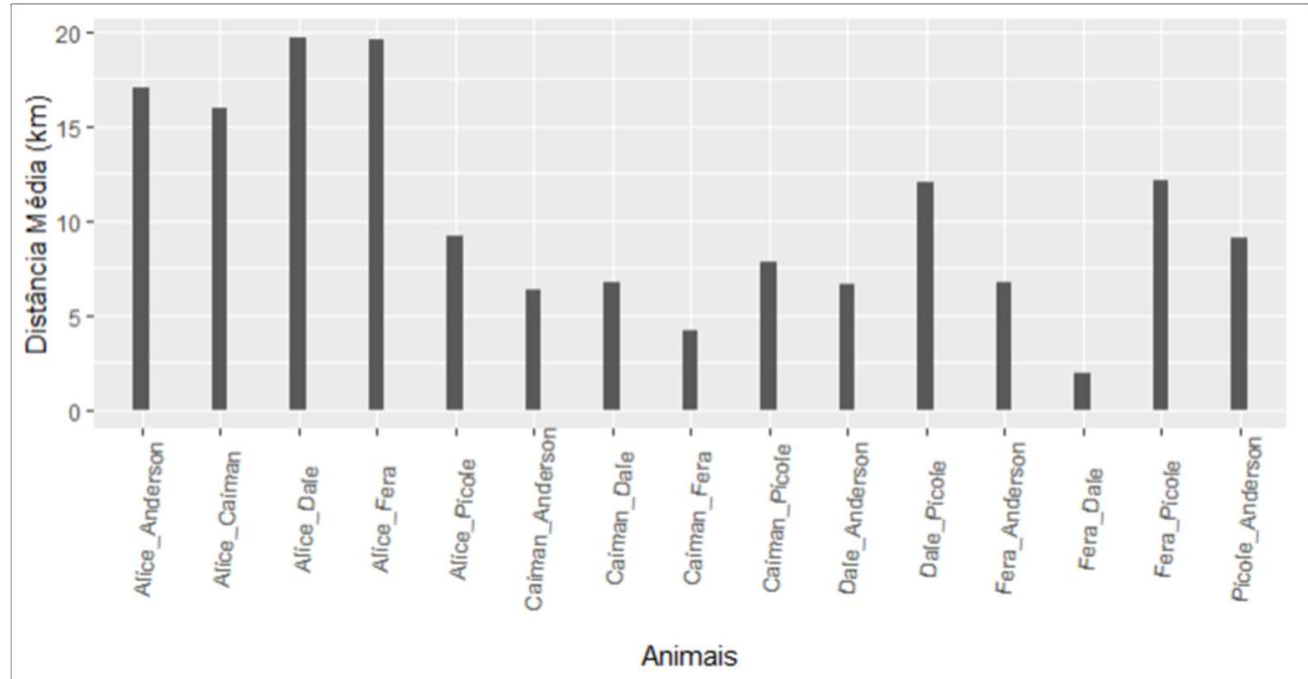

Ano: 2015

Figura 54 - Distância Média entre as onças em 2015

$\mathrm{Na}$ análise exploratória um raio de distância limite é definido para identificar os animais mais próximos. Com a análise da distância média pode-se observar o dia, mês e ano que os pares de animais foram registrados com distância média menor ou igual à distância limite. No gráfico, Figura 55, são mostradas as datas em que Fera e Dale apresentaram distância média menor ou igual à distância limite de 400 metros $(0.4$ km).

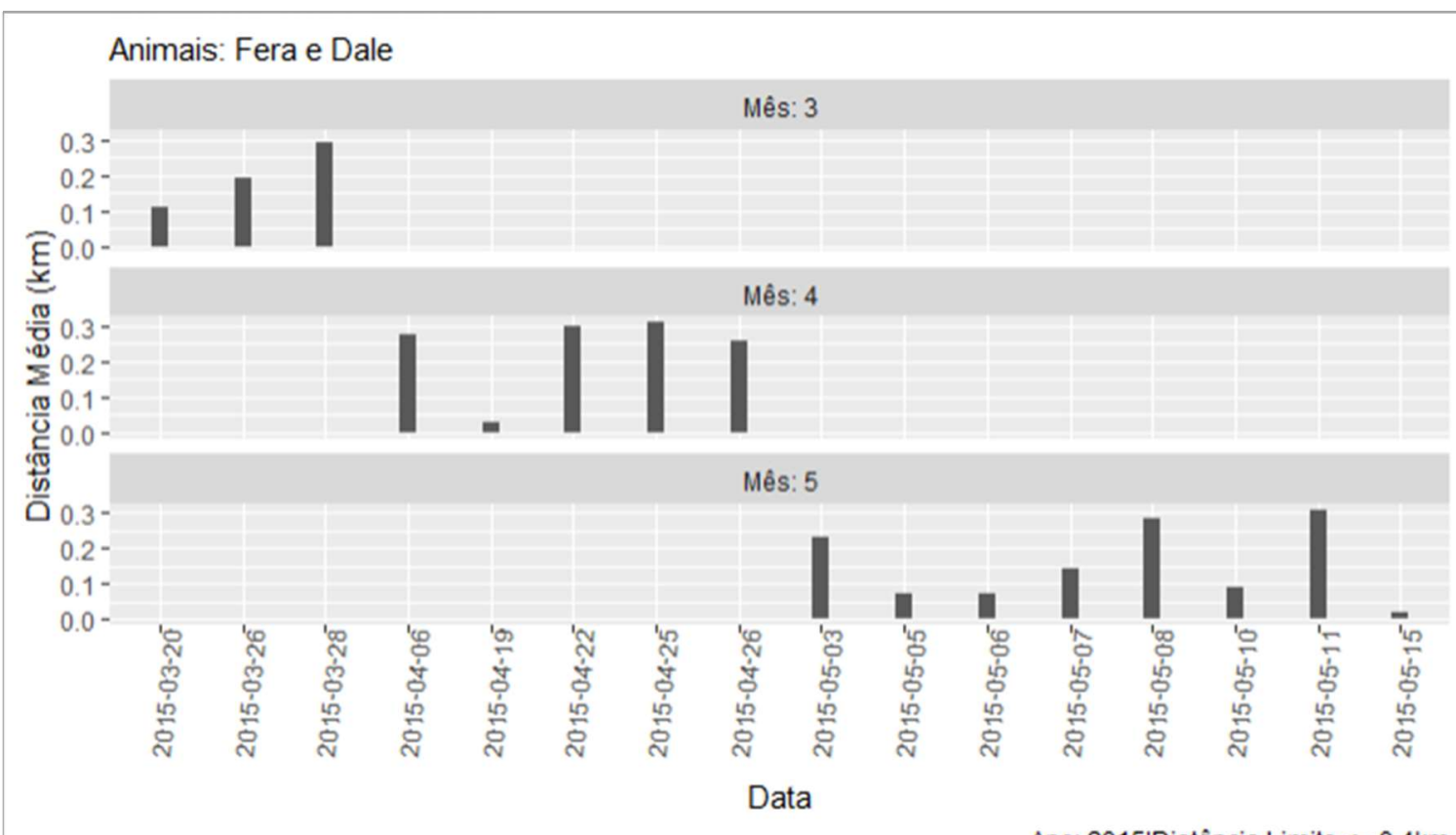

Figura 55 - Distância Média entre as onças Fera e Dale em 2015 para a distância limite igual a 400 metros 
No primeiro estudo o objetivo era responder à questão (1): "A análise exploratória da movimentação de onças permite identificar o nível de correlação entre pares de onças ao longo do tempo e espaço? "

Diante dos resultados observa-se que o framework fornece indicativos sobre o comportamento individual dos animais, a proximidade e os níveis de interação entre esses animais. Desta forma, permite identificar os níveis de correlação entre os animais a partir dos dados de movimentação animal e a frequência com a qual ocorrem ao longo do tempo e espaço.

Como indicativos sobre o comportamento individual são fornecidas as trajetórias dos animais e a classificação do comportamento desses animais em estados (descanso, forrageio e trânsito) ao longo de suas trajetórias.

A frequência de ocorrência e a duração desses estados são obtidos por meio da identificação dos horários (intervalo entre horas) e períodos do dia (noite/dia) em que são mais frequentes. Desta forma, pode-se inclusive identificar o tempo gasto pelo animal em suas atividades diárias. Além disso, são identificadas as áreas ocupadas (home range) pelos animais, individualmente, ou compartilhadas com outros animais ao longo do tempo e espaço por mês, ano ou por mês, ano e estado de comportamento.

A interação entre as onças pode ser analisada por meio das regras de associação que fornecem indicativos de frequência de coocorrência (Sup), probabilidade de um ocorrer em função do outro (Conf), de dependência (Lift) e correlação (Phi) entre os animais, bem como pela distância e a sobreposição de espaço entre esses animais ao longo do tempo e espaço e o coeficiente de Cramer que indica a correlação entre os animais.

\subsubsection{Estudo - Questão (2)}

O segundo estudo teve como finalidade responder a questão (2): "A análise exploratória da movimentação das onças permite identificar o nível de dependência entre as estações do ano e os períodos do dia em que as onças forrageiam?".

A classificação do comportamento das onças e os períodos (dia/noite) e horários obtidos no primeiro estudo foram utilizados para determinar as estações do ano, por meio dos meses nos quais ocorreram os estados de comportamento. As estações do ano em Taiamã são divididas em quatro (ICMBIO, 2017): Cheia 
(a partir de janeiro para março); Baixa (de abril a maio); Seco (de junho a setembro); Inundação (de outubro a dezembro).

Com base nos dados fornecidos pelo primeiro estudo foi aplicada a mineração por regras de associação entre o estado de forrageamento e as estações do ano e as medidas de confiança, suporte, lift e phi foram obtidas. Com a variação dos valores de minSup e minConf, Figura 56, os resultados indicaram que o estado de forrageio e as estações de Seca (Dry) e Baixa (Low) somente ocorrem quando minSup e minConf são extremamente baixos, mas o estado de forrageio apresentou probabilidade de $90 \%$ de ocorrer em função da estação Cheia (Full), mesmo com o aumento do minConf e minSup.

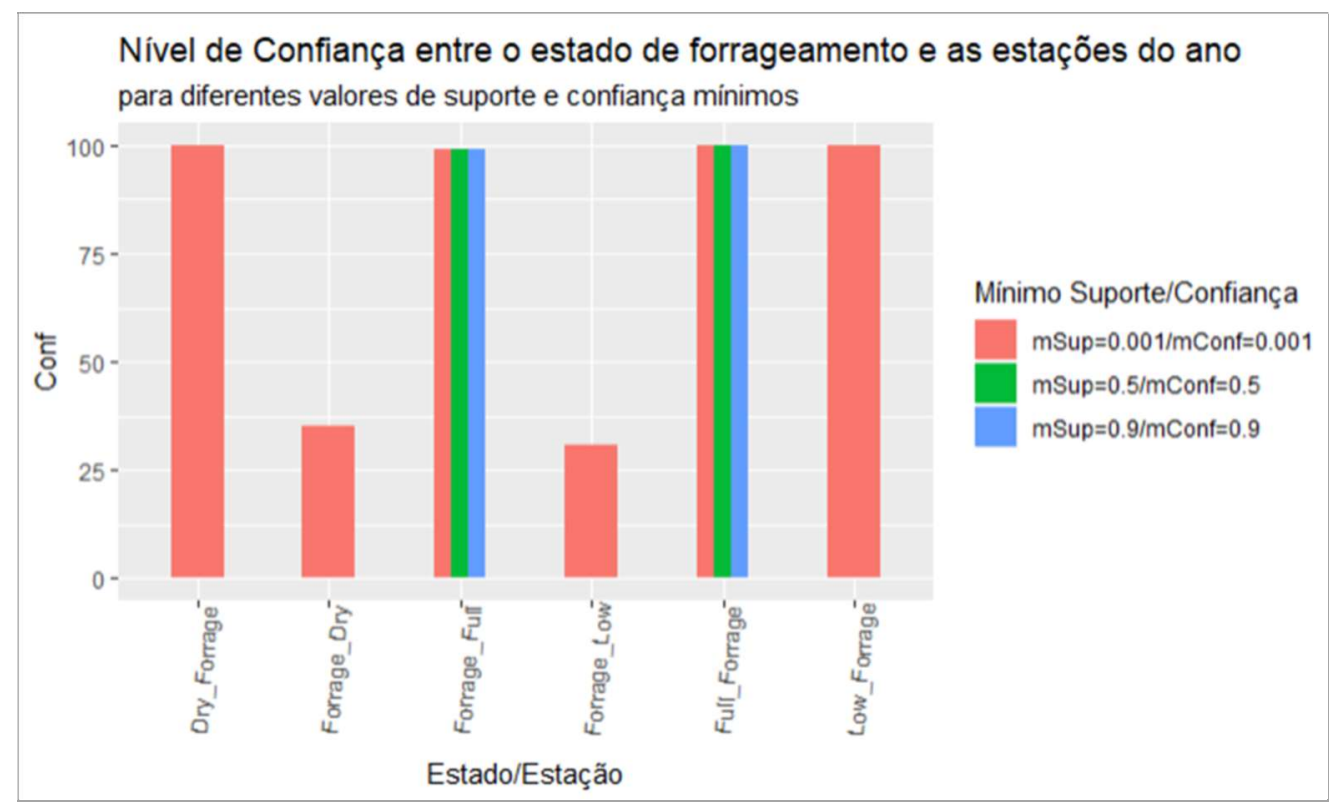

Figura 56 - Gráfico de confiança entre o estado de forrageio e as estações do ano

Os resultados da medida de dependência (Lift $=1$ ), Figura 57, indicaram que não há dependência entre o estado de forrageio e as estações do ano. 


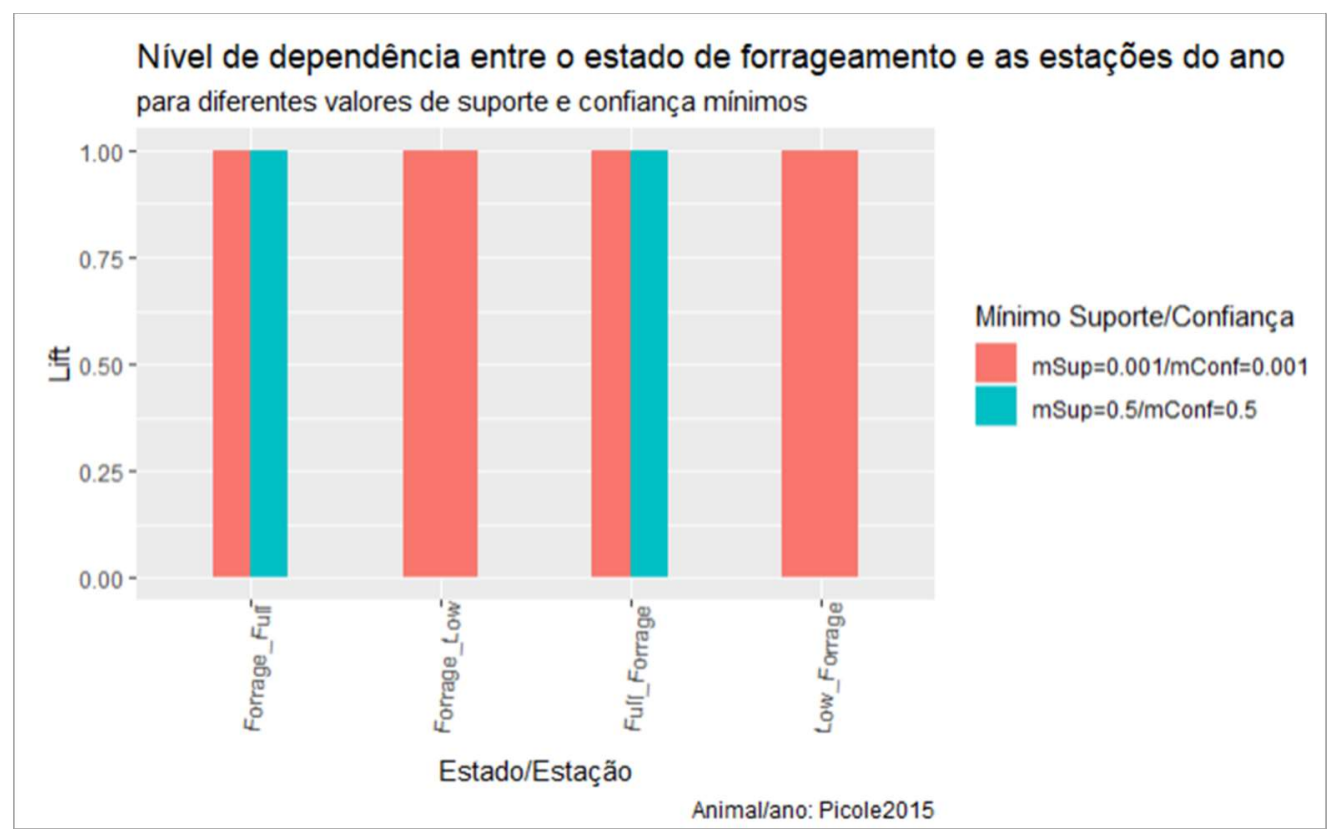

Figura 57 - Nível de Dependência entre o estado de forrageio e as estações do ano

Os resultados da medida de correlação (phi), Figura 58, indicaram maior correlação entre os estados de forrageio e a estação de cheia (full) para todos as onças analisadas e para o minSup e minConf até $50 \%$.

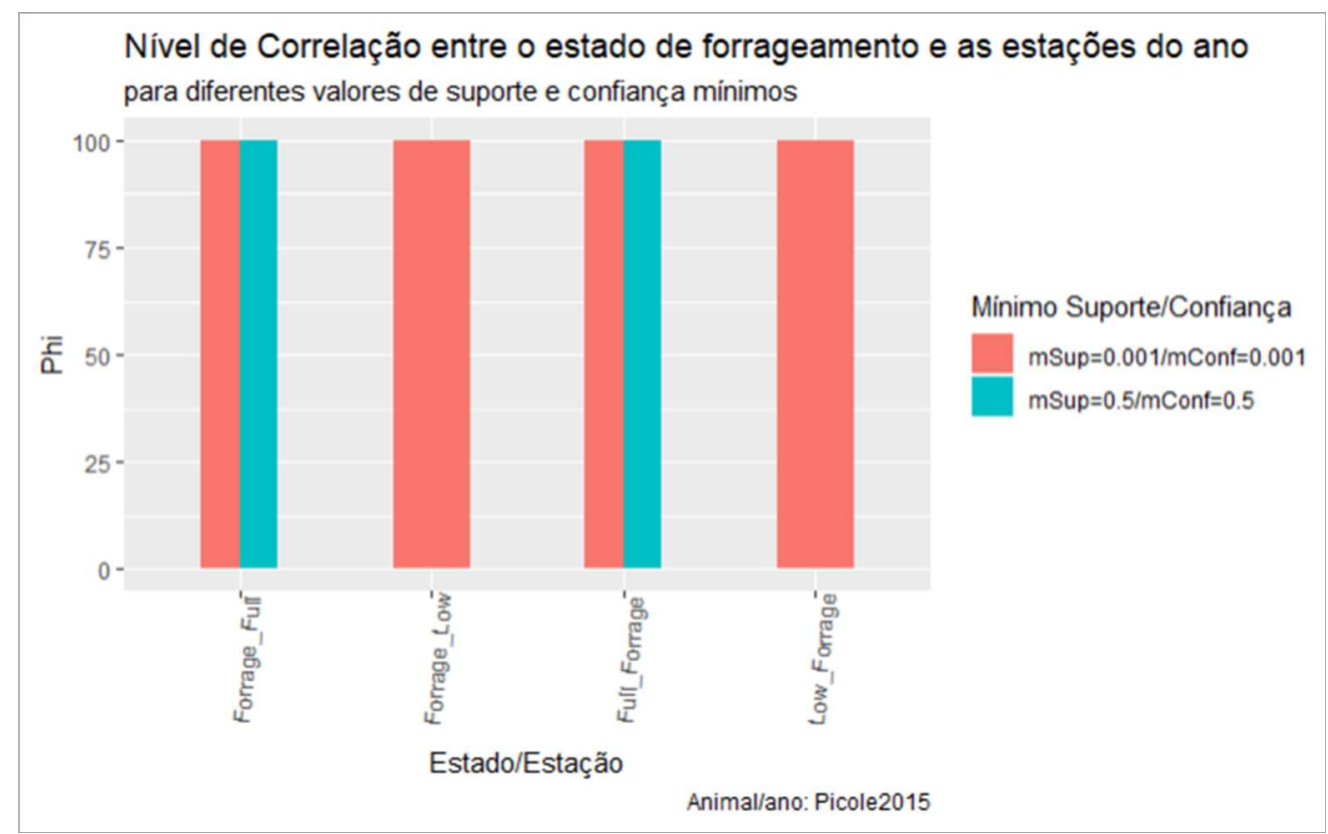

Figura 58 - Nível de Correlação entre o estado de forrageio e as estações do ano

Para validar a correlação entre as variáveis foi realizada uma segunda avaliação com o uso da tabela de contingência e do coeficiente de Cramer. $\mathrm{Na}$ Figura 59, é mostrado o resultado da avaliação que indica maior relação entre o 
estado de forrageio e as cheias, coeficiente de Cramer igual a 0.577. Desta forma, os resultados indicam que há maior registro de forrageamento na estação de cheia, mas o estado e a estação do ano não são dependentes.

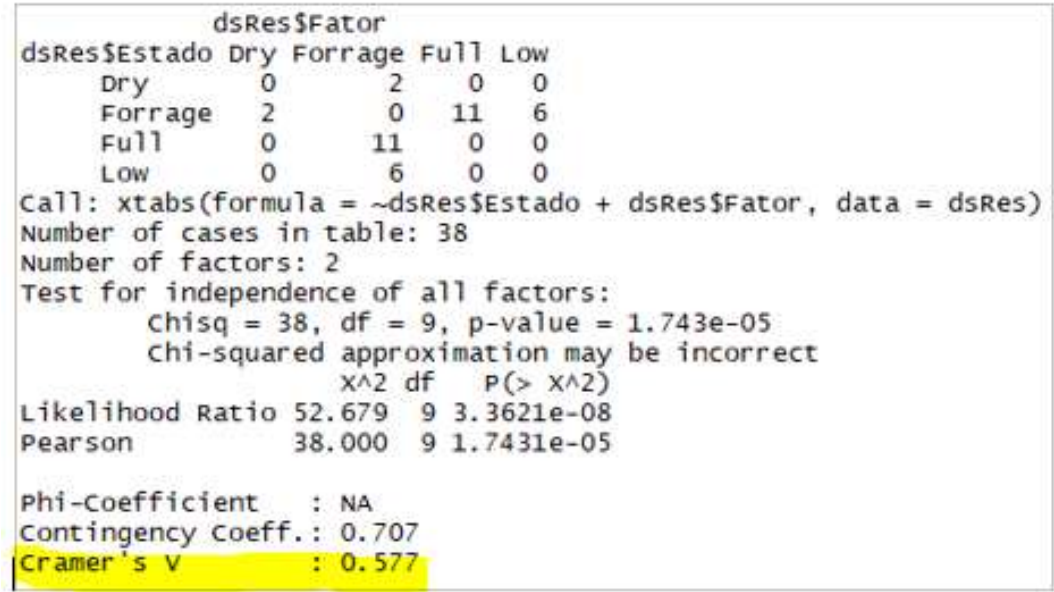

Figura 59 - Resultado do coeficiente de Cramer para a correlação entre o forrageamento e as estações do ano

Outro aspecto analisado com o AniMoveMineR foi a ocorrência do estado de forrageio ao longo dos períodos do dia (dia, noite e dia/noite) e as estações do ano. Observa-se, Figura 60, que para todas as estações a ocorrência do forrageamento é maior no período da noite.

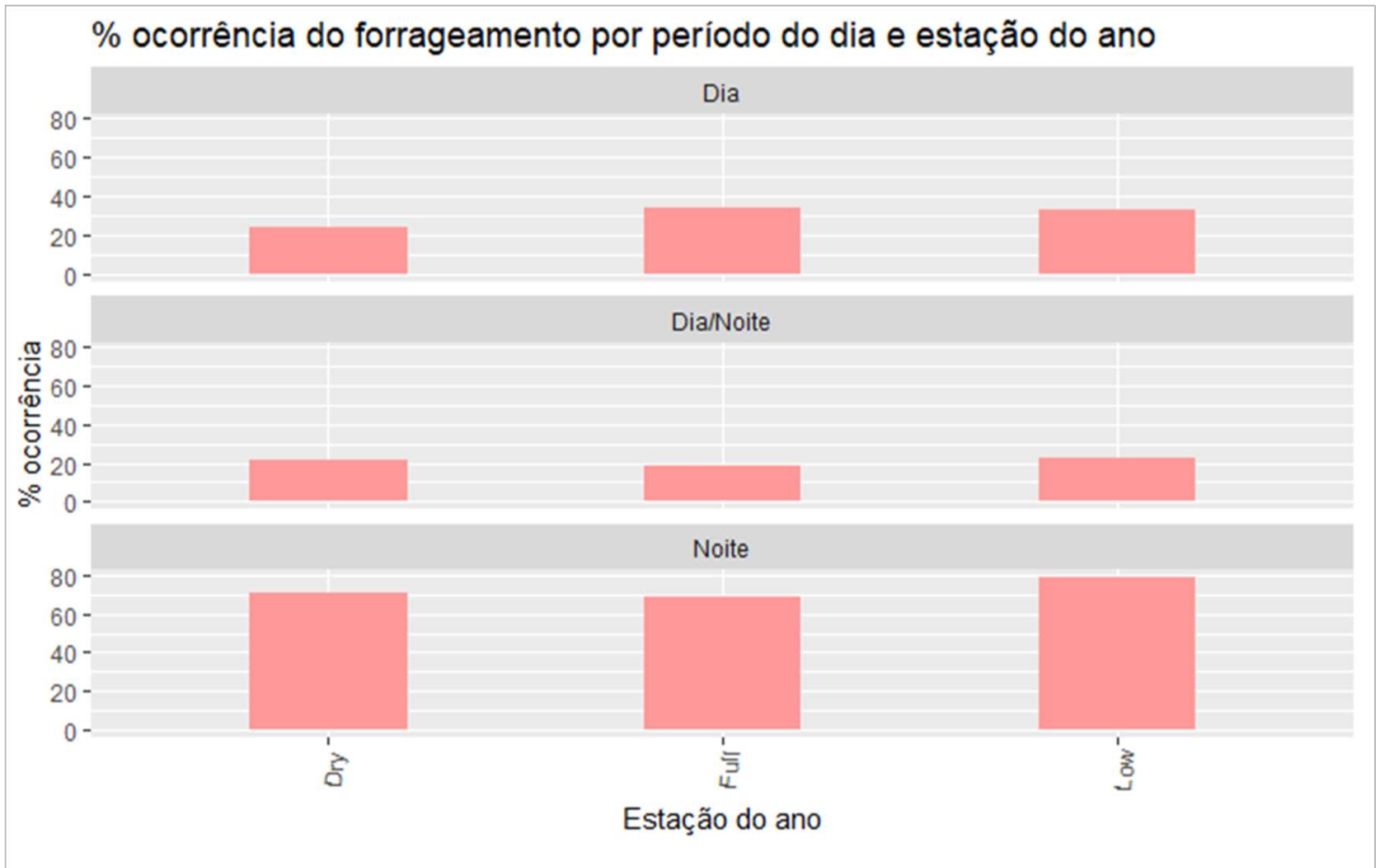

Figura 60 - Gráfico de ocorrência do forrageamento por período do dia e estação do ano 
Na Figura 61, é mostrada a ocorrência dos estados de comportamento ao longo dos períodos do dia e estações do ano para a onça Picolé em 2015.

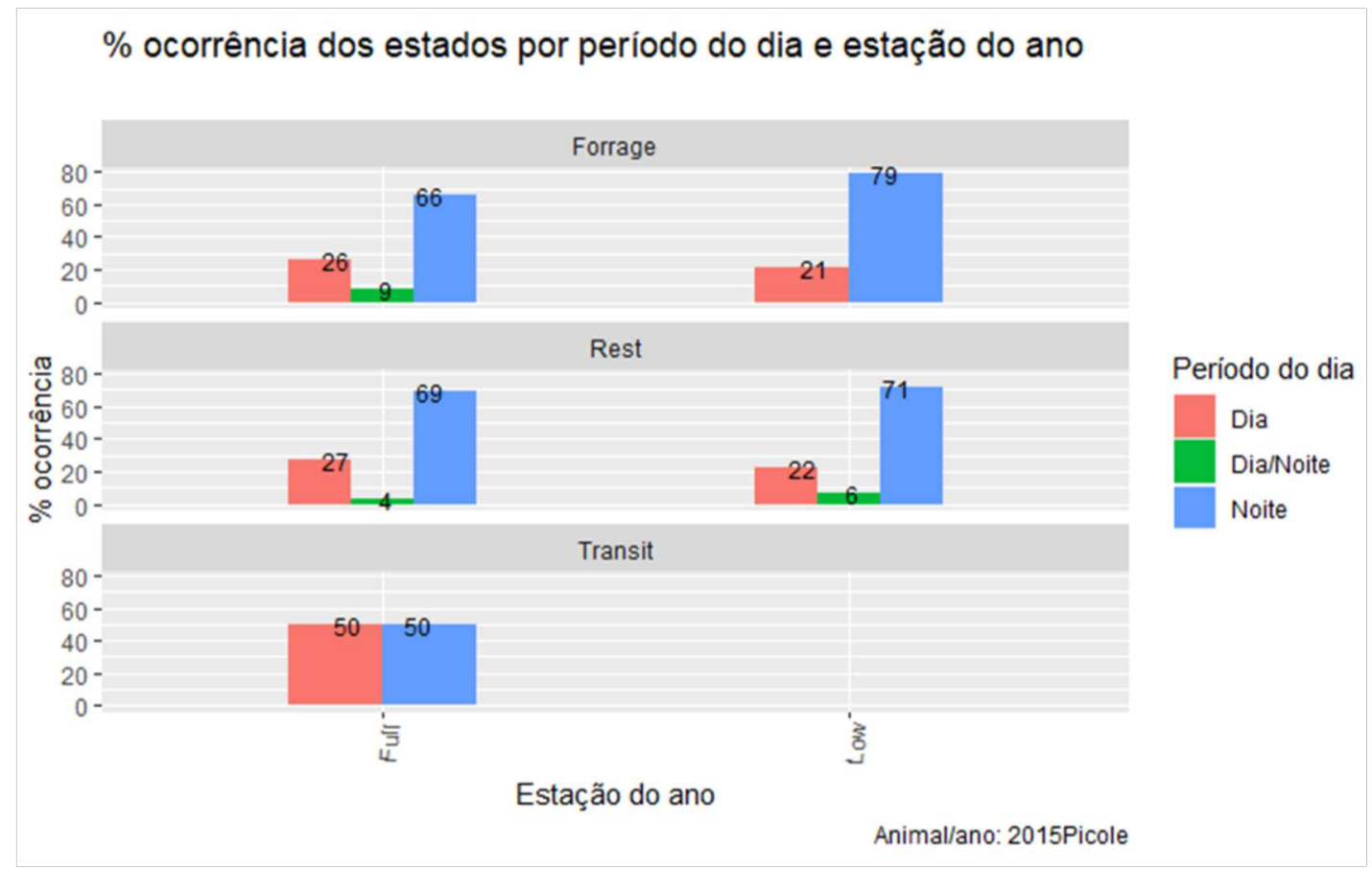

Figura 61 - Gráfico de ocorrência dos estados de comportamento para a onça Picolé por período do dia e estação do ano

O segundo estudo teve como finalidade responder a questão (2): "A análise exploratória da movimentação das onças permite identificar o nível de dependência entre as estações do ano e os períodos do dia em que as onças forrageiam?". A análise da frequência de ocorrência do estado de forrageamento, por período do dia (dia/noite) ao longo dos meses, permite identificar o comportamento das onças em função das estações do ano.

Com a análise exploratória da movimentação são identificados os estados de comportamento animal, os períodos (dia/noite) e horários que ocorreram esses estados. Com base nesses dados pode-se identificar em quais estações do ano foram registradas as ocorrências dos estados do comportamento animal e, desta forma, identificar:

- as estações do ano que têm maior ou menor frequência de ocorrência do estado de forrageio;

- os períodos (dia/noite) que as onças apresentaram maior frequência de forrageamento; 
- o nível de dependência, coocorrência e correlação entre o estado de comportamento de forrageio e as estações do ano.

Com os dois estudos de caso observa-se que o AniMoveMineR permite realizar a análise exploratória do movimento das onças de forma a obter indicativos sobre o comportamento individual desses animais e sua interação com os fatores ambientais, tais como a presença de outros animais ou a variação das estações do ano ao longo do tempo e espaço. 


\subsection{Estudo de Caso II - Análise da interação entre os macacos (Cebus} Capucinus) e as chuvas na região de Barro Colorado Island no Panamá.

Nesta Seção é apresentado o uso do framework AniMoveMineR na análise exploratória de um dataset de movimentação de 12 macacos (Cebus Capucinus), utilizado em (Li et al. 2013), referentes aos anos de 2004 e 2005 na região de Barro Colorado Island - Panamá.

LI et al. (2013) com a análise dos dados de movimentação animal classificou as relações entre pares de macacos como atração e repulsão. A frequência de coocorrência dos pares de animais é determinada e o valor de significância da relação é verificado com base em testes de permutação que consiste na realização de testes de hipóteses. Na Tabela 8, são descritos os pares de macacos divididos em 6 grupos.

Tabela 8 - Grupos de macacos (Cebus Capucinus)

\begin{tabular}{ccccccc}
\hline Grupo & TB & BLT & Top & BL12 & FC & Conrad \\
\hline ID Animal & $51-87$ & $52-53$ & $54-55$ & $57-58$ & $83-84$ & $85-86$ \\
\hline
\end{tabular}

Pergunta: Com a análise exploratória da movimentação dos macacos (Cebus Capucinus) pode-se identificar pares de macacos que pertencem a um mesmo grupo?

A análise exploratória dos dados foi executada com base nas três etapas que compõem este passo: (A) Identificar o comportamento individual do animal; (B) Identificar os fatores ambientais vizinhos da ocorrência do comportamento animal; (C) Identificar a correlação entre os animais e os fatores ambientais.

$\mathrm{Na}$ Etapa A, foi realizada a análise exploratória dos dados de movimentação dos macacos com o foco nos estados do comportamento desses animais, obtendo-se a classificação do comportamento em estados (descanso, trânsito e forrageio), os períodos (dia/noite) e horários de ocorrência dos estados (intervalos entre horas), bem como a duração (hora início e fim) da ocorrência do estado e a área ocupada pelo animal ao longo do tempo.

Com esses indicativos pode-se responder questões sobre 0 comportamento animal, tais como: Quais os horários que ocorrem os estados de comportamento para cada animal, mês e ano? Qual o percentual de ocorrência 
de cada estado por período do dia (dia/noite) para cada animal, mês e ano? Qual a área de vida do animal e quais animais compartilharam o mesmo espaço?

Como resultado da etapa $A$, tem-se um mapa da região onde os dados foram coletados e as trajetórias dos macacos ao longo do tempo (mês e ano) e espaço. Na Figura 62, o mapa mostra a trajetória do macaco 54, em novembro de 2004, e contém um menu com a relação dos macacos e meses nos quais foram registradas as ocorrências de movimentação para cada macaco. Assim, pode-se comparar as trajetórias dos animais ao longo dos meses por ano.

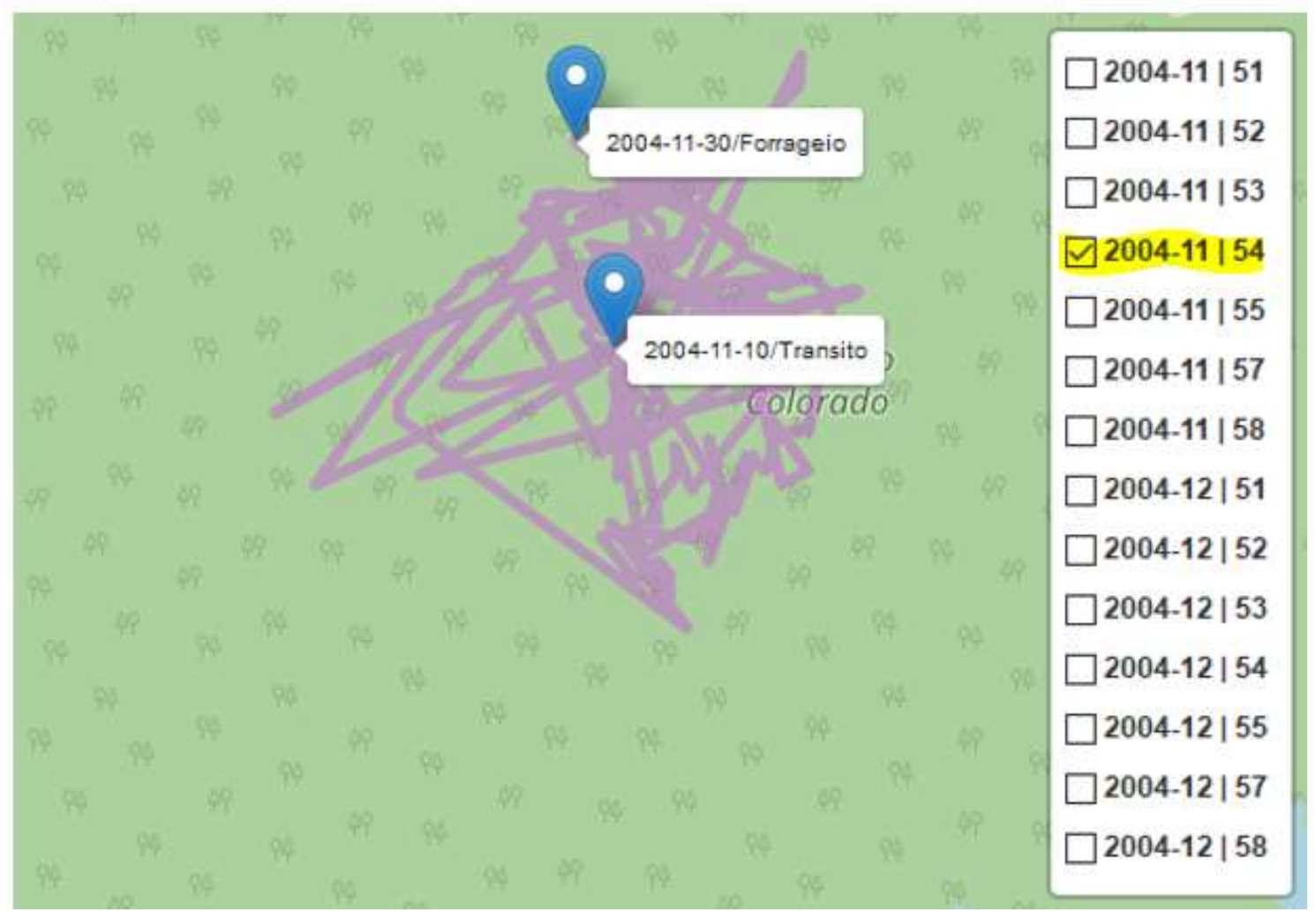

Figura 62 - Mapa de Sobreposição de Home Range - Macaco 51

Outro resultado da etapa A é a matriz de estados de comportamento do macaco 51, que apresenta a distribuição dos estados nos intervalos entre horas ao longo dos dias de cada mês/ano. A matriz, Figura 63, indica o tempo gasto pelo macaco 51 no forrageio, descanso ou em trânsito ao longo dos dias. Na matriz pode-se observar que de 1 a 11 de novembro de 2004 não houve registro de movimentação, mas a partir do dia 15 são mostradas as ocorrências dos estados. 


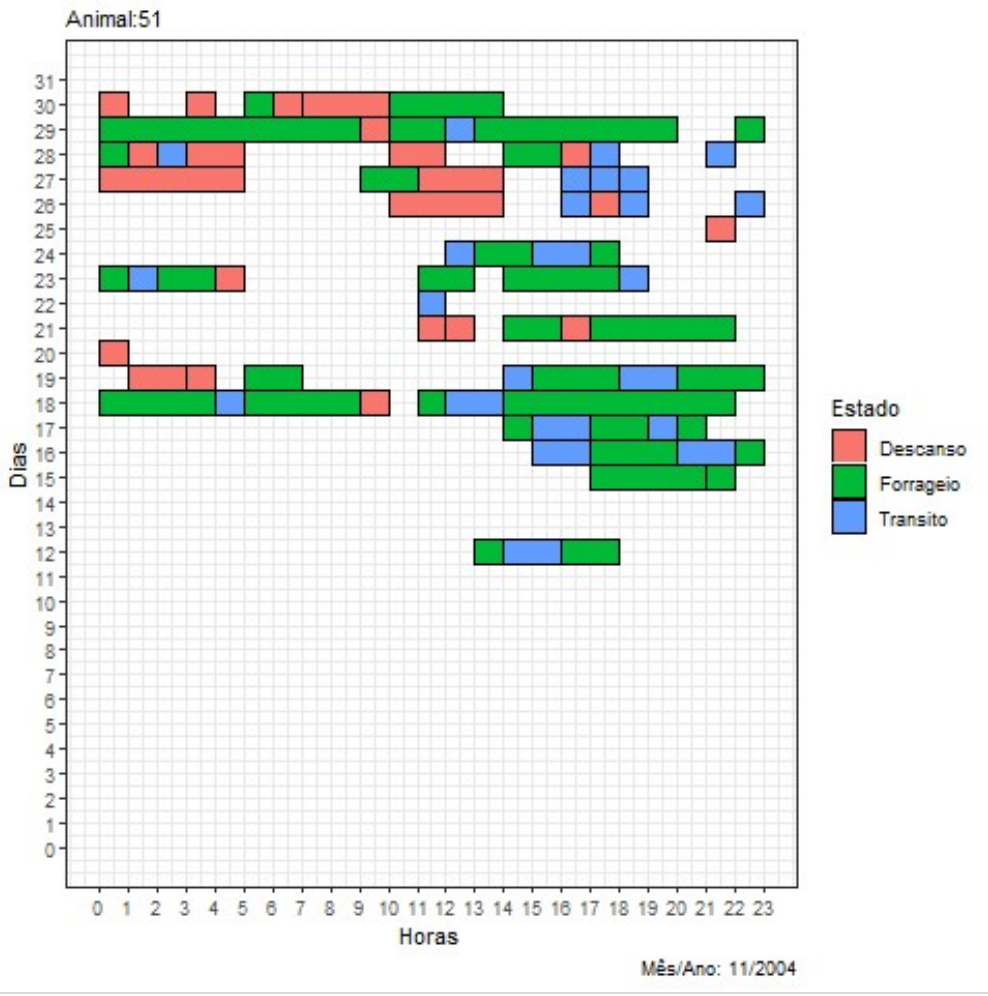

Figura 63 - Matriz de Estados de Comportamento do Macaco 51 - Novembro/2004

Em janeiro de 2005, Figura 64, pode-se observar que a matriz indica maior registro de ocorrências para o macaco 51 nos primeiros dias do mês e não contém registros do dia 25 à 31 .

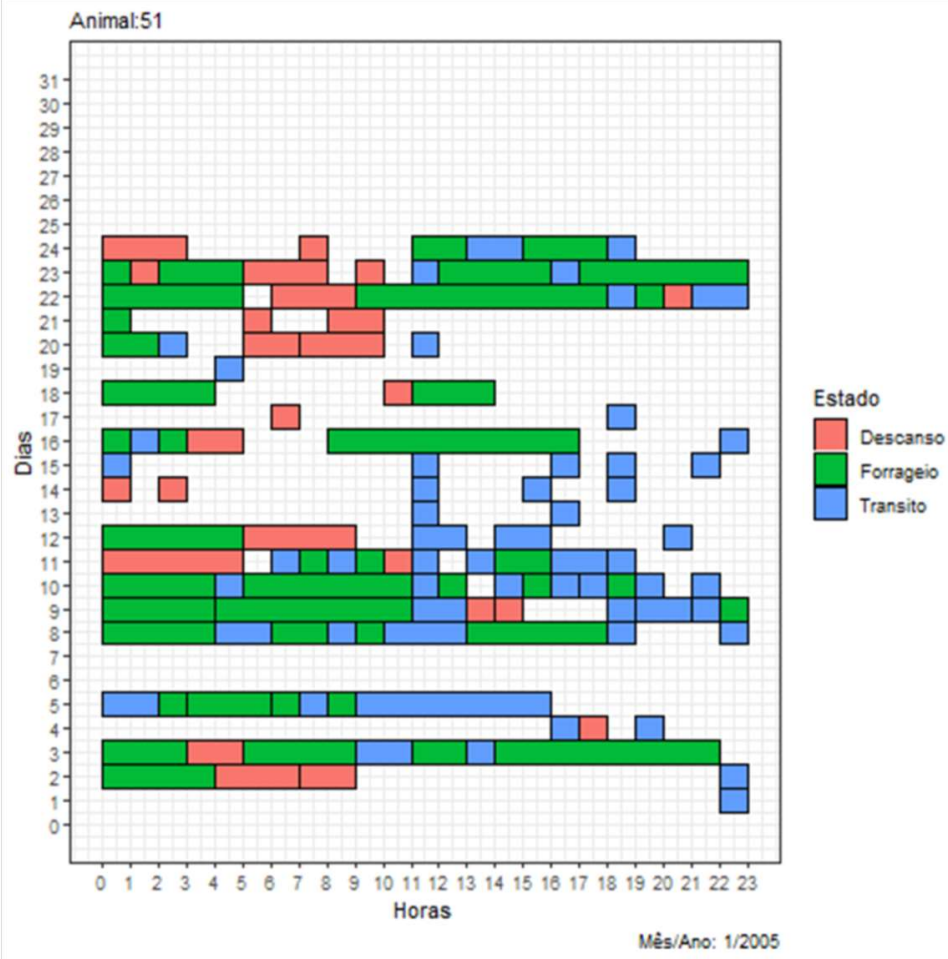

Figura 64 - Matriz de Estados de Comportamento do Macaco 51 - Janeiro/2005 
Com a análise exploratória dos períodos de ocorrência dos estados de comportamento animal são identificados os horários nos quais os estados ocorreram com maior frequência. A Tabela 9, por exemplo, mostra que o macaco 51 forrageou das 11:49:44 às 15:38:14 em novembro/2004.

Tabela 9 - Períodos de ocorrência dos estados do macaco 51 em novembro/2004

\begin{tabular}{lcclll}
\hline Ano & Mês & Animal & Estado & Início & Fim \\
2004 & 11 & 51 & Forrageamento & $11: 49: 55$ & $15: 38: 14$ \\
2004 & 11 & 51 & Descanso & $18: 10: 22$ & $19: 50: 14$ \\
2004 & 11 & 51 & Trânsito & $13: 40: 04$ & $14: 10: 12$ \\
\hline
\end{tabular}

Outro aspecto do comportamento individual dos macacos, fornecido pelo framework, é a duração dos estados de comportamento que indica o tempo médio que o macaco gasta em suas atividades de forrageio, descanso e trânsito. O gráfico, Figura 65, apresenta a duração média de cada estado de comportamento do macaco 51, ao longo dos meses do ano, indicando um aumento na duração do estado de forrageio do mês de novembro para dezembro de 2004 e queda na duração do tempo de descanso.

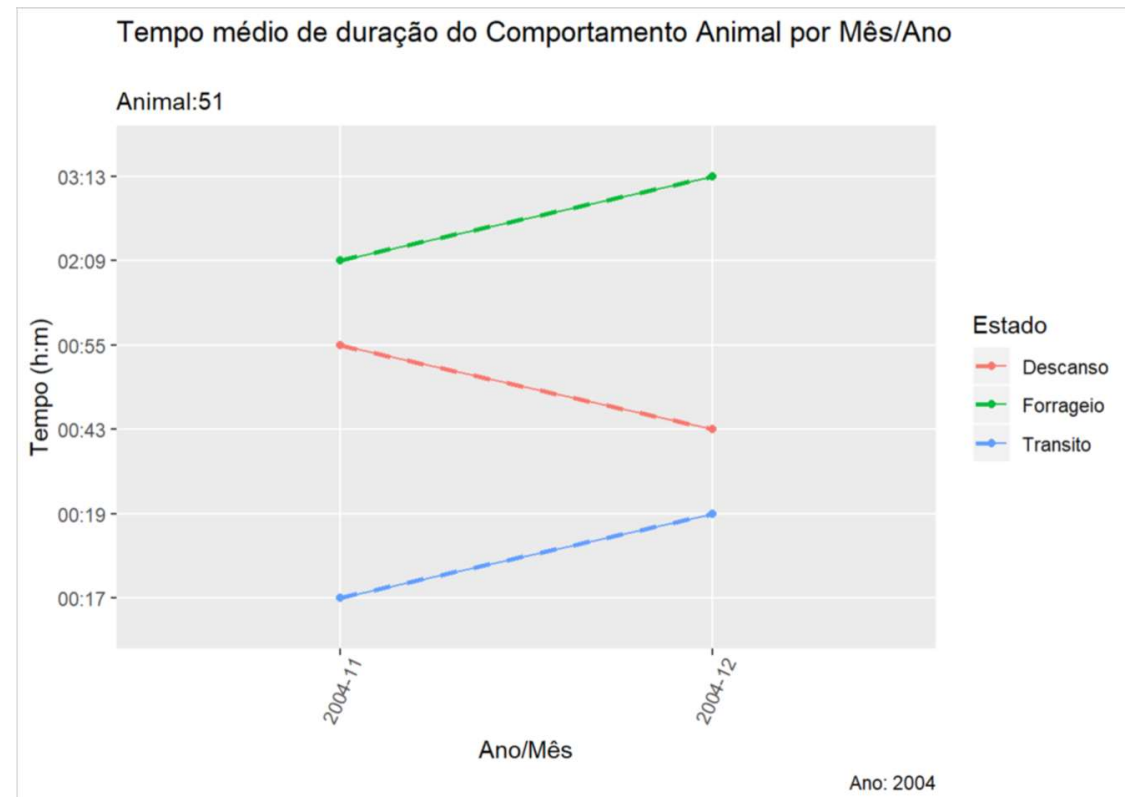

Figura 65 - Duração dos estados de comportamento do Macaco 51 - novembro/2004

O gráfico, Figura 66, ilustra a distribuição da duração média de cada estado de comportamento do macaco 51 para os meses de janeiro a abril de 
2005. Observa-se que em 2004 a duração do estado de forrageio variava entre $2 \mathrm{~h}$ e $3 \mathrm{~h}$, mas houve um aumento em 2005 com duração entre $5 \mathrm{~h}$ e $6 \mathrm{~h}$.

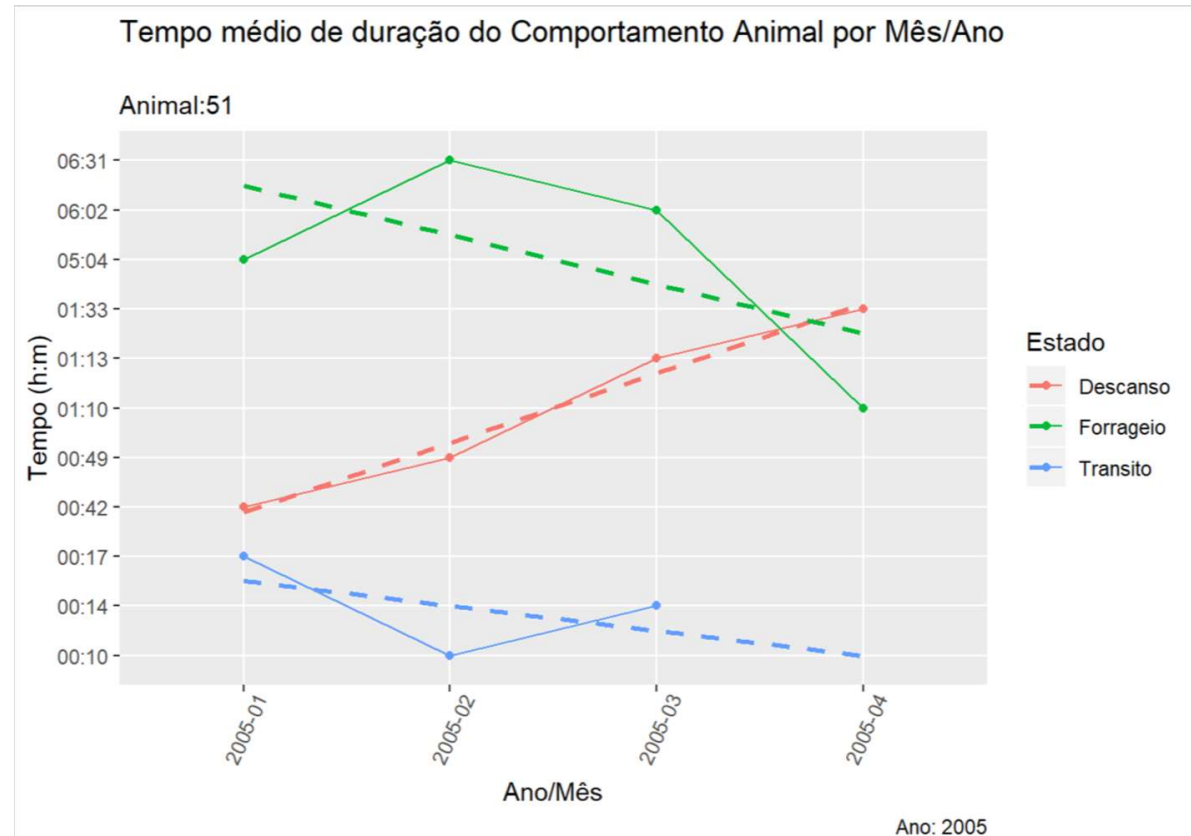

Figura 66 - Duração dos estados de comportamento do Macaco 51 - janeiro à abril de 2005

Com base nos períodos de ocorrência dos estados de comportamento pode-se identificar como um animal se comporta em relação ao dia e noite, Tabela 10, indicando, por exemplo, que o macaco 51 foi identificado forrageando à noite 29 vezes em janeiro de 2005. Os períodos foram classificados como $D$ (dia), N (noite) e DN (Dia/Noite). O período do D (dia) abrange o horário das $6 \mathrm{~h}$ da manhã às 17:59:59h e das $0 \mathrm{~h}$ às 05:59:59h. O período da $\mathrm{N}$ (Noite) abrange das $18 \mathrm{~h}$ às $23: 59: 59 \mathrm{~h}$. O período de DN (Dia/Noite) compreende os intervalos entre horas, que começam durante o dia e terminam a noite.

\begin{tabular}{ccclll} 
Tabela 10 & - Estados do comportamento do animal $\mathbf{5 1}$ por período do dia - janeiro/20 \\
\hline Ano & Mês & Animal & Estado & Período & total \\
2005 & 1 & 51 & Forrageamento & N & 29 \\
2005 & 1 & 51 & Forrageamento & DN & 13 \\
2005 & 1 & 51 & Forrageamento & D & 8 \\
2005 & 1 & 51 & Descanso & N & 12 \\
\hline
\end{tabular}

O gráfico, Figura 67, ilustra a distribuição da frequência de ocorrência de cada estado de comportamento do macaco 51 , ao longo dos meses de novembro 
e dezembro de 2004. Em novembro, há indicativo de que o macaco 51 forrageou mais durante o dia. Já em dezembro, indica que forrageiou mais a noite.

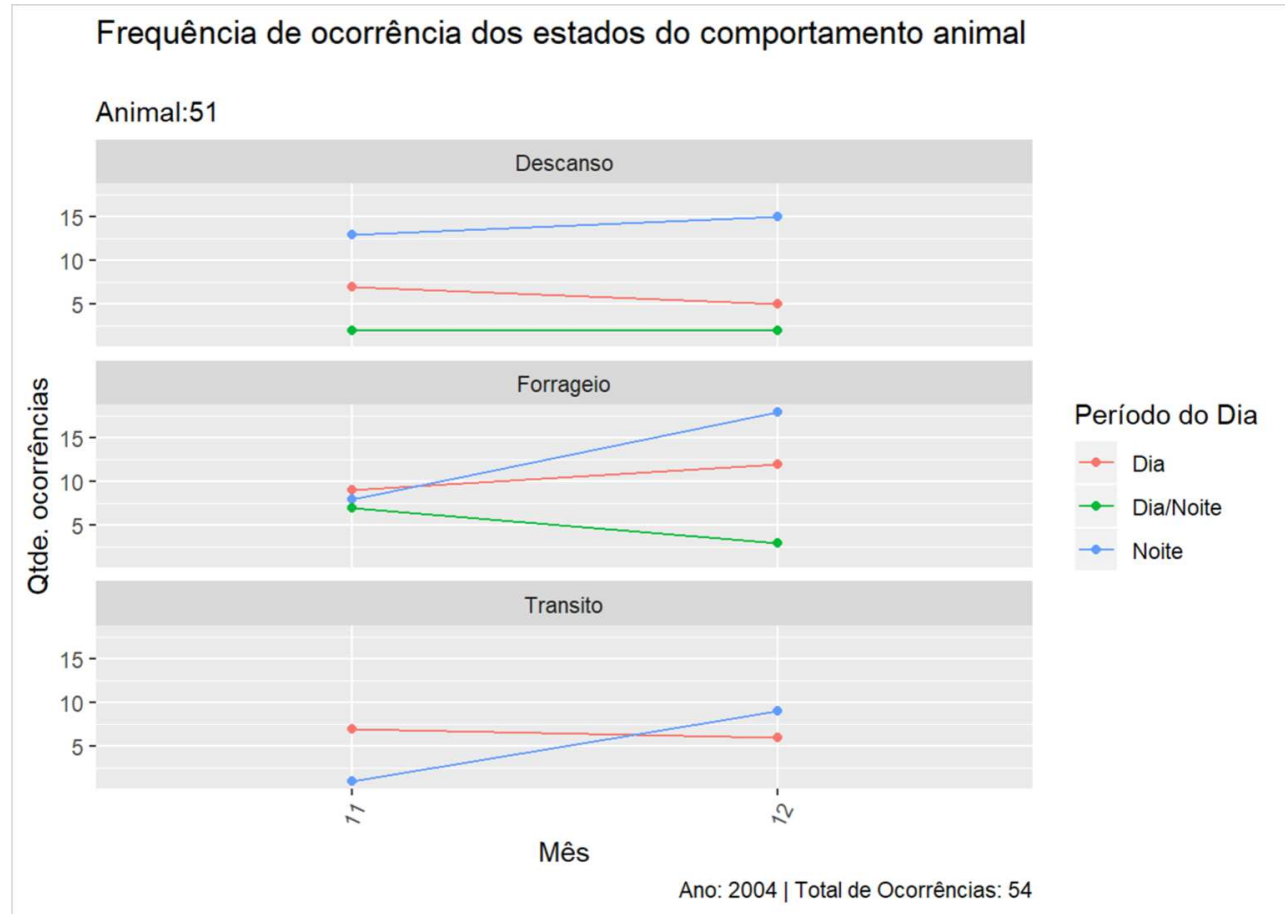

Figura 67 - Frequência de ocorrência dos estados de comportamento do macaco 51 por período do dia em 2004

Analisando os dados do macaco 51 em 2005, Figura 68, observa-se que o estado de forrageio nos meses de janeiro e abril de 2005 , foi maior durante a noite, e em fevereiro e março, foi maior começando de dia e terminando a noite.

$\mathrm{Na}$ Etapa B, foram identificados os fatores ambientais vizinhos da ocorrência do comportamento animal por meio da distância entre os animais e o fator ambiental. Neste caso, o fator ambiental refere-se a presença de outros animais. Desta forma, todas as ocorrências de movimento foram analisadas sincronizando as datas de movimentação e calculando as distâncias entre os pontos (latitude/longitude), utilizando a fórmula de Vincenty para um raio (TD) menor ou igual a 100 metros.

Na Etapa C, a análise dos dados foi aplicada para identificar a correlação entre os animais, usando a mineração por regras de associação com o algoritmo Apriori. Para determinar as regras relevantes o framework realizou as análises com os valores para minSup e minConf iguais a: Baixo (0.01), referente a 1\% para recuperar até mesmo as regras de associação com baixa frequência de coocorrência para as variáveis; Intermediário (0.50), referente a $50 \%$ para 
recuperar as regras de associação com um valor intermediário de frequência de coocorrência das variáveis; Alta (0.9), referente a 90\% para recuperar as regras de associação que apresentam alta frequência de coocorrência das variáveis.

Frequência de ocorrência dos estados do comportamento animal

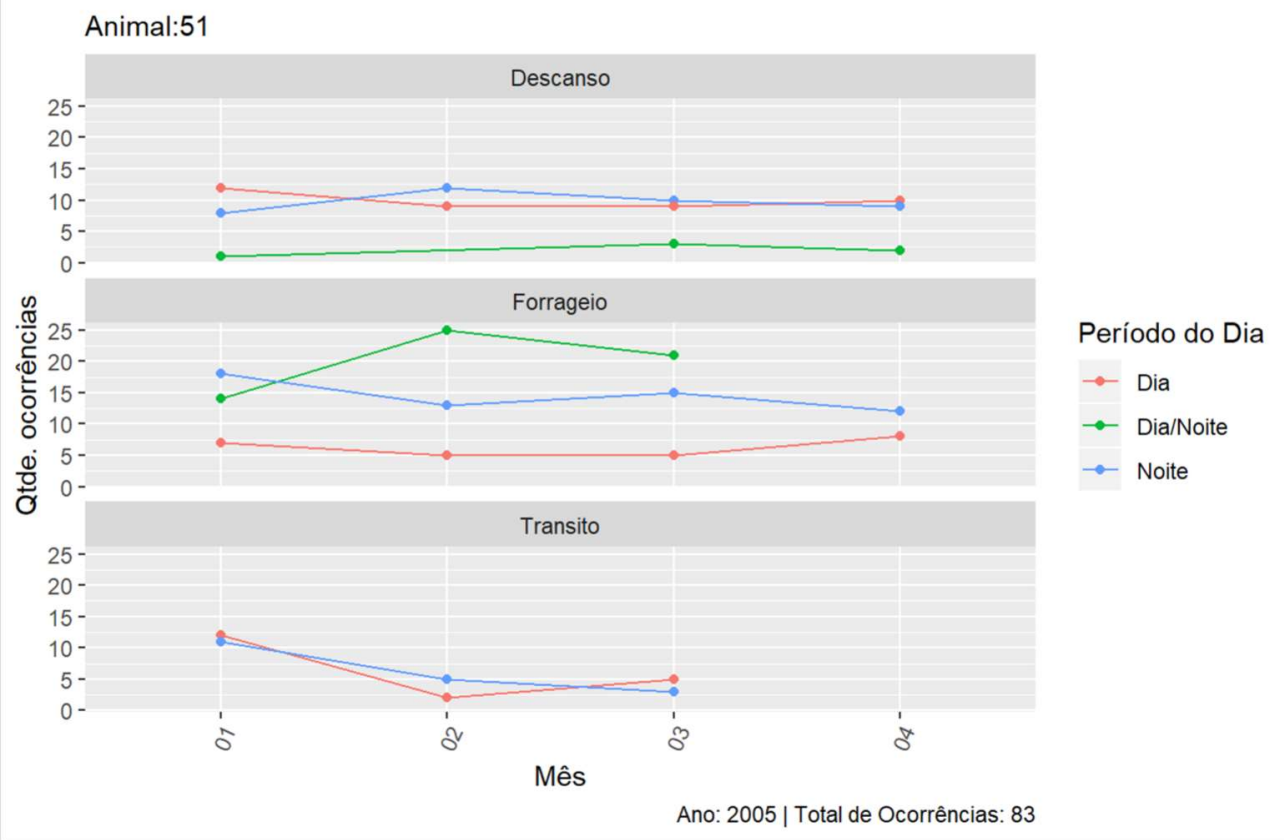

Figura 68 - Frequência de ocorrência dos estados de comportamento do macaco 51 por período do dia em 2004

Com a análise exploratória foi identificado que o dataset continha dados da movimentação dos macacos (Cebus Capucinus) de dois anos: 2004, meses de novembro e dezembro, e 2005, os meses de janeiro, fevereiro, março e abril. Em novembro/2004, a mineração por regras de associação indicou: forte correlação entre os pares de macacos 52/53 e 54/55; moderada correlação entre os macacos 57/58; fraca ou nenhuma correlação entre os pares de macacos $53 / 51,53 / 57$ e 55/58.

Para dezembro/2004, os macacos 52/53 e 54/55 mantiveram a indicação de alta correlação. Na Figura 69, é mostrada a variação dos níveis de correlação entre os animais que indica maior probabilidade de correlação quando os valores estão mais próximos de $100 \%$ e menor probabilidade quando estão mais próximos de $0 \%$. 


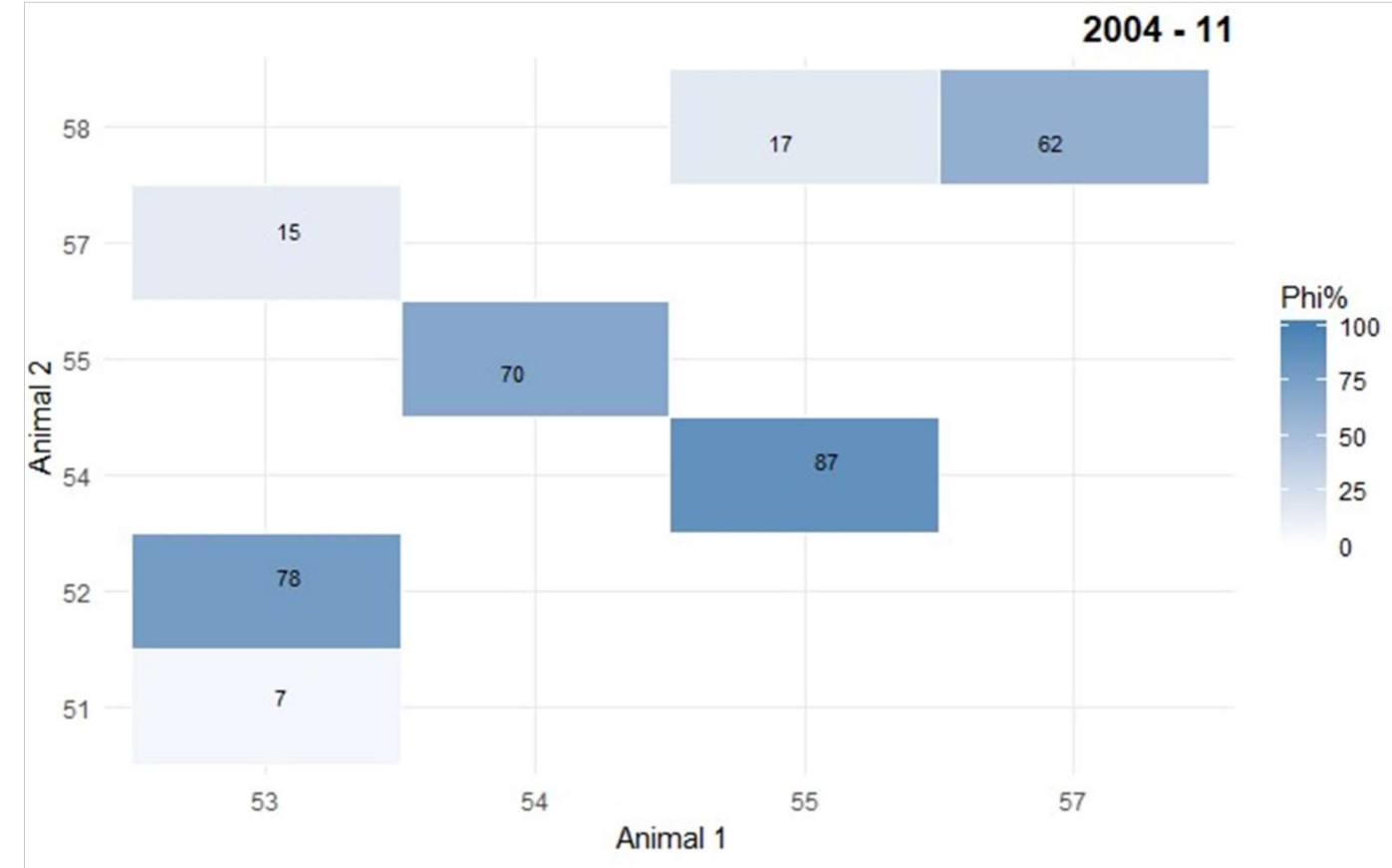

Figura 69 - Nível de correlação entre os macacos em novembro/2004

Os números mostrados em cada quadro referem-se ao \% de correlação entre cada par de macacos. Observa-se que os pares de animais 52/53 e 54/55 foram indicados, em ambos os meses, com alto nível de correlação.

Por meio das regras de associação, também, foram obtidas as medidas, Figura 70, de: suporte, que indica a frequência de coocorrência dos pares de animais, e a confiança, que indica a probabilidade do Animal 1 ocorrer em função da ocorrência do Animal 2. Um exemplo são os macacos 53 e 52, que possuem indicativo de forte correlação, baseado no valor de Phi, e analisando o suporte e confiança para essa relação observa-se que foram registradas 64 ocorrências juntos (Suporte), valor mostrado no quadro. Além, disso a probabilidade do macaco 53 ocorrer quando o macaco 52 ocorre é igual a $88 \%$, indicado pela intensidade da cor do quadro. Para os macacos 54 e 55, o valor de suporte é 16, e a confiança é de $80 \%$. Os dados de movimentação dos macacos em 2004 não contêm os pares de animais 51/87, 83/84 e 85/86. 


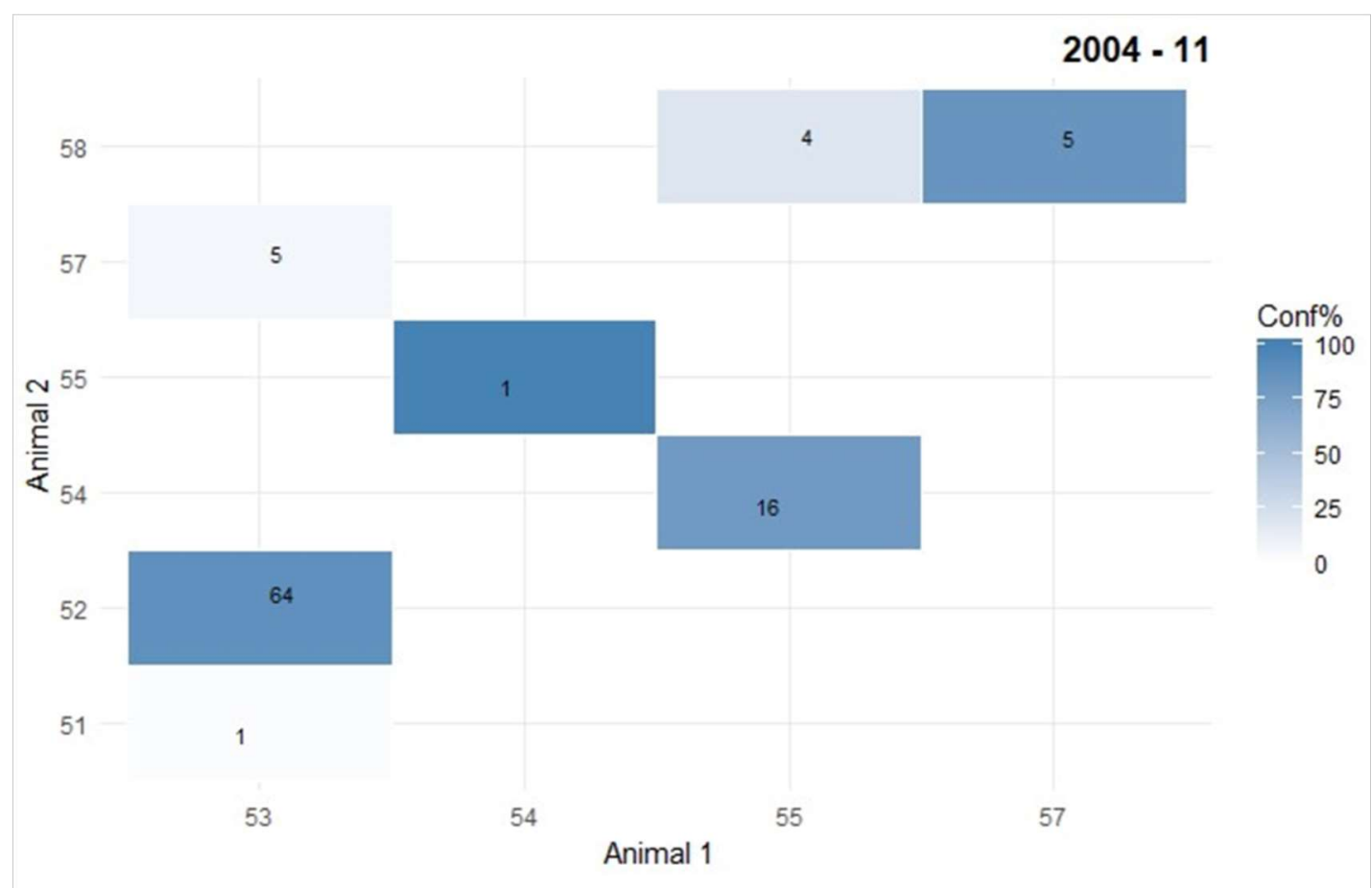

Figura 70 - Medidas de Suporte e Confiança para mineração dos dados dos macacos em 2004

A análise exploratória dos dados para 2005 indicou que os macacos $52 / 53,54 / 55$ e 58/57, que apresentaram perfeita ou forte correlação para o ano de 2004, mantiveram esse nível de correlação em 2005. Já os macacos 51/87 e 85/86 que não constavam nos resultados das análises em 2004, passaram a ser indicados com forte correlação, Figura 71, em março e abril de 2005.

Comparando os grupos de animais, identificados por Li et al. (2013), com os pares de macacos correlacionados indicados pelas regras de associação, observa-se que os animais com forte, perfeita ou moderada correlação são animais que pertencem aos mesmos grupos, como os animais 52/53, 54/55, $57 / 58,51 / 87$ e $85 / 86$. 


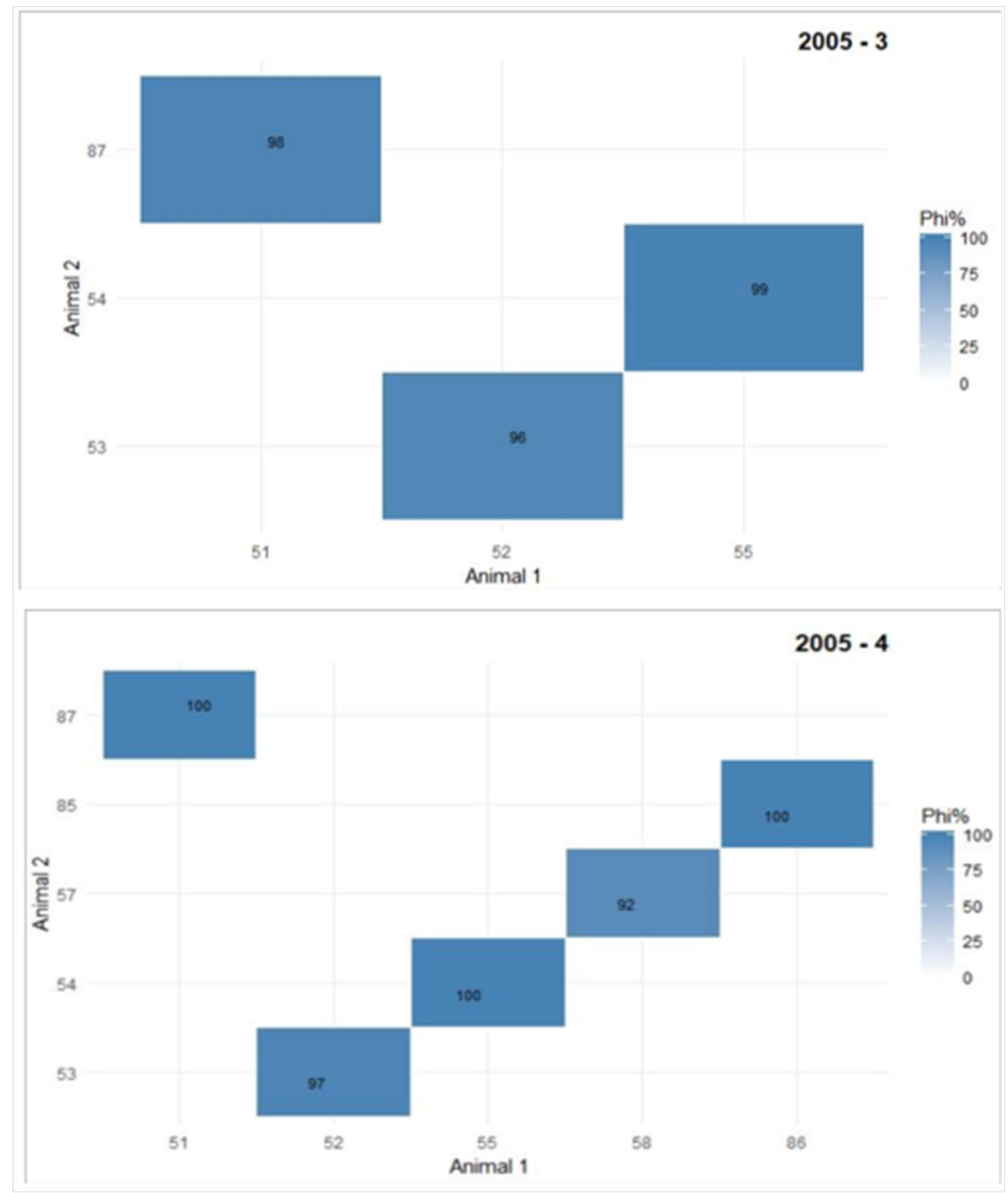

Figura 71 - Nível de Correlação entre macacos em março e abril de 2005

A relação entre esses animais pode ser observada, também, por meio da análise da sobreposição de área de vida (home range) entre os animais (KERNOHAN; GITZEN; MILLSPAUGH, 2001), Figura 72, que mostra a proporção de sobreposição da área de vida de um animal em relação aos outros. Quanto mais próximo o valor de 1 maior a sobreposição, desta forma, observase que em 2004 os animais 52/53 apresentam valor 1 , os animais 54/55 o valor é igual a 0.884 e para os animais 58/57 é igual a 0.772 . 
$\begin{array}{lllllll}51 & 52 & 53 & 54 & 55 & 57 & 58\end{array}$

$\begin{array}{llllllllllll}51 & 1.0000000 & 0.1111111 & 0.1111111 & 0.00000000 & 0.00000000 & 0.00000000 & 0.0000000\end{array}$

$\begin{array}{llllllllll}52 & 0.1481481 & 1.0000000 & 0.8518519 & 0.14814815 & 0.18518519 & 0.33333333 & 0.2962963\end{array}$

$\begin{array}{llllllllllllllll}53 & 0.1739130 & 1.0000009 & 1.0000000 & 0.13043478 & 0.17391304 & 0.30434783 & 0.2608696\end{array}$

$\begin{array}{llllllllll}54 & 0.0000000 & 0.1538462 & 0.1153846 & 1.00000000 & 0.88461538 & 0.03846154 & 0.4615385\end{array}$

$\begin{array}{lllllllllllll}55 & 0.0000000 & 0.1923077 & 0.1538462 & 0.88461538 & 1.00000000 & 0.03846154 & 0.4230769\end{array}$

$\begin{array}{llllllllll}57 & 0.0000000 & 0.4090909 & 0.3181818 & 0.04545455 & 0.04545455 & 1.000000000 .7727273\end{array}$

$\begin{array}{lllllllllll}58 & 0.0000000 & 0.1538462 & 0.1153846 & 0.23076923 & 0.21153846 & 0.32692308 & 1.0000000\end{array}$

Figura 72 - Proporção de sobreposição da área de vida dos macacos em 2004

A correlação entre os animais foi analisada, também, por meio da tabela de contingência e coeficiente de Cramer. Os resultados foram obtidos por mês e ano e indicaram para novembro de 2004, Figura 73, o coeficiente de Cramer igual a 0.797 . O resultado indica que os pares de macacos 52/53, 54/55 e 58/57 são correlacionados por apresentarem valor maior que 1 .

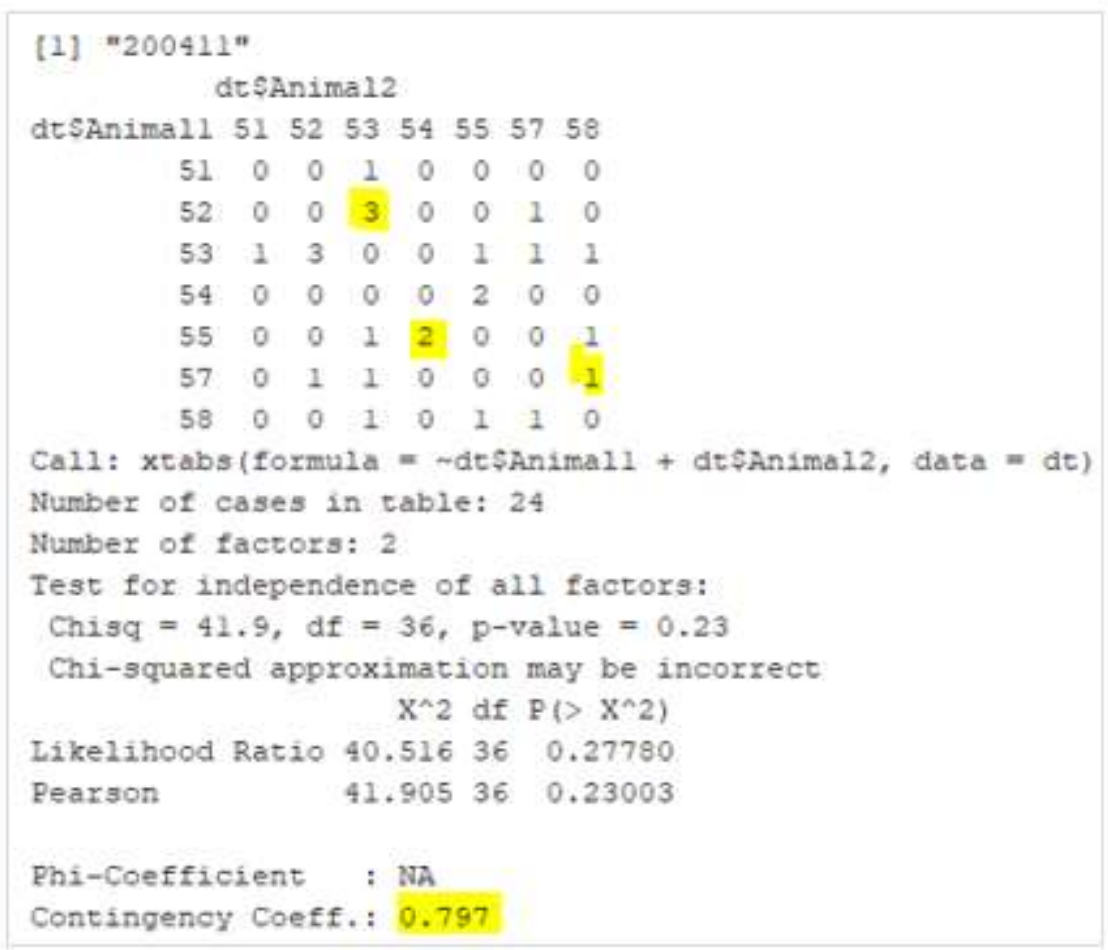

Figura 73 - Resultado do coeficiente de Cramer entre os macacos em novembro de 2004

A sobreposição pode ser observada, também, por meio de mapas que mostram a área de vida por animal, mês e ano ou por animal, mês, ano e estado. 
Na Figura 74, por exemplo, observa-se que a área onde os animais 54 e 55 forragearam (A), descansaram (B) e transitaram (C) apresenta sobreposição, o que indica que esses animais ocuparam a mesma área ao longo do mês de novembro de 2004.
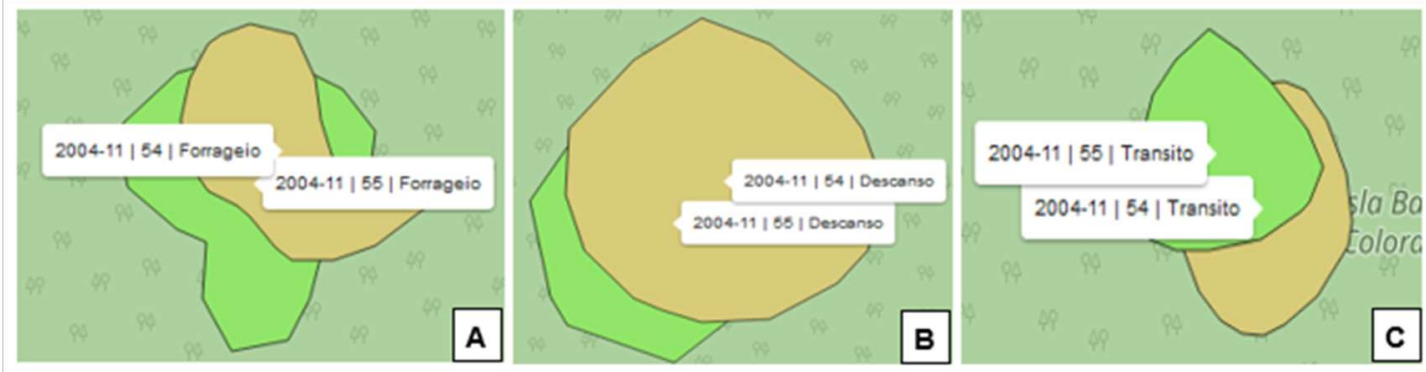

Figura 74 - Mapa do home range dos macacos 54 e 55 em novembro/2004

$\mathrm{Na}$ análise dos dados de 2005, Figura 75, o mapa indicou sobreposição de área de vida para os animais 54/55 para os meses de janeiro $(A)$, fevereiro (B), março (C) e abril (D).

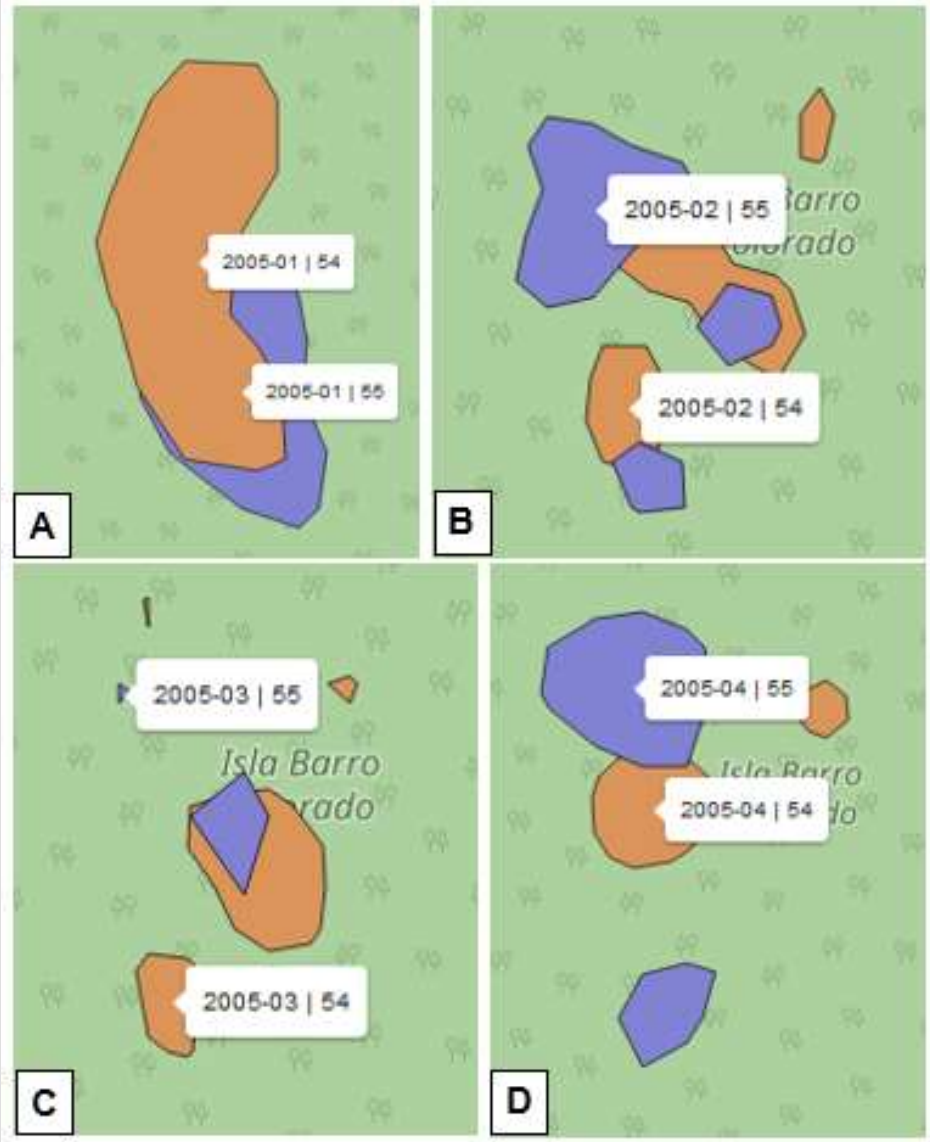

Figura 75 - Mapa do home range dos macacos 54 e 55 em janeiro (A), fevereiro (B), março (C) e abril (D) de 2005 
Os animais 53/57 apresentaram indicativo de fraca ou nenhuma correlação para novembro/2004 e, observando o home range desses animais verifica-se que não houve sobreposição de área. A Figura 76, mostra a área ocupada em novembro (A) e dezembro (B) pelos animais 53 e 57 que indica que não houve sobreposição de área entre esses animais.
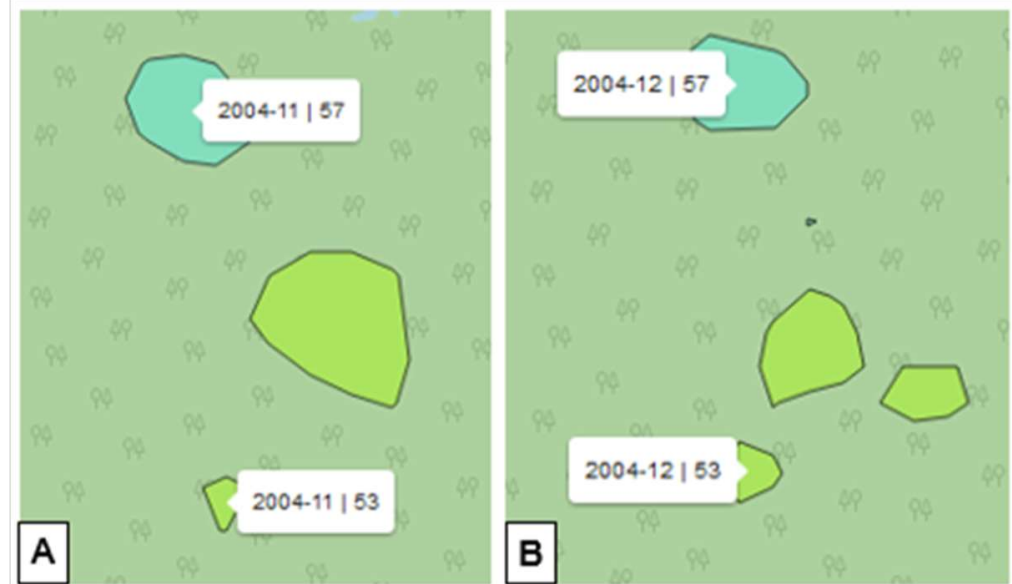

Figura 76 - Mapa do home range dos macacos 53 e 57 em novembro (A) e dezembro (B) de 2004

$\mathrm{Na}$ análise dos dados de 2005, Figura 77, mapa indicou que não houve sobreposição de área de vida para os animais 53/57 para os meses de janeiro $(A)$, fevereiro (B), março (C) e abril (D).

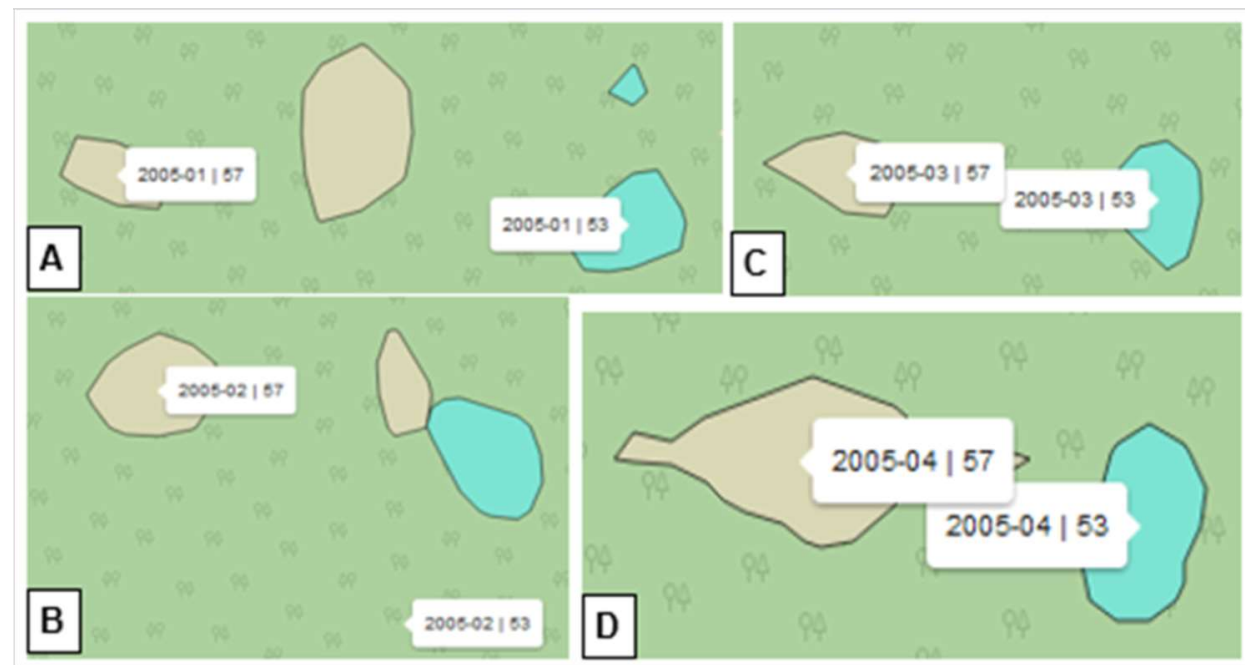

Figura 77 - Mapa do home range dos macacos 53 e 57 em janeiro (A), fevereiro (B), março (C) e abril (D) de 2005

Outro aspecto que pode ser analisado da interação entre os animais é a distância média entre eles ao longo do tempo. No gráfico, Figura 78, é 
apresentada a distância média em quilômetros $(\mathrm{km})$ para os pares de macacos em 2004. Com a análise da distância média pode-se observar o dia, mês e ano que os pares de animais foram registrados com distância média menor ou igual ao raio de distância limite.

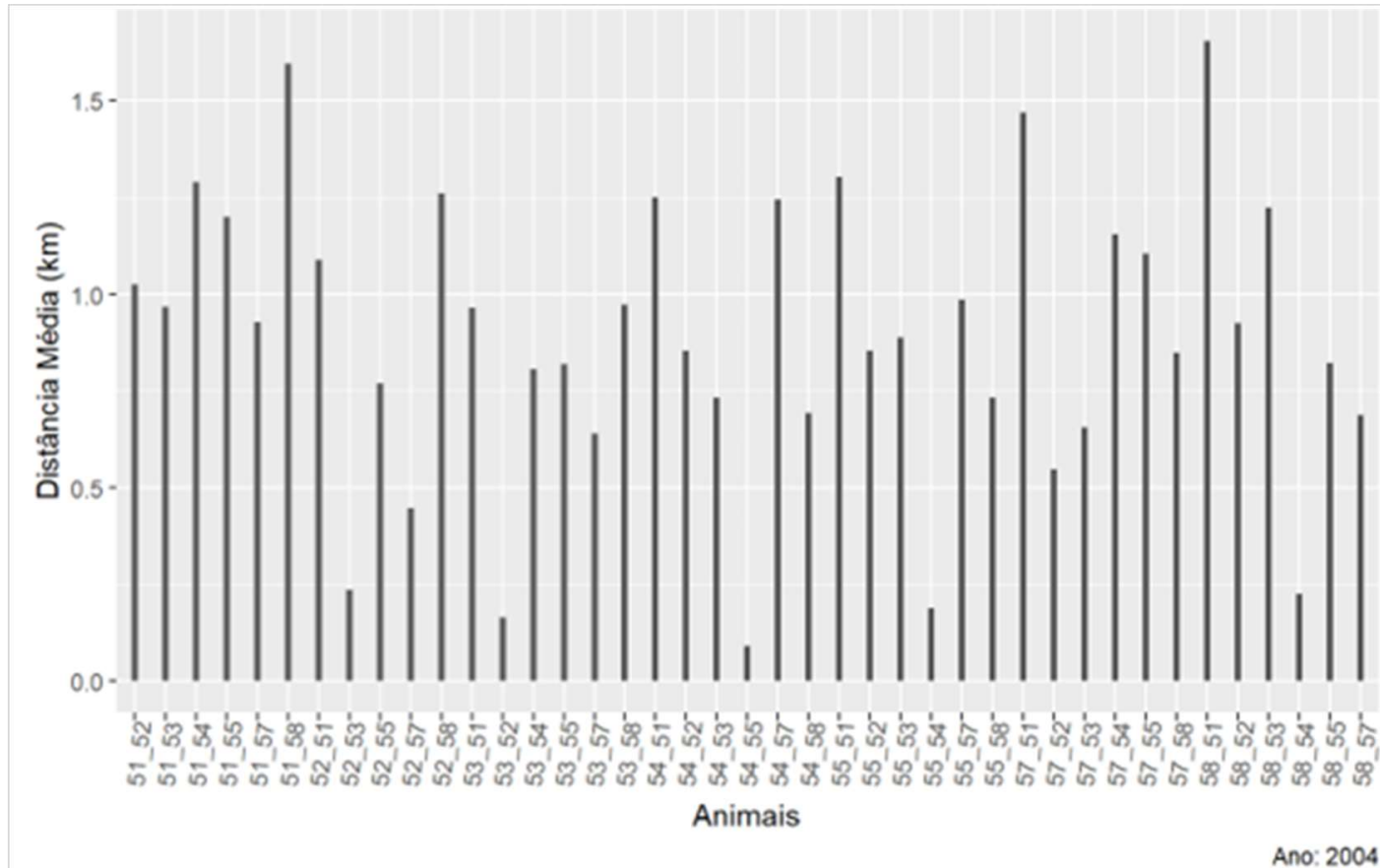

Figura 78 - Distância média entre os macacos em 2004

No gráfico, Figura 79, são mostradas as datas em que os macacos 54/55 apresentaram distância média menor ou igual à distância limite de 100 metros $(0.1 \mathrm{~km})$. 


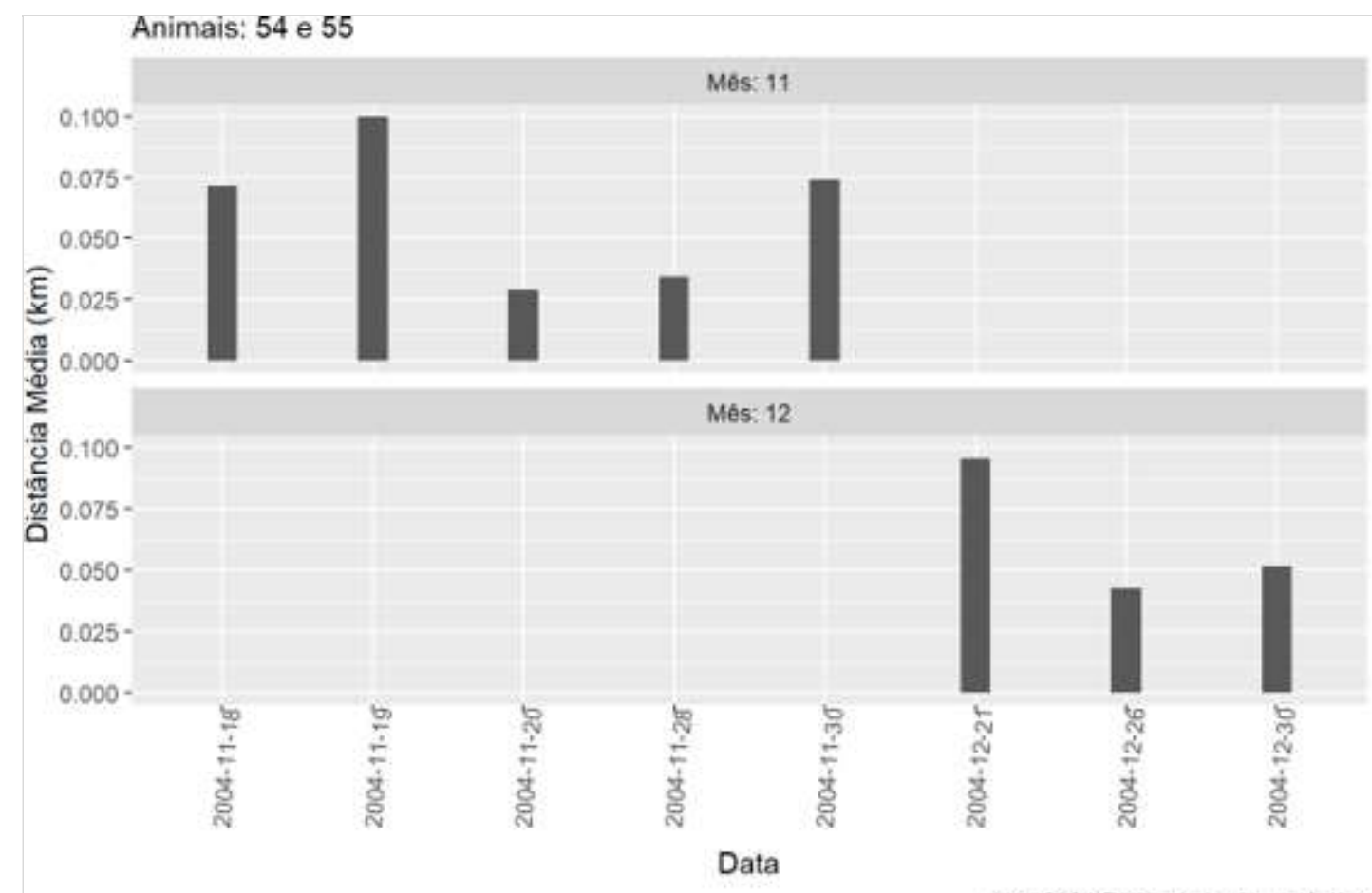

Ano: $2004 \mid$ Distancia Limite $<=0.1 \mathrm{~km}$

Figura 79 - Distância média entre os macacos 54 e 55 em novembro e dezembro de 2004

Com o estudo de caso verifica-se que o framework AniMoveMineR é o primeiro passo para se obter indicativos sobre o comportamento animal e sobre grupos de animais a partir da exploração dos dados de movimentação desses animais. Com o resultado da análise exploratória dos dados espaço-temporais da movimentação dos macacos (Cebus capucinus) com o framework AniMoveMineR, pode-se: classificar o comportamento dos macacos em estados; identificar a proximidade entre os macacos; identificar os grupos de macacos com base nos níveis de correlação, obtidos com as regras de associação; identificar a área de vida por macaco e por macaco e estado de comportamento ao longo do tempo (mês/ano). O framework permite, também, identificar a ausência de dados de rastreamento do movimento dos animais em determinados períodos. 


\section{CONSIDERAÇÕES FINAIS}

Os dados espaço-temporais que descrevem o movimento dos animais estão sendo amplamente coletados por diversos dispositivos, como sensores e sistemas de rastreamento por GPS. Estes dados melhoraram a capacidade de monitorar, estudar e gerenciar os movimentos dos animais, fornecendo informações que podem ser usadas para identificar os padrões de comportamento dos animais e para a obtenção de conhecimento sobre as interações entre os animais e o meio ambiente. O movimento e comportamento animal são largamente pesquisados, geralmente, com o foco em identificar padrões de comportamento, tais como, grupos de animais; identificar a distância entre os animais, segmentar as trajetórias para classificar o comportamento e identificar área de vida do animal. Entretanto, observa-se a ausência de pesquisas que propõem uma solução unificada que agregue recursos para analisar, estatísticamente, o comportamento individual do animal e, também, a interação entre os animais.

O desafio relacionado à análise do movimento animal, para entender a interação entre os animais e o ambiente, é justamente a correlação entre os animais e os diferentes fenômenos, como chuva, variação de temperatura e presença de outros animais. Esses desafios incluem determinar as trajetórias do animal, identificar e classificar o comportamento animal e a ocorrência de fenômenos ambientais ao longo dessas trajetórias.

Como contribuição para superar esses desafios, esta tese apresenta um framework que combina algoritmos de análise de trajetórias e mineração por regras de associação, que permite analisar as interações entre animais e os fatores ambientais ao longo do tempo e espaço, com base nos dados espaçotemporais referentes ao movimento animal e aos fatores ambientais.

Para atender aos objetivos propostos foram realizados estudos de técnicas de descoberta, classificação e análise do comportamento animal por meio das trajetórias dos animais. $\mathrm{Na}$ segmentação de trajetórias para a classificação do comportamento em estados foi utilizado o Método RST por contemplar em suas análises as características de tempo e espaço, sendo mais completo que os métodos BCPA e Lavielle que segmentam as trajetórias somente com o foco no tempo do movimento. $\mathrm{Na}$ análise da área de vida dos 
animais alguns recursos disponíveis, como as funções kernel e kerneloverlap, não consideram o tempo em suas análises. Desta forma, foram realizadas adaptações para usá-las em análises com foco no espaço, tempo e na variação dos estados de comportamento.

Foram estudados mecanismos para identificar os fatores ambientais vizinhos aos pontos de movimentação dos animais e, também, a técnica de mineração de dados por regras de associação e o coeficiente de Cramer para identificar a correlação entre os animais e os fatores ambientais. Para identificar animais vizinhos na literatura recomenda-se que considere-se que o animal se movimenta em uma superfície esférica, a Terra, sendo a Formula de Vincenty a mais adequada nesse contexto. $\mathrm{Na}$ análise da interação entre animais e fatores ambientais a mineração por regras de associação foi adotada por fornecer medidas estatísticas de correlação e dependência entre associações. Quanto maior a frequência de coocorrência dos animais, por exemplo, maior a probabilidade de pertencerem a um mesmo grupo. Na literatura a mineração por agrupamento é amplamente explorada, mas os algoritmos não fornecem medidas estatísticas sobre as interações e em alguns casos ( $k$-means) exige a definição de um número de grupos como parâmetro.

O framework foi elaborado com base nos passos do processo da Ciência dos Dados, considerando que o processo deve se iniciar pela formulação de questões a serem respondidas; o segundo passo, é a aquisição dos dados de fontes de origem, no terceiro passo, os dados devem ser preparados para a análise, sendo limpos e padronizados. No passo quatro têm-se a Análise dos dados, que é o foco principal do framework proposto, sendo dividido em três etapas: (A) identificar o comportamento individual do animal; (B) identificar os fatores ambientais vizinhos da ocorrência do animal; (C) identificar a correlação entre o animal e os fatores ambientais.

Para avaliar o framework foram realizados diversos experimentos dos quais foram selecionados dois estudos para serem detalhados nesta tese que utilizam dados de movimentação de animais das regiões do Pantanal - Brasil e Barro Colorado Island - Panamá. 


\subsection{Contribuições da tese e trabalhos futuros}

Para a Engenharia de Computação, a principal contribuição é o desenvolvimento do framework que combina algoritmos, de segmentação de trajetórias, de classificação de comportamento animal, de determinação de distância e de mineração de dados para permitir a análise do comportamento individual do animal e a correlação entre os animais e os fatores ambientais ao longo do tempo e espaço, com base em dados espaço-temporais de movimentação animal e fatores ambientais.

Para avaliar o framework foram realizados estudos de casos aplicados à área de biodiversidade, dos quais dois são detalhados na tese.

Desta forma, conclui-se que análise exploratória da movimentação animal por meio do AniMoveMineR é um primeiro passo para responder questões sobre o comportamento animal e sua interação com o meio ambiente por fornecer um conjunto de indicativos que permitem:

- Classificar o comportamento animal em estados, como descanso, forrageio e trânsito;

- Determinar a distância entre os animais e fatores ambientais;

- Identificar os grupos de animais correlacionados;

- Identificar a área de vida por animal ou por animal e estado de comportamento ao longo do tempo (mês/ano). Permite, também, acompanhar a evolução do uso do espaço pelo animal ao longo do tempo e, inclusive, qual estado de comportamento apresentado em determinado espaço e tempo;

- Identificar a ausência de dados sobre a movimentação dos animais em determinados períodos do ano;

- Identificar o nível de correlação entre os animais, com base no tempo (mês/ano) que permite uma análise mais detalhada sobre os momentos onde ocorre a interação entre os animais e os fatores ambientais.

Ao longo do desenvolvimento da tese alguns pontos não foram intensivamente explorados e podem ser sugeridos como trabalhos futuros. Destes pontos, destacam-se a necessidade de realizar testes com recursos computacionais mais avançados e com um maior volume de dados para propor melhorias de desempenho e de usabilidade do framework. 
Outros estudos de caso podem ser realizados com diferentes espécies de animais com a inclusão de informações biológicas sobre os animais analisados. Bem como, podem ser realizadas análises sobre a correlação entre animais e a incidência de doenças ao longo do tempo e espaço. Pode-se avaliar a aplicabilidade do framework em outros contextos e a inclusão de análises preditivas.

Todo o material resultante da pesquisa, tais como os algoritmos e artefatos resultantes dos estudos de caso estão disponíveis no repositório GitHub: https://github.com/suelanegarcia/AniMoveMiner. 


\section{REFERÊNCIAS}

ACOCK, A. C.; STAVIG, G. R. A Measure of Association for Nonparametric Statistics. Social Forces, [s.I.], v. 57, n 4, p. 1381-1386, 1979. ISSN: 00377732, DOI: $\underline{10.2307 / 2577276}$.

ALA. Atlas of Living Australia - sharing biodiversity knowledge. 2019.

Disponível em: <http://www.ala.org.au/>. Acesso em: 06 mar 2019.

ALVARES, L. O. et al. A Model for Enriching Trajectories with Semantic Geographical Information. In: Proceedings of the 15th Annual ACM International Symposium on Advances in Geographic Information Systems. New York, NY, USA: ACM, 2007. Disponível em: <http://doi.acm.org/10.1145/ 1341012.1341041>. Acesso em: 19/dez./19. ISBN: 978-1-59593-914-2, DOI: 10.1145/1341012.1341041.

ALVARES, L. O. et al. An algorithm to identify avoidance behavior in moving object trajectories. Journal of the Brazilian Computer Society, [s.I.], v. 17, n 3, p. 193-203, 2011. ISSN: 0104-6500, 1678-4804, DOI: 10.1007/s13173-011-0037-3.

AGRAWAL, R.; SRIKANT, R. Fast Algorithms for Mining Association Rules in Large Databases. In: Proceedings of the 20th International Conference on Very Large Data Bases. San Francisco, CA, USA: Morgan Kaufmann Publishers Inc., 1994. Disponível em: <http://dl.acm.org/citation.cfm?id= 645920.672836>. Acesso em: 21/set./16. ISBN: 978-1-55860-153-6.

AGRESTI, A. An Introduction to Categorical Data Analysis. 2nd Edition ed. New York, United States: John Wiley \& Sons Inc, 2007.

ALVAREZ, S. A. Chi-squared computation for association rules:

Preliminary results. [s.I.]: [s.n.], 2003.

ATLURI, G.; KARPATNE, A.; KUMAR, V. Spatio-Temporal Data Mining: A Survey of Problems and Methods. ACM Comput. Surv., [s.I.], v. 51, n 4, p. 83:1-83:41, 2018. ISSN: 0360-0300, DOI: 10.1145/3161602.

AUNG, H. H.; TAN, K.-L. Discovery of Evolving Convoys. GERTZ, M.; LUDÄSCHER, B. (Orgs.). In: Scientific and Statistical Database Management. Singapore: Springer Berlin Heidelberg, 2010. ISBN: 978-3-642-13818-8. 
AYDIN, B. et al. Spatiotemporal indexing techniques for efficiently mining spatiotemporal co-occurrence patterns. In: 2014 IEEE International Conference on Big Data (Big Data). [s.I.]: [s.n.], 2014. DOI: 10.1109/BigData .2014 .7004398 .

BARRAQUAND, F.; BENHAMOU, S. Animal movements in heterogeneous landscapes: identifying profitable places and homogeneous movement bouts. Ecology, [s.I.], v. 89, n 12, p. 3336-3348, 2008.

BERKHIN, P. A Survey of Clustering Data Mining Techniques. In: KOGAN, J.; NICHOLAS, C.; TEBOULLE, M. (Orgs.). Grouping Multidimensional Data. [s.I.]: Springer Berlin Heidelberg, 2006. p. 25-71. ISBN: 978-3-540-28348-5, DOI: $10.1007 / 3-540-28349-82$.

BISON. Biodiversity Information Serving Our Nation. Disponível em: https:// bison.usgs.gov>. Acesso em: 06 mar 2019.

BOGORNY, V. et al. Weka-STPM: A Software Architecture and Prototype for Semantic Trajectory Data Mining and Visualization. Transactions in GIS, [s.I.], v. 15, no 2, p. 227-248, 2011. ISSN: 1467-9671, DOI: 10.1111/j.14679671.2011.01246.x.

BOYCE, M. S. et al. Evaluating resource selection functions. Ecological Modelling, [s.I.], v. 157, n 2, p. 281-300, 2002. ISSN: 0304-3800, DOI: 10. 1016/S0304-3800(02)00200-4.

BRIN, S. et al. Dynamic Itemset Counting and Implication Rules for Market Basket Data. In: Proceedings of the 1997 ACM SIGMOD International Conference on Management of Data. New York, NY, USA: ACM, 1997. Disponível em: <http://doi.acm.org/10.1145/253260.253325>. Acesso em: 19/ago. /19. ISBN: 978-0-89791-911-1, DOI: 10.1145/253260.253325.

BRUMMELEN, G. V. Heavenly Mathematics: The Forgotten Art of Spherical Trigonometry. [s.I.]: Princeton University Press, 2013. 218 p. ISBN: 978-0-69114892-2.

BUCHIN, M. et al. Segmenting trajectories: A framework and algorithms using spatiotemporal criteria. Journal of Spatial Information Science, [s.I.], v. 2011, n 3, p. 33-63, 2011. ISSN: 1948-660X, DOI: 10.5311/JOSIS.2011.3.66. 
BUCHIN, K. et al. Detecting Movement Patterns Using Brownian Bridges. In: Proceedings of the 20th International Conference on Advances in Geographic Information Systems. New York, NY, USA: ACM, 2012. Disponível em: <http://doi.acm.org/10.1145/2424321.2424338>. Acesso em: 29/abr./16. ISBN: 978-1-4503-1691-0, DOI: 10.1145/2424321.2424338.

BULLARD, F. Estimating the Home Range of an Animal: A Brownian Bridge Approach. [s.I.]: University of North Carolina, 1991. 27 p.

BURT, W. H. Territoriality and Home Range Concepts as Applied to Mammals. Journal of Mammalogy, [s.I.], v. 24, no 3, p. 346-352, 1943. ISSN: 0022-2372, DOI: $10.2307 / 1374834$.

CAGNACCI, F. et al. Animal ecology meets GPS-based radiotelemetry: a perfect storm of opportunities and challenges. Philosophical Transactions of the Royal Society B: Biological Sciences, [s.I.], v. 365, n 1550, p. 2157-2162, 2010. DOI: $10.1098 /$ rstb.2010.0107.

CALENGE, C. The package "adehabitat" for the $\mathbf{R}$ software: A tool for the analysis of space and habitat use by animals. Ecological Modelling, [s.I.], v. 197, no 3, p. 516-519, 2006. ISSN: 0304-3800, DOI: 10.1016/j.ecolmodel. 2006.03.017.

CALENGE, C.; DRAY, S.; ROYER-CARENZI, M. The concept of animals' trajectories from a data analysis perspective. Ecological Informatics, [s.I.], v. 4, n 1, p. 34-41, 2009. ISSN: 1574-9541, DOI: 10.1016/j.ecoinf.2008.10.002.

CALENGE, C.; ROYER, Contributions from S. D. And M. adehabitatLT: Analysis of Animal Movements. France: [s.n.], 2015.

CAO, H.; MAMOULIS, N.; CHEUNG, D. W. Discovery of Collocation Episodes in Spatiotemporal Data. In: Sixth International Conference on Data Mining (ICDM'06). [s.I.]: [s.n.], 2006. DOI: 10.1109/ICDM.2006.59.

CASTRO, L. N. De; FERRARI, D. G. Introdução à Mineração de Dados: conceitos básicos, algoritmos e aplicações. São Paulo: Saraiva, 2016.

CAVALCANTI, S. M. C.; GESE, E. M. Spatial Ecology and Social Interactions of Jaguars (Panthera onca) in the Southern Pantanal, Brazil. Journal of Mammalogy, [s.I.], v. 90, no 4, p. 935-945, 2009. ISSN: 0022-2372, DOI: 10.1644/08-MAMM-A-188.1. 
CENAP. Centro Nacional de Pesquisa e Conservação de Mamíferos Carnívoros. Disponível em: <http://www.icmbio.gov.br/cenap>. Acesso em: 06 mar 2019.

COBB, J. Data Challenges in the DataONE Project. 2011. Symposium on Data-Driven Approaches to Droughts, 21 jun. 2011. Disponível em:

http://docs.lib.purdue.edu/ddad2011/18.

COLCHERO, F. et al. Jaguars on the move: modeling movement to mitigate fragmentation from road expansion in the Mayan Forest. Animal Conservation, [s.I.], v. 14, n² 2, p. 158-166, 2011. ISSN: 1469-1795, DOI: 10.1111/j.1469-1795.2010.00406.x.

CORREAA, P. L. P. et al. Evaluation of biodiversity data portals based on requirement analysis. Ecological Informatics, [s.I.], v. 48, p. 215-225, 2018. ISSN: 1574-9541, DOI: 10.1016/j.ecoinf.2018.09.008.

DAMIANI, M. L.; ISSA, H.; CAGNACCI, F. Extracting Stay Regions with Uncertain Boundaries from GPS Trajectories: A Case Study in Animal Ecology. In: Proceedings of the 22Nd ACM SIGSPATIAL International Conference on Advances in Geographic Information Systems. New York, NY, USA: ACM, 2014. Disponível em: <http://doi.acm.org/10.1145/2666310. 2666417>. Acesso em: 12/Jul./16. ISBN: 978-1-4503-3131-9, DOI: 10.1145/2666310.2666417.

DEMŠAR, $U$. et al. Analysis and visualization of movement: an interdisciplinary review. Movement Ecology, [s.I.], v. 3, no 1, p. 5, 2015. ISSN: 2051-3933, DOI: 10.1186/s40462-015-0032-y.

DEZA, M.; DEZA, E. Encyclopedia of distances. Dordrecht: New York: Springer Verlag, 2009. 590 p. ISBN: 978-3-642-00233-5.

DEKHTYAR, A. Lecture Notes on Data Science - DATA 301. California Polytechnic State University. 2016. Disponível em: http://users.csc.calpoly.edu 1 dekhtyar/DATA301-Spring2016/lectures/lec03.301.pdf

DODGE, S.; WEIBEL, R.; LAUTENSCHÜTZ, A.-K. Towards a taxonomy of movement patterns. Information visualization, [s.I.], v. 7, no 3-4, p. 240-252, 2008. ISSN: 1473-8716. 
DODGE, S.; WEIBEL, R.; LAUBE, P. Exploring Movement-similarity Analysis of Moving Objects. SIGSPATIAL Special, [s.l.], v. 1, n 3, p. 11-16, 2009. ISSN: 1946-7729, DOI: 10.1145/1645424.1645427.

DODGE, S. et al. The environmental-data automated track annotation (EnvDATA) system: linking animal tracks with environmental data. Movement Ecology, [s.I.], v. 1, p. 3, 2013. ISSN: 2051-3933, DOI: 10.1186/2051-3933-1-3.

EDELHOFF, H.; SIGNER, J.; BALKENHOL, N. Path segmentation for beginners: an overview of current methods for detecting changes in animal movement patterns. Movement Ecology, [s.l.], v. 4, no 1, p. 21, 2016. ISSN: 2051-3933, DOI: 10.1186/s40462-016-0086-5.

ESTER, M. et al. A Density-based Algorithm for Discovering Clusters a Density-based Algorithm for Discovering Clusters in Large Spatial Databases with Noise. In: Proceedings of the Second International Conference on Knowledge Discovery and Data Mining. [s.I.]: AAAI Press, 1996. Disponível em: <http://dl.acm.org/citation.cfm?id=3001460.3001507>. Acesso em: 18/dez./19.

FAYYAD, U.; PIATETSKY-SHAPIRO, G.; SMYTH, P. From Data Mining to Knowledge Discovery in Databases. Al Magazine, [s.I.], v. 17, no 3, p. 37, 1996a. ISSN: 0738-4602, DOI: 10.1609/aimag.v17i3.1230.

FAYYAD, U. M.; PIATETSKY-SHAPIRO, G.; SMYTH, P. Advances in Knowledge Discovery and Data Mining. In: FAYYAD, U. M. et al. (Orgs.). Menlo Park, CA, USA: American Association for Artificial Intelligence, 1996b. p. 1-34. ISBN: 978-0-262-56097-9.

FAGHMOUS, J. H.; KUMAR, V. Spatio-temporal Data Mining for Climate Data: Advances, Challenges, and Opportunities. In: $\mathrm{CHU}, \mathrm{W}$. W. (Org.). Data Mining and Knowledge Discovery for Big Data. [s.I.]: Springer Berlin Heidelberg, 2014. p. 83-116. ISBN: 978-3-642-40836-6. 
FAUCHALD, P.; TVERAA, T. Using First-Passage Time in the Analysis of Area-Restricted Search and Habitat Selection. Ecology, [s.I.], v. 84, n 2, p. 282-288, 2003. ISSN: 1939-9170, DOI: 10.1890/0012-9658(2003)084 [0282: UFPTIT12.0.CO;2.

FONTES, S. G.; STANZANI, S. L.; CORREA, P. L. P. A Data Mining Framework for Primary Biodiversity Data Analysis. In: ROCHA, A. et al. (Orgs.). New Contributions in Information Systems and Technologies. [s.I.]: Springer International Publishing, 2015. p. 813-821. ISBN: 978-3-319-16485-4.

GBIF. Global Biodiversity Information Facility. Disponível em:https://www. gbif.org. Acesso em: 06 mar 2019.

GIANNOTTI, F.; PEDRESCHI, D. Mobility, Data Mining and Privacy. Berlin, Heidelberg: Springer Berlin Heidelberg, 2008. ISBN: 978-3-540-75176-2.

GIANNOTTI, F. et al. Trajectory Pattern Mining. In: Proceedings of the 13th ACM SIGKDD International Conference on Knowledge Discovery and Data Mining. New York, NY, USA: ACM, 2007. Disponível em: <http://doi.acm.org/ 10.1145/1281192.1281230>. Acesso em: 23/mar./16. ISBN: 978-1-59593-6097, DOI: $10.1145 / 1281192.1281230$.

GOLDSCHMIDT, R.; PASSOS, E. Data mining: um guia Prático. [s.I.]: Gulf Professional Publishing, 2005. 288 p. ISBN: 978-85-352-1877-0.

GUÉGUEN, L. Segmentation by Maximal Predictive Partitioning According to Composition Biases. In: GASCUEL, O.; SAGOT, M.-F. (Orgs.).

Computational Biology. [s.I.]: Springer Berlin Heidelberg, 2001. p. 32-44. ISBN: 978-3-540-42242-6, DOI: 10.1007/3-540-45727-5 4.

GURARIE, E. et al. What is the animal doing? Tools for exploring behavioural structure in animal movements. Journal of Animal Ecology, [s.I.], v. 85, no 1, p. 69-84, 2016. ISSN: 1365-2656, DOI: $\underline{10.1111 / 1365-}$ 2656.12379.

GURARIE, E.; ANDREWS, R. D.; LAIDRE, K. L. A novel method for identifying behavioural changes in animal movement data. Ecology Letters, [s.I.], v. 12, no 5, p. 395-408, 2009. ISSN: 1461-0248, DOI: 10.1111/j.14610248.2009.01293.x. 
GÜTING, R. H.; VALDÉS, F.; DAMIANI, M. L. Symbolic Trajectories. ACM Trans. Spatial Algorithms Syst., [s.I.], v. 1, nº 2, p. 7:1-7:51, 2015. ISSN: 23740353, DOI: $\underline{10.1145 / 2786756 .}$.

HAI, P. N.; PONCELET, P.; TEISSEIRE, M. Get_Move: An Efficient and Unifying Spatio-temporal Pattern Mining Algorithm for Moving Objects. In: HOLLMÉN, J.; KLAWONN, F.; TUCKER, A. (Orgs.). Advances in Intelligent Data Analysis XI. [s.I.]: Springer Berlin Heidelberg, 2012. p. 276-288. ISBN: 978-3-642-34155-7, DOI: 10.1007/978-3-642-34156-4 26.

HAl, P. N. et al. Mining Time Relaxed Gradual Moving Object Clusters. In: Proceedings of the 20th International Conference on Advances in Geographic Information Systems. New York, NY, USA: ACM, 2012a. Disponível em: <http://doi.acm.org/10.1145/2424321.2424394>. Acesso em: 13/maio/16. ISBN: 978-1-4503-1691-0, DOI: 10.1145/2424321.2424394.

HAl, P. N. et al. Mining Fuzzy Moving Object Clusters. In: ZHOU, S.; ZHANG, S.; KARYPIS, G. (Orgs.). Advanced Data Mining and Applications. [s.I.]: Springer Berlin Heidelberg, 2012b. p. 100-114. ISBN: 978-3-642-35526-4, DOI: $\underline{10.1007 / 978-3-642-35527-19}$.

HAHSLER, M.; GRUEN, B.; HORNIK, K. Arules - A Computational Environment for Mining Association Rules and Frequent Item Sets. Journal of Statistical Software, [s.I.], v. 14, no 15, p. 1-25, 2005. ISSN: 1548-7660.

HEY, T.; TANSLEY, S.; TOLLE, K. The Fourth Paradigm Data-Intensive Scientific Discovery. REDMOND, WASHINGTON: MICROSOFT RESEARCH, 2009. ISBN: 978-0-9825442-0-4.

HIJMANS, R. J.; WILLIAMS, E.; VENNES, C. geosphere: Spherical Trigonometry. [s.l.]: [s.n.], 2016.

HOFFMANN, R.; VIEIRA, S. Análise de regressão, uma introdução à econometria. São Paulo: Hucitec, 1998.

HORNE, J. S. et al. Analyzing Animal Movements Using Brownian Bridges. Ecology, [s.I.], v. 88, no 9, p. 2354-2363, 2007. ISSN: 1939-9170, DOI: 10.1890/06-0957.1.

ICMBIO. Instituto Chico Mendes de Conservação da Biodiversidade.

Disponível em:<http://www. icmbio.gov.br/portal>. Acesso em: 06 mar 2019. 
ICMBIO. Plano de Manejo da Estação Ecológica de Taiamã. Disponível em: <http://www.icmbio.gov.br/portal/images/stories/plano-de-manejo/plano_de_ manejo_esec_taiama_vs_070617.pdf>. 2017.Acesso em: 28 set. 2018. INPE. Instituto Nacional de Pesquisas Espaciais. Disponível em:<http:// www.inpe.br>. Acesso em: 06 mar 2019.

JACOB, G. M.; IDICULA, S. M. Detection of flock movement in spatiotemporal database using clustering techniques - An experience. In: 2012 International Conference on Data Science Engineering (ICDSE). [s.I.]: [s.n.], 2012. DOI: 10.1109/ICDSE.2012.6282312.

JAISWAL, V.; AGARWAL, J. The Evolution of the Association Rules. International Journal of Modeling and Optimization, [s.I.], p. 726-729, 2012. ISSN: 20103697, DOI: 10.7763/IJMO.2012.V2.220.

JEUNG, $\mathrm{H}$. et al. Discovery of Convoys in Trajectory Databases. Proc. VLDB Endow., [s.I.], v. 1, no 1, p. 1068-1080, 2008. ISSN: 2150-8097, DOI: 10.14778/1453856.1453971.

KALNIS, P.; MAMOULIS, N.; BAKIRAS, S. On Discovering Moving Clusters in Spatio-temporal Data. In: Proceedings of the 9th International Conference on Advances in Spatial and Temporal Databases. Berlin, Heidelberg: SpringerVerlag, 2005. Disponível em: <http://dx.doi.org/10.1007/11535331 21>. Acesso em: 17/out./15. ISBN: 978-3-540-28127-6, DOI: 10.1007/11535331 21.

KALVANI, D.; CHATURVEDI, S. K. A Survey on Spatio-Temporal Data Mining. International Journal of Computer Science and Network (IJCSN), India, 2012.

KANDA, C. Z. [UNESP. Ecologia do movimento e dinâmica espaçotemporal da onça-pintada (Panthera onca) no Pantanal sul do Brasil. Aleph, [s.l.], p. 44 f.: il., tabs., 2015.

KAUFMAN, L.; ROUSSEEUW, P. J. Finding Groups in Data: An Introduction to Cluster Analysis. Edição: 1 ed. Hoboken, N.J: Wiley-Interscience, 2005. 342 p. ISBN: 978-0-471-73578-6.

KELLING, S. et al. Data-intensive Science: A New Paradigm for Biodiversity Studies. BioScience, [s.I.], v. 59, n 7, p. 613-620, 2009. ISSN: 0006-3568, 1525-3244, DOI: 10.1525/bio.2009.59.7.12. 
KERNOHAN, B. J.; GITZEN, R. A.; MILLSPAUGH, J. J. Chapter 5 - Analysis of Animal Space Use and Movements. In: MILLSPAUGH, J. J.; MARZLUFF, J. M. (Orgs.). Radio Tracking and Animal Populations. San Diego: Academic Press, 2001. p. 125-166. ISBN: 978-0-12-497781-5, DOI: 10.1016/B978012497781-5/50006-2.

KIHLSTRÖM, P. Literature Study and Assessment of Trajectory Data Mining Tools. [s.I.]: [s.n.], 2015.

KOMSTA, L., 2011. outliers: Tests for outliers. $R$ package version $0.14 ., R$ package version 0.14 . <http:// CRAN.R- project.org/package = outliers. 2011>.

KRANSTAUBER, B. et al. A dynamic Brownian bridge movement model to estimate utilization distributions for heterogeneous animal movement. The Journal of Animal Ecology, [s.I.], v. 81, no 4, p. 738-746, 2012. ISSN: 13652656, DOI: $10.1111 /$ /.1365-2656.2012.01955.x.

LAVIELLE, M. Using Penalized Contrasts for the Change-point Problem. Signal Process., [s.I.], v. 85, no 8, p. 1501-1510, 2005. ISSN: 0165-1684, DOI: 10.1016/j.sigpro.2005.01.012

LAUBE, P.; IMFELD, S. Analyzing Relative Motion within Groups of Trackable Moving Point Objects. In: EGENHOFER, M. J.; MARK, D. M. (Orgs.). Geographic Information Science. [s.l.]: Springer Berlin Heidelberg, 2002. p. 132-144. ISBN: 978-3-540-44253-0, DOI: 10.1007/3-540-45799-2 10.

LAUBE, P.; IMFELD, S.; WEIBEL, R. Discovering relative motion patterns in groups of moving point objects. International Journal of Geographical Information Science, [s.I.], v. 19, nº 6, p. 639-668, 2005. ISSN: 1365-8816.

LI, Z. et al. Swarm: Mining Relaxed Temporal Moving Object Clusters. Proc. VLDB Endow., [s.I.], v. 3, no 1-2, p. 723-734, 2010a. ISSN: 2150-8097, DOI: 10.14778/1920841.1920934.

LI, Z. et al. Mining Periodic Behaviors for Moving Objects. In: Proceedings of the 16th ACM SIGKDD International Conference on Knowledge Discovery and Data Mining. New York, NY, USA: ACM, 2010b. Disponível em: <http://doi. acm.org/10.1145/1835804.1835942>. Acesso em: 13/jun./16. ISBN: 978-14503-0055-1, DOI: $10.1145 / 1835804.1835942$. 
$\mathrm{LI}$, Z. et al. Attraction and Avoidance Detection from Movements. Proc. VLDB Endow., [s.I.], v. 7, no 3, p. 157-168, 2013. ISSN: 2150-8097, DOI: 10.14778/2732232.2732235.

MACQUEEN, J. Some methods for classification and analysis of multivariate observations. In: In 5-th Berkeley Symposium on Mathematical Statistics and Probability. [s.I.]: [s.n.], 1967.

MANIMARAN, J.; VELMURUGAN, T. Analyzing the Quality of Association Rules by Computing an Interestingness Measures. Indian Journal of Science and Technology, [s.I.], v. 8, n 15, 2015. ISSN: 0974 -5645, DOI: 10.17485/ijst/2015/v8i15/76693.

MANLY, B. F. et al. Resource Selection by Animals: Statistical Design and Analysis for Field Studies. 2 ed. [s.I.]: Springer Netherlands, 2002. ISBN: 9781-4020-0677-7.

MAX PLANCK. Instituto Max Planck de Ornitologia. Disponível em: $<$ https:// www.orn.mpg.de/en>. Acesso em: 06 mar 2019.

MICHENER, W. K.; JONES, M. B. Ecoinformatics: supporting ecology as a data-intensive science. Trends in Ecology \& Evolution, [s.I.], v. 27, no 2, p. 8593, 2012. ISSN: 0169-5347, DOI: 10.1016/j.tree.2011.11.016.

MILLER, H. J.; HAN, J. Geographic Data Mining and Knowledge Discovery. [s.I.]: CRC Press, 2009. 488 p. ISBN: 978-1-4200-7398-0.

MITTAL, M.; PAREEK, S.; AGARWAL, R. Efficient Ordering Policy for Imperfect Quality Items Using Association Rule Mining. Encyclopedia of Information Science and Technology, Third Edition, [s.I.], p. 773-786, 2015.

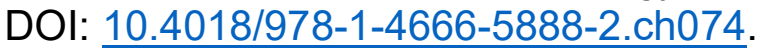

MOORTER, B. V. et al. Identifying Movement States From Location Data Using Cluster Analysis. Journal of Wildlife Management, [s.I.], v. 74, $n^{\circ} 3, p$. 588-594, 2010. ISSN: 0022-541X, 1937-2817, DOI: 10.2193/2009-155.

MORATO, R. G. et al. Jaguar movement database: a GPS-based movement dataset of an apex predator in the Neotropics. Ecology, [s.I.], v. 99, n 7, p. 1691-1691, 2018. ISSN: 1939-9170, DOI: 10.1002/ecy.2379. 
MUKAKA, M. A guide to appropriate use of Correlation coefficient in medical research. Malawi Medical Journal: The Journal of Medical Association of Malawi, [s.I.], v. 24, nº 3, p. 69-71, 2012. ISSN: 1995-7262.

MYSQL. MySQL: MySQL Workbench. [S.I], 2014. Disponível em: $<$ https:// www.mysql.com/products/workbench/>. Acesso em: 13 mar. 2019.

NARAYAN, S.; RAMAKRISHNAN, K. R. A Cause and Effect Analysis of Motion Trajectories for Modeling Actions. In: 2014 IEEE Conference on Computer Vision and Pattern Recognition. [s.I.]: [s.n.], 2014. DOI: 10.1109/CVPR.2014.337.

OLIVEIRA, M. T. P. Análise comportamental de bovinos baseada em trajetórias semânticas aplicada à pecuária de precisão. 2013. Dissertação. Disponível em: <http://repositorio.cbc.ufms.br: 8080/xmlui/handle/123456789/ 1894>. Acesso em: 9 de maio. 2016.

PALMA, A. T. et al. A Clustering-based Approach for Discovering Interesting Places in Trajectories. In: Proceedings of the 2008 ACM Symposium on Applied Computing. New York, NY, USA: ACM, 2008. Disponível em: <http://doi.acm.org/10.1145/1363686.1363886>. Acesso em: 01/jul./19. ISBN: 978-1-59593-753-7, DOI: 10.1145/1363686.1363886.

PATEL, V. et al. Big data analytics of genomic and clinical data for Diagnosis and Prognosis of Cancer. In: 2015 2nd International Conference on Computing for Sustainable Global Development (INDIACom). [s.I.]: [s.n.], 2015.

PHAN, N. Mining Object Movement Patterns from Trajectory Data. [S.I]: Université Monpellier 2, 2013. PhD thesis. Disponível em: <https://hal-lirmm. ccsd.cnrs.fr/tel-01379206/document>. Acesso em: 5 fev. 2018.

PLACKETT, R. L. Karl Pearson and the Chi-Squared Test. International Statistical Review / Revue Internationale de Statistique, [s.I.], v. 51, nº 1, p. 5972, 1983. ISSN: 0306-7734, DOI: $10.2307 / 1402731$.

PILLAI, K. G. et al. Spatio-temporal Co-occurrence Pattern Mining in Data Sets with Evolving Regions. In: 2012 IEEE 12th International Conference on Data Mining Workshops (ICDMW). [s.I.]: [s.n.], 2012. DOI: 10.1109/ICDMW.2012.130. 
PORTALBIO. Portal da Biodiversidade. Disponível em: https://portalda biodiversidade.icmbio.gov.br. Acesso em: 06 mar 2019.

QUINLAN, J. R. C4.5 Programs for Machine Learning. San Mateo, CA: Morgan Kaufmann., 1992.

RAO, K. V.; GOVARDHAN, A.; RAO, K. V. C. R. Spatiotemporal Data Mining: Issues, Tasks and Applications. International Journal of Computer Science \& Enginee ring Survey, 2012. International Journal of Computer Science \& Enginee ring Survey. v. 3, n. 1.

RAPIDMINER. RapidMiner - \#1 Open Source Predictive Analytics Platform. RapidMiner. 2015. Disponível em: <https://rapidminer.com/>. Acesso em: 29/out./15.

RASHEED, Z. Data Mining Framework for Metagenome Analysis. 2013. Disponível em: <http://mars.gmu.edu/handle/1920/8285>. Acesso em: 10 ago. 2016.

REICHMAN, O. J.; JONES, M. B.; SCHILDHAUER, M. P. Challenges and Opportunities of Open Data in Ecology. Science, [s.I.], v. 331, no 6018, p. 703-705, 2011. ISSN: 0036-8075, 1095-9203, DOI: 10.1126/science.1197962.

RSTUDIO. Rstudio. 27 mar. 2014. Disponível em: <https://www. rstudio.com/>. Acesso em: 13 mar. 2019.

SHAUKAT, K.; ZAHEER, S.; NAWAZ, I. Association Rule Mining: An Application Perspective. International Journal of Computer Science and Innovation, 2015. n. 1, p. 29-38.

SARKAR, D. et al. Analyzing Animal Movement Characteristics from Location Data: Analyzing Animal Movement. Transactions in GIS, [s.I.], v. 19, no 4, p. 516-534, 2015. ISSN: 13611682, DOI: 10.1111/tgis.12114.

SATSCAN. SatScan - Software for the spatial, temporal, and space-time scan statistics. [S.I.], 2015. Disponível em: <https://www.satscan.org/>. Acesso em: 13 mar. 2019.

SCOTT, G. Essential Animal Behavior. [s.I.]: John Wiley \& Sons, 2009. 215 p. ISBN: 978-1-4051-4451-3. 
SHEKHAR, S. et al. Spatiotemporal Data Mining: A Computational Perspective. ISPRS International Journal of Geo-Information, [s.I.], v. 4, n 4 , p. 2306-2338, 2015. DOI: 10.3390/ijgi4042306.

SHETTY, Sujala. D.; VADIVEL, S.; VAGHELLA, S. Weka Based Desktop Data Mining as Web Service. World Academy of Science, Engineering and Technology International Journal of Computer and Information Engineering, [s.I.], 2010.

SHIRABE, T. Correlation Analysis of Discrete Motions. In: RAUBAL, M. et al. (Orgs.). Geographic Information Science. [s.l.]: Springer Berlin Heidelberg, 2006. p. 370-382. ISBN: 978-3-540-44526-5, DOI: 10.1007/11863939 24.

SIPPEL, T. et al. Investigating Behaviour and Population Dynamics of Striped Marlin (Kajikia audax) from the Southwest Pacific Ocean with Satellite Tags. PLOS ONE, [s.I.], v. 6, n 6, p. e21087, 2011. ISSN: 1932-6203, DOI: $\underline{10.1371 / \text { journal.pone.0021087. }}$.

SNOWDON, C. T. O significado da pesquisa em Comportamento Animal. Estudos de Psicologia (Natal), [s.I.], v. 4, n ${ }^{\circ}$ 2, p. 365-373, 1999. ISSN: 1413294X, DOI: 10.1590/S1413-294X1999000200011.

SPACCAPIETRA, S. et al. A Conceptual View on Trajectories. Data Knowl. Eng., [s.I.], v. 65, no 1, p. 126-146, 2008. ISSN: 0169-023X, DOI: 10.1016/j. datak.2007.10.008.

STRI. Smithsonian Tropical Research Institute. Physical Monitoring Program, [S.I], 2019. Disponível em: <https://biogeodb.stri.si.edu/ physical monitoring/ research/barrocolorado>. Acesso em: 13 mar. 2019.

TABLEAU. A Tableau simplifica a sua análise de negócios | Tableau Software. [S.I.], 2017. Disponível em: <https://www.tableau.com/>. Acesso em: 13 mar. 2019.

TAYLOR, R. Interpretation of the Correlation Coefficient: A Basic Review. Journal of Diagnostic Medical Sonography, [s.I.], v. 6, p. 35-39, 2016. DOI: 10.1177/875647939000600106.

TANG, L.-A. et al. A Framework of Traveling Companion Discovery on Trajectory Data Streams. ACM Trans. Intell. Syst. Technol., [s.I.], v. 5, no 1, p. 3:1-3:34, 2014. ISSN: 2157-6904, DOI: 10.1145/2542182.2542185. 
TANG, $\mathrm{X}$. et al. A flight profile clustering method combining twed with Kmeans algorithm for 4D trajectory prediction. In: 2015 Integrated Communication, Navigation and Surveillance Conference (ICNS). [s.I.]: [s.n.], 2015. DOI: 10.1109/ICNSURV.2015.7121260.

TEIMOURI, M. et al. Deriving Animal Movement Behaviors Using Movement Parameters Extracted from Location Data. ISPRS International Journal of Geo-Information, [s.I.], v. 7, n 2, p. 78, 2018. DOI: 10.3390/ijgi7020078.

TORRES, L. G. et al. Classification of Animal Movement Behavior through Residence in Space and Time. PLOS ONE, [s.I.], v. 12, n० 1, p. e0168513, 2017. ISSN: 1932-6203, DOI: 10.1371/journal.pone.0168513.

THURFJELL, H.; CIUTI, S.; BOYCE, M. S. Applications of step-selection functions in ecology and conservation. Movement Ecology, [s.I.], v. 2, p. 4, 2014. ISSN: 2051-3933, DOI: 10.1186/2051-3933-2-4.

VAKA TR, GOVINDARAJULU P. A Survey on Trajectory Data Mining. International Journal of Computer Science and Security (IJCSS) [Internet]. 2016. Disponível em: http://www.cscjournals.org/ library/ manuscriptinfo. php?mc=|JCSS-1297

VINCENTY, T. Direct and inverse solutions of geodesics on the ellipsoid with application of nested equations. Survey Review, [s.I.], v. 23, no 176, p. 88-93, 1975. ISSN: 0039-6265, DOI: 10.1179/sre.1975.23.176.88.

ZHANG, J. et al. Extending the Functionality of Behavioural Change-Point Analysis with k-Means Clustering: A Case Study with the Little Penguin (Eudyptula minor). PLoS ONE, [s.I.], v. 10, n 4, 2015. ISSN: 1932-6203, DOI: 10.1371/journal.pone.0122811.

ZHENG, Y. et al. On Discovery of Gathering Patterns from Trajectories. In: Proceedings of the 2013 IEEE International Conference on Data Engineering (ICDE 2013). Washington, DC, USA: IEEE Computer Society, 2013. Disponível em: <http://dx.doi.org/10.1109/ICDE.2013.6544829>. Acesso em: 28/mar. /16. ISBN: 978-1-4673-4909-3, DOI: 10.1109/ICDE.2013.6544829.

ZHENG, Y. Trajectory Data Mining: An Overview. ACM Trans. Intell. Syst. Technol., [s.I.], v. 6, n 3, p. 29:1-29:41, 2015. ISSN: 2157-6904, DOI: 10.1145/2743025. 
WAGNER, R. et al. Mob-Warehouse: A Semantic Approach for Mobility Analysis with a Trajectory Data Warehouse. In: PARSONS, J.; CHIU, D. (Orgs.). Advances in Conceptual Modeling. [s.I.]: Springer International Publishing, 2013. p. 127-136. ISBN: 978-3-319-14138-1, DOI: 10.1007/978-3319-14139-8 15.

WANG, Y. et al. Mining Common Spatial-Temporal Periodic Patterns of Animal Movement. In: Proceedings of the 2013 IEEE 9th International Conference on e-Science. Washington, DC, USA: IEEE Computer Society, 2013. Disponível em: <http://dx.doi.org/10.1109/eScience.2013.11>. Acesso em: 26/jun./19. ISBN: 978-0-7695-5083-1, DOI: 10.1109/eScience.2013.11.

WIKELSKI, M., KAYS R., Movebank: archive, analysis and sharing of animal movement data. Hosted by the Max Planck Institute for Ornithology. Disponível em: www.movebank.org. Acesso em: 10/01/2016 (2016).

WINKLE, W. V. Comparison of Several Probabilistic Home-Range Models. The Journal of Wildlife Management, [s.I.], v. 39, $\mathrm{n}^{\circ}$ 1, p. 118-123, 1975. ISSN: 0022-541X, DOI: 10.2307/3800474.

WITTEN, I. H.; FRANK, E. Data Mining: Practical Machine Learning Tools and Techniques, Second Edition (Morgan Kaufmann Series in Data Management Systems). San Francisco, CA, USA: Morgan Kaufmann Publishers Inc., 2005. ISBN: 978-0-12-088407-0.

WORLDCLIM. WorldClim - Global Climate Data | Free climate data for ecological modeling and GIS. [s.d.]. Disponível em: <http://www.worldclim. org./>. Acesso em: 03/jun./19.

WORTON, B. J. Kernel Methods for Estimating the Utilization Distribution in Home-Range Studies. Ecology, [s.I.], v. 70, no 1, p. 164-168, 1989. ISSN: 1939-9170, DOI: 10.2307/1938423.

WU, F. et al. MoveMine 2.0: Mining Object Relationships from Movement Data. Proc. VLDB Endow., [s.I.], v. 7, no 13, p. 1613-1616, 2014. ISSN: 21508097, DOI: $10.14778 / 2733004.2733043$.

WU, H.; YEH, M.; CHEN, M. Profiling Moving Objects by Dividing and Clustering Trajectories Spatiotemporally. IEEE Transactions on Knowledge and Data Engineering, [s.I.], v. 25, no 11, p. 2615-2628, 2013. ISSN: 10414347, DOI: 10.1109/TKDE.2012.249. 


\section{APÊNDICE A - Pseudocódigos - AniMoveMineR}

\section{A1. Pseudocódigo da etapa A1 - Identificar o Comportamento Animal}

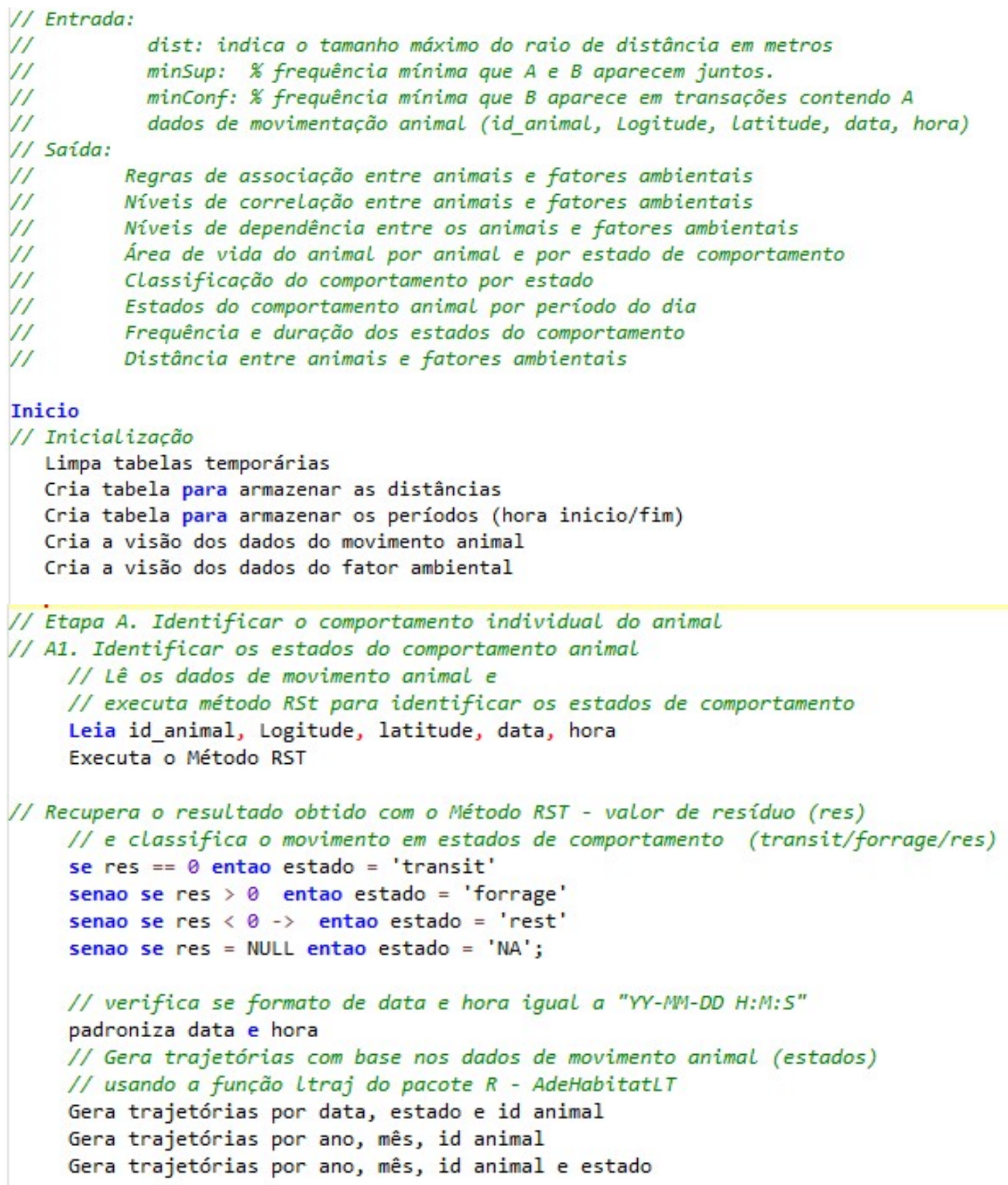




\section{A2. Pseudocódigo da etapa A2 - Identificar os períodos e duração da ocorrência dos estados por animal e dia}

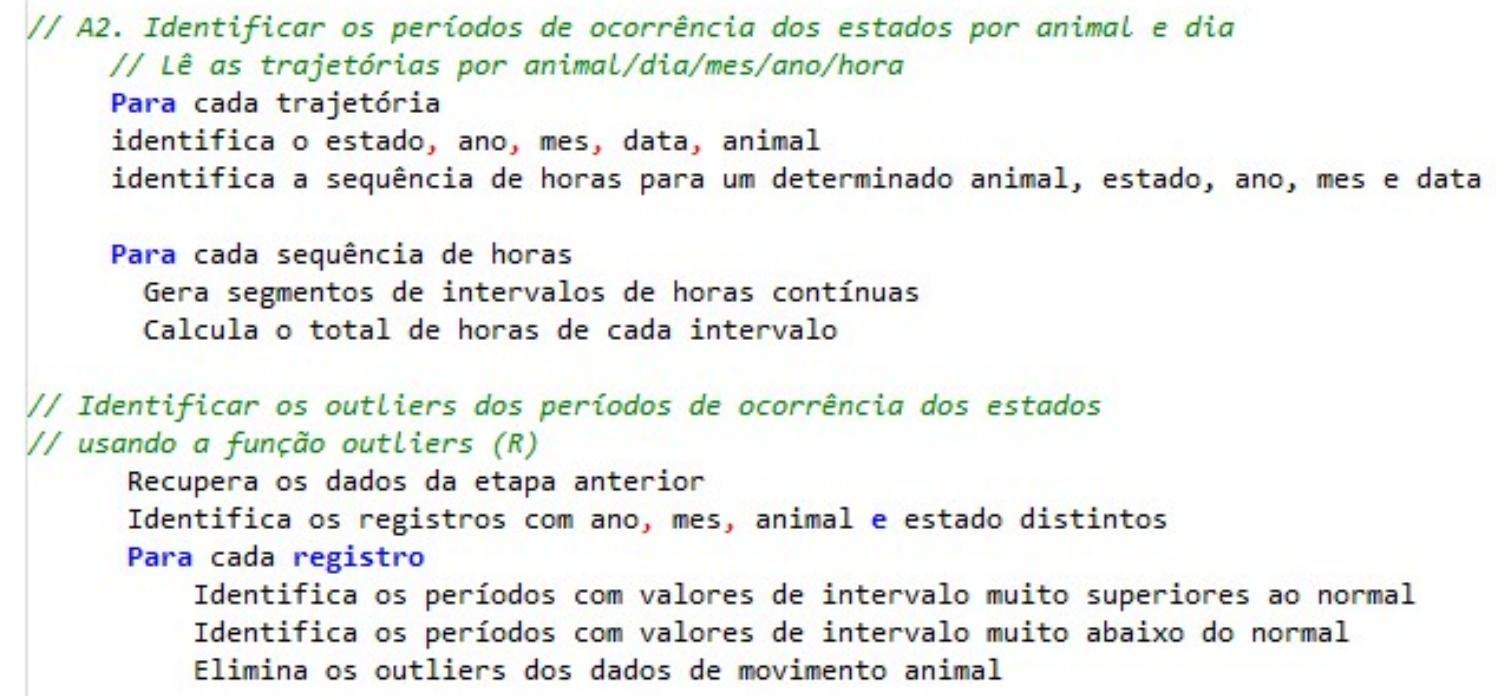

\section{A3. Pseudocódigo da etapa A3 - Identificar a frequência de ocorrência do estado de comportamento por período}

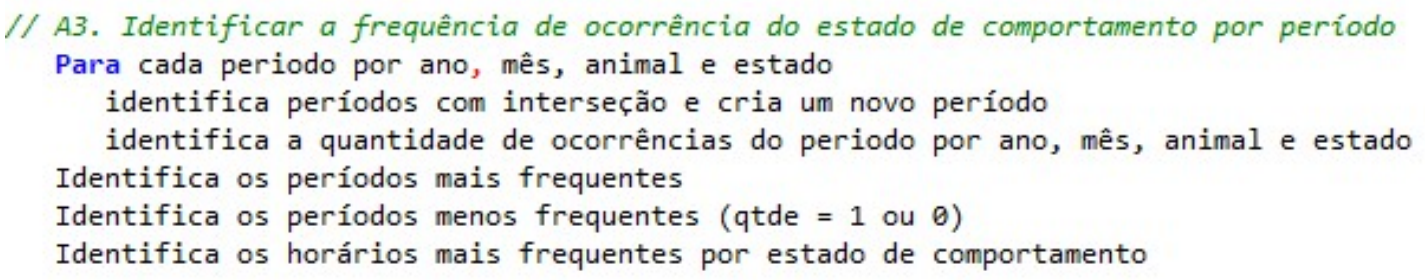

\section{A4. Pseudocódigo da etapa A4 - Identificar o home range animal}

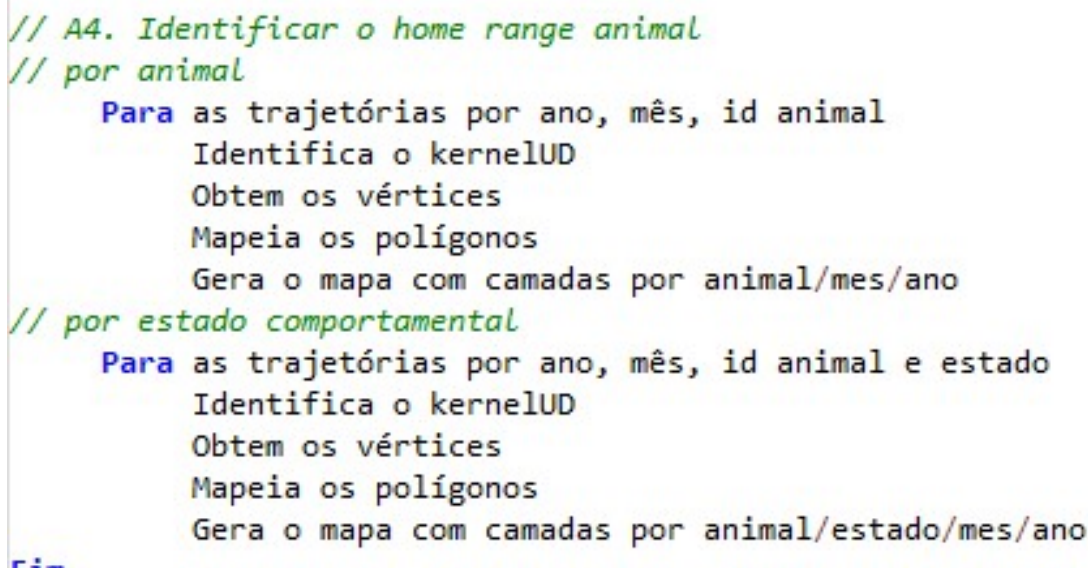




\section{A5. Pseudocódigo da etapa B1 e B2 - Identificar os fatores ambientais da}

\section{vizinhança}

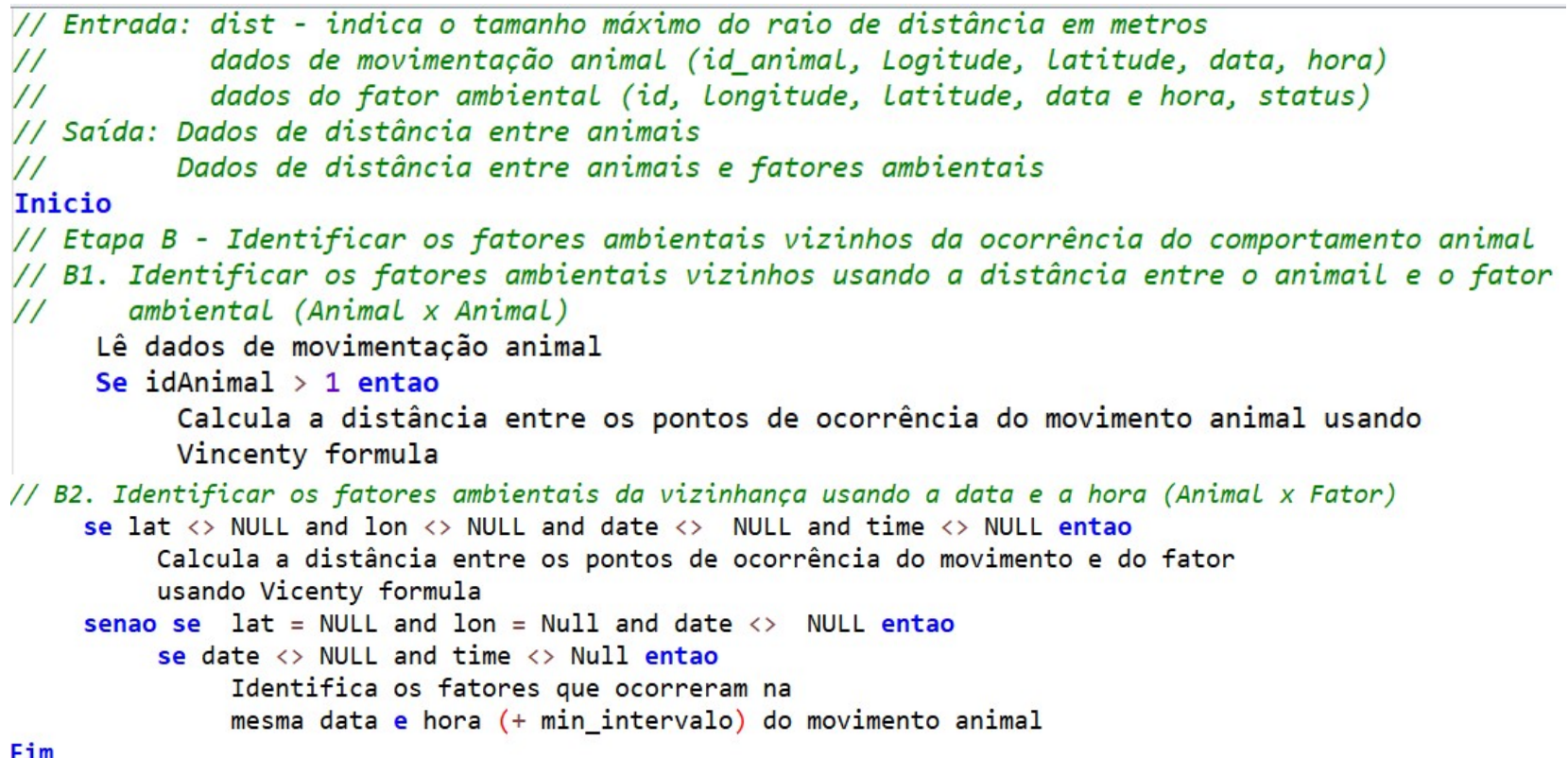

\section{A6. Pseudocódigo da etapa C1 e C2 - Identificar a correlação entre o animal e os fatores ambientais}

// Etapa C - Identificar a correlação entre o comportamento animal e os fatores ambientais vizinhos

// C1. Identifica a correlação entre animais vizinhos

Lê Dados de distância entre animais com distância menor que dist

Executa a mineração por regras de associação usando algoritmo Apriori

Apresenta o resultado da análise de dependência e correlação entre os animais

Executa análise da correlação com Cramer

// C2. Identifica a correlação entre estados de comportamento e fatores ambientais

Lê Dados de distância entre animais e fatores ambientais com distância menor que dist

Executa a mineração por regras de associação usando algoritmo Apriori

Apresenta o resultado da análise de dependência e correlação entre os animais e

os fatores ambientais

Executa análise da correlação com Cramer 


\section{APÊNDICE B - ALGORITMO APRIORI}

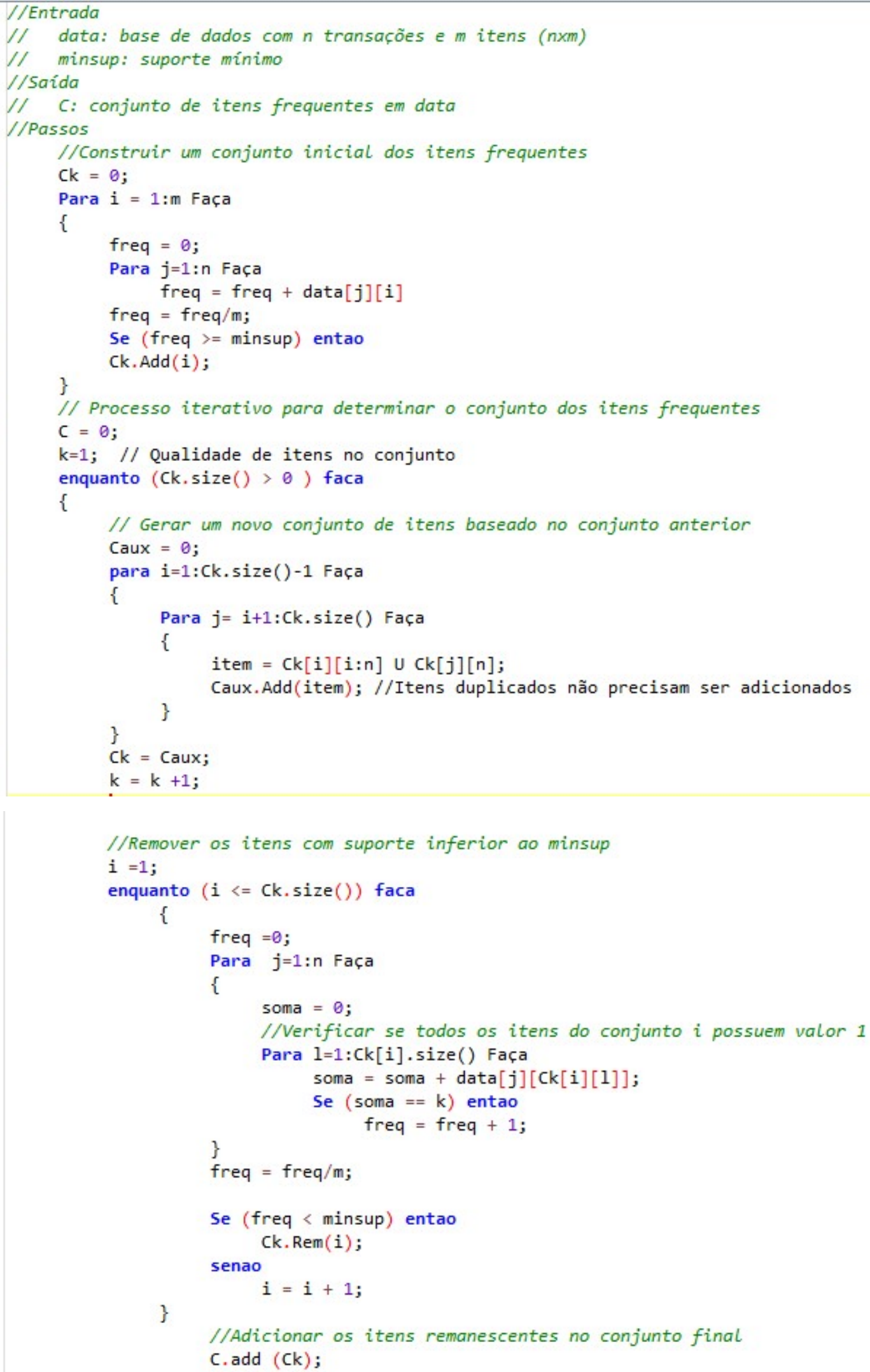




\section{APÊNDICE C - ARQUITETURA DO FRAMEWORK ANIMOVEMINER}

Neste apêndice é apresentada a arquitetura do algoritmo AniMoveMineR detalhando como foram organizados os recursos, tais como, ferramentas, técnicas e rotinas que compõem esse framework. Bem como, a finalidade de cada recurso e com ênfase nos recursos desenvolvidos, total ou parcialmente, pela autora mostrados em amarelo.

A Figura 80 ilustra a relação entre os componentes da etapa A que identifica o comportamento individual do animal e está dividida em quatro atividades.

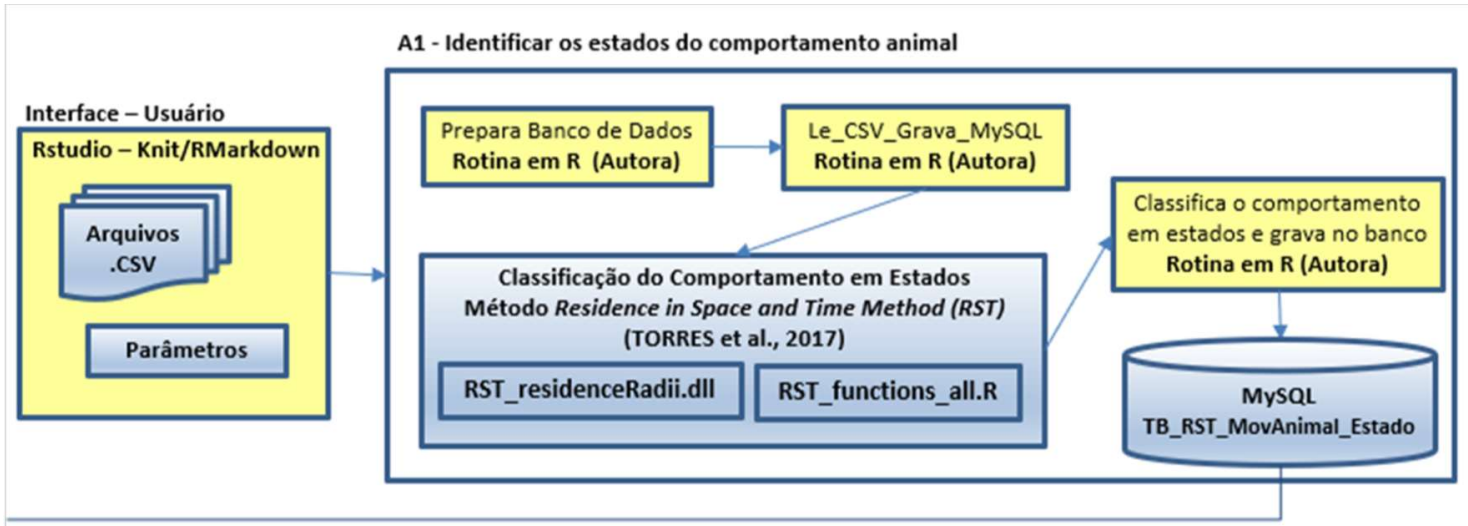

A2 - Identificar os períodos e a duração da ocorrência dos estados por animal e dia

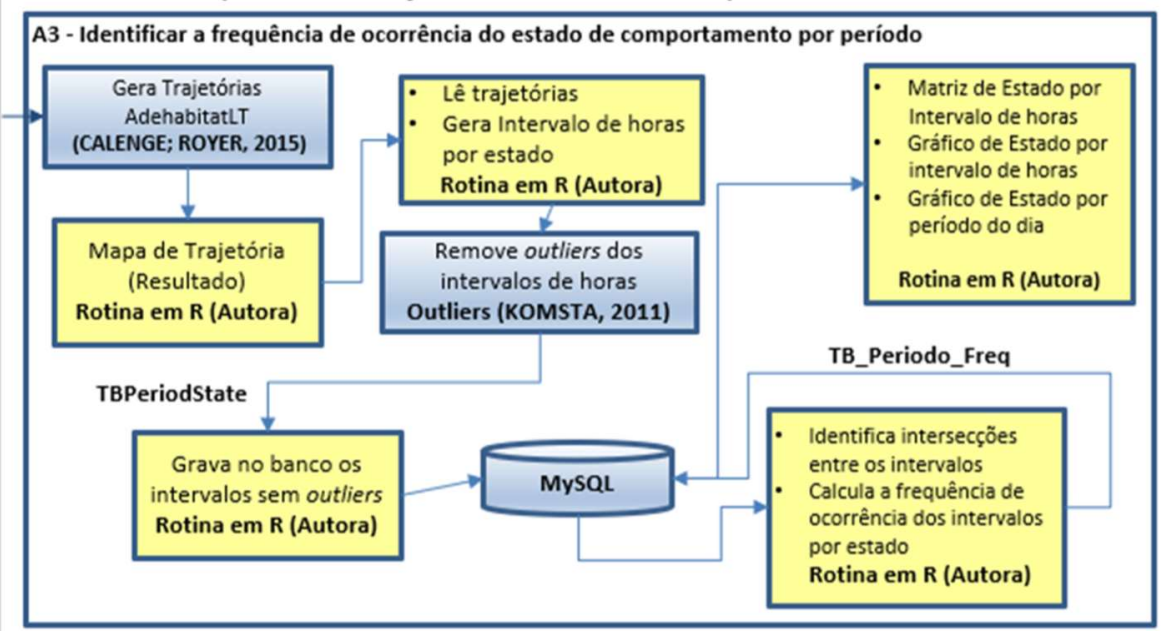

A4 - Identificar a área de vida do animal

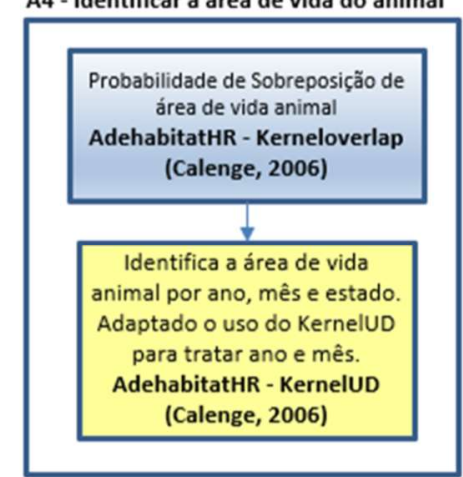

Figura 80 - Arquitetura de Componentes do algoritmo AniMoveMineR - Etapa A

A Figura 81 ilustra a relação entre os componentes da etapa B que identifica os fatores ambientais vizinhos das ocorrências dos animais. 
Etapa B - Identificar os fatores ambientais vizinhos das ocorrências dos animais

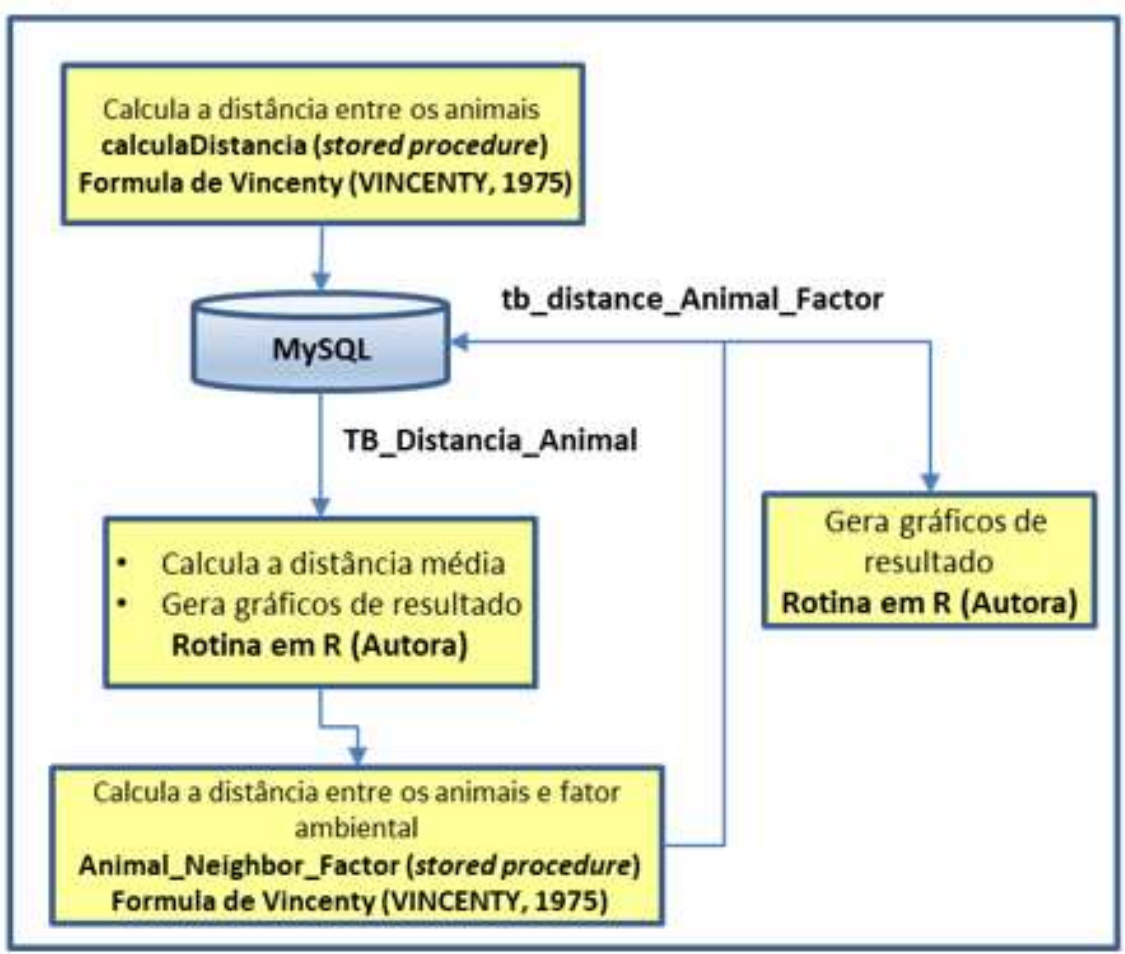

Figura 81 - Arquitetura de Componentes do algoritmo AniMoveMineR - Etapa B

A Figura 82 ilustra a relação entre os componentes da etapa C que identifica a correlação entre o comportamento animal e os fatores ambientais vizinhos.

Etapa C - Identificar a correlação entre o comportamento animal e os fatores ambientais vizinhos

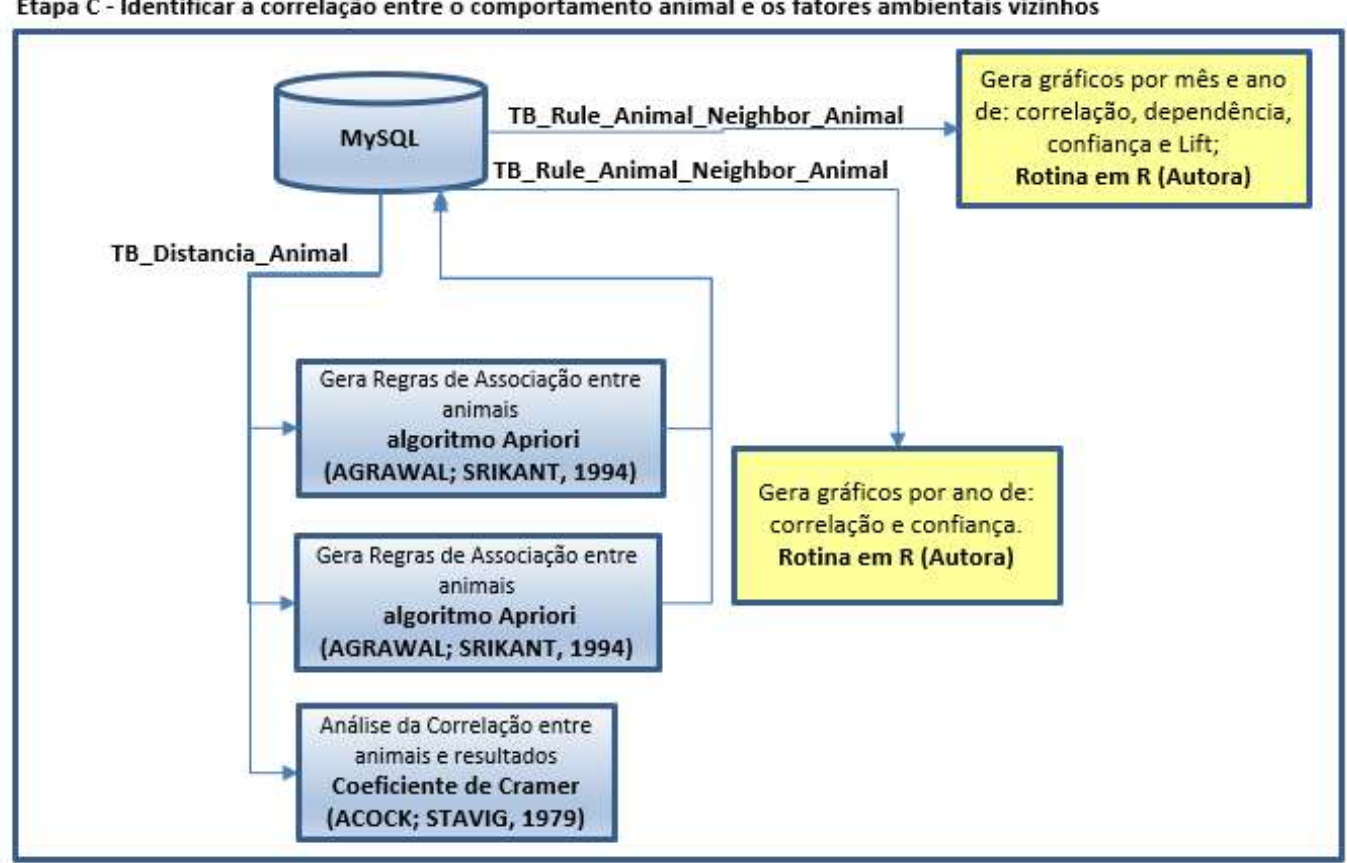

Figura 82 - Arquitetura de Componentes do algoritmo AniMoveMineR - Etapa C 


\section{APÊNDICE D - COMPARATIVO ENTRE TRABALHOS RELACIONADOS E O ANIMOVEMINER}

\begin{tabular}{|c|c|c|c|c|c|}
\hline Referência & Finalidade & Segmentação & $\begin{array}{l}\text { Tarefa de } \\
\text { Mineração }\end{array}$ & Recurso & Resultado \\
\hline Lavielle (2005) & $\begin{array}{l}\text { Método estatístico para detectar os pontos de } \\
\text { mudança na trajetória do movimento. }\end{array}$ & $\begin{array}{l}\text { Tempo de } \\
\text { residência }\end{array}$ & & $\begin{array}{l}\text { Método Lavielle (LAVIELLE, } \\
\text { 2005) }\end{array}$ & $\begin{array}{l}\text { Segmenta trajetória e classifica } \\
\text { comportamento }\end{array}$ \\
\hline $\begin{array}{l}\text { Barraquand e } \\
\text { Benhamou (2008) }\end{array}$ & $\begin{array}{l}\text { Identificar lugares onde os animais permaneceram } \\
\text { por um longo tempo. }\end{array}$ & $\begin{array}{l}\text { Tempo de } \\
\text { residência }\end{array}$ & & $\begin{array}{l}\text { Método Lavielle (LAVIELLE, } \\
\text { 2005) }\end{array}$ & Uso do espaço \\
\hline Guéguen ( 2001) & $\begin{array}{l}\text { Desenvolvido para sequenciar DNA, mas usado no } \\
\text { particionar o movimento animal e classificar o } \\
\text { comportamento. }\end{array}$ & Topologia & & $\begin{array}{l}\text { Bayesian Partitioning of } \\
\text { Markov Models (BPMM) } \\
\text { (GUÉGUEN, 2001) }\end{array}$ & $\begin{array}{l}\text { Segmenta trajetória e classifica } \\
\text { comportamento }\end{array}$ \\
\hline $\begin{array}{l}\text { Gurarie; Andrews; } \\
\text { Laidre (2009) }\end{array}$ & $\begin{array}{l}\text { Método baseado em probabilidade para detectar } \\
\text { pontos de mudança significativos no movimento } \\
\text { animal. }\end{array}$ & $\begin{array}{l}\text { Velocidade e } \\
\text { direção }\end{array}$ & & $\begin{array}{l}\text { Método Behavioural Change } \\
\text { Point Analysis } \\
\text { (BCPA)(GURARIE; } \\
\text { ANDREWS; LAIDRE, 2009) } \\
\end{array}$ & $\begin{array}{l}\text { Segmenta trajetória e classifica } \\
\text { comportamento }\end{array}$ \\
\hline $\begin{array}{l}\text { Torres et al. } \\
(2017)\end{array}$ & $\begin{array}{l}\text { Método RST segmenta as trajetórias com base } \\
\text { nas características de tempo e distância de } \\
\text { residência e classifica o comportamento nos } \\
\text { estados de forrageio, descanso e trânsito }\end{array}$ & $\begin{array}{l}\text { Tempo de } \\
\text { residência e } \\
\text { distância }\end{array}$ & & $\begin{array}{l}\text { Método Residence in Space } \\
\text { and Time (RST) Torres et al. } \\
(2017)\end{array}$ & $\begin{array}{l}\text { Segmenta trajetória e classifica } \\
\text { comportamento }\end{array}$ \\
\hline Oliveira (2013) & $\begin{array}{l}\text { Estuda o comportamento de bovinos para } \\
\text { identificar pontos de parada e movimento do } \\
\text { animal e os desvios ao longo de suas trajetórias. }\end{array}$ & & Agrupamento & $\begin{array}{l}\text { Algoritmo IB-SMOT (ALVARES } \\
\text { et al., 2007) e CB-SMOT } \\
\text { (PALMA et al., 2008) }\end{array}$ & $\begin{array}{l}\text { Identifica pontos de parada e } \\
\text { movimento com uso de semântica. }\end{array}$ \\
\hline Palma et al.(2008) & $\begin{array}{l}\text { Aplica a definição semântica de paradas e } \\
\text { movimentos ao longo de uma trajetória. IB-SMOT } \\
\text { é aplicado para marcar os pontos de parada na } \\
\text { trajetória. }\end{array}$ & & Agrupamento & $\begin{array}{l}\text { Algoritmo IB-SMOT (ALVARES } \\
\text { et al., 2007) e CB-SMOT } \\
\text { (PALMA et al., 2008) }\end{array}$ & $\begin{array}{l}\text { Identifica pontos de parada e } \\
\text { movimento com uso de semântica. }\end{array}$ \\
\hline $\begin{array}{l}\text { Jacob e Idicula } \\
(2012)\end{array}$ & $\begin{array}{l}\text { Mineração por agrupamento para identificar } \\
\text { padrões de comportamento flock. O algoritmo } \\
\text { Sparrow determina os padrões frequentes de } \\
\text { movimento e identifica grupos. }\end{array}$ & & Agrupamento & $\begin{array}{l}\text { Algoritmo Sparrow } \\
\text { (JACOB;IDICULA, 2012) }\end{array}$ & Classifica comportamento \\
\hline
\end{tabular}




\begin{tabular}{|c|c|c|c|c|c|}
\hline Referência & Finalidade & Segmentação & $\begin{array}{l}\text { Tarefa de } \\
\text { Mineração }\end{array}$ & Recurso & Resultado \\
\hline $\begin{array}{l}\text { Moorer et al. } \\
(2010)\end{array}$ & $\begin{array}{l}\text { Apresenta um framework baseado em mineração por } \\
\text { agrupamento com k-means para identificar estados do } \\
\text { movimento e avalia o framework com o uso de dados de } \\
\text { movimentação de cervos do Canadá. }\end{array}$ & & Agrupamento & $\begin{array}{l}\text { Algoritmo K-means } \\
\text { (MACQUEEN, 1967) }\end{array}$ & Classifica comportamento \\
\hline $\begin{array}{l}\text { Zhang et al. } \\
\text { (2015) }\end{array}$ & $\begin{array}{l}\text { Analisa o comportamento animal e classifica as trajetórias } \\
\text { dos animais em estados de comportamento. Apresenta a } \\
\text { relação entre a trajetória do animal e os dados ambientais } \\
\text { somente por meio da sobreposição de mapas. }\end{array}$ & $\begin{array}{l}\text { Tempo do } \\
\text { movimento, } \\
\text { com o uso da } \\
\text { velocidade e } \\
\text { na direção } \\
\end{array}$ & Agrupamento & $\begin{array}{l}\text { Behavioral Change Point } \\
\text { Analysis (BCPA) (GURARIE; } \\
\text { ANDREWS; LAIDRE, 2009); } \\
\text { Algoritmo K-means } \\
\text { (MACQUEEN, 1967) } \\
\end{array}$ & $\begin{array}{l}\text { Segmentação de trajetórias; } \\
\text { Interação entre animais e fatores } \\
\text { ambientais por meio de } \\
\text { sobreposição de mapas }\end{array}$ \\
\hline LI et al (2010a) & $\begin{array}{l}\text { Sistema de mineração de dados de movimento para } \\
\text { descoberta de comportamento. ObjectGrowth extrai os } \\
\text { padrões de swarm, usando agrupamento por densidade } \\
\text { com o DBSCAN (HAl et al., 2012a), e o Periodica detecta } \\
\text { comportamentos periódicos. }\end{array}$ & & $\begin{array}{l}\text { Agrupamento } \\
\text { hierárquico }\end{array}$ & $\begin{array}{l}\text { Algoritmo Periodica (LI et al } \\
(2010 \mathrm{a})\end{array}$ & $\begin{array}{l}\text { Classifica comportamento e } \\
\text { interação entre animais }\end{array}$ \\
\hline $\begin{array}{l}\text { Sarkar et al. } \\
(2015)\end{array}$ & $\begin{array}{l}\text { Adapta o uso do Periodica para extrair comportamento } \\
\text { periódico do movimento de gansos. }\end{array}$ & & & $\begin{array}{l}\text { Algoritmo Periodica (LI et al } \\
(2010 \mathrm{a})\end{array}$ & Classifica comportamento \\
\hline $\begin{array}{l}\text { Método } \\
\text { ObjectGrowth (LI } \\
\text { et al., 2010b) }\end{array}$ & $\begin{array}{l}\text { Identifica grupos (closed swarms) com o agrupamento } \\
\text { baseado no algoritmo DBSCAN e o uso do método Monte } \\
\text { Carlo para calcular a significância do relacionamento. }\end{array}$ & & & $\begin{array}{l}\text { Algoritmo DBSCAN (ESTER et } \\
\text { al., 1996). } \\
\text { Monte Carlo }\end{array}$ & Interação entre animais \\
\hline $\begin{array}{l}\text { MoveMine (WU et } \\
\text { al., 2014) }\end{array}$ & $\begin{array}{l}\text { Sistema de mineração de dados de movimento para } \\
\text { descoberta de comportamento. ObjectGrowth extrai os } \\
\text { padrões de swarm, usando agrupamento por densidade } \\
\text { com o DBSCAN (HAl et al., 2012a), e o Periodica detecta } \\
\text { comportamentos periódicos. }\end{array}$ & & Agrupamento & $\begin{array}{l}\text { ObjectGrowth (LI et al., } \\
\text { 2010b); } \\
\text { Algoritmo Periodica (LI et al } \\
\text { (2010a) }\end{array}$ & Interação entre animais \\
\hline
\end{tabular}




\begin{tabular}{|c|c|c|c|c|c|}
\hline Referência & Finalidade & Segmentação & $\begin{array}{l}\text { Tarefa de } \\
\text { Mineração }\end{array}$ & Recurso & Resultado \\
\hline $\begin{array}{l}\text { Hai; Poncelet; } \\
\text { Teisseire (2012) }\end{array}$ & $\begin{array}{l}\text { Get_Move com o algoritmo de densidade DBSCAN (HAI } \\
\text { et all., 2012a) são utilizados numa abordagem unificada } \\
\text { para a descoberta dos padrões de movimento closed } \\
\text { swarms, convoys e padrões de grupo. }\end{array}$ & & Agrupamento & $\begin{array}{l}\text { Algoritmo Get_Move (HAl et } \\
\text { al., 2012a); } \\
\text { DBSCAN (ESTER et al., } \\
\text { 1996). }\end{array}$ & Interação entre animais \\
\hline $\begin{array}{l}\text { Algoritmos Traj- } \\
\text { Dbscan e simple } \\
\text { slice-by-slice } \\
\text { (AUNG; TAN, 2010), }\end{array}$ & $\begin{array}{l}\text { Algoritmo baseado no DBSCan que permite a descoberta } \\
\text { de padrões de movimento dos animais. }\end{array}$ & & Agrupamento & $\begin{array}{l}\text { Algoritmo DBSCAN (ESTER } \\
\text { et al., 1996). }\end{array}$ & Classifica comportamento \\
\hline $\begin{array}{l}\text { Kalnis; Mamoulis; } \\
\text { Bakiras (2005) }\end{array}$ & $\begin{array}{l}\text { DBSCan utilizado na descoberta de padrões de grupos de } \\
\text { movimento }\end{array}$ & & Agrupamento & $\begin{array}{l}\text { Algoritmo DBSCAN (ESTER } \\
\text { et al., 1996). }\end{array}$ & Interação entre animais \\
\hline Wang et al.(2013). & $\begin{array}{l}\text { Padrões de movimento baseados na periodicidade dos } \\
\text { dados são identificados, utilizando o algoritmo Apriori } \\
\text { (AGRAWAL; SRIKANT, 1994) para encontrar padrões de } \\
\text { movimento de aves e espécies com movimento coletivo } \\
\text { periódico }\end{array}$ & & $\begin{array}{r}\text { Regras de } \\
\text { associação } \\
\end{array}$ & $\begin{array}{l}\text { Algoritmo Apriori (AGRAWAL; } \\
\text { SRIKANT, 1994) }\end{array}$ & Interação entre animais \\
\hline $\begin{array}{l}\text { Cao, Mamoulis e } \\
\text { Cheung (2006) }\end{array}$ & $\begin{array}{l}\text { Mineração por regras de associação para identificar co- } \\
\text { localização de episódios que capturam as regularidades } \\
\text { intermovimento entre diferentes animais. }\end{array}$ & & $\begin{array}{r}\text { Regras de } \\
\text { associação }\end{array}$ & & Interação entre animais \\
\hline Ll et al. (2013) & $\begin{array}{l}\text { Analisa a interação entre animais e classifica as relações } \\
\text { como atração e repulsão entre pares de objetos em } \\
\text { movimento e determina a significância da relação com os } \\
\text { testes de permutação }\end{array}$ & & & $\begin{array}{l}\text { Teste de Permutação e Monte } \\
\text { Carlo (LI et al., 2013) }\end{array}$ & Interação entre animais \\
\hline
\end{tabular}




\begin{tabular}{|c|c|c|c|c|c|}
\hline Referência & Finalidade & Segmentação & $\begin{array}{l}\text { Tarefa de } \\
\text { Mineração }\end{array}$ & Recurso & Resultado \\
\hline KANDA (2015) & $\begin{array}{l}\text { Analisa os fatores que influenciam no uso do espaço } \\
\text { pelas onças-pintadas no Pantanal - Brasil. Step Selection } \\
\text { Functions (SSF)(THURFJELL; CIUTI; BOYCE, 2014) } \\
\text { segmenta a trajetória e a regressão logistica condicional } \\
\text { (AGRESTI, 2007) identifica a relação entre o movimento } \\
\text { animal e o ambiente. }\end{array}$ & $\begin{array}{c}\text { Comprimento e } \\
\text { direção }\end{array}$ & & $\begin{array}{l}\text { Step Selection Functions } \\
\text { (SSF)(THURFJELL; CIUTI; } \\
\text { BOYCE, 2014); } \\
\text { Regressão logística condicional } \\
\text { (AGRESTI, 2007) } \\
\end{array}$ & $\begin{array}{l}\text { Segmentação de trajetórias } \\
\text { Interação entre animais }\end{array}$ \\
\hline $\begin{array}{l}\text { Teimouri et al. } \\
\text { (2018) }\end{array}$ & $\begin{array}{l}\text { Metodologia para classificar o comportamento animal em } \\
\text { estados. Trajetórias segmentadas por uma versão } \\
\text { modificada do método BCPA e distância entre os pares } \\
\text { de segmentos calculada com a métrica Kolmogorov- } \\
\text { Smirnov e um modelo de agrupamento hierárquico } \\
\text { aglomerativo dos segmentos (MILLER; HAN, 2009). }\end{array}$ & & $\begin{array}{l}\text { Agrupamento } \\
\text { hierárquico } \\
\text { aglomerativo } \\
\text { dos } \\
\text { segmentos } \\
\text { (MILLER; } \\
\text { HAN, 2009). }\end{array}$ & $\begin{array}{l}\text { Behavioral Change Point Analysis } \\
\text { (BCPA) (GURARIE; ANDREWS; } \\
\text { LAIDRE, 2009); agrupamento } \\
\text { hierarquico (MILLER; HAN, 2009). } \\
\end{array}$ & $\begin{array}{l}\text { Segmenta trajetória; } \\
\text { Classifica comportamento } \\
\end{array}$ \\
\hline $\begin{array}{l}\text { Wikelski e Kays } \\
\text { (2016) e Dodge et } \\
\text { al (2013) }\end{array}$ & $\begin{array}{l}\text { Disponibilizam a plataforma Movebank que é um portal de } \\
\text { dados abertos de rastreamento de animais. ENV-Data } \\
\text { que consiste em um conjunto de ferramentas de análise } \\
\text { que vinculam, por meio de mapas e gráficos, dados de } \\
\text { movimentação animal com dados ambientais co- } \\
\text { localizados. }\end{array}$ & & & $\begin{array}{l}\text { Movebank (Wikelski e Kays, } \\
\text { 2016); } \\
\begin{array}{ll}\text { (Dodge et al, 2013) } & \text { ENV-Data }\end{array}\end{array}$ & $\begin{array}{l}\text { Trajetória animal; } \\
\text { Interação entre animais e } \\
\text { fatores ambientais. }\end{array}$ \\
\hline $\begin{array}{l}\text { Colchero et al. } \\
\text { (2011) }\end{array}$ & $\begin{array}{l}\text { Apresenta a modelagem da movimentação de onças. } \\
\text { Markov Chain Monte Carlo (MCMC) utilizado para obter a } \\
\text { distribuição da localização das onças. O Resource } \\
\text { Selection Functions (RSF)(MANLY et al., 2002) aplicado } \\
\text { para estimar a probabilidade da onça mover-se de um } \\
\text { lugar para outro em função das variáveis ambientais }\end{array}$ & & & $\begin{array}{l}\text { algoritmo de Markov Chain Monte } \\
\text { Carlo (MCMC); Resource } \\
\text { Selection Functions (RSF)(MANLY } \\
\text { et al., 2002) }\end{array}$ & $\begin{array}{l}\text { Uso do espaço; interação } \\
\text { entre animais e fatores } \\
\text { ambientais. }\end{array}$ \\
\hline $\begin{array}{l}\text { Cavalcanti e Gese } \\
\text { (2009) }\end{array}$ & $\begin{array}{l}\text { Analisaram a frequência de coocorrência e as interações } \\
\text { de onça-pintada com o uso do kernel (WORTON, 1989) }\end{array}$ & & & kernel (WORTON, 1989) & Uso do espaço \\
\hline
\end{tabular}




\begin{tabular}{|c|c|c|c|c|c|}
\hline Referência & Finalidade & Segmentação & $\begin{array}{c}\text { Tarefa de } \\
\text { Mineração }\end{array}$ & Recurso & Resultado \\
\hline $\begin{array}{l}\text { Kranstauber;Manser } \\
(2019)\end{array}$ & $\begin{array}{l}\text { Usou a função kerneloverlap para obter a sobreposição } \\
\text { de espaço pelos mangustos. }\end{array}$ & & & kerneloverlap (CALENGE, 2006) & Uso do espaço \\
\hline $\begin{array}{l}\text { AniMoveMineR } \\
\text { (proposta tese) }\end{array}$ & $\begin{array}{l}\text { Um framework para a análise exploratória dos dados de } \\
\text { movimentação animal para a obtenção de conhecimento } \\
\text { sobre as interaçães entre animais e fatores ambientais ao } \\
\text { longo do tempo e espaço. }\end{array}$ & $\begin{array}{l}\text { Tempo e } \\
\text { distância de } \\
\text { residência }\end{array}$ & $\begin{array}{l}\text { Regras de } \\
\text { Associação }\end{array}$ & $\begin{array}{l}\text { Método RST (Torres et al., 2017); } \\
\text { Formula de Vincenty (VINCENTY, } \\
\text { 1975); Algoritmo Apriori (AGRAWAL; } \\
\text { SRIKANT, 1994); } \\
\text { AdehabitatLT (CALENGE; ROYER, } \\
\text { 2015); AdehabitatHR (CALENGE, } \\
\text { 2006); Outliers (KOMSTA, 2011); } \\
\text { Coeficiente de cramer (ACOCK; } \\
\text { STAVIG, 1979) }\end{array}$ & $\begin{array}{l}\text { Segmentação das trajetórias; } \\
\text { classificaão do } \\
\text { comportamento; interação } \\
\text { entre animais;Interação entre } \\
\text { animais e fatores ambientais; } \\
\text { Área de vida do animal; } \\
\text { Sobreposição de área de vida; } \\
\text { distância entre os animais e } \\
\text { distância entre os animais e } \\
\text { fatores ambientais. }\end{array}$ \\
\hline
\end{tabular}

